\title{
Catheter ablation of atrial fibrillation
}

Citation for published version (APA):

Nedios, S. (2021). Catheter ablation of atrial fibrillation: the association between atrial anatomy and clinical outcomes. [Doctoral Thesis, Maastricht University]. Maastricht University. https://doi.org/10.26481/dis.20210414sn

Document status and date:

Published: 01/01/2021

DOI:

10.26481/dis.20210414sn

Document Version:

Publisher's PDF, also known as Version of record

\section{Please check the document version of this publication:}

- A submitted manuscript is the version of the article upon submission and before peer-review. There can be important differences between the submitted version and the official published version of record.

People interested in the research are advised to contact the author for the final version of the publication, or visit the DOI to the publisher's website.

- The final author version and the galley proof are versions of the publication after peer review.

- The final published version features the final layout of the paper including the volume, issue and page numbers.

Link to publication

\footnotetext{
General rights rights.

- You may freely distribute the URL identifying the publication in the public portal. please follow below link for the End User Agreement:

www.umlib.nl/taverne-license

Take down policy

If you believe that this document breaches copyright please contact us at:

repository@maastrichtuniversity.nl

providing details and we will investigate your claim.
}

Copyright and moral rights for the publications made accessible in the public portal are retained by the authors and/or other copyright owners and it is a condition of accessing publications that users recognise and abide by the legal requirements associated with these

- Users may download and print one copy of any publication from the public portal for the purpose of private study or research.

- You may not further distribute the material or use it for any profit-making activity or commercial gain

If the publication is distributed under the terms of Article $25 \mathrm{fa}$ of the Dutch Copyright Act, indicated by the "Taverne" license above, 


\section{Catheter ablation of atrial fibrillation: the association between atrial anatomy and clinical outcomes.}

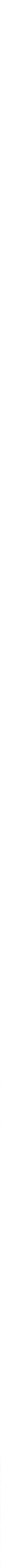




\title{
Catheter ablation of atrial fibrillation:
}

the association between atrial anatomy and clinical outcomes.

\author{
Dissertation
}

to obtain the degree of Doctor at Maastricht University, on the authority of the Rector Magnificus Prof.dr. Rianne M. Letschert in accordance with the decision of the Board of Deans, to be defended in public on Wednesday 14th of April 2021 at 13.00 hours

by

Sotirios Nedios, MD 


\section{Promoters:}

Prof. dr. H.J.G.M. Crijns, Maastricht University, the Netherlands

Prof. dr. Gerhard Hindricks, Heart Center Leipzig, University of Leipzig, Germany

\section{Co-Promoters:}

Prof. dr. Andreas Bollmann, Heart Center Leipzig, University of Leipzig, Germany Dr. Jordi Heijman, Maastricht University, the Netherlands

\section{Assessment Committee:}

Prof. dr. Ulrich Schotten, Maastricht University, the Netherlands

Prof. dr. Frits W. Prinzen, Maastricht University, the Netherlands

Prof. dr. Jeroen J. Bax, Leiden University, the Netherlands

Prof. dr. Panyiotis Vardas, Heraklion University, Greece

The research described in this thesis was supported by a grant of the National State Scholarship Foundation, Greece (IKY) and a grant from the "Konstantin Vellios" Legacy Foundation. Additional support for educational and research purposes by the Heart Center Leipzig, University of Leipzig, Germany and the Massachusetts General Hospital, Harvard University, Boston, USA is gratefully acknowledged as well.

All rights reserved. No part of this publication may be reproduced, stored in a retrieval system or transmitted, in any form or by any means, electronic, mechanical, photocopying, recording or otherwise, without prior permission of the author or the copyright-owning journals for previous published chapters.

(C) Sotirios Nedios, 2021 ISBN 978-94-6423-247-9 


\section{Table of contents}

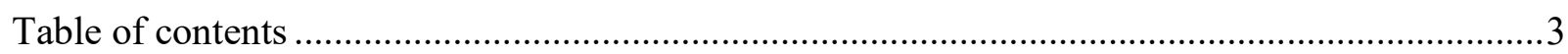

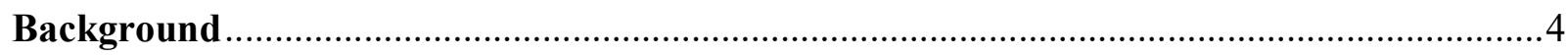

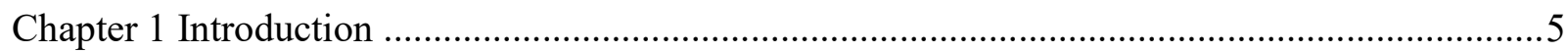

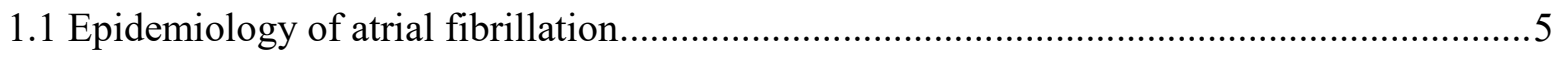

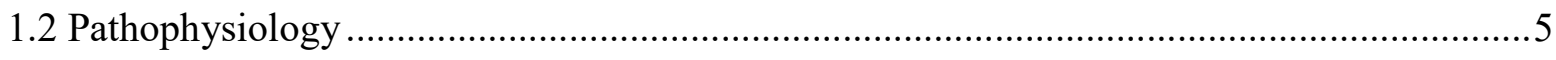

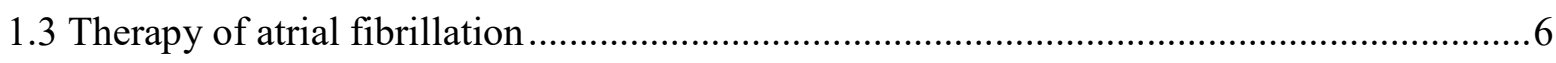

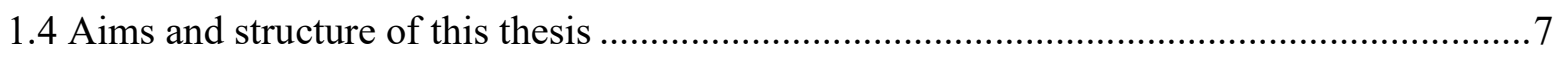

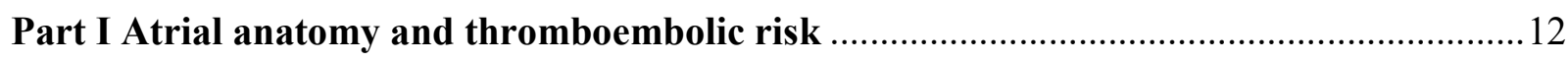

Chapter 2 Atrial fibrillation and thromboembolic risk after AF ablation ....................................13

Chapter 3 Atrial fibrillation and thromboembolic risk in low-risk patients................................2

Chapter 4 Atrial fibrillation and peri-interventional thromboembolic risk .................................. 41

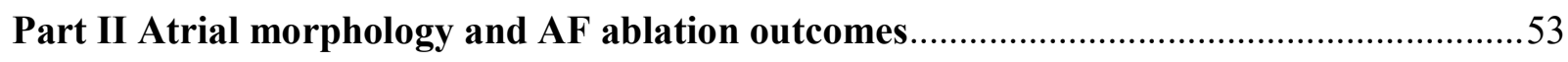

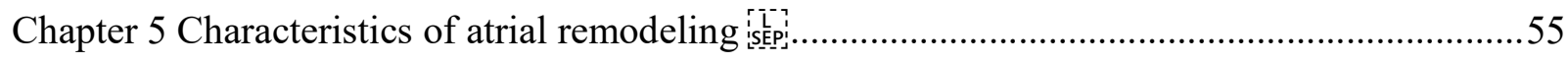

Chapter 6 Atrial diameters as predictors of success after AF ablation

Chapter 7 Atrial remodeling and long-term success after AF ablation........................................ 81

Chapter 8 Atrial remodeling and ventricular diastolic dysfunction

Chapter 9 Atrial remodeling and plasma markers

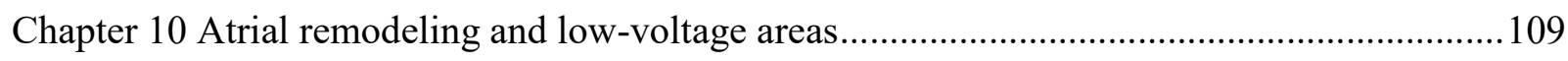

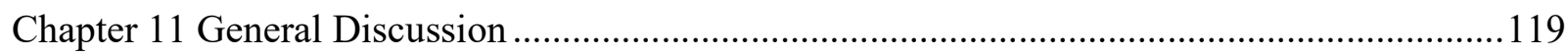

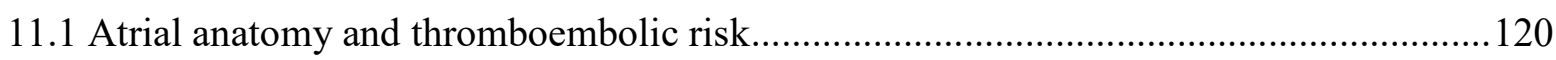

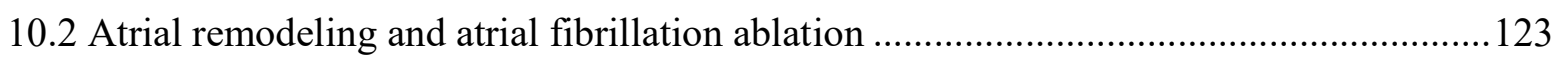

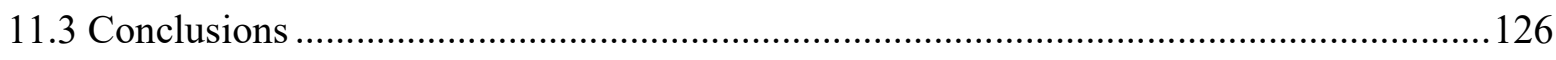

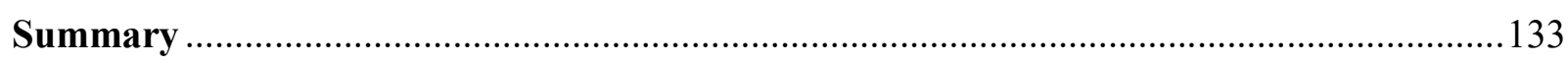

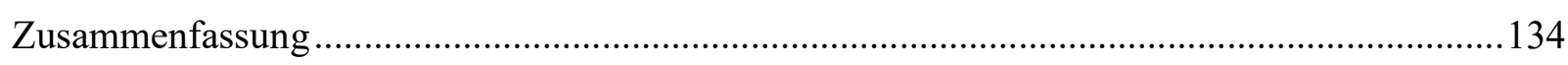

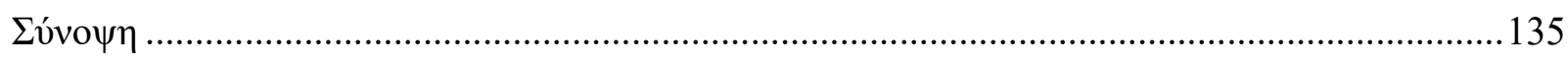

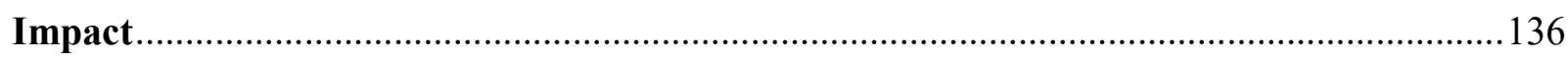

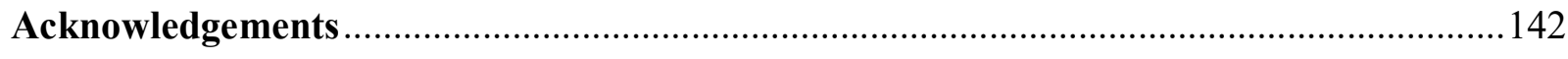

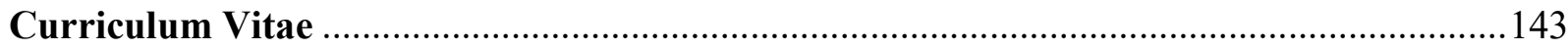


Background 


\section{Chapter 1 Introduction}

\subsection{Epidemiology of atrial fibrillation}

Atrial fibrillation is the most common arrhythmia with an increasing prevalence in an aging population and significant public health implications. AF is currently affecting more than 3 million people in the United States and approximately 34 million around the world. ${ }^{1,2}$ AF prevalence is about to double in the next 30 years and exceed 14-17 million in Europe alone with one in four middle-aged adults developing $\mathrm{AF}^{3}$ This increase in AF prevalence can be partially attributed to a better ability to diagnose AF, but also due to the improved medical treatment that allows for longer survival of patients. ${ }^{4,5}$

Despite improvement in the management of AF patients, this arrhythmia remains one of the major causes of stroke, heart failure, sudden death, and cardiovascular morbidity in the world. ${ }^{6}$ Death due to stroke can largely be mitigated by anticoagulation, but other cardiovascular events remain common even in patients treated according to current guidelines. ${ }^{7}$ Additionally, cognitive impairment, decreased quality of life and depressed mood are more common in AF patients. ${ }^{8-10}$ Since the AF epidemic poses a significant burden on public health, identification of surrogates associated with AF pathophysiology that could improve treatment of patients is very important.

\subsection{Pathophysiology}

The pathophysiology of AF is multifactorial including both genetic predisposition and electromechanical and structural remodeling of the atria. A few young AF patients suffer from inherited disease-causing mutations, but up to one-third of AF patients carry common genetic variants that predispose to atrial remodeling and $\mathrm{AF}$, albeit with a relatively low added risk. ${ }^{11,12}$ Although the principal clinical determinant of susceptibility to AF is age, potent adjuvants include external stressors such as hypertension, heart failure, structural heart disease, obesity, diabetes, respiratory obstructive disease, ventricular dysfunction, but also AF itself. These determinants are unified by their tendency to increase atrial pressure and volume; resulting in structural remodeling with dilatation and chronic elevation in atrial wall stress that elicits an adverse biological response, culminating in the AF substrate i.e. fibrosis and scarring. ${ }^{13,14}$ In addition, atrial fatty infiltration, inflammation, myocyte hypertrophy, necrosis, and amyloidosis are concomitant precipitating factors. ${ }^{15,16}$ Structural remodeling results in electrical dissociation between muscle bundles and local conduction heterogeneities, ${ }^{17}$ facilitating re-entry and perpetuation of the arrhythmia. ${ }^{18}$ Since the structural remodeling occurs in many cases before the onset of $\mathrm{AF},{ }^{19}$ and progresses to an irreversible state, early treatment initiation seems desirable. ${ }^{20}$

Additionally, the functional and structural changes in atrial myocardium and the stasis of blood, especially in the left atrial appendage (LAA) amplify thrombus formation. AF could cause endothelial damage and expression of prothrombotic factors, which together activated platelets 
and inflammatory cells contribute to a thrombotic milieu. ${ }^{21}$ The activation of local and systemic coagulation could explain the long-term stroke risk and deserves further evaluation.

\subsection{Therapy of atrial fibrillation}

The therapy of AF provides prognostic impact and symptomatic relief. Therapies with prognostic importance include the prevention of thromboembolic events by means of anticoagulation or LAA elimination and the treatment of comorbidities that aggravate AF, like hypertension, heart failure, diabetes, coronary or valvular disease. On the other hand, rate and rhythm control by means of drug therapy or catheter ablation can provide symptomatic relief. Both medical and invasive therapies are associated with potential risks and thus selection of patients is crucial in order to individualize therapy, maximize benefits and minimize harms. In this sense prediction of outcomes is very important for patient-tailored therapeutic decisions.

\section{Stroke prevention}

The cornerstone for prevention of thromboembolic events in AF patients is oral anticoagulation (OAC). OAC therapy can prevent the majority of ischemic strokes; improve survival and quality of life. ${ }^{22}$ However, OAC therapy in specific subgroups of patients with very low stroke risk remains troublesome and underuse or OAC termination due to bleeding is still common. ${ }^{23,24}$ The considerable stroke risk without OAC though often exceeds the bleeding risk on OAC, even in elderly patients, with cognitive dysfunction or with frequent falls. ${ }^{25,26}$

The decision for OAC therapy in AF patients has been simplified by stroke risk-stratification schemes that have been validated in large populations. The most widespread risk-score is the $\mathrm{CHA}_{2} \mathrm{DS}_{2}$-VASc score that accounts for the following risk factors: congestive heart failure (C), hypertension (H), age (A), diabetes (D), stroke history (S), vascular disease (V) and female sex (S). ${ }^{27}$ Accordingly, patients without clinical stroke risk factors do not need antithrombotic therapy, while patients with stroke risk factors (i.e. $\mathrm{CHA}_{2} \mathrm{DS}_{2}$-VASc score of 1 or more for men, and 2 or more for women) are likely to benefit from OAC. Alternatively, LAA elimination can reduce embolic and bleeding risk, but is associated with risk for (4\%) complications and warrants further studies. ${ }^{28-32}$ Recently, this increased attention for the LAA anatomy has helped to better identify patients that may suffer thromboembolic events despite low clinical risk score. ${ }^{33,34}$

Although the LAA is regarded as the primary source of thrombus formation, it is not included in the above stratification models. Di Biase et al. ${ }^{35}$ reported different LAA morphologies and found that an anatomy without bends (non-Chicken-Wing) is associated with a 3-fold risk of prior thromboembolic event (TE). The current work further elaborates on the role of LAA anatomy for post- (Chapter 2), peri-interventional (Chapter 4) or baseline risk in AF patients with clinically low thromboembolic risk (Chapter 3). ${ }^{36-38}$

\section{Catheter ablation of atrial fibrillation}

Catheter ablation is a safe and effective therapy for drug-refractory symptomatic AF patients. Since the description of AF initiated by triggers in the pulmonary veins (PV), ${ }^{39} \mathrm{PV}$ isolation 
(PVI) with catheter ablation has developed into an established therapy with better results and less side effects than drugs. ${ }^{40}$ Although most of the patients achieve long-term rhythm stability, some patients require more than one procedure or additional ablation of the atrial substrate to avoid arrhythmia recurrence. ${ }^{41}$ Additional targets beyond PVI may include linear lesions along the LA roof, the septum or between the pulmonary veins and the mitral annulus, ${ }^{42,43}$ low-voltage areas or MRI-detected fibrosis, ${ }^{44-46}$ but their clinical value remains to be further evaluated. ${ }^{47}$ Dominant frequencies and sites with fractionated electrograms or spiral-circuits have been targeted too, but with no clear benefit. ${ }^{48}$ Thus, the optimal ablation strategy remains an ongoing research subject.

Accordingly, identification of predictors of success after AF ablation could help identify patients, who need additional attention and probably modified treatment or follow-up. Common predictors like age, AF type and burden, structural or valvular disease and ventricular impairment share a common pathway of atrial remodeling. ${ }^{49}, 50$ This could explain why LA enlargement repeatedly emerges as an important predictor of cardiovascular endpoints or rhythm stability. ${ }^{51-54}$ Consequently, current guidelines recommend an assessment of the LA for all AF patients. ${ }^{55}$ Since echocardiography can not reliably represent the true size of the rather asymmetrical LA dilation in the limited space between the sternum and spine, ${ }^{56}$ we aimed to examine the characterization and prognostic value of the three-dimensional left atrial remodeling.

\subsection{Aims and structure of this thesis}

The general aim of this thesis is to unravel the role of pre-procedural imaging concerning the relationship between anatomical characteristics and the clinical outcomes in AF patients, especially thromboembolic events (Chapters 2-4) and rhythm outcomes after catheter ablation therapy (Chapter 5-9). We used tomography (CT) or magnetic resonance imaging (MRI) data to evaluate $3 \mathrm{D}$ changes and elaborate the following aspects:

\section{Part I: Atrial anatomy and thromboembolic risk}

1. What is the prevalence of thromboembolic events after AF ablation (Chapter 2)?

2. Is LAA anatomy associated with thromboembolic events after AF ablation (Chapter 2)?

3. What is the role of LAA anatomy in patients with low CHADS-VASc score (Chapter 3)?

4. What is the prevalence of peri-procedural thromboembolic events (Chapter 4)?

5. Are peri-procedural thromboembolic events related to the LAA anatomy (Chapter 4)?

\section{Part II: Atrial remodeling and atrial fibrillation ablation}

6. What are the characteristics of atrial remodeling in different AF types (Chapter 5)?

7. Can the remodeling of atrial anatomy predict long-term success after AF ablation (Chapter 6)?

8. Could atrial anatomy be used to improve patient selection and ablation outcomes (Chapter 7)?

9. Is atrial remodeling related to left ventricular diastolic dysfunction (Chapter 8)?

10. What is the association between atrial remodeling and plasma markers (Chapter 9)?

11. Is there an association between anatomical atrial remodeling and AF substrate (Chapter 10)?

Finally, the thesis is concluded with a general discussion (Chapter 11) in which the main findings are discussed in a more integrative manner. 


\section{References}

1. Kirchhof P, Benussi S, Kotecha D, et al. 2016 ESC Guidelines for the management of atrial fibrillation developed in collaboration with EACTS: The Task Force for the management of atrial fibrillation of the European Society of Cardiology (ESC)Developed with the special contribution of the European Heart Rhythm Association (EHRA) of the ESCEndorsed by the European Stroke Organisation (ESO). Eur Heart J Aug 272016.

2. January CT, Wann LS, Alpert JS, et al. 2014 AHA/ACC/HRS guideline for the management of patients with atrial fibrillation: a report of the American College of Cardiology/American Heart Association Task Force on practice guidelines and the Heart Rhythm Society. Circulation Dec 2 2014;130:e199-267.

3. Ball J, Carrington MJ, McMurray JJ, Stewart S. Atrial fibrillation: profile and burden of an evolving epidemic in the 21st century. Int J Cardiol Sep 1 2013;167:1807-1824.

4. Schnabel RB, Yin X, Gona P, et al. 50 year trends in atrial fibrillation prevalence, incidence, risk factors, and mortality in the Framingham Heart Study: a cohort study. Lancet Jul 11 2015;386:154-162.

5. Kishore A, Vail A, Majid A, Dawson J, Lees KR, Tyrrell PJ, Smith CJ. Detection of atrial fibrillation after ischemic stroke or transient ischemic attack: a systematic review and metaanalysis. Stroke Feb 2014;45:520-526.

6. Benjamin EJ, Wolf PA, D'Agostino RB, Silbershatz H, Kannel WB, Levy D. Impact of atrial fibrillation on the risk of death: the Framingham Heart Study. Circulation Sep 8 1998;98:946952.

7. Andersson T, Magnuson A, Bryngelsson IL, Frobert O, Henriksson KM, Edvardsson N, Poci D. All-cause mortality in 272,186 patients hospitalized with incident atrial fibrillation 19952008: a Swedish nationwide long-term case-control study. Eur Heart J Apr 2013;34:10611067.

8. Knecht S, Oelschlager C, Duning T, Lohmann H, Albers J, Stehling C, Heindel W, Breithardt G, Berger K, Ringelstein EB, Kirchhof P, Wersching H. Atrial fibrillation in stroke-free patients is associated with memory impairment and hippocampal atrophy. Eur Heart J Sep 2008;29:2125-2132.

9. Marzona I, O'Donnell M, Teo K, Gao P, Anderson C, Bosch J, Yusuf S. Increased risk of cognitive and functional decline in patients with atrial fibrillation: results of the ONTARGET and TRANSCEND studies. Cmaj Apr 3 2012;184:E329-336.

10. von Eisenhart Rothe A, Hutt F, Baumert J, Breithardt G, Goette A, Kirchhof P, Ladwig KH. Depressed mood amplifies heart-related symptoms in persistent and paroxysmal atrial fibrillation patients: a longitudinal analysis--data from the German Competence Network on Atrial Fibrillation. Europace Sep 2015;17:1354-1362.

11. Oyen N, Ranthe MF, Carstensen L, Boyd HA, Olesen MS, Olesen SP, Wohlfahrt J, Melbye M. Familial aggregation of lone atrial fibrillation in young persons. J Am Coll Cardiol Sep 4 2012;60:917-921.

12. Husser D, Adams V, Piorkowski C, Hindricks G, Bollmann A. Chromosome 4q25 variants and atrial fibrillation recurrence after catheter ablation. J Am Coll Cardiol Feb 23 2010;55:747-753.

13. Chimenti C, Russo MA, Carpi A, Frustaci A. Histological substrate of human atrial fibrillation. Biomed Pharmacother Mar 2010;64:177-183.

14. Nguyen BL, Fishbein MC, Chen LS, Chen PS, Masroor S. Histopathological substrate for chronic atrial fibrillation in humans. Heart Rhythm Apr 2009;6:454-460. 
15. Venteclef N, Guglielmi V, Balse E, Gaborit B, Cotillard A, Atassi F, Amour J, Leprince P, Dutour A, Clement K, Hatem SN. Human epicardial adipose tissue induces fibrosis of the atrial myocardium through the secretion of adipo-fibrokines. Eur Heart J Apr 1 2015;36:795805a.

16. Schotten U, Ausma J, Stellbrink C, Sabatschus I, Vogel M, Frechen D, Schoendube F, Hanrath P, Allessie MA. Cellular mechanisms of depressed atrial contractility in patients with chronic atrial fibrillation. Circulation Feb 6 2001;103:691-698.

17. Allessie MA, de Groot NM, Houben RP, Schotten U, Boersma E, Smeets JL, Crijns HJ. Electropathological substrate of long-standing persistent atrial fibrillation in patients with structural heart disease: longitudinal dissociation. Circ Arrhythm Electrophysiol Dec 2010;3:606-615.

18. Spach MS, Josephson ME. Initiating reentry: the role of nonuniform anisotropy in small circuits. Journal of cardiovascular electrophysiology Feb 1994;5:182-209.

19. Anne W, Willems R, Roskams T, Sergeant P, Herijgers P, Holemans P, Ector H, Heidbuchel $\mathrm{H}$. Matrix metalloproteinases and atrial remodeling in patients with mitral valve disease and atrial fibrillation. Cardiovasc Res Sep 1 2005;67:655-666.

20. Shinagawa K, Shi YF, Tardif JC, Leung TK, Nattel S. Dynamic nature of atrial fibrillation substrate during development and reversal of heart failure in dogs. Circulation Jun 4 2002;105:2672-2678.

21. Lim HS, Willoughby SR, Schultz C, et al. Effect of atrial fibrillation on atrial thrombogenesis in humans: impact of rate and rhythm. J Am Coll Cardiol Feb 26 2013;61:852-860.

22. Hart RG, Pearce LA, Aguilar MI. Meta-analysis: antithrombotic therapy to prevent stroke in patients who have nonvalvular atrial fibrillation. Ann Intern Med Jun 19 2007;146:857-867.

23. O'Brien EC, Holmes DN, Ansell JE, et al. Physician practices regarding contraindications to oral anticoagulation in atrial fibrillation: findings from the Outcomes Registry for Better Informed Treatment of Atrial Fibrillation (ORBIT-AF) registry. American heart journal Apr 2014;167:601-609 e601.

24. Le Heuzey JY, Ammentorp B, Darius H, De Caterina R, Schilling RJ, Schmitt J, Zamorano JL, Kirchhof P. Differences among western European countries in anticoagulation management of atrial fibrillation. Data from the PREFER IN AF registry. Thromb Haemost May 5 2014;111:833-841.

25. Donze J, Clair C, Hug B, Rodondi N, Waeber G, Cornuz J, Aujesky D. Risk of falls and major bleeds in patients on oral anticoagulation therapy. Am J Med Aug 2012;125:773-778.

26. Man-Son-Hing M, Nichol G, Lau A, Laupacis A. Choosing antithrombotic therapy for elderly patients with atrial fibrillation who are at risk for falls. Arch Intern Med Apr 12 1999;159:677-685.

27. Lip GY, Nieuwlaat R, Pisters R, Lane DA, Crijns HJ. Refining clinical risk stratification for predicting stroke and thromboembolism in atrial fibrillation using a novel risk factor-based approach: the euro heart survey on atrial fibrillation. Chest Feb 2010;137:263-272.

28. Meier B, Blaauw Y, Khattab AA, Lewalter T, Sievert H, Tondo C, Glikson M. EHRA/EAPCI expert consensus statement on catheter-based left atrial appendage occlusion. Europace Oct 2014;16:1397-1416.

29. Boersma LV, Schmidt B, Betts TR, Sievert H, Tamburino C, Teiger E, Pokushalov E, Kische $\mathrm{S}$, Schmitz T, Stein KM, Bergmann MW. Implant success and safety of left atrial appendage closure with the WATCHMAN device: peri-procedural outcomes from the EWOLUTION registry. Eur Heart J Aug 2016;37:2465-2474.

30. Holmes DR, Jr., Kar S, Price MJ, Whisenant B, Sievert H, Doshi SK, Huber K, Reddy VY. Prospective randomized evaluation of the Watchman Left Atrial Appendage Closure device 
in patients with atrial fibrillation versus long-term warfarin therapy: the PREVAIL trial. J Am Coll Cardiol Jul 8 2014;64:1-12.

31. Reddy VY, Doshi SK, Sievert H, Buchbinder M, Neuzil P, Huber K, Halperin JL, Holmes D. Percutaneous left atrial appendage closure for stroke prophylaxis in patients with atrial fibrillation: 2.3-Year Follow-up of the PROTECT AF (Watchman Left Atrial Appendage System for Embolic Protection in Patients with Atrial Fibrillation) Trial. Circulation Feb 12 2013;127:720-729.

32. Reddy VY, Sievert H, Halperin J, Doshi SK, Buchbinder M, Neuzil P, Huber K, Whisenant B, Kar S, Swarup V, Gordon N, Holmes D. Percutaneous left atrial appendage closure vs warfarin for atrial fibrillation: a randomized clinical trial. Jama Nov 19 2014;312:1988-1998.

33. Lip GY, Skjoth F, Rasmussen LH, Larsen TB. Oral anticoagulation, aspirin, or no therapy in patients with nonvalvular AF with 0 or 1 stroke risk factor based on the CHA2DS2-VASc score. J Am Coll Cardiol Apr 14 2015;65:1385-1394.

34. Chao TF, Liu CJ, Wang KL, Lin YJ, Chang SL, Lo LW, Hu YF, Tuan TC, Chen TJ, Lip GY, Chen SA. Should atrial fibrillation patients with 1 additional risk factor of the CHA2DS2VASc score (beyond sex) receive oral anticoagulation? J Am Coll Cardiol Feb 24 2015;65:635-642.

35. Di Biase L, Santangeli P, Anselmino M, et al. Does the left atrial appendage morphology correlate with the risk of stroke in patients with atrial fibrillation? Results from a multicenter study. J Am Coll Cardiol Aug 7 2012;60:531-538.

36. Nedios S, Kornej J, Koutalas E, Bertagnolli L, Kosiuk J, Rolf S, Arya A, Sommer P, Husser D, Hindricks G, Bollmann A. Left atrial appendage morphology and thromboembolic risk after catheter ablation for atrial fibrillation. Heart Rhythm Dec 2014;11:2239-2246.

37. Kosiuk J, Nedios S, Kornej J, Koutalas E, Bertagnolli L, Rolf S, Arya A, Sommer P, Husser D, Hindricks G, Bollmann A. Impact of Left Atrial Appendage Morphology on Periinterventional Thromboembolic Risk during Catheter Ablation of Atrial Fibrillation. Heart Rhythm May 222014.

38. Nedios S, Koutalas E, Kornej J, Rolf S, Arya A, Sommer P, Husser D, Hindricks G, Bollmann A. Cardiogenic Stroke Despite Low CHA2 DS2 -VASc Score: Assessing Stroke risk by Left Atrial Appendage Anatomy (ASK LAA). J Cardiovasc Electrophysiol Sep 2015;26:915-921.

39. Haissaguerre M, Jais P, Shah DC, Takahashi A, Hocini M, Quiniou G, Garrigue S, Le Mouroux A, Le Metayer P, Clementy J. Spontaneous initiation of atrial fibrillation by ectopic beats originating in the pulmonary veins. N Engl J Med Sep 3 1998;339:659-666.

40. Mont L, Bisbal F, Hernandez-Madrid A, et al. Catheter ablation vs. antiarrhythmic drug treatment of persistent atrial fibrillation: a multicentre, randomized, controlled trial (SARA study). Eur Heart J Feb 2014;35:501-507.

41. Calkins H, Kuck KH, Cappato R, et al. 2012 HRS/EHRA/ECAS expert consensus statement on catheter and surgical ablation of atrial fibrillation: recommendations for patient selection, procedural techniques, patient management and follow-up, definitions, endpoints, and research trial design. Heart Rhythm Apr 2012;9:632-696 e621.

42. Jais P, Hocini M, Hsu LF, et al. Technique and results of linear ablation at the mitral isthmus. Circulation Nov 9 2004;110:2996-3002.

43. Hocini M, Jais P, Sanders P, Takahashi Y, Rotter M, Rostock T, Hsu LF, Sacher F, Reuter S, Clementy J, Haissaguerre M. Techniques, evaluation, and consequences of linear block at the left atrial roof in paroxysmal atrial fibrillation: a prospective randomized study. Circulation Dec 13 2005;112:3688-3696. 
44. Rolf S, Kircher S, Arya A, Eitel C, Sommer P, Richter S, Gaspar T, Bollmann A, Altmann D, Piedra C, Hindricks G, Piorkowski C. Tailored atrial substrate modification based on lowvoltage areas in catheter ablation of atrial fibrillation. Circ Arrhythm Electrophysiol Oct 2014; 7:825-833.

45. Marrouche NF, Wilber D, Hindricks G, et al. Association of atrial tissue fibrosis identified by delayed enhancement MRI and atrial fibrillation catheter ablation: the DECAAF study. Jama Feb 5 2014;311:498-506.

46. Oakes RS, Badger TJ, Kholmovski EG, et al. Detection and quantification of left atrial structural remodeling with delayed-enhancement magnetic resonance imaging in patients with atrial fibrillation. Circulation Apr 7 2009;119:1758-1767.

47. Nedios S, Sommer P, Bollmann A, Hindricks G. Advanced Mapping Systems To Guide Atrial Fibrillation Ablation: Electrical Information That Matters. Journal of Atrial Fibrillation (JAFIB) Apr-May 2016;8:96-102.

48. Verma A, Jiang CY, Betts TR, et al. Approaches to catheter ablation for persistent atrial fibrillation. N Engl J Med May 7 2015;372:1812-1822.

49. Balk EM, Garlitski AC, Alsheikh-Ali AA, Terasawa T, Chung M, Ip S. Predictors of atrial fibrillation recurrence after radiofrequency catheter ablation: a systematic review. Journal of cardiovascular electrophysiology Nov 2010;21:1208-1216.

50. D'Ascenzo F, Corleto A, Biondi-Zoccai G, et al. Which are the most reliable predictors of recurrence of atrial fibrillation after transcatheter ablation?: a meta-analysis. Int J Cardiol Sep 1 2013;167:1984-1989.

51. Tsang MY, Barnes ME, Tsang TS. Left atrial volume: clinical value revisited. Curr Cardiol Rep Jun 2012;14:374-380.

52. Berruezo A, Tamborero D, Mont L, Benito B, Tolosana JM, Sitges M, Vidal B, Arriagada G, Mendez F, Matiello M, Molina I, Brugada J. Pre-procedural predictors of atrial fibrillation recurrence after circumferential pulmonary vein ablation. Eur Heart J Apr 2007;28:836-841.

53. Shin SH, Park MY, Oh WJ, Hong SJ, Pak HN, Song WH, Lim DS, Kim YH, Shim WJ. Left atrial volume is a predictor of atrial fibrillation recurrence after catheter ablation. J Am Soc Echocardiogr Jun 2008;21:697-702.

54. Abecasis J, Dourado R, Ferreira A, Saraiva C, Cavaco D, Santos KR, Morgado FB, Adragao P, Silva A. Left atrial volume calculated by multi-detector computed tomography may predict successful pulmonary vein isolation in catheter ablation of atrial fibrillation. Europace Oct 2009;11:1289-1294.

55. January CT, Wann LS, Alpert JS, et al. 2014 AHA/ACC/HRS guideline for the management of patients with atrial fibrillation: a report of the American College of Cardiology/American Heart Association Task Force on Practice Guidelines and the Heart Rhythm Society. J Am Coll Cardiol Dec 2 2014;64:e1-76.

56. Badano LP, Pezzutto N, Marinigh R, Cinello M, Nucifora G, Pavoni D, Gianfagna P, Fioretti PM. How many patients would be misclassified using M-mode and two-dimensional estimates of left atrial size instead of left atrial volume? A three-dimensional echocardiographic study. J Cardiovasc Med (Hagerstown) May 2008;9:476-484. 
Part I Atrial anatomy and thromboembolic risk 
Chapter 2 Atrial fibrillation and thromboembolic risk after AF ablation

Adapted from "Left atrial appendage morphology and thromboembolic risk after catheter ablation for atrial fibrillation."

Published in Heart Rhythm Dec 2014;11:2239-2246. DOI: 10.1016/j.hrthm.2014.08.016

Sotirios Nedios,* Jelena Kornej, * Emmanuel Koutalas, Livio Bertagnolli, Jedrzej Kosiuk, Sascha Rolf, Arash Arya, Philipp Sommer, Daniela Husser, Gerhard Hindricks, Andreas Bollmann

*both authors contributed equally 


\begin{abstract}
Background:

In patients with atrial fibrillation (AF), left atrial appendage (LAA) morphology has been suggested to modify risk for thromboembolic events (TE). In this study we tested the hypothesis that TE after AF catheter ablation (CA) is associated with LAA characteristics.
\end{abstract}

\title{
Methods:
}

Of 2,069 patients form the Leipzig Heart Center AF Ablation Registry, 15 suffered TE (excluding events within 30 days) during follow-up (i.e. 3.078 patient-years). Those patients were matched for $\mathrm{CHA}_{2} \mathrm{DS}_{2}-\mathrm{VASc}$ criteria with 115 TE-free patients and CT $(n=120)$ or MRI $(n=10)$ data were compared. LAA volume, morphology (Cactus, Chicken-Wing, Windsock, Cauliflower) and takeoff in relation (higher/lower) to the adjacent pulmonary vein (PV) were determined.

\section{Results:}

After 24 months (median), 67\% of the patients remained in sinus rhythm. Patients with TE had a higher AF recurrence rate $(73 \%$ vs. $28 \%, \mathrm{p}=0.001)$, and a higher incidence of superior LAA takeoff (i.e. higher than the left superior PV; $80 \%$ vs. $37 \%, \mathrm{p}=0.002$ ), while the LAA morphologies and other LAA characteristics were similar between groups. Multivariable coxregression analysis revealed $\mathrm{AF}$ recurrence (HR: 6.2, 95\% CI: 2.0-19.6, $\mathrm{p}=0.002$ ) and superior LAA takeoff (HR: $4.9,95 \% \mathrm{CI}: 1.4-17.4, \mathrm{p}=0.014$ ) as TE predictors. There was a negative correlation between heart rate and LAA flow $(\mathrm{r}=-0.22 \mathrm{~cm} / \mathrm{s}$ pro bpm, $\mathrm{p}=0.016)$, that was even more pronounced for the superior LAA takeoff $(\mathrm{r}=-0.28 \mathrm{~cm} / \mathrm{s}$ pro bpm, $\mathrm{p}=0.045)$.

\section{Conclusion:}

AF recurrence and higher LAA takeoff are associated with thromboembolism after AF ablation, while LAA morphology is not. These results may have an implication for improved post-ablation management. 


\section{Introduction}

The left atrial appendage (LAA) plays a major role as a thromboembolic source in patients with atrial fibrillation (AF). The LAA anatomy with different shapes, lobes and trabeculations has been regarded as the primary source of stasis and thrombus formation. ${ }^{1-3}$ Left atrial (LA) ablation and LAA occlusion procedures for AF patients have drawn more attention to this structure. ${ }^{4-7}$

Recently, Di Biase et al. ${ }^{8}$ reported 4 different LAA morphologies (Cactus, Chicken-Wing, Windsock, Cauliflower) and found that the non-Chicken-Wing morphologies were associated with a 3-fold risk of prior thromboembolic events (TE). Although some concern was raised about the actual causation, ${ }^{9}$ these findings were supplemented by following studies ${ }^{10-12}$ and were found useful for the prediction of $\mathrm{TE}$ in low-risk $\mathrm{AF}$ patients. ${ }^{12}$ However, the impact of LAA morphology on TE risk after CA is unknown.

Therefore, the main objective of the present study was to examine LAA characteristics in AF patients undergoing catheter ablation in order to identify their association with thromboembolic events during follow-up, using a case-control study.

\section{Methods}

Of 2,069 patients included prospectively (2007-2011) in our institutional AF ablation registry, $31(1.5 \%)$ had a TE: stroke, transient ischemic attack (TIA) or systemic embolism during followup. Ischemic stroke was a clinical diagnosis based on typical symptoms lasting $\geq 24$ hours. A TIA was defined as sudden-onset focal neurological deficit of $<24$ hours. Systemic embolism was defined as TE events that occurred in peripheral organs or extremities. Brain imaging was available in the vast majority of patients and other embolic sources (e.g. valvular or vascular) were excluded.

Peri-interventional events within the first 30 days were excluded, so that the final study population comprised $15(0.7 \%)$ patients. Those patients were matched for the $\mathrm{CHA}_{2} \mathrm{DS}_{2}$-VASc criteria with 115 TE-free patients and CT $(n=120)$ or MRI $(n=10)$ data were compared. Renal function was assessed by the estimated glomerular filtration rate (eGFR) using the CockroftGault equation. AF type and oral anticoagulation were defined and used according to current guidelines. All patients gave written informed consent according to the Declaration of Helsinki. Table 1 shows the patients' characteristics.

\section{Computed tomography}

Cardiac-CT was performed with a multidetector 64-row helical system (Brilliance 64, Philips Medical Systems, The Netherlands). Image acquisition was electrogram-gated when possible and the parameters included: $70-120 \mathrm{KV}, 850 \mathrm{mAs}, 0.6 \mathrm{~mm}$ beam collimation, $0.625-1.25 \mathrm{~mm}$ thickness and 20-30 cm field-of-view. During an end-inspiratory breath-hold of 20 seconds, and following a timing bolus-chase injection $(20 \mathrm{~mL}, 5 \mathrm{~mL} / \mathrm{s}), 90 \mathrm{~mL}$ of an iodinated contrast medium (Ultravist 370, Bayer Vital, Germany) was administered. Finally end-systolic imaging data were used for three-dimensional (3D) reconstruction.

\section{Magnetic resonance imaging}

Contrast-enhanced MRI of the LA was performed with a 1.5T MRI scanner (Intera CV, Philips Healthcare, Best, the Netherlands) and a 5-channel phased array surface cardiac coil. After bolus tracking technique with gadopentetate dimeglumine $(0.2 \mathrm{mmol} / \mathrm{kg} / \mathrm{body}$ weight, Magnevist, Bayer HealthCare Pharmaceuticals, Berlin, Germany) images of $8 \mathrm{~mm}$ thickness were acquired. Breath hold standard cine steady-state free precession sequences in short-axis 4-chamber view were acquired covering the whole heart gapless from the apex to the base. To provide T1- 
weighting and minimize artifacts, echo time was $1.8 \mathrm{~ms}$, repetition time $3.6 \mathrm{~ms}$, flip angle $15-20^{\circ}$ and in-plane resolution was $1.7 \times 1.8 \mathrm{~mm}$. Electrocardiogram-gating was used when possible.

\section{LAA measurements and classification}

Imaging data were reviewed using multiplanar 3D reconstruction in a specialized processing software (EnSite Verismo, SJM, MN). LAA volume, ostium-diameters (antero-posterior and supero-inefrior) and total length (adjusted for bends) were measured. The takeoff of the superior or inferior LAA edge in relation (higher or lower) to the respective superior takeoff of the adjacent pulmonary vein (PV) was determined similarly to a previously described method (Figure 2.1). ${ }^{7}, 12$ Two physicians experienced with cardiac imaging and blinded to the clinical data, analyzed LAA morphology. In case of disagreement, a decision was made based on common consent with a third expert physician.

The LAA morphology was classified as previously defined (Figure 2.2): ${ }^{8}$

1. The Cactus LAA, with a dominant central lobe and secondary lobes extending in both superior and inferior directions.

2. The Chicken-Wing LAA, with an obvious bend of the dominant lobe, or folding back on itself at some distance from the ostium, with or without secondary lobes.

3. The Windsock LAA, with a dominant lobe of sufficient length as the primary structure. Variations of this type with different location and number of smaller secondary or tertiary lobes were included here.

4. The Cauliflower LAA, with limited overall length and more complex internal characteristics. Variations of ostium and a variable number of lobes, without a dominant lobe, fall into this type.

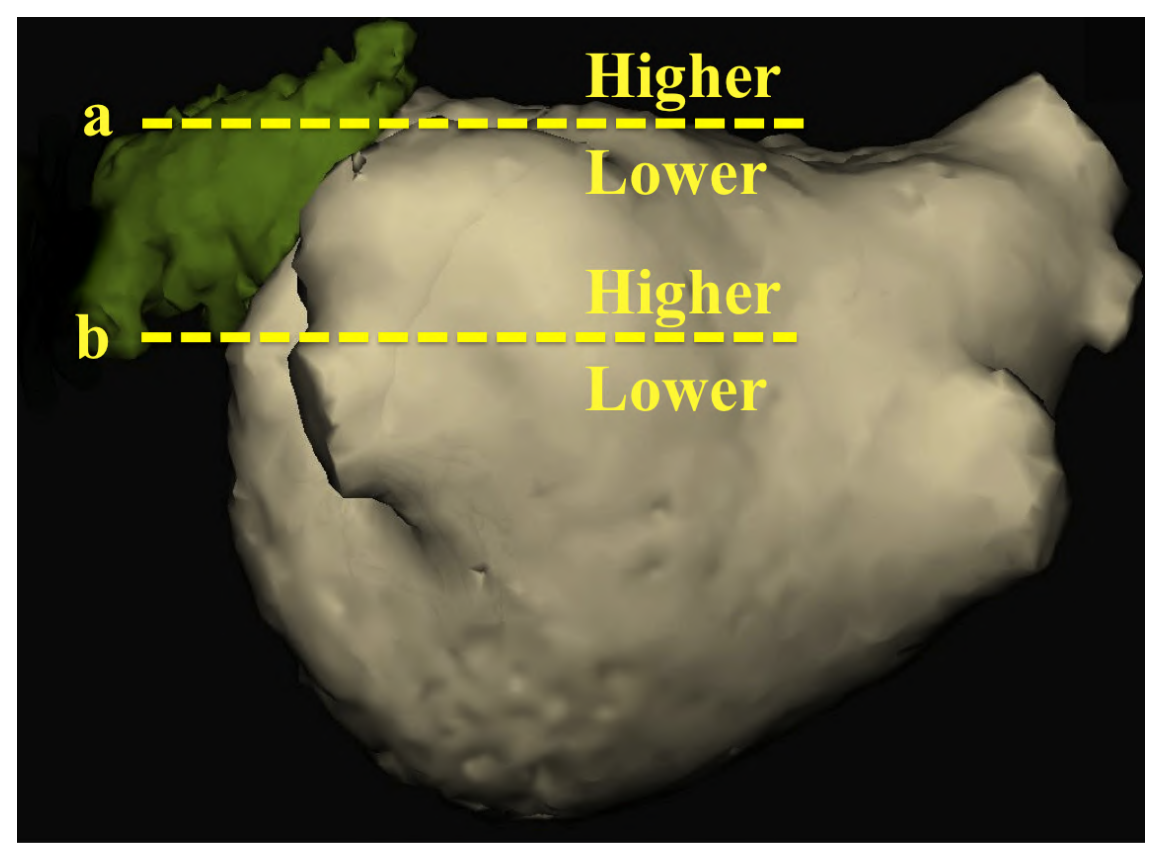

Figure 2.1. Classification of the "takeoff" a. of the superior LAA ostium in relation to the left superior pulmonary vein (PV) and b. the inferior LAA portion in relation to the left inferior PV. 


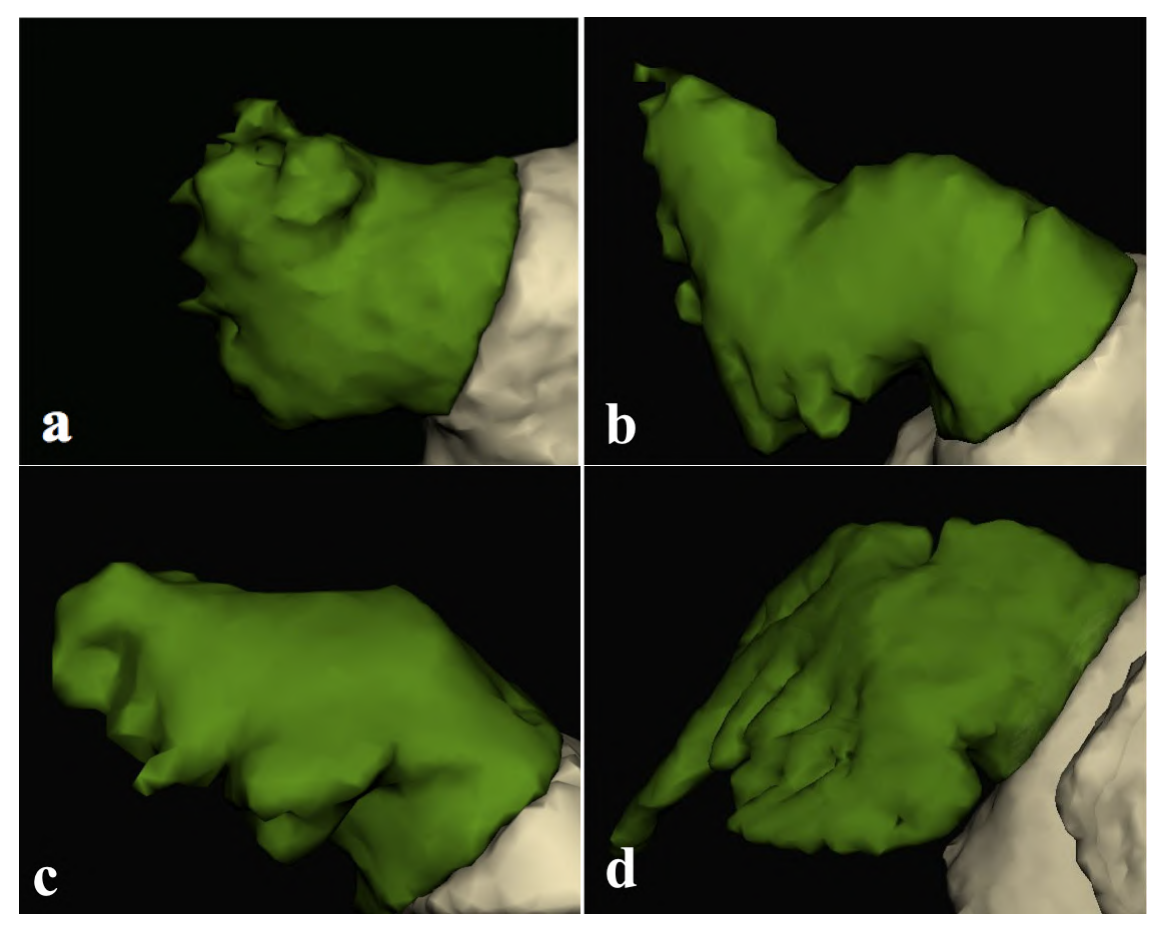

Figure 2.2. LAA morphologies classified as previously described: a. Cactus, b. Chicken-Wing, c. Windsock and d. Cauliflower LAA.

\begin{abstract}
Ablation procedure and follow-up
Catheter ablation was performed as previously described. ${ }^{13}$ Trans-oesophageal echocardiography was used to exclude LAA thrombi and register outflow profiles (5-10 cycles) together with the heart rate. Transseptal access and catheter navigation were performed with a steerable sheath (Agilis, St. Jude Medical, St. Paul, MN, USA) and electroanatomic mapping systems (EnSite ${ }^{\mathrm{TM}} \mathrm{NavX}{ }^{\mathrm{TM}}$, St. Jude Medical; or CARTO ${ }^{\mathrm{TM}}$, Biosense Webster, Diamond Bar, CA, USA), after integration of CT image datasets. All patients received circumferential ablation lines around the antrum of the ipsilateral pulmonary veins (irrigated tip catheter, temperature of $\leq 48^{\circ} \mathrm{C}$, power of $30-45 \mathrm{~W}$ ). Complete pulmonary vein isolation was verified with a multipolar circular mapping catheter. In patients with persistent AF, additional linear lesions were added between the circular lesions, at the mitral isthmus and the posterior LA wall to create a "box" lesion.

Rhythm follow-up was performed with repeated 7-day-holter ECG recordings (Lifecard CF, Delmar-Reynolds Medical Inc, Irvine, CA, USA) immediately after the procedure and during 6, 12, 24 and 36 months of follow-up. Patients with symptomatic episodes were encouraged to refer to a physician. Recurrence was defined as any documented atrial tachycardia or fibrillation episodes lasting more than 30 seconds. Recurrences within the 3 months blanking period were classified as early recurrences.

All patients were already on or were placed on anticoagulation with vitamin $\mathrm{K}$ antagonists right after the ablation procedure and continued the regimen according to $\mathrm{CHADS}_{2}$ or $\mathrm{CHA}_{2} \mathrm{DS}_{2-}$ VASc score after 6 months. Class I and III antiarrhythmic drugs were discontinued after the ablation procedure and the medication was adapted on an individual basis in case of $\mathrm{AF}$ recurrence.
\end{abstract}




\section{Statistical analysis}

Continuous variables are expressed as mean and standard deviation (SD) when normally distributed (positive Kolmogorov-Smirnoff test) or as median and interquartile range (IQR). Categorical variables are reported as frequencies and percentage. Parametric variables were compered by means of paired Student's t-test and non-parametric variables by Wilcoxon-test or chi-square test. Comparison of $\geq 2$ groups was performed with ANOVA analysis and post-hoc Bonferoni test for parametric variables and with Kruskal-Wallis test for non-parametric variables. Cohen's kappa $(\kappa)$ coefficient was used as a statistical measure of inter-rater agreement. A good level of agreement was defined as $\kappa>0.61 .^{14}$

To determine independent associations with TE events, logistic regression analysis was performed. Variables with a p-value $\leq 0.1$ in univariate analysis were then included in the multivariate cox-regression analysis for the determination of hazard ratio (HR) and its 95\% confidence interval (CI). With the observed 15 events and a 1:7 case-control ratio, a 35\% difference in LAA morphology distribution (as previously reported) ${ }^{12}$ was detectable with $80 \%$ power and $\mathrm{P}$-value $<0.05$. A two-tailed $\mathrm{P}$-value less than 0.05 was considered statistically significant. Analysis was performed with SPSS v20.0 (SPSS Inc., Chicago, USA).

\section{Patient population}

\section{Results}

Study patients $(64 \pm 10$ years, $61 \%$ male) were followed regularly for a median time of 24 months (IQR: 14-38). At the end of follow-up and after $1.4 \pm 0.7$ ablations, $67 \%$ of the patients remained in sinus rhythm (cumulative success). The percentage of patients with antiarrhythmic drug treatment was similar between the study and the control group (Table 2.1).

The clinical characteristics of patients with TE during follow-up are shown in Table 2.2. The median time to event was 11 (IQR: 6-19) months. All patients with TE were anticoagulated at the time of the event. The mean INR for the TE cohort was $1.5 \pm 0.5$ at discharge and $2.37 \pm 0.75$ at the time of the TE. The rest of the patients without TE during follow-up retained anticoagulation throughout the study. There were few patients $(5 \%)$ with novel anticoagulants equally distributed in both groups (Table 2.1).

In the entire population, LAA had a volume of $8 \pm 4 \mathrm{ml}$, a length of $36 \pm 11 \mathrm{~mm}$ and an ostium of $22 \pm 6 \mathrm{~mm}$. The superior LAA-takeoff was higher than the left superior pulmonary vein (LSPV) in $42 \%$ of the patients, and the inferior LAA-takeoff was higher than the left inferior pulmonary vein (LIPV) in 56\% of the patients. A higher superior LAA-takeoff was associated with a higher inferior LAA-takeoff in the total population (44\% frequency in combination, $\mathrm{p}=0.001$ ).

The prevalence of Cactus, Chicken-Wing, Windsock, and Cauliflower types was $23 \%, 20 \%$, $19 \%$, and $38 \%$ respectively. Peripheral vascular disease was more prevalent in patients with a Cactus-LAA compared to a non-Cactus-LAA. There were no other significant differences among the LAA morphologies in respect to other characteristics (Table 2.3). No statistically significant difference was noted in the rates of agreement in classifying LAA morphology (kappa $0.70 ; 95 \%$ CI: 0.39-0.92, $\mathrm{p}<0.001)$. 
Table 2.1. Characteristics of 15 patients with thromboembolic events (TE) during follow-up and 115 event-free patients, matched for the $\mathrm{CHA}_{2} \mathrm{DS}_{2}$-VASc score criteria.

\begin{tabular}{|c|c|c|c|c|}
\hline & \multirow{2}{*}{$\begin{array}{r}\text { All patients } \\
(\mathrm{n}=130)\end{array}$} & \multicolumn{2}{|c|}{ TE after AF ablation } & \multirow[b]{2}{*}{$\mathrm{P}$} \\
\hline & & Yes $(n=15)$ & No $(n=115)$ & \\
\hline Age, years & $64 \pm 10$ & $64 \pm 11$ & $65 \pm 10$ & 0.82 \\
\hline Female, n (\%) & $50(39 \%)$ & $6(40 \%)$ & $44(38 \%)$ & 1.00 \\
\hline Paroxysmal AF, n (\%) & $66(51 \%)$ & $8(53 \%)$ & $58(50 \%)$ & 1.00 \\
\hline Persistent AF, n (\%) & $64(49 \%)$ & $7(47 \%)$ & $57(50 \%)$ & 1.00 \\
\hline $\mathrm{BMI}, \mathrm{kg} / \mathrm{m}^{2}$ & $29 \pm 3$ & $28 \pm 2$ & $29 \pm 3$ & 0.97 \\
\hline $\mathrm{eGFR}, \mathrm{ml} / \mathrm{min} / 1.73 \mathrm{~m}^{2}$ & $89 \pm 27$ & $89 \pm 28$ & $88 \pm 25$ & 0.83 \\
\hline Hypertension, n (\%) & $113(87 \%)$ & $13(87 \%)$ & $100(87 \%)$ & 1.00 \\
\hline Diabetes mellitus, n (\%) & $37(29 \%)$ & $6(40 \%)$ & $31(27 \%)$ & 0.36 \\
\hline Prior stroke/TIA, n (\%) & $31(26 \%)$ & $4(27 \%)$ & $27(26 \%)$ & 1.00 \\
\hline Coronary artery disease, $\mathrm{n}(\%)$ & $36(28 \%)$ & $6(40 \%)$ & $30(26 \%)$ & 0.36 \\
\hline Dilated cardiomyopathy, n (\%) & $10(8 \%)$ & $2(13 \%)$ & $8(7 \%)$ & 0.32 \\
\hline Heart failure, $\mathrm{n}(\%)$ & $22(17 \%)$ & $4(27 \%)$ & $18(16 \%)$ & 0.47 \\
\hline Peripheral vascular disease, $\mathrm{n}(\%)$ & $17(13 \%)$ & $2(13 \%)$ & $15(13 \%)$ & 1.00 \\
\hline $\mathrm{CHADS}_{2}$ score, $\mathrm{n}$ & $1.9 \pm 1.1$ & $2.2 \pm 1.0$ & $1.9 \pm 1.2$ & 0.35 \\
\hline $\mathrm{CHA}_{2} \mathrm{DS}_{2}-\mathrm{VASc}$ score, $\mathrm{n}$ & $2.9 \pm 1.3$ & $3.1 \pm 1.4$ & $2.9 \pm 1.3$ & 0.48 \\
\hline Novel anticoagulants, $\mathrm{n}(\%)$ & $5(4 \%)$ & $1(6 \%)$ & $4(3 \%)$ & 0.56 \\
\hline Follow-up time, months (median, IQR) & $24(14-38)$ & $24(13-37)$ & $24(14-39)$ & 0.58 \\
\hline Antiarrhythmic drug use, $\mathrm{n}(\%)$ & $16(12 \%)$ & $2(13 \%)$ & $14(12 \%)$ & 0.82 \\
\hline Re-ablation, $\mathrm{n}(\%)$ & $32(25 \%)$ & $3(20 \%)$ & $29(25 \%)$ & 0.78 \\
\hline AF recurrence rate, $\mathrm{n}(\%)$ & $43(33 \%)$ & $11(73 \%)$ & $32(28 \%)$ & 0.001 \\
\hline \multicolumn{5}{|l|}{ Imaging parameters } \\
\hline Left ventricular ejection fraction, $\%$ & $57 \pm 10$ & $53 \pm 15$ & $58 \pm 9$ & 0.28 \\
\hline Left atrial diameter, $\mathrm{mm}$ & $44 \pm 6$ & $46 \pm 5$ & $43 \pm 6$ & 0.15 \\
\hline Left ventricular ed. Diameter, mm & $49 \pm 8$ & $53 \pm 9$ & $48 \pm 8$ & 0.042 \\
\hline Interventricular septum diameter, $\mathrm{mm}$ & $12 \pm 3$ & $11 \pm 2$ & $12 \pm 3$ & 0.55 \\
\hline LAA flow velocity, $\mathrm{cm} / \mathrm{sec}$ & $47 \pm 19$ & $39 \pm 18$ & $49 \pm 21$ & 0.07 \\
\hline LAA volume, $\mathrm{ml}$ & $8 \pm 4$ & $7 \pm 3$ & $8 \pm 4$ & 0.35 \\
\hline LAA length, mm & $36 \pm 11$ & $37 \pm 12$ & $35 \pm 11$ & 0.61 \\
\hline LAA diameter antero-posterior, $\mathrm{mm}$ & $22 \pm 6$ & $21 \pm 4$ & $23 \pm 6$ & 0.27 \\
\hline LAA diameter supero-inferior, $\mathrm{mm}$ & $22 \pm 6$ & $22 \pm 4$ & $23 \pm 6$ & 0.45 \\
\hline Superior LAA-takeoff over LSPV, n (\%) & $54(42 \%)$ & $12(80 \%)$ & $42(37 \%)$ & 0.002 \\
\hline Inferior LAA-takeoff over LIPV, n (\%) & $73(56 \%)$ & $11(73 \%)$ & $62(54 \%)$ & 0.97 \\
\hline LAA morphologies & & & & 0.90 \\
\hline Cactus LAA & $30(23 \%)$ & $4(27 \%)$ & $26(23 \%)$ & \\
\hline Chicken-Wing LAA & $26(20 \%)$ & $3(20 \%)$ & $23(20 \%)$ & \\
\hline Windsock LAA & $25(19 \%)$ & $3(20 \%)$ & $22(19 \%)$ & \\
\hline Cauliflower LAA & $49(38 \%)$ & $5(33 \%)$ & $44(38 \%)$ & \\
\hline
\end{tabular}

$\mathrm{BMI}=$ body mass index; $\mathrm{eGFR}=$ estimated glomerular filtration rate; $\mathrm{LAA}=$ left atrial appendage; $\mathrm{IQR}=$ interquartile range. 
Table 2.2. Characteristics of patients with postinterventional thromboembolic (TE) events.

\begin{tabular}{|c|c|c|c|c|c|c|c|c|c|c|}
\hline & نัّ & $\underbrace{80}_{0}$ & 華 & 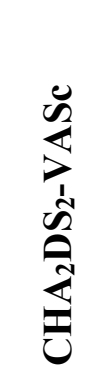 & 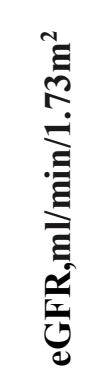 & 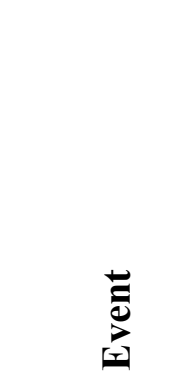 & 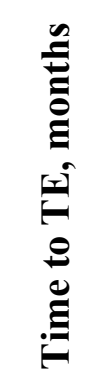 & 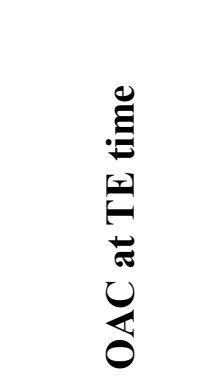 & 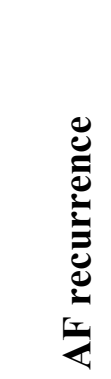 & 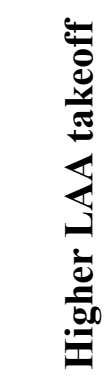 \\
\hline$\# 1$ & Female & 32 & 1 & 1 & 80 & Stroke & 2 & $\begin{array}{l}\text { Aspirin, } \\
\text { Clopidogrel, } \\
\text { LMWH* }^{*}\end{array}$ & No & Yes \\
\hline$\# 2$ & Male & 55 & 1 & 1 & 120 & Stroke & 37 & Warfarin & No & Yes \\
\hline$\# 3$ & Female & 54 & 3 & 3 & 69 & Stroke & 11 & LMWH & Yes & $\mathrm{No}$ \\
\hline$\# 4$ & Female & 58 & 4 & 5 & 139 & Stroke & 24 & Warfarin & Yes & Yes \\
\hline$\# 5$ & Male & 59 & 2 & 2 & 100 & Stroke & 16 & Warfarin & Yes & Yes \\
\hline$\# 6$ & Male & 64 & 3 & 3 & 124 & Stroke & 5 & $\begin{array}{l}\text { Aspirin, } \\
\text { Clopidogrel }\end{array}$ & No & Yes \\
\hline$\# 7$ & Male & 64 & 0 & 0 & 75 & TIA & 9 & Dabigatran & Yes & Yes \\
\hline$\# 8$ & Male & 66 & 4 & 6 & 59 & $\begin{array}{l}\text { A. } \\
\text { opliteal } \\
\text { Embolism }\end{array}$ & 40 & Warfarin & Yes & Yes \\
\hline$\# 9$ & Female & 69 & 3 & 3 & 88 & TIA & 6 & Warfarin & Yes & No \\
\hline$\# 10$ & Female & 68 & 1 & 1 & 77 & TIA & 15 & Warfarin & Yes & Yes \\
\hline$\# 11$ & Male & 71 & 4 & 4 & 93 & TIA & 5 & Warfarin & Yes & Yes \\
\hline$\# 12$ & Male & 72 & 1 & 1 & 97 & TIA & 11 & Warfarin & Yes & No \\
\hline$\# 13$ & Male & 74 & 1 & 1 & 58 & TIA & 3 & Warfarin & No & Yes \\
\hline$\# 14$ & Male & 76 & 2 & 2 & 55 & Stroke & 10 & Warfarin & Yes & Yes \\
\hline$\# 15$ & Female & 77 & 2 & 2 & 82 & TIA & 17 & Warfarin & Yes & Yes \\
\hline
\end{tabular}

$\mathrm{AF}=$ atrial fibrillation, $\mathrm{eGFR}=$ estimated glomerular filtration rate, $\mathrm{LMWH}=$ low molecular weight heparin, $\mathrm{OAC}=$ oral anticoagulation, $\mathrm{TIA}=$ transient ischemic attack 
Table 2.3. Characteristics and LAA measurements according to LAA morphology.

\begin{tabular}{|c|c|c|c|c|c|}
\hline & \multicolumn{4}{|c|}{ LAA morphology } & \multirow[b]{2}{*}{$\mathrm{P}$} \\
\hline & Cactus & Chicken-Wing & Windsock & Cauliflower & \\
\hline Patients, n (\%) & $30(25 \%)$ & $26(20 \%)$ & $25(20 \%)$ & $49(35 \%)$ & \\
\hline Age, years & $67 \pm 10$ & $64 \pm 10$ & $64 \pm 7$ & $63 \pm 12$ & 0.60 \\
\hline Female, n (\%) & $11(40 \%)$ & $9(38 \%)$ & $10(40 \%)$ & $20(37 \%)$ & 0.97 \\
\hline Paroxysmal atrial fibrillation, n (\%) & $18(60 \%)$ & $12(46 \%)$ & $12(48 \%)$ & $24(49 \%)$ & 0.71 \\
\hline Persistent atrial fibrillation, $\mathrm{n}(\%)$ & $12(40 \%)$ & $14(54 \%)$ & $13(52 \%)$ & $25(51 \%)$ & 0.71 \\
\hline BMI, $\mathrm{kg} / \mathrm{m}^{2}$ & $28 \pm 2$ & $29 \pm 3$ & $28 \pm 4$ & $29 \pm 2$ & 0.46 \\
\hline eGFR, $\mathrm{ml} / \mathrm{min} / 1.73 \mathrm{~m}^{2}$ & $89 \pm 28$ & $88 \pm 27$ & $94 \pm 26$ & $89 \pm 28$ & 0.84 \\
\hline Hypertension, $\mathrm{n}(\%)$ & $26(87 \%)$ & $23(89 \%)$ & $23(92 \%)$ & $41(84 \%)$ & 0.78 \\
\hline Diabetes mellitus, $\mathrm{n}(\%)$ & $8(25 \%)$ & $6(23 \%)$ & $9(35 \%)$ & $14(31 \%)$ & 0.75 \\
\hline Prior stroke/TIA, n (\%) & $4(15 \%)$ & $6(26 \%)$ & $5(22 \%)$ & $16(33 \%)$ & 0.50 \\
\hline Stroke/TIA during follow-up, n (\%) & $4(13 \%)$ & $3(12 \%)$ & $3(12 \%)$ & $5(10 \%)$ & 0.98 \\
\hline Coronary artery disease, $\mathrm{n}(\%)$ & $7(23 \%)$ & $10(39 \%)$ & $6(24 \%)$ & $13(27 \%)$ & 0.57 \\
\hline Dilated cardiomyopathy, n (\%) & $2(7 \%)$ & $2(8 \%)$ & $2(8 \%)$ & $4(8 \%)$ & 0.99 \\
\hline Heart failure, $\mathrm{n}(\%)$ & $4(13 \%)$ & $5(19 \%)$ & $7(28 \%)$ & $7(14 \%)$ & 0.45 \\
\hline Peripheral vascular disease, $\mathrm{n}(\%)$ & $9(30 \%)^{*}$ & $2(8 \%)$ & $2(8 \%)$ & $4(9 \%)$ & 0.03 \\
\hline CHADS $_{2}$ score, $\mathrm{n}$ & $1.8 \pm 1.1$ & $1.9 \pm 1.1$ & $2.0 \pm 1.0$ & $1.9 \pm 1.2$ & 0.70 \\
\hline $\mathrm{CHA}_{2} \mathrm{DS}_{2}$-VASc score, $\mathrm{n}$ & $2.7 \pm 1.6$ & $2.8 \pm 1.3$ & $2.9 \pm 1.2$ & $3.0 \pm 1.3$ & 0.76 \\
\hline Novel anticoagulants, $\mathrm{n}(\%)$ & $1(3 \%)$ & $1(4 \%)$ & $1(4 \%)$ & $2(4 \%)$ & 0.77 \\
\hline Follow-up time, months (median, IQR) & $22(14-36)$ & $25(13-39)$ & $26(14-38)$ & $24(12-37)$ & 0.66 \\
\hline Antiarrhythmic drug use, $\mathrm{n}(\%)$ & $4(13 \%)$ & $4(15 \%)$ & $3(12 \%)$ & $5(10 \%)$ & 0.74 \\
\hline Re-ablation, n (\%) & $7(23 \%)$ & $6(24 \%)$ & $6(23 \%)$ & $13(27 \%)$ & 0.65 \\
\hline AF recurrence rate, $\mathrm{n}(\%)$ & $11(37 \%)$ & $7(27 \%)$ & $10(40 \%)$ & $15(31 \%)$ & 0.73 \\
\hline \multicolumn{6}{|l|}{ Imaging parameters } \\
\hline Left ventricular ejection fraction, $\%$ & $57 \pm 10$ & $57 \pm 8$ & $54 \pm 12$ & $58 \pm 10$ & 0.45 \\
\hline Left atrial diameter, $\mathrm{mm}$ & $46 \pm 5$ & $43 \pm 6$ & $44 \pm 5$ & $42 \pm 7$ & 0.07 \\
\hline Left ventricular ed. Diameter, $\mathrm{mm}$ & $48 \pm 8$ & $49 \pm 6$ & $49 \pm 8$ & $50 \pm 8$ & 0.81 \\
\hline Interventricular septum diameter, $\mathrm{mm}$ & $13 \pm 2$ & $11 \pm 8$ & $12 \pm 2$ & $12 \pm 3$ & 0.32 \\
\hline LAA flow velocity, $\mathrm{cm} / \mathrm{sec}$ & $50 \pm 19$ & $47 \pm 18$ & $44 \pm 18$ & $47 \pm 20$ & 0.77 \\
\hline LAA volume, $\mathrm{ml}$ & $7 \pm 3$ & $9 \pm 4$ & $8 \pm 4$ & $8 \pm 4$ & 0.60 \\
\hline LAA length, mm & $35 \pm 6$ & $40 \pm 16$ & $35 \pm 12$ & $34 \pm 9$ & 0.32 \\
\hline LAA diameter antero-posterior, $\mathrm{mm}$ & $22 \pm 5$ & $27 \pm 5$ & $22 \pm 5$ & $23 \pm 6$ & 0.32 \\
\hline LAA diameter supero-inferior, $\mathrm{mm}$ & $22 \pm 6$ & $28 \pm 6$ & $24 \pm 6$ & $23 \pm 6$ & 0.26 \\
\hline Superior LAA-takeoff over LSPV, n (\%) & $11(37 \%)$ & $10(39 \%)$ & $13(52 \%)$ & $20(43 \%)$ & 0.68 \\
\hline Inferior LAA-takeoff over LIPV, n (\%) & $17(57 \%)$ & $15(58 \%)$ & $16(64 \%)$ & $25(51 \%)$ & 0.38 \\
\hline
\end{tabular}

$\mathrm{BMI}=$ body mass index; $\mathrm{LAA}=$ left atrial appendage; $\mathrm{LSPV}=$ left superior pulmonary vein; $\mathrm{LIPV}=$ left inferior pulmonary vein; $\mathrm{eGFR}=$ estimated glomerular filtration rate; IQR= interquartile range, ${ }^{*}$ statistically significant.

\section{LAA characteristics and thromboembolism during follow-up}

Clinical characteristics and LAA measurements according to the occurrence of a TE are presented in Table 2.2. Patients that suffered a TE during follow-up time had a higher AF recurrence rate $(73 \%$ vs. $28 \%, \mathrm{p}=0.001)$ and a higher incidence of superior LAA-takeoff (i.e. higher than the left superior PV; $80 \%$ vs. $37 \%, p=0.002$ ) in comparison to the control group. TE during follow-up was thus more prevalent in patients with AF recurrence $(26 \%$ vs. $4 \%, p=0.001)$ or a higher superior LAA-takeoff $(80 \%$ vs. $4 \%, \mathrm{p}=0.002)$. Further comparison between study and 
control group revealed a higher left ventricular end-diastolic diameter ( $53 \pm 9$ vs. $48 \pm 8 \mathrm{~mm}$, $\mathrm{p}=0.042)$ and a tendency for reduced LAA flow ( $39 \pm 18$ vs. $49 \pm 21 \mathrm{~cm} / \mathrm{sec}, \mathrm{p}=0.07)$.

In contrast, the prevalence of LAA types was similar between the study and the control group: 27\% Cactus, 20\% Chicken-Wing, 20\% Windsock, 33\% Cauliflower vs. 23\%, 20\%, 19\%, 38\% respectively $(\mathrm{p}=0.98)$. No further differences were found in the prevalence of an inferior LAAtakeoff, clinical TE scores or other LAA measurements.

Multivariable analysis including AF recurrence, superior takeoff of LAA, LAA flow and left ventricular end-diastolic diameter in a forward, stepwise model, showed that patients with TE after CA were more likely to have AF recurrence (HR: 6.2, 95\% CI: 2.0-19.6, $p=0.002$ ) and superior LAA takeoff (HR: 4.9, 95\% CI: 1.4-17.4, $\mathrm{p}=0.014$ ). In sub-analysis of patients with AF recurrence during follow-up, a superior LAA-takeoff was more prevalent in TE patients (82\% vs. $28 \%, \mathrm{p}=0.004$ ) and thus independently associated with a higher risk of an embolic event (HR: 5.6, 95\% CI: $1.2-25.7, \mathrm{p}=0.029)$. Analysis of the relationship between heart rate and LAA flow (Figure 2.3) revealed a negative correlation $(\mathrm{r}=-0.22 \mathrm{~cm} / \mathrm{s}$ pro $\mathrm{bpm}, \mathrm{p}=0.016)$, that was more pronounced for the superior LAA takeoff $(\mathrm{r}=-0.28, \mathrm{p}=0.045)$ and did not reach statistical significance for the lower LAA takeoff $(r=-0.18, p=0.141)$.

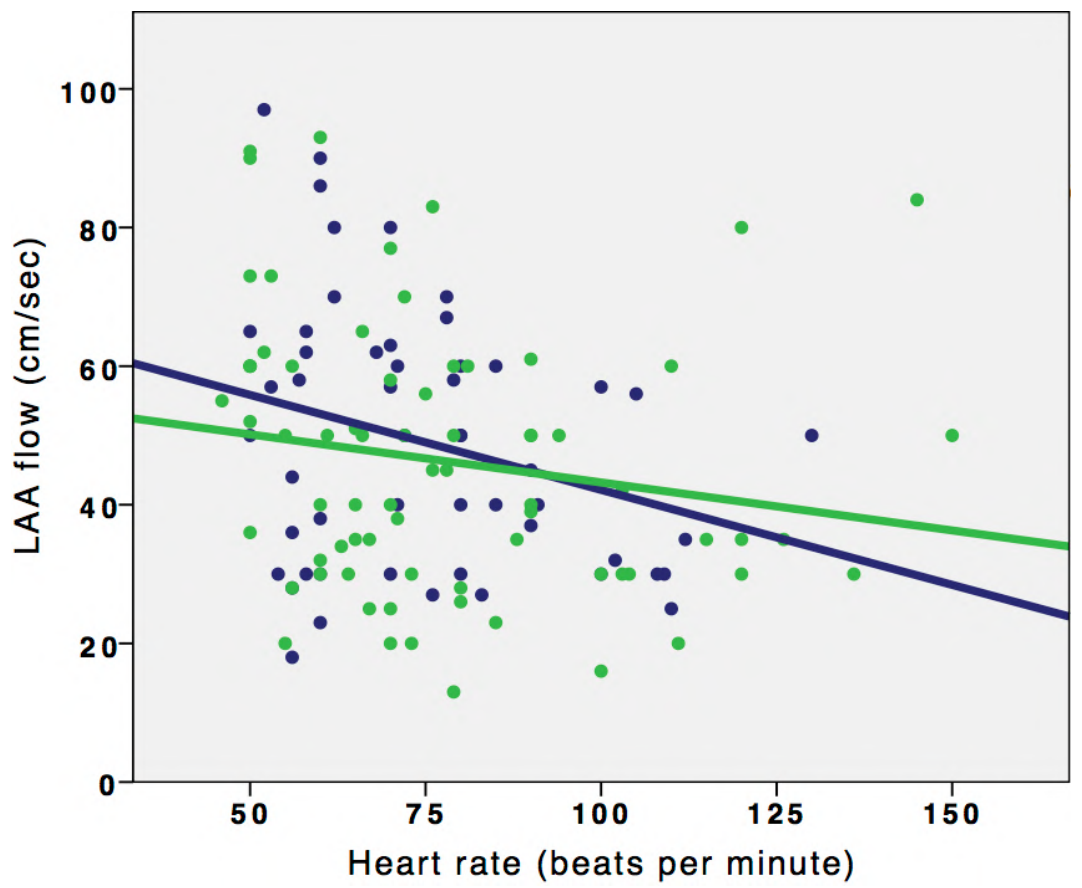

Figure 2.3. Correlation between heart rate and left atrial appendage (LAA) flow in patients with higher (blue: $r=-0.28, p=0.045$ ) and lower (green: $r=-0.18, p=0.141$ ) superior takeoff.

\section{Main findings}

\section{Discussion}

This study illuminates the role of AF recurrence and the LAA anatomy for TE after AF catheter ablation by comparing two $\mathrm{CHA}_{2} \mathrm{DS}_{2}$-VASc matched patient-groups, which were closely followed over a median period of 24 months. We found that the occurrence of a TE after AF-CA is associated with AF recurrence and a higher position of the superior LAA-takeoff, above the respective left superior pulmonary vein (LSPV). The thromboembolic risk during follow-up increases six times if the patient experiences an AF recurrence and almost five times if the LAA 
has a superior takeoff over the LSPV. In patients with AF recurrence, superior LAA takeoff means almost six-fold higher TE risk. In contrast, LAA morphology was not associated with TE after AF ablation.

\section{TE predictors after AF ablation}

Thromboembolic risk is significantly reduced in AF patients undergoing an ablation procedure, but still remains a significant clinical issue. ${ }^{15,}{ }^{16}$ Previous studies have identified CHADS or $\mathrm{CHA}_{2} \mathrm{DS}_{2}$-VASc scores, ${ }^{17-19}$ and $\mathrm{AF}$ recurrence ${ }^{19,20}$ as predictors of embolic events after $\mathrm{AF}$ ablation. This study aimed to eliminate the effect of $\mathrm{CHA}_{2} \mathrm{DS}_{2}-\mathrm{VASc}$ factors in order to clarify the role of rhythm maintenance and LAA anatomy for TE after AF ablation.

\section{AF recurrence}

The results of this and previous studies indicate that AF recurrence is independently associated with embolic events after AF ablation. ${ }^{19,20}$ We found that in this case, AF reappearance was associated with a six times higher embolic risk. This highlights the importance of sinus rhythm maintenance and the significant role of AF in thrombogenesis, despite the continuation of anticoagulation. Considering these results, patients with AF recurrence after an ablative procedure must be followed very closely for adequate anticoagulation and timely recognition or treatment of TE.

\section{Anatomical and functional aspects}

Embolic events in AF patients derive mainly from reduced blood flow and thrombus formation in LAA that could be prevented by anticoagulation or obliteration. ${ }^{3-5}$ In accordance with previous studies, we found that an increased heart rate reduces the LAA peak flow velocity and promotes blood stasis. ${ }^{21,22}$ However, we found that this mechanism is more pronounced in patients with a higher LAA takeoff, remote to the mitral valve. Therefore, this kind of LAA anatomy is susceptible to thrombogenic flow during increased heart rate. A possible explanation of this observation would be a strong dependence of the hemodynamic LAA profile on the distance from the mitral annulus and the underlying arrhythmia and deserves further investigation. Our findings imply a possible tachycardia-mediated thrombogenic risk for these patients that can be assessed by LAA location (Figure 2.4).

Previous studies have associated a larger LAA $^{23-25}$ or a narrow ostium ${ }^{11,26}$ with an increased thromboembolic risk in AF patients. In our patient cohort though, there was no significant correlation between LAA dimensions and TE after CA (Table 1). Similarly, three recent studies found no significant correlation between LAA size and the prevalence of TE prior to CA. ${ }^{8}, 10,12$ Recently, the morphology of non-Chicken-Wing LAA ${ }^{8}$ or Cauliflower-LAA have been related with an increased thromboembolic risk. ${ }^{10-12}$ In our study though, LAA morphology was not associated with embolic events after AF-CA. A possible explanation may be the difference of the analyzed patients. In comparison to the study of Di Biase et al., ${ }^{8}$ patients in our cohort had a higher prevalence of prior TE (26\% vs. $8 \%$ ) along with higher $\mathrm{CHADS}_{2}$ score $(\geq 2: 79 \%$ vs. $14 \%)$ and a higher prevalence of non-Chicken-Wing LAA ( $80 \%$ vs. 52\%). In comparison to the study of Kimura et al., ${ }^{12}$ patients in our cohort had also a higher $\mathrm{CHADS}_{2}$ score $(\geq 2: 79 \%$ vs. $13 \%)$ and a higher prevalence of non-Chicken-Wing LAA ( $80 \%$ vs. $60 \%)$. In fact, since the prevalence of non-Chicken-Wing morphology was higher in our patient population, our findings could support the observation that these patients have increased embolic risk as expressed by clinical riskscores. However, when it comes to post-interventional thromboembolic risk, we found that it is not the LAA morphology but a tachycardia-mediated thrombogenic flow of a higher LAA take off that matters. 


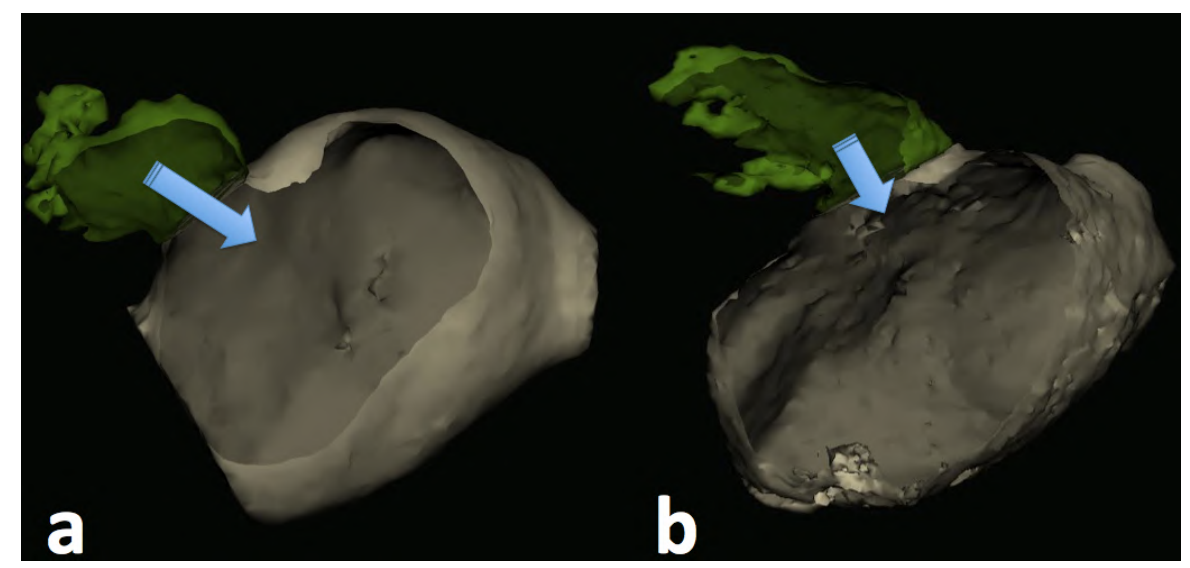

Figure 2.4. Example of $\mathbf{a}$. a low and $\mathbf{b}$. a high superior LAA takeoff in relation to the pulmonary vein. A higher takeoff is associated with reduced LAA flow (blue arrow) on higher heart rates.

Indeed, TE was more prevalent in patients with a higher LAA-takeoff. After adjusting for confounding factors, follow-up time and AF recurrence, a higher LAA-takeoff was independently associated with thromboembolism after AF ablation. To date, there are no further data correlating the various LAA positions with TE risk in patients with AF. A thorough examination of LAA anatomy in relation to flow-velocity and heart rate in previous studies might have drawn a different picture. Our results though reveal a tachycardia-associated thrombogenic flow as a possible pathophysiological mechanism for the increased TE risk of a higher LAA position. Since LAA orientation increases TE risk especially in case of a tachyarrhythmic recurrence, these patients warrant a closer follow-up for appropriate therapy adjustment and timely AF treatment.

\section{Limitations}

The present study is a single-center study with the inherent limitations of a post-hoc analysis. Imaging was based mainly on CT and MRI use was similar between groups ( $7 \%$ vs. $8 \%, p=0.8)$, so that imaging bias was limited. The incidence of manifested events was low and silent cerebral strokes were not examined. However, patients had meticulous medical records and were followed closely, allowing the collection of fairly complete data. In addition, our data refer to a selected population of patients undergoing AF ablation and further studies are needed to prove if these findings can be extended to other AF patients undergoing a different rhythm maintaining therapy. We were not able to retrieve the quality of anticoagulation in terms of individual time spent within target range. We included though a homogenous patient cohort, the majority of which were treated with vitamin $\mathrm{K}$ antagonists throughout the study. The limited use of novel anticoagulants in this study prohibits analysing their effect on TE. AF recurrence is not a baseline characteristic and the analysis implies a novel mechanistic insight rather than a predictive value. Despite these limitations, statistical relation between embolic risk, AF recurrence and LAA position remains significant and reveals a plausible association. Therefore, future studies assessing TE risk in AF patients should evaluate both LAA position and flow velocity in relation to heart rate, in order to examine the effect of a higher LAA takeoff.

\section{Conclusion}

Atrial fibrillation recurrence and higher takeoff of the left atrial appendage are associated with thromboembolic risk after catheter ablation, while LAA morphology is not. If confirmed, these findings may have implications for an appropriate post-ablation clinical and anticoagulation management. 


\section{References}

1. Al-Saady NM, Obel OA, Camm AJ. Left atrial appendage: structure, function, and role in thromboembolism. Heart Nov 1999;82:547-554.

2. Zabalgoitia M, Halperin JL, Pearce LA, Blackshear JL, Asinger RW, Hart RG. Transesophageal echocardiographic correlates of clinical risk of thromboembolism in nonvalvular atrial fibrillation. Stroke Prevention in Atrial Fibrillation III Investigators. J Am Coll Cardiol Jun 1998;31:1622-1626.

3. Blackshear JL, Odell JA. Appendage obliteration to reduce stroke in cardiac surgical patients with atrial fibrillation. Ann Thorac Surg Feb 1996;61:755-759.

4. Sievert H, Lesh MD, Trepels $\mathrm{T}$, et al. Percutaneous left atrial appendage transcatheter occlusion to prevent stroke in high-risk patients with atrial fibrillation: early clinical experience. Circulation Apr 23 2002;105:1887-1889.

5. Ostermayer $\mathrm{SH}$, Reisman $\mathrm{M}$, Kramer $\mathrm{PH}$, et al. Percutaneous left atrial appendage transcatheter occlusion (PLAATO system) to prevent stroke in high-risk patients with nonrheumatic atrial fibrillation: results from the international multi-center feasibility trials. J Am Coll Cardiol Jul 5 2005;46:9-14.

6. Heist EK, Refaat M, Danik SB, Holmvang G, Ruskin JN, Mansour M. Analysis of the left atrial appendage by magnetic resonance angiography in patients with atrial fibrillation. Heart Rhythm Nov 2006;3:1313-1318.

7. Budge LP, Shaffer KM, Moorman JR, Lake DE, Ferguson JD, Mangrum JM. Analysis of in vivo left atrial appendage morphology in patients with atrial fibrillation: a direct comparison of transesophageal echocardiography, planar cardiac CT, and segmented three-dimensional cardiac CT. J Interv Card Electrophysiol Nov 2008;23:87-93.

8. Di Biase L, Santangeli P, Anselmino M, et al. Does the left atrial appendage morphology correlate with the risk of stroke in patients with atrial fibrillation? Results from a multicenter study. J Am Coll Cardiol Aug 7 2012;60:531-538.

9. Ren JF, Callans DJ, Marchlinski FE. What is the natural relationship between left atrial appendage morphology and history of stroke? J Am Coll Cardiol Feb 12 2013;61:689-690.

10. Anselmino M, Scaglione M, Di Biase L, Gili S, Santangeli P, Corsinovi L, Pianelli M, Cesarani F, Faletti R, Righi D, Natale A, Gaita F. Left atrial appendage morphology and silent cerebral ischemia in atrial fibrillation patients. Heart Rhythm Jan 2014;11:2-7.

11. Khurram IM, Dewire J, Mager M, et al. Relationship between left atrial appendage morphology and stroke in patients with atrial fibrillation. Heart Rhythm Dec 2013;10:18431849.

12. Kimura T, Takatsuki S, Inagawa K, Katsumata Y, Nishiyama T, Nishiyama N, Fukumoto K, Aizawa Y, Tanimoto Y, Tanimoto K, Jinzaki M, Fukuda K. Anatomical characteristics of the left atrial appendage in cardiogenic stroke with low CHADS2 scores. Heart Rhythm Jun 2013;10:921-925.

13. Eitel C, Hindricks G, Sommer P, et al. Circumferential pulmonary vein isolation and linear left atrial ablation as a single-catheter technique to achieve bidirectional conduction block: the pace-and-ablate approach. Heart Rhythm 2010;7:157-164.

14. Landis JR, Koch GG. The measurement of observer agreement for categorical data. Biometrics Mar 1977;33:159-174.

15. Bunch TJ, Crandall BG, Weiss JP, May HT, Bair TL, Osborn JS, Anderson JL, Muhlestein JB, Horne BD, Lappe DL, Day JD. Patients treated with catheter ablation for atrial fibrillation have long-term rates of death, stroke, and dementia similar to patients without atrial fibrillation. Journal of cardiovascular electrophysiology Aug 2011;22:839-845. 
16. Bunch TJ, May HT, Bair TL, Weiss JP, Crandall BG, Osborn JS, Mallender C, Anderson JL, Muhlestein BJ, Lappe DL, Day JD. Atrial fibrillation ablation patients have long-term stroke rates similar to patients without atrial fibrillation regardless of CHADS2 score. Heart Rhythm Sep 2013;10:1272-1277.

17. Chao TF, Lin YJ, Tsao HM, et al. CHADS(2) and CHA(2)DS(2)-VASc scores in the prediction of clinical outcomes in patients with atrial fibrillation after catheter ablation. J Am Coll Cardiol Nov 29 2011;58:2380-2385.

18. Guiot A, Jongnarangsin K, Chugh A, et al. Anticoagulant therapy and risk of cerebrovascular events after catheter ablation of atrial fibrillation in the elderly. Journal of cardiovascular electrophysiology Jan 2012;23:36-43.

19. Kornej J, Hindricks G, Kosiuk J, Arya A, Sommer P, Husser D, Rolf S, Richter S, Piorkowski C, Gaspar T, Lip GY, Bollmann A. Renal dysfunction, stroke risk scores (CHADS2, CHA2DS2-VASc, and R2CHADS2), and the risk of thromboembolic events after catheter ablation of atrial fibrillation: the Leipzig Heart Center AF Ablation Registry. Circ Arrhythm Electrophysiol Oct 2013;6:868-874.

20. Hunter RJ, McCready J, Diab I, et al. Maintenance of sinus rhythm with an ablation strategy in patients with atrial fibrillation is associated with a lower risk of stroke and death. Heart Jan 2012;98:48-53.

21. Noda T, Arakawa M, Miwa H, Ito Y, Kagawa K, Nishigaki K, Hirakawa S, Fujiwara H. Effects of heart rate on flow velocity of the left atrial appendage in patients with nonvalvular atrial fibrillation. Clin Cardiol Apr 1996;19:295-300.

22. Obel OA, Luddington L, Maarouf N, Aytemir K, Ekwall C, Malik M, Camm AJ. Effects of ventricular rate and regularity on the velocity and magnitude of left atrial appendage flow in atrial fibrillation. Heart Jun 2005;91:764-768.

23. Somerville W, Chambers RJ. Systemic Embolism in Mitral Stenosis: Relation to the Size of the Left Atrial Appendix. Br Med J Nov 7 1964;2:1167-1169.

24. Ernst G, Stollberger C, Abzieher F, Veit-Dirscherl W, Bonner E, Bibus B, Schneider B, Slany J. Morphology of the left atrial appendage. Anat Rec Aug 1995;242:553-561.

25. Park HC, Shin J, Ban JE, Choi JI, Park SW, Kim YH. Left atrial appendage: morphology and function in patients with paroxysmal and persistent atrial fibrillation. Int $\mathrm{J}$ Cardiovasc Imaging Apr 2013;29:935-944.

26. Beinart R, Heist EK, Newell JB, Holmvang G, Ruskin JN, Mansour M. Left atrial appendage dimensions predict the risk of stroke/TIA in patients with atrial fibrillation. Journal of cardiovascular electrophysiology Jan 201 1;22:10-15. 
Chapter 3 Atrial fibrillation and thromboembolic risk in low-risk patients

Adapted from "Cardiogenic Stroke Despite Low CHA2DS2-VASc Score: Assessing Stroke risK by Left Atrial Appendage Anatomy (ASK LAA)"

Published in J Cardiovasc Electrophysiol Sep 2015;26:915-921. doi: 10.1111/jce.12749

Sotirios Nedios, Emmanuel Koutalas, Jelena Kornej, Sascha Rolf, Arash Arya, Philipp Sommer, Daniela Husser, Gerhard Hindricks, Andreas Bollmann 


\begin{abstract}
Background:

In patients with atrial fibrillation (AF), LAA morphology has been suggested to modify thromboembolic event (TE) risk. We tested the hypothesis that TE in low-risk patients is associated with LAA characteristics.

\section{Methods:}

Of 2069 patients who underwent AF ablation, $25(1.2 \%)$ had a prior TE and a low $\mathrm{CHA}_{2} \mathrm{DS}_{2}-$ VASc score $(\leq 1)$. Those patients were matched for the $\mathrm{CHA}_{2} \mathrm{DS}_{2}-\mathrm{VASc}$ criteria with 75 event-free patients and CT data were compared. LAA measurements, morphology (Cactus, Chicken-Wing, Windsock, Cauliflower) and takeoff of the superior and inferior edge in relation (higher or lower) to the respective takeoff of the adjacent pulmonary vein (PV) were determined. LAA flow in relation to heart rate was also compared.
\end{abstract}

\title{
Results:
}

Univariate analysis showed that TE-patients had a higher incidence of superior LAA takeoff (i.e. higher than the left superior PV; $28 \%$ vs. 4\%, $\mathrm{p}=0.002$ ) and a higher incidence of hyperlipidemia $(40 \%$ vs. $17 \%, \mathrm{p}=0.028)$, while LAA morphologies, inferior takeoff and other LAA characteristics were similar between groups. Logistic regression revealed that a superior LAA takeoff (OR: 9.1, 95\% CI: 2.1 to $38.6, p=0.003$ ) was the only independent predictor of TE. There was a negative correlation between heart rate and LAA flow $(\mathrm{r}=-0.2 \mathrm{~cm} / \mathrm{s}$ pro bpm, $\mathrm{p}=0.048)$, that was even more pronounced for the superior LAA takeoff $(\mathrm{r}=-0.67 \mathrm{~cm} / \mathrm{s}$ pro bpm, $\mathrm{p}=0.035)$.

\section{Conclusion:}

A higher LAA takeoff is associated with a tachycardia-mediated thrombogenic flow and an increased thromboembolic risk. These findings may have implications for anticoagulation management of AF patients with low $\mathrm{CHA}_{2} \mathrm{DS}_{2}$-VASc scores and higher LAA takeoff. 


\section{Introduction}

Atrial fibrillation (AF) is one of the most common causes of cardiogenic strokes, associated with an enormous health and economic burden. AF associated strokes are usually severe and confer an increased risk of morbidity and poor functional outcome. Validated stratification models, like $\mathrm{CHADS}_{2}$ and $\mathrm{CHA}_{2} \mathrm{DS}_{2}$-VASc score, have helped identify individuals with high risk and guide anticoagulation therapy. ${ }^{1,2}$ However, stratification and anticoagulation of low-risk patients remains a hurdle.

The left atrial appendage (LAA) is regarded as the primary source of thrombus formation, but is not included in the above stratification models. Di Biase et al. ${ }^{3}$ reported 4 different LAA morphologies (Cactus, Chicken-Wing, Windsock, Cauliflower) and found that the non-ChickenWing morphology is associated with a 3-fold risk of prior thromboembolic event (TE). Recent data have supplemented these findings, revealed the significance of LAA orientation for TE after $\mathrm{AF}$ ablation and found LAA anatomy useful for TE prediction in patients with low $\mathrm{CHADS}_{2}$ score. $^{4-8}$ In clinical use though, the $\mathrm{CHA}_{2} \mathrm{DS}_{2}$-VASc score that gives a better low-risk stratification has superseded the $\mathrm{CHADS}_{2}$ score. $^{2}$ Therefore, the role of LAA anatomy in patients with low $\mathrm{CHA}_{2} \mathrm{DS}_{2}$-VASc scores remains to be clarified.

The main objective of the present study was to analyze the morphology and other LAA characteristics in AF patients with low $\mathrm{CHA}_{2} \mathrm{DS}_{2}$-VASc score $(\leq 1)$ in order to identify their association with prior thromboembolic events, using a case-control study.

\section{Methods}

Of 2,069 patients included prospectively between 2007 and 2011 in our institutional AF catheter ablation registry, 25 (1.2\%) had a prior TE (12 strokes, 13 transient ischemic attacks) and a low $\mathrm{CHA}_{2} \mathrm{DS}_{2}$-VASc score at the time of the event. Ischemic stroke was a clinical diagnosis based on typical symptoms lasting $\geq 24$ hours. A transient schemic attack was defined as a sudden-onset focal neurological deficit of $<24$ hours' duration. Brain imaging was available in the vast majority of patients, and other embolic sources (eg, valvular or vascular) were excluded. Those patients were matched (1:3) for the $\mathrm{CHA}_{2} \mathrm{DS}_{2}-\mathrm{VASc}$ criteria with 75 event-free patients and CT data were compared. There were no patients with significant kidney disease. All patients gave written informed consent according to the Declaration of Helsinki and the institutional research committee approved the study. AF type and oral anticoagulation were defined and used according to current guidelines. Table 1 summarizes the characteristics of the patients.

\section{Echocardiographic measurements}

Transthoracic echocardiography was performed before ablation ( $2 \pm 1$ days) at a designated laboratory (Vivid-9 General Electric Vingmed, Milwaukee, WI) by a team of certified echocardiographers. Transesophageal echocardiography was performed on fasting patients after sedation with midazolam when necessary. A longitudinal section of the LAA was imaged by systematic multiplane views $\left(30-90^{\circ}\right)$. The Doppler sample volume was placed in the proximal third of the LAA for measurement of the end-diastolic outflow velocity. The outflow profiles were recorded and the values of 3 cycles were averaged and heart rate during LAA flow measurement was registered. Antiarrhythmic drugs (except amiodarone and beta-blocker) were withheld from all patients two days prior to AF ablation. 


\section{Computed tomography}

Cardiac-CT was performed with a multidetector 64-row helical system (Brilliance 64, Philips Medical Systems, Best, The Netherlands). Image acquisition was electrogram-gated when possible and the parameters included: $70-120 \mathrm{KV}, 850 \mathrm{mAs}, 0.6 \mathrm{~mm}$ beam collimation, $0.625-$ $1.25 \mathrm{~mm}$ thickness and 20-30 cm field-of-view. During an end-inspiratory breath-hold of 20 seconds, and following a timing bolus-chase injection $(20 \mathrm{~mL}, 5 \mathrm{~mL} / \mathrm{s}), 90 \mathrm{~mL}$ of an iodinated contrast medium (Ultravist 370, Bayer Vital, Cologne, Germany) was administered. Finally endsystolic imaging data were used for three-dimensional (3D) reconstruction.

\section{LAA measurements and classification}

CT data were reviewed using 3D volume rendering (EnSite Verismo, SJM, MN). LAA volume, ostium-diameters (antero-posterior and supero-inferior) and total length (adjusted for bends) were measured. Ostium surface area and circumference were then calculated. The takeoff of the superior and inferior LAA edge in relation (higher or lower) to the respective superior takeoff of the adjacent pulmonary vein (PV) was determined similarly to a previously described method (see Figure 2.1) on a standardized postero-anterior view. ${ }^{9}$ Two physicians experienced with imaging and blinded to the data of the patients, analyzed LAA morphology. In case of disagreement, a third expert physician was consulted and a decision was made based on common consent. The LAA (see Figure 2.1) was classified as previously described. ${ }^{3}$

1. The Cactus LAA, with a dominant central lobe and secondary lobes extending in superior and inferior directions.

2. The Chicken-Wing LAA, with an obvious bend of the dominant lobe, or folding back of the anatomy on itself, with or without secondary lobes.

3. The Windsock LAA, with a dominant lobe of sufficient length as the primary structure. Variations of this type location and number of smaller lobes were included here.

4. The Cauliflower LAA, with limited overall length and more complex internal characteristics. Variations of ostium and a variable number of lobes, without a dominant lobe, fall into this type.

\section{Statistical analysis}

Continuous variables are expressed as mean and standard deviation (SD) when normally distributed (positive Kolmogorov-Smirnoff test). Categorical variables are reported as frequencies and percentage. Parametric variables were compared by means of paired Student's ttest and non-parametric variables by Wilcoxon-test or chi-square test. Comparison of more than two groups was performed with ANOVA analysis and post-hoc Bonferoni test for parametric variables and with Kruskal-Wallis test for non-parametric variables. Cohen's $\kappa$ coefficient was used as a statistical measure of inter-rater agreement and a good level was defined as $\kappa>0.61$.

To determine independent associations with TE events, univariate logistic regression analysis was performed. Variables with a p-value $\leq 0.1$ were then included in the multivariate analysis for the determination of odds ratio (OR) and its $95 \%$ confidence intervals (CI). With the observed 25 events and a 1:3 case-control ratio, a 35\% difference in LAA morphology distribution (as reported previously) ${ }^{5}$ was detectable with $75 \%$ power and $p$-value $<0.05$. A two-tailed $p \leq 0.05$ was considered statistically significant. Analysis was performed with SPSS v20.0 (SPSS Inc., Chicago, USA).

\section{Results}

\section{Patient population}

Clinical characteristics and LAA measurements are summarized in Table 3.1. 
Table 3.1. Characteristics of 25 patients with low $\mathrm{CHA}_{2} \mathrm{DS}_{2}$-VASc score $(\leq 1)$ at the time of a prior thromboembolic event and 75 matched event-free patients as control group.

\begin{tabular}{|c|c|c|c|c|}
\hline & Total & Prior TE & Control & $\mathrm{P}$ \\
\hline Patients, $\mathrm{n}$ & 100 & 25 & 75 & NA \\
\hline Age, years & $55 \pm 9$ & $57 \pm 9$ & $55 \pm 9$ & 1.00 \\
\hline Age $>65, \mathrm{n}(\%)$ & $15(15)$ & $4(16)$ & $11(15)$ & 0.55 \\
\hline Female, $\mathrm{n}(\%)$ & $12(12)$ & $3(12)$ & $9(12)$ & 1.00 \\
\hline Paroxysmal AF, n (\%) & $69(69)$ & $18(72)$ & $51(68)$ & 1.00 \\
\hline Persistent AF, n (\%) & $31(31)$ & $7(28)$ & $24(32)$ & \\
\hline BMI, $\mathrm{kg} / \mathrm{m}^{2}$ & $27 \pm 7$ & $27 \pm 6$ & $27 \pm 9$ & 0.97 \\
\hline Hypertension, $\mathrm{n}(\%)$ & $46(46)$ & $11(44)$ & $35(47)$ & 1.00 \\
\hline Coronary artery disease, $\mathrm{n}(\%)$ & $2(2)$ & 0 & $2(3)$ & 1.00 \\
\hline Peripheral vascular disease, $\mathrm{n}(\%)$ & $3(3)$ & 0 & $3(4)$ & 0.57 \\
\hline Hyperlipidemia, n (\%) & $23(23)$ & $10(40 \%)$ & $13(17)$ & 0.028 \\
\hline $\mathrm{CHADS}_{2}$ score, $\mathrm{n}$ & $0.45 \pm 0.5$ & $0.44 \pm 0.5$ & $0.47 \pm 0.5$ & 0.35 \\
\hline $\mathrm{CHA}_{2} \mathrm{DS}_{2}$-VASc score, $\mathrm{n}$ & $0.76 \pm 0.43$ & $0.72 \pm 0.46$ & $0.77 \pm 0.42$ & 0.59 \\
\hline \multicolumn{5}{|l|}{ Echocardiography } \\
\hline Left ventricular ejection fraction, $\%$ & $60 \pm 7$ & $60 \pm 8$ & $60 \pm 7$ & 0.68 \\
\hline Left ventricular ed. Diameter, mm & $48 \pm 6$ & $49 \pm 6$ & $48 \pm 6$ & 0.35 \\
\hline Interventricular septum diameter, $\mathrm{mm}$ & $12 \pm 2$ & $12 \pm 2$ & $11 \pm 1$ & 0.11 \\
\hline Left atrial diameter, $\mathrm{mm}$ & $41 \pm 3$ & $44 \pm 6$ & $42 \pm 8$ & 0.18 \\
\hline Mitral valve regurgitation $1-2^{\circ}, \mathrm{n}(\%)$ & $59(59)$ & $49(65)$ & $15(60)$ & 0.58 \\
\hline Aortic valve regurgitation $1-2^{\circ}, \mathrm{n}(\%)$ & $17(17)$ & $13(17)$ & $4(16)$ & 0.19 \\
\hline Aortic valve stenosis $1-2^{\circ}, \mathrm{n}(\%)$ & $2(2)$ & $2(8)$ & 0 & 0.06 \\
\hline LAA flow, $\mathrm{cm} / \mathrm{sec}$ & $55 \pm 20$ & $50 \pm 17$ & $56 \pm 21$ & 0.92 \\
\hline Heart rate by flow measurement, bpm & $77 \pm 23$ & $78 \pm 29$ & $77 \pm 21$ & 0.93 \\
\hline Spontaneous echo contrast, $\mathrm{n}(\%)$ & $1(1)$ & $1(4)$ & 0 & 0.25 \\
\hline Sinus rhythm during TEE, $\mathrm{n}(\%)$ & $46(46)$ & $14(56)$ & $32(43)$ & 0.26 \\
\hline Anticoagulation during TEE, $\mathrm{n}(\%)$ & $72(72)$ & $25(100)$ & $47(63)$ & 0.14 \\
\hline \multicolumn{5}{|l|}{ Imaging parameters } \\
\hline Left atrial volume, $\mathrm{ml}$ & $129 \pm 43$ & $132 \pm 50$ & $127 \pm 43$ & 0.63 \\
\hline LAA volume, $\mathrm{ml}$ & $8 \pm 4$ & $9 \pm 5$ & $8 \pm 3$ & 0.24 \\
\hline LAA length, mm & $43 \pm 15$ & $45 \pm 12$ & $42 \pm 15$ & 0.42 \\
\hline LAA diameter antero-posterior, $\mathrm{mm}$ & $19 \pm 4$ & $20 \pm 5$ & $19 \pm 4$ & 0.29 \\
\hline LAA diameter supero-inferior, $\mathrm{mm}$ & $22 \pm 6$ & $21 \pm 7$ & $22 \pm 5$ & 0.57 \\
\hline LAA ostium circumference, $\mathrm{mm}$ & $65 \pm 15$ & $65 \pm 16$ & $65 \pm 14$ & 0.98 \\
\hline LAA ostium area, $\mathrm{cm}^{2}$ & $0.35 \pm 0.16$ & $0.35 \pm 0.18$ & $0.35 \pm 0.15$ & 0.94 \\
\hline Superior LAA-takeoff over LSPV, n (\%) & $10(10)$ & $7(28)$ & $3(4)$ & 0.002 \\
\hline Inferior LAA-takeoff over LIPV, n (\%) & $43(43)$ & $9(36)$ & $34(75)$ & 0.49 \\
\hline LAA morphologies, n (\%) & & & & 0.97 \\
\hline Cactus LAA & $18(18)$ & $5(16)$ & $13(17)$ & \\
\hline Chicken-Wing LAA & $32(32)$ & $6(32)$ & $26(35)$ & \\
\hline Windsock LAA & $10(10)$ & $3(8)$ & $7(9)$ & \\
\hline Cauliflower LAA & $40(40)$ & $11(44)$ & $29(39)$ & \\
\hline
\end{tabular}

$\mathrm{BMI}=$ body mass index; $\mathrm{LAA}=$ left atrial appendage; $\mathrm{LSPV}=$ left superior/LIPV=left inferior pulmonary vein

Patients were of $55 \pm 9$ years with low TE scores. No patient had an age $\geq 75$ years, heart failure, diabetes, a stroke or a transient ischemic attack. The superior LAA-takeoff was higher than the 
left superior pulmonary vein (LSPV) in $10 \%$ of the patients, and the inferior LAA-takeoff was higher than the left inferior pulmonary vein (LIPV) in $43 \%$ of the patients (Table 3.2).

Table 3.2. Characteristics and measurements according to superior LAA takeoff.

\begin{tabular}{|c|c|c|c|}
\hline Superior LAA-takeoff in relation to LSPV & Higher & Lower & $\mathrm{P}$ \\
\hline Patients, $\mathrm{n}$ & 10 & 90 & NA \\
\hline Age, years & $56 \pm 9$ & $55 \pm 9$ & 0.67 \\
\hline Age $>65, \mathrm{n}(\%)$ & $1(10)$ & $14(16)$ & 0.54 \\
\hline Female, $\mathrm{n}(\%)$ & $1(10)$ & $11(12)$ & 1.00 \\
\hline Paroxysmal AF, n (\%) & $10(100)$ & $59(66)$ & 0.09 \\
\hline Persistent AF, n (\%) & 0 & $30(34)$ & \\
\hline BMI, $\mathrm{kg} / \mathrm{m}^{2}$ & $27 \pm 6$ & $27 \pm 9$ & 0.97 \\
\hline Hypertension, $\mathrm{n}(\%)$ & $6(60)$ & $40(44)$ & 0.50 \\
\hline Prior stroke/TIA, n (\%) & $7(70)$ & $18(20)$ & 0.002 \\
\hline Coronary artery disease, $\mathrm{n}(\%)$ & 0 & $2(1)$ & 1.00 \\
\hline Peripheral vascular disease, $\mathrm{n}(\%)$ & 0 & $3(3)$ & 1.00 \\
\hline Hyperlipidemia, n (\%) & $4(40)$ & $19(21)$ & 0.23 \\
\hline $\mathrm{CHADS}_{2}$ score, $\mathrm{n}$ & $0.60 \pm 0.5$ & $0.44 \pm 0.5$ & 0.35 \\
\hline $\mathrm{CHA}_{2} \mathrm{DS}_{2}$-VASc score, $\mathrm{n}$ & $0.80 \pm 0.42$ & $0.76 \pm 0.43$ & 0.76 \\
\hline \multicolumn{4}{|l|}{ Echocardiography } \\
\hline Left ventricular ejection fraction, $\%$ & $59 \pm 10$ & $60 \pm 7$ & 0.73 \\
\hline Left ventricular ed. diameter, $\mathrm{mm}$ & $47 \pm 3$ & $48 \pm 6$ & 0.72 \\
\hline Interventricular septum diameter, $\mathrm{mm}$ & $13 \pm 2$ & $12 \pm 1$ & 0.42 \\
\hline Left atrial diameter, $\mathrm{mm}$ & $41 \pm 3$ & $43 \pm 7$ & 0.55 \\
\hline Mitral valve regurgitation $1-2^{\circ}, \mathrm{n}(\%)$ & $8(80)$ & $56(63)$ & 0.48 \\
\hline Aortic valve regurgitation $1-2^{\circ}, \mathrm{n}(\%)$ & $3(30)$ & $14(16)$ & 0.44 \\
\hline Aortic valve stenosis $1-2^{\circ}, \mathrm{n}(\%)$ & $1(10)$ & $1(1)$ & 0.19 \\
\hline LAA flow, $\mathrm{cm} / \mathrm{sec}$ & $51 \pm 15$ & $55 \pm 21$ & 0.60 \\
\hline Heart rate by flow measurement, bpm & $66 \pm 21$ & $78 \pm 23$ & 0.12 \\
\hline Spontaneous echo contrast, $\mathrm{n}(\%)$ & $1(10)$ & 0 & 0.10 \\
\hline Sinus rhythm during TEE, n (\%) & $7(70)$ & $39(43)$ & 0.06 \\
\hline Anticoagulation during TEE, $\mathrm{n}(\%)$ & $8(80)$ & $59(66)$ & 0.49 \\
\hline \multicolumn{4}{|l|}{ Imaging parameters } \\
\hline Left atrial volume, $\mathrm{ml}$ & $131 \pm 35$ & $129 \pm 44$ & 0.89 \\
\hline LAA volume, $\mathrm{ml}$ & $10 \pm 5$ & $8 \pm 4$ & 0.17 \\
\hline LAA length, mm & $38 \pm 12$ & $43 \pm 15$ & 0.27 \\
\hline LAA diameter antero-posterior, $\mathrm{mm}$ & $18 \pm 4$ & $19 \pm 4$ & 0.28 \\
\hline LAA diameter supero-inferior, $\mathrm{mm}$ & $22 \pm 5$ & $22 \pm 6$ & 0.78 \\
\hline LAA ostium circumference, $\mathrm{mm}$ & $68 \pm 18$ & $65 \pm 14$ & 0.48 \\
\hline LAA ostium area, $\mathrm{cm}^{2}$ & $0.39 \pm 0.22$ & $0.34 \pm 0.15$ & 0.42 \\
\hline Inferior LAA-takeoff over LIPV, n (\%) & $9(90)^{*}$ & $34(38 \%)$ & 0.002 \\
\hline LAA morphologies & & & 0.04 \\
\hline Cactus LAA & $1(10)$ & $17(19)$ & \\
\hline Chicken-Wing LAA & $0(0) *$ & $32(36)$ & \\
\hline Windsock LAA & $1(10)$ & $9(10)$ & \\
\hline Cauliflower LAA & $8(80)^{*}$ & $32(36)$ & \\
\hline
\end{tabular}

BMI=body mass index; LAA=left atrial appendage; LSPV=left superior/LIPV=left inferior pulmonary vein, *statistically significant. 
A higher superior LAA-takeoff was more prevalent in patients with Cauliflower LAA ( $80 \%$ vs. $36 \%, \mathrm{p}=0.04)$ and was associated with an inferior LAA-takeoff over the LIPV ( $90 \%$ vs. $38 \%$, $\mathrm{p}=0.002)$. Therefore a higher ostium was more common in patients with Cauliflower LAA.

Table 3.2 shows the prevalence of different LAA morphology types. Patients with Cactus LAA had greater LA volume $(157 \pm 65$ vs. $123 \pm 35 \mathrm{ml}, \mathrm{p}=0.047)$ and higher incidence of persistent AF $(61 \%$ vs. $23 \%, p=0.005)$. Patients with Chicken-Wing LAA had significantly longer LAA $(56 \pm 16$ vs. $37 \pm 9 \mathrm{~mm}, \mathrm{p}<0.001)$. Patients with Cauliflower LAA were younger $(51 \pm 10$ vs. $58 \pm 8$ years, $\mathrm{p}=0.012)$, had a higher incidence of higher superior takeoff $(20 \%$ vs. $3 \%, \mathrm{p}=0.01)$ and greater LAA volume ( $9 \pm 4$ vs. $7 \pm 3 \mathrm{ml}, \mathrm{p}=0.001)$. LAA flow was higher $(63 \pm 21 \mathrm{vs.} 49 \pm 18 \mathrm{~cm} / \mathrm{s}, \mathrm{p}<0.001)$ and heart rate was lower $(71 \pm 21$ vs. $82 \pm 24 \mathrm{bpm}, \mathrm{p}=0.02)$ in those patients (Table 3.3).

Table 3.3. Characteristics and measurements according to LAA morphology.

\begin{tabular}{|c|c|c|c|c|c|}
\hline LAA morphology & Cactus & Chicken-Wing & Windsock & Cauliflower & $\mathrm{p}$ \\
\hline Patients, $\mathrm{n}(\%)$ & 18 & 32 & 10 & 40 & \\
\hline Age, years & $57 \pm 6$ & $57 \pm 9$ & $61 \pm 7$ & $51 \pm 10^{*}$ & 0.005 \\
\hline Age $>65, \mathrm{n} \mathrm{( \% )}$ & $2(11)$ & $5(16)$ & $4(40)$ & $4(10)$ & 0.12 \\
\hline Female, n (\%) & $1(6)$ & $6(19)$ & $1(11)$ & $4(10)$ & 0.52 \\
\hline Paroxysmal atrial fibrillation, $\mathrm{n}(\%)$ & $7(39)$ & $25(78)$ & $6(67)$ & $31(76)$ & 0.038 \\
\hline Persistent atrial fibrillation, $\mathrm{n}(\%)$ & $11(61)^{*}$ & $7(22)$ & $3(33)$ & $9(23)$ & 0.03 \\
\hline BMI, $\mathrm{kg} / \mathrm{m}^{2}$ & $27 \pm 6$ & $27 \pm 8$ & $27 \pm 7$ & $27 \pm 9$ & 0.46 \\
\hline Hypertension, $\mathrm{n}(\%)$ & $12(67)$ & $11(34)$ & $4(40)$ & $19(48)$ & 0.17 \\
\hline Prior stroke/TIA, n (\%) & $5(28)$ & $6(19)$ & $3(30)$ & $11(28)$ & 0.79 \\
\hline Coronary artery disease, $\mathrm{n}(\%)$ & 0 & $2(6)$ & 0 & 0 & 0.23 \\
\hline Peripheral vascular disease, $\mathrm{n}(\%)$ & 0 & $3(9)$ & 0 & 0 & 0.09 \\
\hline CHADS$_{2}$ score, $\mathrm{n}$ & $0.8 \pm 0.4$ & $0.8 \pm 0.4$ & $0.9 \pm 0.3$ & $0.7 \pm 0.5$ & 0.17 \\
\hline $\mathrm{CHA}_{2} \mathrm{DS}_{2}$-VASc score, $\mathrm{n}$ & $0.7 \pm 0.5$ & $0.3 \pm 0.5$ & $0.4 \pm 0.5$ & $0.5 \pm 0.5$ & 0.36 \\
\hline \multicolumn{6}{|l|}{ Echocardiography } \\
\hline Left ventricular ejection fraction, $\%$ & $60 \pm 10$ & $60 \pm 6$ & $59 \pm 5$ & $60 \pm 7$ & 0.96 \\
\hline Left ventricular ed. diameter, mm & $50 \pm 6$ & $46 \pm 6$ & $44 \pm 6$ & $42 \pm 6$ & 0.81 \\
\hline Interventricular septum diameter, $\mathrm{mm}$ & $13 \pm 3$ & $12 \pm 2$ & $12 \pm 1$ & $12 \pm 1$ & 0.49 \\
\hline Left atrial diameter, $\mathrm{mm}$ & $42 \pm 11$ & $41 \pm 5$ & $44 \pm 6$ & $42 \pm 6$ & 0.94 \\
\hline Mitral valve regurgitation $1-2^{\circ}, \mathrm{n}(\%)$ & $10(56)$ & $24(75)$ & $6(60)$ & $24(60)$ & 0.35 \\
\hline Aortic valve regurgitation $1-2^{\circ}, \mathrm{n}(\%)$ & $2(11)$ & $9(28)$ & $1(10)$ & $5(13)$ & 0.38 \\
\hline Aortic valve stenosis $1-2^{\circ}, \mathrm{n}(\%)$ & 0 & 0 & $1(10)$ & $1(3)$ & .24 \\
\hline LAA flow, $\mathrm{cm} / \mathrm{sec}$ & $48 \pm 18$ & $49 \pm 19$ & $49 \pm 19$ & $63 \pm 21 *$ & 0.004 \\
\hline Heart rate by flow measurement, bpm & $89 \pm 25$ & $81 \pm 24$ & $69 \pm 17 *$ & $71 \pm 21 *$ & 0.014 \\
\hline Spontaneous echo contrast, $\mathrm{n}(\%)$ & 0 & 0 & 0 & $1(3)$ & 0.67 \\
\hline Sinus rhythm during examination, $\mathrm{n}(\%)$ & $3(17) *$ & $15(47)$ & $6(60)$ & $22(55)$ & 0.04 \\
\hline Anticoagulation during TEE, $\mathrm{n}(\%)$ & $15(83)$ & $19(59)$ & $9(90)$ & $24(60)$ & 0.10 \\
\hline \multicolumn{6}{|l|}{ Imaging parameters } \\
\hline Left atrial volume, $\mathrm{ml}$ & $157 \pm 65^{*}$ & $124 \pm 32$ & $134 \pm 43$ & $119 \pm 35$ & 0.017 \\
\hline LAA volume, $\mathrm{ml}$ & $6 \pm 3$ & $8 \pm 3$ & $6 \pm 3$ & $9 \pm 4 *$ & 0.005 \\
\hline LAA length, $\mathrm{mm}$ & $32 \pm 10$ & $56 \pm 16^{*}$ & $35 \pm 6$ & $39 \pm 8$ & $<0.001$ \\
\hline LAA diameter antero-posterior, $\mathrm{mm}$ & $21 \pm 4$ & $20 \pm 4$ & $18 \pm 4$ & $19 \pm 5$ & 0.32 \\
\hline LAA diameter supero-inferior, $\mathrm{mm}$ & $23 \pm 6$ & $22 \pm 5$ & $20 \pm 5$ & $23 \pm 6$ & 0.26 \\
\hline LAA ostium circumference, $\mathrm{mm}$ & $63 \pm 15$ & $66 \pm 14$ & $72 \pm 22$ & $63 \pm 12$ & 0.14 \\
\hline LAA ostium area, $\mathrm{cm}^{2}$ & $0.32 \pm 0.15$ & $0.36 \pm 0.15$ & $0.45 \pm 0.28$ & $0.35 \pm 0.16$ & 0.27 \\
\hline Superior LAA-takeoff over LSPV, n (\%) & $1(6)$ & 0 & $1(10)$ & $8(20)^{*}$ & 0.04 \\
\hline Inferior LAA-takeoff over LIPV, n (\%) & $6(33)$ & $12(38)$ & $3(30)$ & $22(55)$ & 0.25 \\
\hline
\end{tabular}

$\mathrm{BMI}=$ body mass index; LAA = left atrial appendage; LSPV=left superior/LIPV=left inferior pulmonary vein, *statistically significant. 
The rate of agreement in LAA classification was good (kappa $=0.7 ; 95 \%$ CI: 0.39-0.92, $\mathrm{p}<0.001$ ).

\section{LAA characteristics and thromboembolic risk}

Detailed characteristics of the TE patients are presented in Table 3.4. At the TE time, $17(68 \%)$ patients had no anticoagulation, $3(12 \%)$ were on aspirin, $2(8 \%)$ on warfarin, $1(4 \%)$ in both warfarin and aspirin and $1(4 \%)$ on clopidogrel. Palpitations or AF were already known in 16 $(64 \%)$ of the patients, $6(24 \%)$ patients were diagnosed with AF at the time of the event and 2 $(8 \%)$ afterwards.

Table 3.4. Clinical characteristics, palpitations and atrial fibrillation history (in months) as well as previous cardioversions and anticoagulation status of the patients at the time of the thromboembolic event, in relation to the superior LAA takeoff. AF burden was calculated according to the history of the patient as low (short but frequent episodes, up to several minutes), moderate (longer episodes up to several hours) or high ( $\geq 48$ hours duration).

\begin{tabular}{|c|c|c|c|c|c|c|c|c|c|c|c|}
\hline تِ & 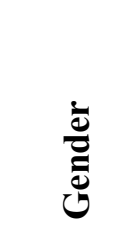 & $\underset{<}{80}$ & 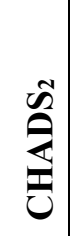 & 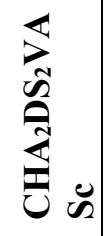 & & $\frac{\substack{0 \\
0}}{\frac{0}{0}}$ & 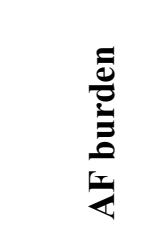 & 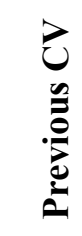 & 营 & 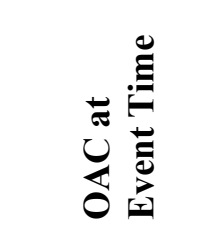 & 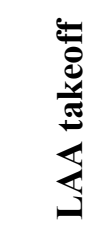 \\
\hline$\# 1$ & Male & 57 & 0 & 0 & 60 & 0 & Low & - & Stroke & None & Low \\
\hline$\# 2$ & Male & 51 & 0 & 0 & 160 & 48 & High & 5 & 2xTIA & Aspirin & Low \\
\hline$\# 3$ & Female & 64 & 0 & 1 & 106 & 106 & Moderate & - & 2xTIA & Clopidogrel & High \\
\hline \#4 & Female & 45 & 0 & 1 & - & $-*$ & High & - & Stroke & None & Low \\
\hline$\# 5$ & Male & 57 & 1 & 1 & 0 & 0 & High & - & Stroke & None & High \\
\hline$\# 6$ & Male & 53 & 1 & 1 & 24 & 12 & High & 3 & TIA & Warfarin & Low \\
\hline$\# 7$ & Male & 69 & 0 & 1 & 72 & 24 & Moderate & - & TIA & Aspirin & Low \\
\hline$\# 8$ & Male & 63 & 0 & 0 & 12 & 0 & High & - & Stroke & None & Low \\
\hline$\# 9$ & Male & 59 & 1 & 1 & 0 & 0 & Moderate & - & TIA & None & Low \\
\hline$\# 10$ & Male & 55 & 1 & 1 & 24 & 18 & Moderate & - & TIA & Aspirin & Low \\
\hline$\# 11$ & Male & 47 & 1 & 1 & 84 & 84 & Moderate & - & Stroke & None & High \\
\hline$\# 12$ & Male & 67 & 0 & 1 & 0 & 0 & Moderate & - & TIA & None & Low \\
\hline$\# 13$ & Male & 55 & 1 & 1 & - & $-*$ & Moderate & - & Stroke & None & Low \\
\hline$\# 14$ & Female & 61 & 0 & 1 & 2 & 2 & High & - & TIA & Warfarin & Low \\
\hline$\# 15$ & Male & 45 & 0 & 0 & - & 0 & NA & - & TIA & None & Low \\
\hline$\# 16$ & Male & 52 & 1 & 1 & NA & NA & NA & - & TIA & NA & Low \\
\hline$\# 17$ & Male & 55 & 1 & 1 & 12 & 0 & Moderate & - & Stroke & None & Low \\
\hline$\# 18$ & Male & 51 & 0 & 0 & 0 & 0 & Moderate & - & Stroke & None & High \\
\hline$\# 19$ & Male & 64 & 1 & 1 & - & 0 & High & - & Stroke & None & High \\
\hline \#20 & Male & 69 & 0 & 1 & 48 & 48 & High & 1 & TIA & $\begin{array}{l}\text { Aspirin, } \\
\text { Warfarin }\end{array}$ & High \\
\hline$\# 21$ & Male & 62 & 0 & 0 & - & 36 & High & 3 & TIA & None & High \\
\hline$\# 22$ & Male & 70 & 0 & 1 & 12 & 36 & Moderate & - & TIA & None & Low \\
\hline$\# 23$ & Male & 56 & 1 & 1 & 84 & 12 & Moderate & - & Stroke & None & Low \\
\hline$\# 24$ & Male & 54 & 1 & 1 & 60 & 70 & High & - & TIA & None & Low \\
\hline$\# 25$ & Male & 33 & 0 & 0 & - & 62 & High & 9 & Stroke & None & Low \\
\hline
\end{tabular}

$\mathrm{AF}=$ atrial fibrillation; $\mathrm{CV}=$ cardioversion; $\mathrm{OAC}=$ oral anticoagulation; $\mathrm{TE}=$ thromboembolic event; TIA= transient ischemic attack, * first AF diagnosis after the TE. 
Patients with prior TE are compared with the control group in Table 3.1. Patients with a prior TE had a higher incidence of superior LAA takeoff ( $28 \%$ vs. $4 \%, \mathrm{p}=0.002)$, higher incidence of hyperlipidemia $(40 \%$ vs. $17 \%, \mathrm{p}=0.028)$ and a tendency for higher incidence of aortic valve stenosis $(8 \%$ vs. $0 \%, p=0.06)$. Spontaneous echo contrast was present in one patient with a prior TE and a higher LAA takeoff. The prevalence of LAA types was similar between groups and no further differences were found in other LAA measurements or clinical characteristics.

Multivariable analysis including superior LAA-takeoff, hyperlipidaemia and aortic valve stenosis in a forward, stepwise model, showed that a high superior LAA-takeoff (OR: 9.1, 95\% CI: 2.1 to $38.6, \mathrm{p}=0.003$ ) was the only independent predictor of thromboembolic events. Adjusting for LA size, rhythm or anticoagulation status during the TEE examination did not significantly change the above results. Analysis of the relationship between heart rate and LAA flow (Figure 3.1) revealed a negative correlation $(\mathrm{r}=-0.2 \mathrm{~cm} / \mathrm{s}$ pro $\mathrm{bpm}, \mathrm{p}=0.048)$ that was even more pronounced for the superior LAA takeoff $(\mathrm{r}=-0.67 \mathrm{~cm} / \mathrm{s}$ pro $\mathrm{bpm}, \mathrm{p}=0.035)$, but not significant for the inferior LAA takeoff $(\mathrm{r}=-0.18, \mathrm{p}=0.1)$.
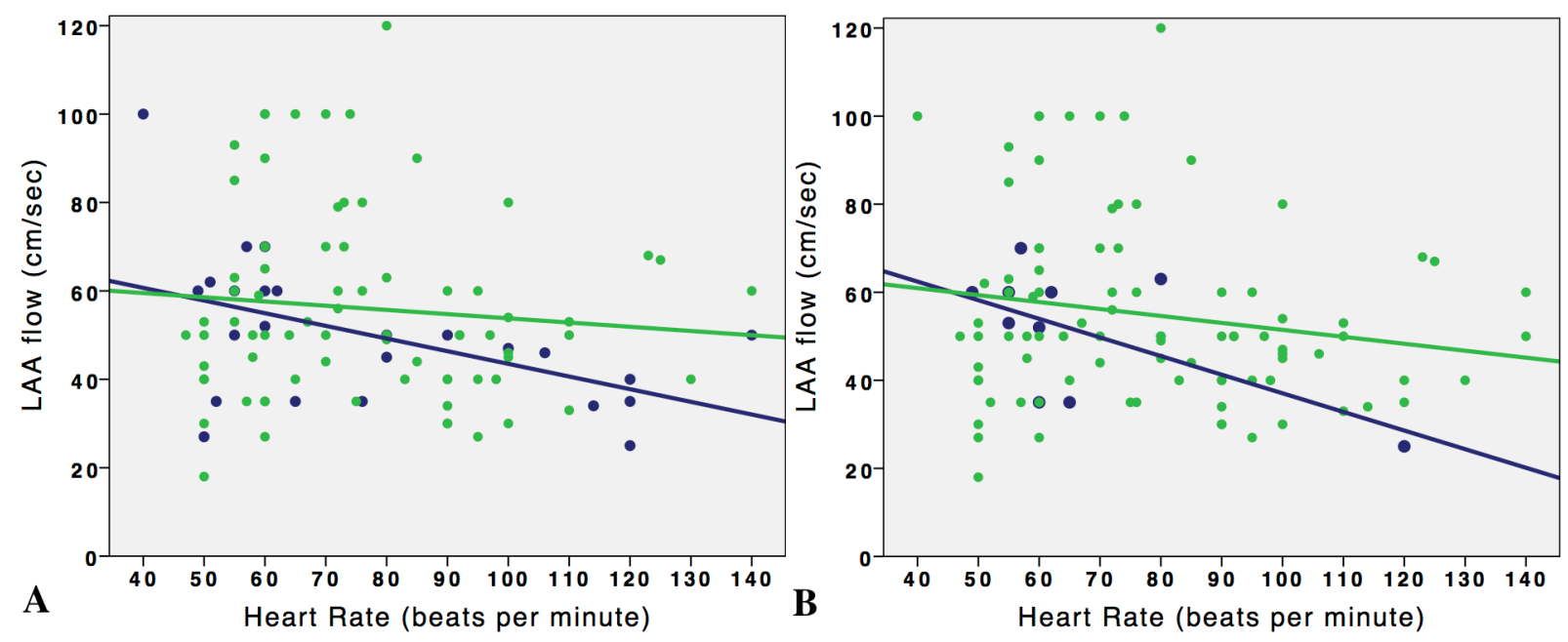

Figure 3.1. Correlation between heart rate and left atrial appendage (LAA) flow in patients A. with (blue) or without (green) previous stroke and B. higher (blue) or lower (green) superior takeoff.

\section{Main findings}

\section{Discussion}

This study illuminates the role of the left atrial appendage in the occurrence of thromboembolic events in patients with low $\mathrm{CHA}_{2} \mathrm{DS}_{2}$-VASc score $(\leq 1)$. Systematic analysis of the characteristics and quantitative parameters of LAA in low-risk patients with and without TE allowed us to carefully assess the impact of LAA anatomy. Despite the limitations of this small case-control study, we found that a high superior LAA-takeoff is associated with a nine-fold higher risk of thrombogenesis. Therefore the LAA anatomy might be useful for predicting strokes and guide anticoagulation management of patients with $\mathrm{AF}$ and low $\mathrm{CHA}_{2} \mathrm{DS}_{2}-\mathrm{VASc}$ score.

\section{Clinical implications}

Currently anticoagulation therapy for TE prevention is based on validated clinical scores like $\mathrm{CHADS}_{2}$ and $\mathrm{CHA}_{2} \mathrm{DS}_{2}-\mathrm{VASc}$. Although the last one has refined differentiation of low-risk 
patients, severe and disabling TEs still remain a problem for relatively young and healthy patients. Most of the patients $(\mathrm{n}=17,68 \%)$ had no anticoagulation at the TE time, although half of them $(n=9,53 \%)$ had a $\mathrm{CHADS}_{2}$ or $\mathrm{CHA}_{2} \mathrm{DS}_{2}$-VASc score of 1 . Using the $\mathrm{CHA}_{2} \mathrm{DS}_{2}$-VASc score would reclassify 7 patients, of which 3 would be female. Therefore, one-third of the TE group $(n=7,28 \%)$ would have a score of 0 and $12 \%(n=3)$ a score of 1 due to female sex. These patients would be classified as 'truly low risk', and thus no antithrombotic therapy would be prescribed. ${ }^{10}$ The results of this study though show that a high LAA takeoff is associated with a higher stroke-risk despite conventionally clinical low stroke-risk. This could have implications for the anticoagulation management of these patients.

\section{Anatomical and functional aspects}

Thromboembolic risk in AF patients is driven by reduced blood flow and can be reduced by anticoagulation or obliteration. ${ }^{11}$ An increased heart rate reduces the LAA peak flow velocity and promotes blood stasis in patients with non-valvular AF. ${ }^{12}$ Recent data comparing patients with $\mathrm{TE}$ after AF ablation and matched control patients (for the $\mathrm{CHA}_{2} \mathrm{DS}_{2}-\mathrm{VASc}$ criteria), revealed that this mechanism is more pronounced in patients with higher LAA takeoff and leads to a higher TE risk especially in a case of an AF recurrence. ${ }^{7}$ In accordance with these findings we found that this mechanism also accounts for the thrombogenic flow during increased heart rate in patients with low $\mathrm{CHA}_{2} \mathrm{DS}_{2}$-VASc score. This could be explained by a reduction in LAA flow driven by the distance from the mitral annulus and the concomitant arrhythmia (Figure 3.2). This mechanism is more pronounced in case of a higher LAA takeoff and correlates with a tachycardia-mediated TE risk. Therefore, the LAA location might predict strokes in patients who cannot be discriminated by the $\mathrm{CHA}_{2} \mathrm{DS}_{2}-\mathrm{VASc}$ score and deserves further investigation.

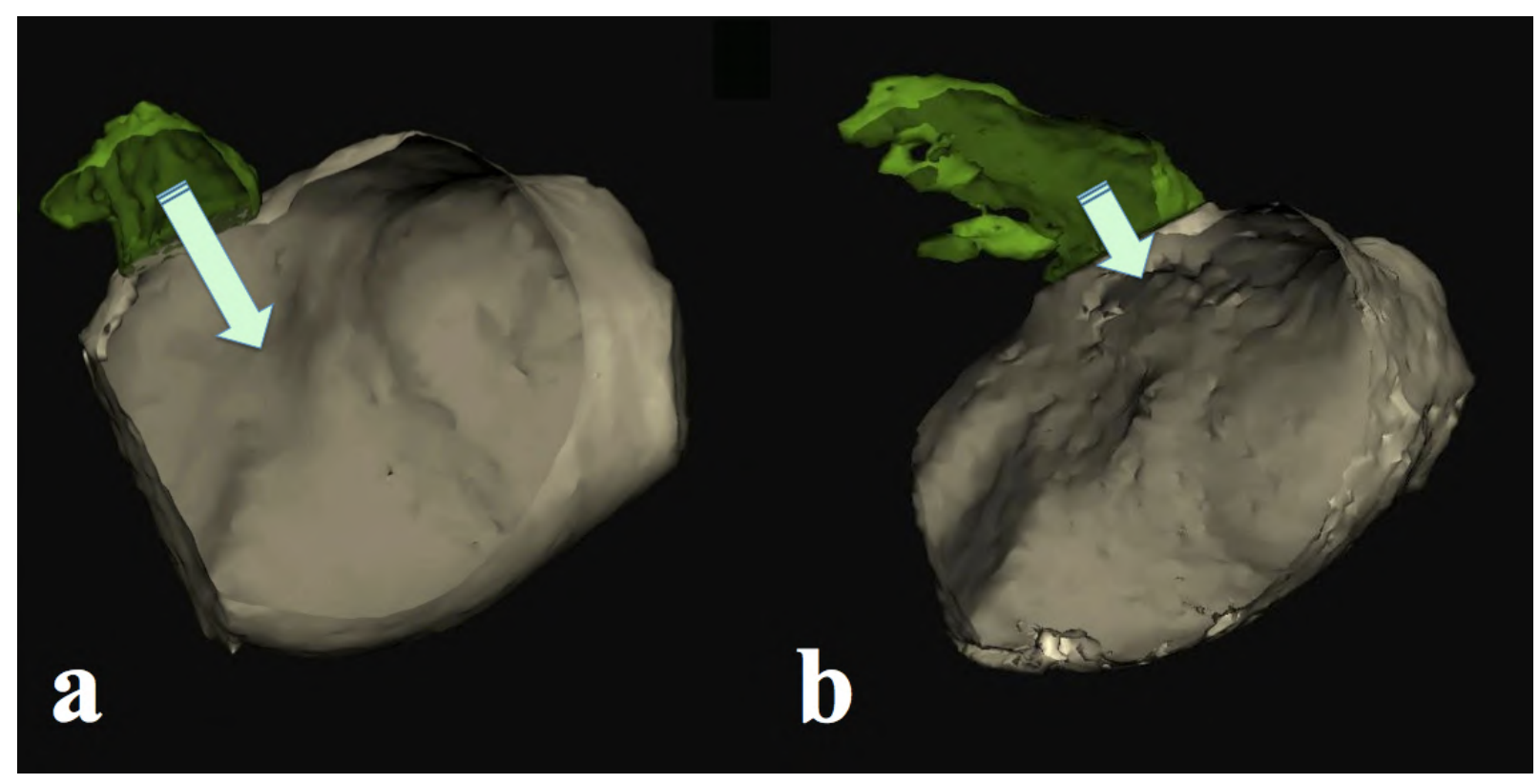

Figure 3.2. Example illustrating though a cutting view a. a low and b. a high superior LAA takeoff in relation to the left superior pulmonary vein. A higher LAA takeoff is associated with reduced LAA flow (arrow) during increased heart rate. 
Previous studies have associated ostium ${ }^{6,13}$ or LAA size ${ }^{14-16}$ with an increased thromboembolic risk in AF patients. In our patient cohort though and in more recent studies, ${ }^{3-5}$ there was no significant correlation between LAA dimensions and thromboembolic risk.

Recently, the LAA morphology with extended trabeculations like in Cauliflower-LAA has been related to an increased thromboembolic risk. ${ }^{4-6}$ Kimura et al. found that in a cohort of 80 patients with low $\mathrm{CHADS}_{2}$ score, this LAA type is associated with a three-fold increase of the TE risk. In our patient cohort though, LAA morphology was not associated with embolic events. This could be explained by the difference of the analyzed patients and the inclusion criteria that have been more sensitive (for TE risk) in the present study. However, we found that Cauliflower-LAA was associated with higher LAA-takeoff ( $80 \%$ vs. $36 \%, p=0.04)$, which could support the observation that these patients have increased embolic risk not only because of the LAA anatomy, but also through a different anatomical position. In accordance to that we found no Chicken-Wing LAA with a high superior LAA-takeoff.

Indeed, after adjusting for confounding factors, a superior LAA-takeoff over the LSPV was the only factor associated with a nine-fold increased stroke risk. A higher LAA-takeoff comes together with a reduced blood-flow during tachycardia, implying an underlying mechanism that was also confirmed for patients with TE after AF ablation. ${ }^{7}$ Therefore, a detailed study of LAA anatomy in relation to flow-velocity and heart rate is very important for the understanding of the association between LAA function and anatomy and might have led to different conclusions in previous studies. Our findings reveal a possible pathophysiological mechanism for the impact of a higher LAA position on TE risk and warrant further examination. Since LAA orientation increases TE risk especially in case of tachyarrhythmia, these patients warrant a more aggressive anticoagulation and rhythm/rate control.

\section{Limitations}

This is a single-center study with the limitations of a post-hoc analysis. The number of TE patients was small because we included AF patients that survived a cardiogenic stroke, which is usually associated with serious symptoms and a poor prognosis. The restriction of the study in patients with CHADS-VASc $\leq 1$ limited the power of the study but allowed for an association with LAA anatomy. We were not able to retrieve the quality of anticoagulation (compliance, time in target) at the time of the event, although we know that $68 \%$ of the patients had initially no anticoagulation. Rate control data at the time of the event are not available and HR at the time of TEE (partially under sedation) could underestimate the real impact of HR. Similarly, analysis of rhythm control is hampered by temporal changes and the low number of TE patients. Finally, despite the tendency for more spontaneous echo in case of higher LAA take-off, its low incidence and the use of anticoagulation during TEE prohibit analysis of its significance. Despite these limitations, these findings support the association of a higher LAA position with a tachycardiarelated thrombogenic flow and thus with a higher thromboembolic risk. Since data for patients with low clinical TE risk are scarce, these preliminary data should be seen as hypothesis generating. They supplement previous observations that may also apply to higher risk patients or prove useful to plan pharmacologic or device based therapies for those who cannot tolerate oral anticoagulants. ${ }^{7}$ Certainly, future studies should evaluate both LAA position and flow velocity in relation to heart rate, in order to examine the effect and the significance of a higher LAA takeoff.

\section{Conclusion}

A higher LAA takeoff is associated with a tachycardia-mediated thrombogenic flow and an increased thromboembolic risk. These findings may have implications for anticoagulation management of AF patients with low $\mathrm{CHA}_{2} \mathrm{DS}_{2}-\mathrm{VASc}$ scores and higher LAA takeoff. 


\section{References}

1. Gage BF, Waterman AD, Shannon W, Boechler M, Rich MW, Radford MJ. Validation of clinical classification schemes for predicting stroke: results from the National Registry of Atrial Fibrillation. JAMA : the journal of the American Medical Association Jun 13 2001;285:2864-2870.

2. Lip GY, Nieuwlaat R, Pisters R, Lane DA, Crijns HJ. Refining clinical risk stratification for predicting stroke and thromboembolism in atrial fibrillation using a novel risk factor-based approach: the euro heart survey on atrial fibrillation. Chest Feb 2010;137:263-272.

3. Di Biase L, Santangeli P, Anselmino M, et al. Does the left atrial appendage morphology correlate with the risk of stroke in patients with atrial fibrillation? Results from a multicenter study. J Am Coll Cardiol Aug 7 2012;60:531-538.

4. Anselmino M, Scaglione M, Di Biase L, Gili S, Santangeli P, Corsinovi L, Pianelli M, Cesarani F, Faletti R, Righi D, Natale A, Gaita F. Left atrial appendage morphology and silent cerebral ischemia in atrial fibrillation patients. Heart Rhythm Jan 2014;11:2-7.

5. Kimura T, Takatsuki S, Inagawa K, Katsumata Y, Nishiyama T, Nishiyama N, Fukumoto K, Aizawa Y, Tanimoto Y, Tanimoto K, Jinzaki M, Fukuda K. Anatomical characteristics of the left atrial appendage in cardiogenic stroke with low CHADS2 scores. Heart Rhythm Jun 2013;10:921-925.

6. Khurram IM, Dewire J, Mager $\mathrm{M}$, et al. Relationship between left atrial appendage morphology and stroke in patients with atrial fibrillation. Heart Rhythm Dec 2013;10:18431849.

7. Nedios S, Kornej J, Koutalas E, Bertagnolli L, Kosiuk J, Rolf S, Arya A, Sommer P, Husser D, Hindricks G, Bollmann A. Left atrial appendage morphology and thromboembolic risk after catheter ablation for atrial fibrillation. Heart Rhythm Dec 2014;11:2239-2246.

8. Kosiuk J, Nedios S, Kornej J, Koutalas E, Bertagnolli L, Rolf S, Arya A, Sommer P, Husser D, Hindricks G, Bollmann A. Impact of Left Atrial Appendage Morphology on Periinterventional Thromboembolic Risk during Catheter Ablation of Atrial Fibrillation. Heart Rhythm May 222014.

9. Budge LP, Shaffer KM, Moorman JR, Lake DE, Ferguson JD, Mangrum JM. Analysis of in vivo left atrial appendage morphology in patients with atrial fibrillation: a direct comparison of transesophageal echocardiography, planar cardiac CT, and segmented three-dimensional cardiac CT. J Interv Card Electrophysiol Nov 2008;23:87-93.

10. Heidbuchel H, Verhamme P, Alings M, Antz M, Hacke W, Oldgren J, Sinnaeve P, Camm AJ, Kirchhof P. EHRA practical guide on the use of new oral anticoagulants in patients with nonvalvular atrial fibrillation: executive summary. Eur Heart J Jul 2013;34:2094-2106.

11. Ostermayer SH, Reisman M, Kramer $\mathrm{PH}$, et al. Percutaneous left atrial appendage transcatheter occlusion (PLAATO system) to prevent stroke in high-risk patients with nonrheumatic atrial fibrillation: results from the international multi-center feasibility trials. J Am Coll Cardiol Jul 5 2005;46:9-14.

12. Obel OA, Luddington L, Maarouf N, Aytemir K, Ekwall C, Malik M, Camm AJ. Effects of ventricular rate and regularity on the velocity and magnitude of left atrial appendage flow in atrial fibrillation. Heart Jun 2005;91:764-768.

13. Beinart R, Heist EK, Newell JB, Holmvang G, Ruskin JN, Mansour M. Left atrial appendage dimensions predict the risk of stroke/TIA in patients with atrial fibrillation. Journal of cardiovascular electrophysiology Jan 2011;22:10-15.

14. Somerville W, Chambers RJ. Systemic Embolism in Mitral Stenosis: Relation to the Size of the Left Atrial Appendix. Br Med J Nov 7 1964;2:1167-1169. 
15. Ernst G, Stollberger C, Abzieher F, Veit-Dirscherl W, Bonner E, Bibus B, Schneider B, Slany J. Morphology of the left atrial appendage. Anat Rec Aug 1995;242:553-561.

16. Park HC, Shin J, Ban JE, Choi JI, Park SW, Kim YH. Left atrial appendage: morphology and function in patients with paroxysmal and persistent atrial fibrillation. Int $\mathrm{J}$ Cardiovasc Imaging Apr 2013;29:935-944. 

Chapter 4 Atrial fibrillation and peri-interventional thromboembolic risk

Adapted from "Impact of left atrial appendage morphology on peri-interventional thromboembolic risk during catheter ablation of atrial fibrillation"

Published in Heart Rhythm May 22 2014. doi: 10.1016/j.hrthm.2014.05.022

Jedrzej Kosiuk*, Sotirios Nedios*, Jelena Kornej, Emmanuel Koutalas, Livio Bertagnolli, Sascha Rolf, Arash Arya, Philipp Sommer, Daniela Husser, Gerhard Hindricks, MD, Andreas Bollmann *both authors contributed equally 


\begin{abstract}

\section{Background:}

Very recently, left atrial appendage (LAA) morphology has been suggested to influence thromboembolic risk in patients with atrial fibrillation (AF). To examine the impact of LAA morphology on peri-interventional thromboembolic events in patients undergoing AF catheter ablation.
\end{abstract}

\title{
Methods:
}

Of 2,570 consecutive patients undergoing $\mathrm{AF}$ ablation, 17 patients with cerebral thromboembolic events within 30 days after AF ablation were selected and matched for $\mathrm{CHA}_{2} \mathrm{DS}_{2} \mathrm{VASc}$ score, peri-interventional anticoagulation and procedural characteristics with 68 event-free patients. The LAA morphology was visualized by means of cardiac CT and classified in four types (cactus, chicken wing, windsock, cauliflower).

\section{Results:}

The baseline, echocardiographic and procedural characteristics of both patient groups were similar. Patients with embolic complications had a significantly higher incidence of chicken wing morphology compared to event-free controls $(65 \%$ chicken wing, $18 \%$ cactus, $12 \%$ windsock, $5 \%$ cauliflower vs. $21 \%, 24 \%, 13 \%, 42 \%$ respectively, $\mathrm{p}<0.001)$ what translates into more than 7 time higher risk when compared to other morphologies (OR 7.2, CI 95\% 1.353-38.328, $\mathrm{p}=0.021$ ) when adjusted for possible confounders associated with chicken wing morphology.

\section{Conclusion:}

The LAA chicken wing morphology is associated with higher peri-procedural thromboembolic risk in patients undergoing AF ablation. Further studies are needed to illuminate the mechanisms and possible implications of this observation. 


\section{Introduction}

Atrial fibrillation (AF) is generally acknowledged as one of the most important causes of cerebral thromboembolic events. ${ }^{1}$ Multiple risk factors and different risk assessment models have been proposed, ${ }^{2,3}$ but the predictive value of those schemes is still limited when applied to real world populations ${ }^{4}$ or so called low-risk patient groups. ${ }^{5}$

Since the left atrial appendage (LAA) plays a major role as a thromboembolic source ${ }^{6}$ in patients with AF its impact on thromboembolic risk has been addressed. Very recently, LAA morphology classified into four types, i.e. cactus, chicken wing, windsock, cauliflower, has been suggested to influence the thromboembolic risk in AF patients ${ }^{7-9}$ and to give additional value for the prediction of thromboembolic events in low-risk patient group. ${ }^{10}$

The risk of thromboembolic events is also present or even increased during and early after AF catheter ablation. ${ }^{11,} 12$ Although different pathophysiological mechanisms and anatomical predispositions may determine the risk of such an event in this specific setting, the role of the LAA and its morphology has not been taken into account.

Therefore, the aim of this case-control study was to examine the impact of LAA morphology on peri-interventional thromboembolic risk in patients undergoing AF catheter ablation.

\section{Patients}

\section{Methods}

Of 2,570 patients undergoing AF ablation between 2007 and 2012 at our institution, 17 consecutive patients with cerebral thromboembolic events within 30 days after AF ablation were selected and matched for $\mathrm{CHA}_{2} \mathrm{DS}_{2} \mathrm{VASc}$ score criteria (Congestive heart failure, Hypertension, Age, Diabetes mellitus, prior Stroke/TIA and vascular disease), peri-interventional anticoagulation and procedural characteristics with randomly chosen 68 event-free patients (1:4 ratio). Table 4.1 shows the baseline characteristics of both patients groups.

Stroke $(n=9)$ was defined as a neurologic deficit lasting more than 24 hours or with imaging study showing new infarction. Transient ischemic attack (TIA, $n=8$ ) was defined as a deficit lasting less than 24 hours and without documented infarction, with the diagnosis made by an experienced competent physician (usually a neurologist). Haemorrhagic stroke was ruled out by computer tomography. $\mathrm{CHADS}_{2}$ and $\mathrm{CHA}_{2} \mathrm{DS}_{2}-\mathrm{VASc}$ were calculated as previously defined. ${ }^{2,3}$

\section{Echocardiography}

Patients underwent a comprehensive transthoracic echocardiographic exam before the catheter ablation according to the recommendations of the American Society of Echocardiography. ${ }^{13}$ Prior to the ablation, the presence of intracardiac thrombi was ruled out by transesophagal echocardiography (TEE) in all patients. The LAA flow was measured by a pulsed-wave Doppler placed in LAA as recommended by guidelines. ${ }^{14}$

\section{Computed tomography}

Cardiac CT imaging was performed with a multidetector 64-row helical system (Brilliance 64, Philips Medical Systems, The Netherlands). Image acquisition thickness ranged from 0.625 to $1.25 \mathrm{~mm}$ and was electrogram-gated when possible. Imaging parameters included: $70-120 \mathrm{KV}$, $850 \mathrm{mAs}, 0.6 \mathrm{~mm}$ beam collimation, image acquisition thickness of 0.625 to $1.25 \mathrm{~mm}$ and fieldof-view 20-30 cm. During an end-inspiratory breath-hold of approximately 20 seconds, and following a timing bolus-chase injection $(20 \mathrm{~mL}, 5 \mathrm{~mL} / \mathrm{s}), 90 \mathrm{~mL}$ of an iodinated contrast medium (Ultravist 370, Bayer Vital, Germany) was administered. Finally end-systolic imaging data were recorded and used for 3D cardiac reconstruction and further image processing. 
Table 4.1. Characteristics of patients with peri-interventional TE and matched TE-free patients.

\begin{tabular}{|c|c|c|c|}
\hline & \multicolumn{2}{|c|}{ Thromboembolic event (TE) } & \multirow[b]{2}{*}{$\mathrm{P}$} \\
\hline & No $(n=68)$ & Yes $(n=17)$ & \\
\hline Age, (years) & $64 \pm 11$ & $64 \pm 11$ & 0.972 \\
\hline Males, n (\%) & $40(59)$ & $10(59)$ & 1.000 \\
\hline Body mass index, $(\mathrm{kg} / \mathrm{m} 2)$ & $28 \pm 4$ & $28 \pm 4$ & 0.796 \\
\hline Persistent AF, n (\%) & $24(36)$ & $9(53)$ & 0.197 \\
\hline Hypertension, $\mathrm{n}(\%)$ & $53(78)$ & $10(65)$ & 0.258 \\
\hline Diabetes, $\mathrm{n}(\%)$ & $17(25)$ & $2(12)$ & 0.241 \\
\hline Congestive heart failure, $\mathrm{n}(\%)$ & $5(7)$ & $2(12)$ & 0.554 \\
\hline History of stroke/TIA, n (\%) & $19(28)$ & $4(24)$ & 0.714 \\
\hline Peripheral vascular disease, $\mathrm{n}(\%)$ & $9(13)$ & $4(24)$ & 0.292 \\
\hline Coronary artery disease, $\mathrm{n}(\%)$ & $20(29)$ & $4(24)$ & 0.630 \\
\hline $\mathrm{CHA}_{2} \mathrm{DS}_{2}-\mathrm{VASc}$, median (IQR) & $3(2-4)$ & $3(2-4)$ & 0.357 \\
\hline ACE inhibitors, $\mathrm{n}(\%)$ & $42(62)$ & $12(71)$ & 0.499 \\
\hline Beta-blockers, n (\%) & $54(79)$ & $12(71)$ & 0.435 \\
\hline Statins, $\mathrm{n}(\%)$ & $27(39)$ & $6(35)$ & 0.738 \\
\hline Cardiac glycoside, $\mathrm{n}(\%)$ & $12(18)$ & $6(35)$ & 0.111 \\
\hline Systolic blood pressure, $(\mathrm{mmHg})$ & $137 \pm 20$ & $134 \pm 24$ & 0.694 \\
\hline Diastolic blood pressure, $(\mathrm{mmHg})$ & $84 \pm 14$ & $74 \pm 13$ & 0.978 \\
\hline Resting heart rate, $(\mathrm{bpm})$ & $81 \pm 27$ & $85 \pm 25$ & 0.567 \\
\hline Bridging with heparin, $\mathrm{n}(\%)$ & $47(69)$ & $14(82)$ & 0.278 \\
\hline Mean INR & $1.4 \pm 0.4$ & $1.3 \pm 0.3$ & 0.338 \\
\hline Procedure duration, (min) & $173 \pm 54$ & $170 \pm 41$ & 0.604 \\
\hline Total RF time, (min) & $43 \pm 24$ & $51 \pm 19$ & 0.187 \\
\hline Mean procedural ACT $(\mathrm{sec})$ & $264 \pm 34$ & $258 \pm 25$ & 0.613 \\
\hline Left ventricular ejection fraction, $(\%)$ & $57 \pm 12$ & $51 \pm 14$ & 0.202 \\
\hline Left atrial diameter, $(\mathrm{mm})$ & $44 \pm 7$ & $46 \pm 4$ & 0.244 \\
\hline LAA flow, $(\mathrm{m} / \mathrm{s})$ & $0.5 \pm 0.2$ & $0.4 \pm 0.2$ & 0.111 \\
\hline LAA volume, $(\mathrm{ml})$ & $9 \pm 4$ & $10 \pm 4$ & 0.138 \\
\hline LAA-morphology & & & $<0.001$ \\
\hline Chicken Wing, n (\%) & $14(21)$ & $11(65)$ & \\
\hline Cactus, $\mathrm{n}(\%)$ & $16(24)$ & $3(18)$ & \\
\hline Windsock, n (\%) & $9(13)$ & $2(12)$ & \\
\hline Cauliflower, n (\%) & $29(42)$ & $1(5)$ & \\
\hline
\end{tabular}

\section{LAA measurements and classification}

CT data were reviewed using multiplanar reconstruction, maximum intensity projection, and $3 \mathrm{D}$ volume rendering in a specialized image processing software (EnSite Verosimo, SJM, MN, USA). LAA volume was measured. Three physicians experienced with cardiac imaging and blinded to the clinical data of the patients, analyzed LAA morphology. In case of disagreement, further expert physician was consulted and a decision was made based on common consent. The LAA morphology was classified in 4 types, as previously defined (see Figure 2.2): ${ }^{7}$ 
1. The Cactus LAA, with a dominant central lobe and secondary lobes extending in superior and inferior directions.

2. The Chicken-Wing LAA, with an obvious bend of the dominant lobe, or folding back of the anatomy on itself, with or without secondary lobes.

3. The Windsock LAA, with a dominant lobe of sufficient length as the primary structure. Variations of this type location and number of smaller lobes were included here.

4. The Cauliflower LAA, with limited overall length and more complex internal characteristics. Variations of ostium and a variable number of lobes, without a dominant lobe, fall into this type.

\section{Catheter ablation}

Left atrial catheter ablation was performed using a previously described approach. ${ }^{15}$ In brief, patients were studied under deep propofol sedation with continuous invasive monitoring of arterial blood pressure and oxygen saturation. Non-fluoroscopic 3D catheter orientation, CT image integration, and tagging of the ablation sites were performed using Ensite NavX, Ensite Velocity (St. Jude Medical, St. Paul, MN, USA) or CARTO 3 (Biosense Webster, Diamond Bar, CA, USA). Trans-septal access and catheter navigation were performed with a steerable sheath (Agilis, St. Jude Medical., St. Paul, MN, USA). In all patients circumferential left atrial ablation lines were placed around the antrum of the ipsilateral pulmonary veins (irrigated tip catheter, preselected tip temperature of $48^{\circ} \mathrm{C}$, and maximum power of $30-50 \mathrm{~W}$ ). In patients with persistent $\mathrm{AF}$, additional linear lesions were added at the left atrial roof, the basal posterior wall and the left atrial isthmus. Ablation of complex fractionated electrograms was not performed.

After circumferential line placement, voltage and pace mapping along the ablation line were used to identify and close gaps. The isolation of all pulmonary veins with bidirectional block was verified with a multipolar circular mapping catheter and was defined as the procedural endpoint.

\section{Peri-interventional anticoagulation management}

Pre-procedural anticoagulation management changed over the study period from discontinued warfarin bridged with heparin to uninterrupted warfarin according to guideline recommendations valid at the time of ablation. During the procedure a weight-adjusted dose of intravenous heparin was administered immediately after the first transseptal access to target an activated clotting time (ACT) of $300 \mathrm{~s}$ before starting ablation to obtain homogeneous levels of anticoagulation during ablation. ACT levels were measured every 30 minutes with a target ACT of 300-350 seconds. Transseptal sheaths were continuously perfused with heparinized saline solution to avoid clot formation or air embolism. On the first postprocedural day oral anticoagulation was resumed and/or heparin-bridging initiated till the target INR was reached. The anticoagulation was continued for at least 3 months with a target INR of 2-3. Since the events occurred after a mean time of $24 \mathrm{~h}$ [IQR $0-96 \mathrm{~h}$ ] a detailed analysis of periinterventional anticoagulation management including periprocedural INR and heparin bridging was conducted.

\section{Statistical analysis}

Continuous variables are reported as mean \pm one standard deviation and categoric variables are reported as frequencies. Comparisons of categorical data were performed using a Chi-square test and normally distributed continuous data with Student t-test. Nonparametric continues date were analysed with Mann-Whitney test. For comparison of four different LAA morphologies an ANOVA test and Bonferroni post hoc analysis were used. Cohen's kappa ( $\kappa)$ coefficient was used as a statistical measure of inter-rater agreement and bootstrapping was performed to calculate confidence intervals. A good level of agreement was defined as $\kappa>0.61$. The multivariate 
logistic regression analysis was performed in order to detect independent predictors of thromboembolic events. In order to eliminate potential confounders the multivariate model was adjusted for potential confounders associated with chicken-wing morphology (Table 4.2). With the observed 17 events and an 1:4 case-control ratio, a 35\% difference in LAA morphology distribution was detectable with $80 \%$ power and $\mathrm{p}$ value $<0.05$. A two-tailed P-value less than 0.05 was considered statistically significant. Analysis was performed with SPSS v 20.0 (SPSS Inc., Chicago, USA).

Table 4.2. Characteristics of patients with chicken wing and non-chicken wing LAA morphology

\begin{tabular}{|l|c|c|c|}
\hline Chicken wing & No $(\mathrm{n}=60)$ & Yes $(\mathrm{n}=25)$ & $\mathrm{P}$ \\
\hline Age, $($ years) & $64 \pm 11$ & $64 \pm 11$ & 0.751 \\
\hline Males, $\mathrm{n}(\%)$ & $35(58)$ & $15(60)$ & 0.887 \\
\hline Body mass index, $(\mathrm{kg} / \mathrm{m} 2)$ & $28 \pm 4$ & $28 \pm 4$ & 0.827 \\
\hline Persistent AF, $\mathrm{n}(\%)$ & $24(36)$ & $9(53)$ & 0.197 \\
\hline Hypertension, $\mathrm{n}(\%)$ & $49(82)$ & $15(60)$ & 0.035 \\
\hline Diabetes, $\mathrm{n}(\%)$ & $16(27)$ & $3(12)$ & 0.139 \\
\hline Congestive heart failure, $\mathrm{n}(\%)$ & $6(10)$ & $1(4)$ & 0.359 \\
\hline History of stroke/TIA, $\mathrm{n}(\%)$ & $18(30)$ & $5(20)$ & 0.344 \\
\hline Peripheral vascular disease, $\mathrm{n}(\%)$ & $7(12)$ & $6(24)$ & 0.150 \\
\hline Coronary artery disease, $\mathrm{n}(\%)$ & $18(30)$ & $6(24)$ & 0.576 \\
\hline CHA2DS2-VASc, median (IQR) & $3(2-4)$ & $2(1-5)$ & 0.204 \\
\hline ACE inhibitors, $\mathrm{n}(\%)$ & $35(58)$ & $19(76)$ & 0.123 \\
\hline Beta-blockers, $\mathrm{n}(\%)$ & $47(78)$ & $19(76)$ & 0.814 \\
\hline Statins, $\mathrm{n}(\%)$ & $24(40)$ & $9(36)$ & 0.730 \\
\hline Cardiac glycoside, $\mathrm{n}(\%)$ & $14(23)$ & $4(16)$ & 0.451 \\
\hline Systolic blood pressure, $(\mathrm{mmHg})$ & $134 \pm 18$ & $139 \pm 25$ & 0.411 \\
\hline Diastolic blood pressure, $(\mathrm{mmHg})$ & $84 \pm 14$ & $74 \pm 13$ & 0.459 \\
\hline Resting heart rate, $(\mathrm{bpm})$ & $84 \pm 27$ & $76 \pm 23$ & 0.236 \\
\hline Bridging with heparin, $\mathrm{n}(\%)$ & $43(72)$ & $18(72)$ & 0.975 \\
\hline Mean INR & $1.4 \pm 0.3$ & $1.4 \pm 0.5$ & 0.873 \\
\hline Procedure duration, (min) & $168 \pm 48$ & $191 \pm 55$ & 0.078 \\
\hline Total RF time, $(\mathrm{min})$ & $44 \pm 23$ & $45 \pm 24$ & 0.884 \\
\hline Mean procedural ACT (sec) & $261 \pm 30$ & $268 \pm 41$ & 0.482 \\
\hline Left ventricular ejection fraction, $(\%)$ & $57 \pm 12$ & $56 \pm 14$ & 0.963 \\
\hline Left atrial diameter, (mm) & $43 \pm 6$ & $48 \pm 6$ & 0.045 \\
\hline LAA flow, (m/s) & $0.5 \pm 0.2$ & $0.5 \pm 0.2$ & 0.952 \\
\hline LAA volume, (ml) & $9 \pm 4$ & $9 \pm 3$ & 0.654 \\
\hline Peri-interventional stroke/TIA, $\mathrm{n}(\%)$ & $6(10)$ & $11(44)$ & $<0.001$ \\
\hline
\end{tabular}

\section{Results}

\section{Patient characteristics in different LAA morphologies}

In the whole population the following distribution of four morphology types was observed: 19 patients (22\%) had cactus morphology, 25 patients (29\%) chicken wing, 11 patients $(13 \%)$ windsock and 30 patients $(35 \%)$ cauliflower. Satisfactory level of inter-observer agreements was reached (kappa 0,70; 95\% CI: 0.38-0.90, $\mathrm{p}<0.001$ ). 
The baseline characteristics, medication and procedural data were not significantly different in patients with different LAA types (Table 4.3). However, the prevalence of previous thromboembolic events was higher in patients with LAA cauliflower type $(\mathrm{n}=13,57 \%)$ compared to chicken wing morphology $(n=5,22 \%$, cactus $(n=4,17 \%)$, or windsock $(n=1,4 \% ; p=0.062)$. This resulted in more than three times greater likelihood of a history of stroke or TIA in patients with cauliflower compared to non-cauliflower morphologies (OR 3.441, CI 95\% 1.272-9.312, $\mathrm{p}=0.013)$.

Table 4.3. Patient characteristics according to LAA morphology.

\begin{tabular}{|c|c|c|c|c|c|}
\hline & \multicolumn{4}{|c|}{ LAA-morphology } & \multirow[b]{2}{*}{$\mathrm{P}$} \\
\hline & Chicken wing & Cactus & Windsock & Cauliflower & \\
\hline Count, $\mathrm{n}$ & 25 & 19 & 11 & 30 & \\
\hline Age, (years) & $64 \pm 11$ & $64 \pm 9$ & $63 \pm 7$ & $64 \pm 13$ & 0.962 \\
\hline Males, n (\%) & $15(60)$ & $14(74)$ & $4(36)$ & $17(57)$ & 0.474 \\
\hline Body mass index, $(\mathrm{kg} / \mathrm{m} 2)$ & $28 \pm 4$ & $27 \pm 4$ & $30 \pm 5$ & $27 \pm 3$ & 0.225 \\
\hline Persistent AF, n (\%) & $9(53)$ & $9(53)$ & $9(53)$ & $9(53)$ & 0.197 \\
\hline Hypertension, $\mathrm{n}(\%)$ & $15(60)$ & $15(79)$ & $9(82)$ & $25(83)$ & 0.059 \\
\hline Diabetes, $\mathrm{n}(\%)$ & $3(12)$ & $5(26)$ & $4(36)$ & $7(23)$ & 0.326 \\
\hline Congestive heart failure, $\mathrm{n}(\%)$ & $1(4)$ & $4(16)$ & $1(9)$ & $2(7)$ & 0.947 \\
\hline History of stroke/TIA, n (\%) & $5(20)$ & $4(21)$ & $1(9)$ & $13(43)$ & 0.062 \\
\hline Peripheral vascular disease, n (\%) & $6(24)$ & $3(16)$ & $0(0)$ & $4(13)$ & 0.225 \\
\hline Coronary artery disease, $\mathrm{n}(\%)$ & $6(24)$ & $7(37)$ & $4(36)$ & $7(23)$ & 0.849 \\
\hline $\mathrm{CHA}_{2} \mathrm{DS}_{2}-\mathrm{VASc}$, median (IQR) & $2(1-5)$ & $3(2-4)$ & $3(2-4)$ & $4(2-5)$ & 0.353 \\
\hline ACE inhibitors, n (\%) & $19(76)$ & $8(42)$ & $7(64)$ & $20(67)$ & 0.825 \\
\hline Beta-blockers, n (\%) & $19(76)$ & $14(74)$ & $11(100)$ & $30(27)$ & 0.953 \\
\hline Statins, $\mathrm{n}(\%)$ & $9(36)$ & $6(32)$ & $7(63)$ & $11(37)$ & 0.703 \\
\hline Cardiac glycoside, n (\%) & $4(16)$ & $3(16)$ & $3(27)$ & $8(27)$ & 0.264 \\
\hline Systolic blood pressure (mmHg) & $139 \pm 25$ & $130 \pm 13$ & $132 \pm 19$ & $138 \pm 19$ & 0.493 \\
\hline Diastolic blood pressure (mmHg) & $82 \pm 11$ & $84 \pm 18$ & $85 \pm 13$ & $84 \pm 13$ & 0.895 \\
\hline Resting heart rate (bpm) & $76 \pm 23$ & $74 \pm 18$ & $81 \pm 21$ & $84 \pm 13$ & 0.142 \\
\hline Bridging with heparin, $\mathrm{n}(\%)$ & $18(72)$ & $11(58)$ & $8(73)$ & $24(80)$ & 0.336 \\
\hline Mean INR & $1.4 \pm 0.5$ & $1.4 \pm 0.3$ & $1.4 \pm 0.4$ & $1.4 \pm 0.3$ & 0.920 \\
\hline Procedure duration, (min) & $191 \pm 55$ & $153 \pm 37$ & $180 \pm 53$ & $172 \pm 41$ & 0.108 \\
\hline Total RF time, (min) & $45 \pm 24$ & $41 \pm 19$ & $51 \pm 28$ & $43 \pm 25$ & 0.812 \\
\hline Mean procedural ACT $(\mathrm{sec})$ & $268 \pm 41$ & $241 \pm 13$ & $271 \pm 24$ & $269 \pm 33$ & 0.110 \\
\hline Left ventricular ejection fraction $(\%)$ & $56 \pm 14$ & $54 \pm 11$ & $52 \pm 14$ & $58 \pm 12$ & 0.627 \\
\hline Left atrial diameter $(\mathrm{mm})$ & $48 \pm 6$ & $46 \pm 4$ & $45 \pm 7$ & $41 \pm 6$ & 0.014 \\
\hline LAA flow $(\mathrm{m} / \mathrm{s})$ & $0.5 \pm 0.2$ & $0.4 \pm 0.2$ & $0.5 \pm 0.2$ & $0.5 \pm 0.2$ & 0.111 \\
\hline LAA volume $(\mathrm{ml})$ & $9 \pm 3$ & $10 \pm 4$ & $9 \pm 5$ & $9 \pm 4$ & 0.855 \\
\hline
\end{tabular}




\section{Impact of LAA morphology on peri-interventional thromboembolic risk}

No significant differences in baseline characteristics, medication, or thromboembolic risk defined as $\mathrm{CHA}_{2} \mathrm{DS}_{2}$-VASc score were observed between patients with and without periinterventional events. The analysis of procedural data did not show significant differences in procedural settings and techniques (i.e. ACT, procedure duration, ablation time, use of cardioversion, mapping system, ablation catheter, operator's experience or rhythm prior ablation) between the groups.

The chicken wing morphology was the most frequently observed type among patients with peri-interventional events (11 patients). When compared with distribution in event-free patients (65\% chicken wing, $18 \%$ cactus, $12 \%$ windsock, $5 \%$ cauliflower vs. $21 \%, 24 \%, 13 \%, 42 \%$ respectively) a significant difference was detected $(\mathrm{p}<0.001)$. This difference translated into more than 7 time higher peri-interventional risk in patients with chicken wing morphology when compared to all other types (OR 7.071, CI 95\% 2.227-22.454, $\mathrm{p}<0.001$ ).

There were no significant differences with respect to LAA morphology between 9 patients with lasting stroke and 8 patients without sequelae (TIA): $44 \%$ chicken wing, 33\% cactus, $22 \%$ windsock, $0 \%$ cauliflower vs. $87 \%, 0 \%, 0 \%, 13 \%$ respectively ( $\mathrm{p}=0.378$. Table 4.4.)

Table 4.4. Characteristics of patients with peri-interventional thromboembolic events.

\begin{tabular}{|c|c|c|c|c|c|c|c|c|}
\hline 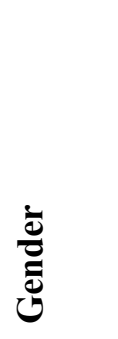 & 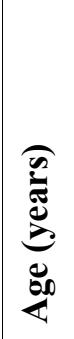 & 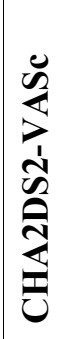 & 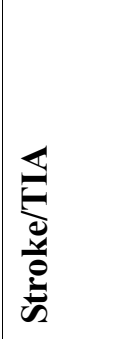 & 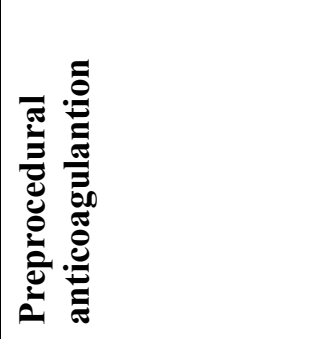 & 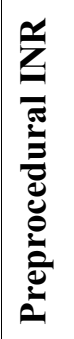 & 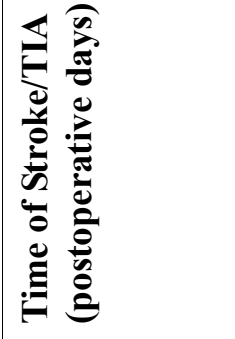 & 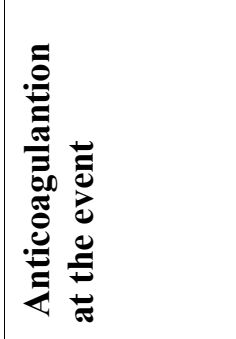 & 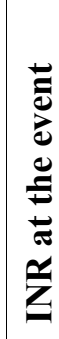 \\
\hline female & 68 & 3 & TIA & unbridged VKA & 2.0 & 7 & VKA & 2.7 \\
\hline male & 61 & 2 & Stroke & bridged with LMWH & 1.2 & 2 & VKA+LMWH & 1.4 \\
\hline female & 71 & 2 & Stroke & bridged with LMWH & 1.0 & 4 & VKA+LMWH & 1.0 \\
\hline male & 32 & 0 & TIA & none & 1.0 & 4 & VKA & 1.9 \\
\hline female & 67 & 2 & TIA & bridged with LMWH & 1.2 & 1 & VKA & 2.0 \\
\hline female & 70 & 2 & TIA & bridged with LMWH & 1.1 & 2 & VKA & 3.3 \\
\hline male & 48 & 1 & TIA & bridged with LMWH & 1.1 & Wake-up event & - & - \\
\hline male & 62 & 2 & Stroke & bridged with LMWH & 1.0 & Wake-up event & - & - \\
\hline female & 72 & 5 & Stroke & bridged with heparin & 1.0 & Wake-up event & - & - \\
\hline female & 69 & 4 & Stroke & bridged with heparin & 1.1 & 5 & VKA+heparin & 1.0 \\
\hline male & 61 & 3 & Stroke & bridged with heparin & 1.4 & Wake-up event & - & - \\
\hline male & 63 & 1 & Stroke & bridged with LMWH & 1.0 & Wake-up event & - & - \\
\hline male & 79 & 3 & Stroke & unbridged VKA & 1.8 & 1 & VKA & 2.0 \\
\hline male & 68 & 3 & Stroke & bridged with heparin & 1.8 & 1 & VKA & 1.8 \\
\hline male & 54 & 4 & TIA & bridged with LMWH & 1.5 & 1 & VKA+LMWH & 1.3 \\
\hline female & 74 & 5 & TIA & bridged with LMWH & 1.5 & 5 & VKA+LMWH & 1.7 \\
\hline male & 70 & 5 & TIA & bridged with LMWH & 1.7 & Wake-up event & - & - \\
\hline
\end{tabular}

LMWH - low-molecular-weight heparin; VKA vitamin K antagonist 
The characteristics of patients with chicken wing and non-chicken wing morphologies were not significantly different with the exception of a larger LA diameter, less hypertension and a trend to longer procedure time (Table 4.2). In a multivariate model including these factors as potential confounders, chicken wing morphology remained an independent predictor of peri-interventional event (OR 7.2, CI 95\% 1.352-38.328, $\mathrm{p}=0.021$ ) (Figure 4.1). Furthermore, adding the mean procedural ACT to the logistic model did not influence the impact of chicken wing morphology on peri-interventional risk (OR 7.2, CI 95\% 1.353-38.328, $\mathrm{p}=0.022$ ).

\section{Left atrial diameter \\ Hypertension \\ Chicken wing morphology \\ Procedure duration}

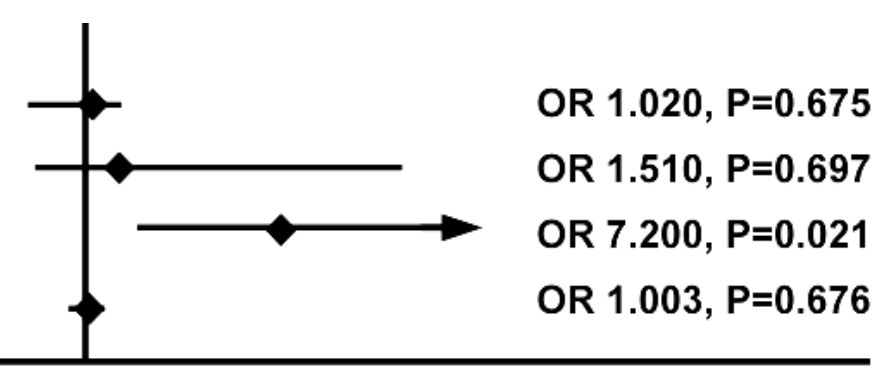

$\begin{array}{llllllllllll}0 & 0.2 & 0.4 & 0.6 & 0.8 & 1 & 2 & 4 & 6 & 8 & 10\end{array}$

Figure 4.1. Multivariate model of predictors of peri-interventional thromboembolic events.

\section{Main findings}

\section{Discussion}

To the best of our knowledge this is the first study illustrating the impact of LAA-morphology on peri-interventional thromboembolic risk associated with catheter ablation of AF. In this case control study we observed chicken wing morphology to be associated with seven time higher risk of peri-interventional thromboembolic event. This association remained significant after adjustment for possible confounders associated with chicken wing morphology.

\section{Influence of LAA morphology on peri-interventional thromboembolic risk}

Several independent groups have recently presented the impact of different LAA morphologies on thromboembolic risk prior AF ablation. In their study, Kimura et al. ${ }^{10}$ found that the prevalence of prior thromboembolic events in patients with low $\mathrm{CHA}_{2} \mathrm{DS}_{2}-\mathrm{VASc}$ score was the highest in patients with cauliflower morphology. These results have been in agreement with an other larger trial ${ }^{7}$ describing the correlation of cauliflower morphology and eight times higher risk when compared to "protective" chicken wing morphology. In our study we have also observed more than three times increased likelihood of prior stroke or TIA in patients with cauliflower LAA morphology. Therefore, our results also support this thesis and are in agreement with previous reports. Moreover, the unity of these results reassures us about the validity of our findings and the correctness of our methodology.

However, those results and risk factors cannot be translated into the interventional setting for prediction of peri-procedural thromboembolic events. In contrast to the previous studies, the chicken wing morphology, which was described as protective, turned out to be the most dangerous one, when it comes to thromboembolic risk after AF ablation.

The fact that acknowledged echocardiographic parameters like LAA volume and LAA flow velocity did not differ significantly between LAA morphologies or between event and event-free patients, suggests that the peri-procedural thrombus formation and triggering of thromboembolic events have different mechanisms and different predictors. 
In our opinion, the conventional criteria like LAA volume have no implication in periinterventional risk stratification. It is probably the distribution of that volume into different shapes, partly modulating also the LAA hemodynamics, which is of great importance. Similarly, Di Biase et al. also found no significant correlation between LAA size and the prevalence of previous stroke/TIA. ${ }^{7}$

The elongated, stretched and curved shape of a chicken wing LAA might be protective against spontaneous thromboembolic events by preventing uninhibited release of prominent, large thrombi into the circulation and enhancing the resolution or adhesion of minor ones. However, this protective three-dimensional configuration might act just the opposite during AF ablation: it might become a reservoir for microthrombi generated at the catheter tip or on fresh lesions and flashed into LAA by the flow of nowadays universally used catheter irrigation. When considering the spatial relationship to the LA ridge, frequently requiring intensive and extended ablation, this hypothesis becomes persuasive. The load of loose thrombogeneous material might afterwards become the source of thromboembolism itself or start a cascade of solid thrombus formation.

Further possible mechanisms mediating this phenomenon could be the differences in concentration of coagulations plasma markers, endothelial function or platelet activation potentially related to LAA-morphology and function. However since this is the first such analysis no sufficient data to support this thesis are available at this moment. Nevertheless, such fundings would be of great clinical benefit as they can guide the suitable periprocedural anticoagulation or the needed ACT level during ablation as shown in patients with spontaneous echo contrast. ${ }^{16}$

However, at this point, no presumptions can be made and further studies are necessary to illuminate the pathophysiological mechanisms and clinical implications in order to improve the safety of patients undergoing AF ablation.

\section{Limitations}

The study is based on a single-center registry and reflects results of a highly specialized tertiary care hospital. Since we only used radiofrequency energy, our findings cannot be extrapolated to other energy sources. Although for the purpose of this study we have analysed data of 2,570 patients undergoing over 3,300 procedures the study is limited by a low incidence of manifest thromboembolic events. The incidence of silent cerebral was not examined in this study. Although in the multivariate model adjusted for LA dimension and procedural time the LAAmorphology remained a single independent predictor, both those parameters could become relevant in a larger cohort. Finally, the study was designed to examine the impact of LAAmorphologies on peri-interventional risk and the employed statistical method did not enable the identification of further risk factors. However, given the very high incidence $(65 \%)$ of chickenwing morphology in the event group it is to expect that the results would remain significant after adjustment for further confounders.

\section{Conclusion}

The chicken wing morphology of LAA is associated with higher peri-procedural thromboembolic risk in patients undergoing AF ablation. Further studies are needed to illuminate the pathophysiological mechanisms and clinical implications of this phenomenon. 


\section{References}

1. Wolf PA, Abbott RD, Kannel WB. Atrial fibrillation as an independent risk factor for stroke: the Framingham Study. Stroke Aug 1991;22:983-988.

2. Gage BF, Waterman AD, Shannon W, Boechler M, Rich MW, Radford MJ. Validation of clinical classification schemes for predicting stroke: results from the National Registry of Atrial Fibrillation. JAMA : the journal of the American Medical Association Jun 13 2001;285:2864-2870.

3. Lip GY, Nieuwlaat R, Pisters R, Lane DA, Crijns HJ. Refining clinical risk stratification for predicting stroke and thromboembolism in atrial fibrillation using a novel risk factor-based approach: the euro heart survey on atrial fibrillation. Chest Feb 2010;137:263-272.

4. Fang MC, Go AS, Chang Y, Borowsky L, Pomernacki NK, Singer DE, Group AS. Comparison of risk stratification schemes to predict thromboembolism in people with nonvalvular atrial fibrillation. J Am Coll Cardiol Feb 26 2008;51:810-815.

5. Olesen JB, Torp-Pedersen C, Hansen ML, Lip GY. The value of the CHA2DS2-VASc score for refining stroke risk stratification in patients with atrial fibrillation with a CHADS2 score 0-1: a nationwide cohort study. Thromb Haemost Jun 2012;107:1172-1179.

6. Watson T, Shantsila E, Lip GY. Mechanisms of thrombogenesis in atrial fibrillation: Virchow's triad revisited. Lancet Jan 10 2009;373:155-166.

7. Di Biase L, Santangeli P, Anselmino M, et al. Does the left atrial appendage morphology correlate with the risk of stroke in patients with atrial fibrillation? Results from a multicenter study. J Am Coll Cardiol Aug 7 2012;60:531-538.

8. Anselmino M, Scaglione M, Di Biase L, Gili S, Santangeli P, Corsinovi L, Pianelli M, Cesarani F, Faletti R, Righi D, Natale A, Gaita F. Left atrial appendage morphology and silent cerebral ischemia in patients with atrial fibrillation. Heart Rhythm Jan 2014;11:2-7.

9. Khurram IM, Dewire J, Mager M, et al. Relationship between left atrial appendage morphology and stroke in patients with atrial fibrillation. Heart Rhythm Dec 2013;10:18431849 .

10. Kimura T, Takatsuki S, Inagawa K, Katsumata Y, Nishiyama T, Nishiyama N, Fukumoto K, Aizawa Y, Tanimoto Y, Tanimoto K, Jinzaki M, Fukuda K. Anatomical characteristics of the left atrial appendage in cardiogenic stroke with low CHADS2 scores. Heart Rhythm Jun 2013;10:921-925.

11. Cappato R, Calkins H, Chen SA, et al. Updated worldwide survey on the methods, efficacy, and safety of catheter ablation for human atrial fibrillation. Circ Arrhythm Electrophysiol Feb 2010;3:32-38.

12. Lang RM, Bierig M, Devereux RB, et al. Recommendations for chamber quantification: a report from the American Society of Echocardiography's Guidelines and Standards Committee and the Chamber Quantification Writing Group, developed in conjunction with the European Association of Echocardiography, a branch of the European Society of Cardiology. J Am Soc Echocardiogr Dec 2005;18:1440-1463.

13. Lang RM, Bierig M, Devereux RB, et al. Recommendations for chamber quantification: a report from the American Society of Echocardiography's Guidelines and Standards Committee and the Chamber Quantification Writing Group, developed in conjunction with the European Association of Echocardiography, a branch of the European Society of Cardiology. J Am Soc Echocardiogr Dec 2005;18:1440-1463.

14. Hahn RT, Abraham T, Adams MS, Bruce CJ, Glas KE, Lang RM, Reeves ST, Shanewise JS, Siu SC, Stewart W, Picard MH. Guidelines for performing a comprehensive transesophageal echocardiographic examination: recommendations from the American Society of 
Echocardiography and the Society of Cardiovascular Anesthesiologists. J Am Soc Echocardiogr Sep 2013;26:921-964.

15. Eitel C, Hindricks G, Sommer P, et al. Circumferential pulmonary vein isolation and linear left atrial ablation as a single-catheter technique to achieve bidirectional conduction block: the pace-and-ablate approach. Heart Rhythm 2010;7:157-164.

16. Ren JF, Marchlinski FE, Callans DJ, Gerstenfeld EP, Dixit S, Lin D, Nayak HM, Hsia HH. Increased intensity of anticoagulation may reduce risk of thrombus during atrial fibrillation ablation procedures in patients with spontaneous echo contrast. J Cardiovasc Electrophysiol May 2005;16:474-477. 
Part II Atrial morphology and AF ablation outcomes 


\section{Chapter 5 Characteristics of atrial remodeling}

Adapted from "Characteristic changes of volume and three-dimensional structure of the left atrium in different forms of atrial fibrillation: predictive value after ablative treatment."

Published in J Interv Card Electrophysiol Nov 2011;32:87-94. DOI: 10.1007/s10840-011-9591-Z

Sotirios Nedios, Min Tang, Mattias Roser, Natalia Solowjowa, Jin-Hong Gerds-Li, Eckart Fleck, Charalampos Kriatselis 


\begin{abstract}
Introduction:

Atrial fibrillation (AF) is associated with electroanatomical remodeling of the left atrium (LA), especially with LA dilatation. However, little is known about the changes of the threedimensional structure of the LA in different AF types and their prognostic value after an ablative treatment.
\end{abstract}

\title{
Methods:
}

One hundred fifteen patients (72 males, $59 \pm 11$ years) with an indication for AF ablation were prospectively included. Preoperatively, all patients underwent cardiac computed tomography (CCT). A reconstruction of the LA and the pulmonary veins (PV) was made from CCT data using specialized software (EP Navigator, Philips, The Netherlands). Left atrial volume (LAV) after exclusion of the atrial appendage (LAA) and the PV was determined. The LA was then arbitrarily divided by a cutting plane, between the anterior segment of the PV ostia and the atrial appendage and parallel to the posterior wall, to anterior- (LA-Ant.) and posterior-LA (LA-Post.). The ratio LA- Ant./LAV was defined as asymmetry index (ASI). The cardiac CT data, of 25 patients (11 women, $47 \pm 11$ years) without organic heart disease, were similarly studied for the same parameters, as a control group.

\section{Results:}

Patients with paroxysmal AF $(\mathrm{n}=63)$ had significantly higher LAV $(131 \pm 31$ vs. $95 \pm 18 \mathrm{ml}, \mathrm{p}$ $<0.001)$ and higher ASI $(61 \pm 6 \%$ vs. $57 \pm 4, \mathrm{p}=0.002)$ than the control group. Patients with persistent AF $(\mathrm{n}=34)$ in comparison with paroxysmal AF showed significantly larger volumes $(154 \pm 44$ vs. $131 \pm 31 \mathrm{ml}, \mathrm{p}=0.007)$ but no difference in the ASI $(60 \pm 8 \%$ vs. $61 \pm 6 \%, \mathrm{p}=$ $0.63)$. Finally, patients with long-standing persistent AF $(n=18)$ showed a bigger asymmetry index than patients with persistent AF $(64 \pm 5 \%$ vs. $60 \pm 8 \%, \mathrm{p}=0.06)$ but no significant difference in volumes $(161 \pm 21$ vs. $154 \pm 44 \mathrm{ml}, \mathrm{p}=0.49)$. LAA and partial LA volumes had a dilatation pattern similar to LAV. During a follow-up of over $25 \pm 7$ months, AF recurred in 31 (27\%) patients. Multivariate analysis showed that ASI and LAV were the only two significant predictors of AF recurrence after ablative treatment. Independent of LAV, an ASI over $60 \%$ predicted AF recurrence with $74 \%$ sensitivity and $73 \%$ specificity.

\section{Conclusion:}

Characteristic differences of both left atrial volume and geometry exist between the different forms of atrial fibrillation (paroxysmal, persistent and long-standing persistent). The asymmetry index is a simple parameter derived from cardiac CT data that reflects these changes of LA geometry and predicts the outcome after the PV isolation. 


\section{Introduction}

Atrial fibrillation (AF) is the most common arrhythmia with an increasing prevalence and incidence, mainly due to ageing of the population, higher prevalence of chronic heart disease and more emphasis on early diagnosis. ${ }^{1}$ Percutaneous catheter ablation with pulmonary vein isolation (PVI) has emerged as an important treatment and becomes increasingly prevalent, as a rising number of specialized centers and physicians offer this option to patients with symptomatic, drug-refractory AF. ${ }^{2}$

However, the success rates are highly variable as different techniques and follow-up protocols are applied in a large and heterogeneous population. ${ }^{1}$ In the pursuit of better results, several studies have identified predictors of success after an ablation (age, left atrial (LA) size, mitral valve disease, cardiomyopathy, AF type and burden, BMI, sleep apnea). ${ }^{3-10}$ These factors could help identify patients with higher recurrence rate, who need additional attention and probably modified treatment or follow-up.

LA enlargement is known to be associated with advanced AF disease. ${ }^{11}$ This enlargement, termed atrial remodeling, corresponds to the presence of an arrhythmia promoting substrate $e^{12-15}$ and may be reversed with rhythm control. ${ }^{16-20}$ Based on these facts, LA size soon became a common diagnostic criterion for patient selection before $\mathrm{PVI}^{7}$ and many trials restricted patient enrolment to those with LA diameter less than $5 \mathrm{~cm}$ in echocardiography. Newer imaging modalities though, revealed that this measurement has poor correlation with LA volume ${ }^{21}$ and provided a better understanding of the LA structure ${ }^{22}$ and its significance. ${ }^{5}$ However, to date, little is known about the characteristic changes of the LA in terms of size and symmetry associated with the progression of atrial fibrillation from paroxysmal to persistent and longstanding persistent.

The present study had two aims: (1) to identify characteristic changes of the left atrial geometry in patients with different types of atrial fibrillation (paroxysmal, persistent, long-standing persistent) as compared to healthy subjects, (2) to explore whether such changes have any influence on the outcome of atrial fibrillation ablation.

\section{Patient characteristics}

\section{Methods}

This study prospectively enrolled, from January 2007 to June 2009, a total of 115 patients (72 males, mean age of $59 \pm 11$ years) with indication for an AF ablation. All patients underwent preprocedural CCT and pre-procedural transesophageal echocardiography to exclude atrial thrombi. Patients with advanced mitral valve disease (grade $>$ II), impaired renal function (GFR $<90$ $\mathrm{ml} / \mathrm{min}$ ) or iodine allergy were excluded from the study. Patients were divided into three groups according to their AF type, based on the clinical classification of the current guidelines. ${ }^{23} \mathrm{AF}$ was defined as paroxysmal if it self-terminated in less than 7 days; when sustained beyond 7 days, AF was defined as persistent. AF with duration of more than 12 months was classified as longstanding persistent.

Twenty-five individuals (14 males, mean age of $47 \pm 11$ years) from the same time period, with no AF history and without evidence for organic heart disease were used as a control group. The local Institutional Review Board approved the study protocol and all patients gave written informed consent prior to every procedure.

\section{Pre-procedural cardiac CT evaluation}

All patients underwent contrast-enhanced CCT using a dual source, 64 multi-slice scanner (Somatom Definition, Siemens Inc., Germany). Image acquisition was performed during end- 
inspiratory breath-hold and a contrast injection of $100 \mathrm{ml}$ iodinated contrast (Imeron 400, Altana Pharma, Wesel, Germany), at a rate of $5 \mathrm{ml} / \mathrm{s}$, following a timing bolus- chase injection $(20 \mathrm{ml}, 5$ $\mathrm{ml} / \mathrm{s}$ ). Scanning was performed gated to the cardiac cycle in cranio-caudal direction from the aortic arch to the diaphragm. Imaging parameters included: $120 \mathrm{KV}, 850 \mathrm{mAs}, 0.6 \mathrm{~mm}$ beam collimation and $0.32 \mathrm{~s}$ rotation time. Reconstructed image slice thickness was $0.76 \mathrm{~mm}$ and fieldof-view was $20 \mathrm{~cm}$.

Ten phases over one cardiac cycle were extracted and transferred to specialized software (EP PreNavigator, Philips, The Netherlands). A 3D reconstruction of the LA and the pulmonary veins (PV) was performed on a $512 \times 512$ pixel matrix. In patients with sinus rhythm, the end-systolic phase corresponding to the atrial end-diastole, just before mitral valve opening, was selected for evaluation. Respectively, in patients with AF, the phase with the maximal LA volume was selected and assessed.

The maximum LA volume of the left atrium (LAV), after exclusion of the atrial appendage (LAA) and the PV, was calculated by an automated algorithm from the segmented 3D reconstruction. The LAA volume was not included in LA volume, because in some patients, contrast filled the append- age poorly, attenuating the delineation accuracy. The LA was then arbitrarily divided by a cutting plane, between the anterior segment of the PV ostia and the atrial appendage and parallel to the posterior wall. The partial volumes of LA, the anterior (LA-Ant.) and the posterior (LA-Post.) were calculated and the ratio LA-Ant./LAV was defined as an index of asymmetry (ASI). The same parameters were similarly studied from the cardiac CT data of the control group.

Measurements were obtained by a single blinded operator and then compared with measurements of 20 random patients made 4 weeks later, by the same investigator and a second independent reviewer in a blinded fashion.

\begin{abstract}
Ablation procedure
Oral anticoagulation was stopped 3-7 days before the scheduled ablation, and when INR fell below 1.8, the patient was started on low-molecular heparin subcutaneously until the day before the procedure.

Ablation procedure was performed during sedation with propofol, respiratory and circulatory monitoring, as previously described. ${ }^{24}$ In brief, a quadripolar catheter (Josephson type, Bard, Lowell, MA, USA) was inserted through the femoral vein and placed at a stable position on the right ventricular apex. A diagnostic decapolar catheter (Inquiry, St. Jude Medical, St.Paul, MN, USA) was inserted into the coronary sinus, and two transseptal punctures were performed. Intravenous heparin was then administered to maintain the clotting time at about $300 \mathrm{~s}$. After rotational angiography and 3D reconstruction of the LA-PVs.' Anatomy, ${ }^{24,25}$ an irrigated $3.5 \mathrm{~mm}$ tip ablation catheter (Navistar Thermocool, Biosense Web- ster) and a decapolar mapping catheter (Lasso, Biosense Webster, Diamond Bar, CA, USA) were inserted into the LA and the respective $\mathrm{PV}$, to facilitate ostial ablation. The endpoint of the procedure was the electrical isolation of all pulmonary veins defined as both entrance block (elimination of PV potentials at the Lasso catheter) and exit block (no LA capture during pacing at all poles of Lasso catheter).
\end{abstract}

\title{
Follow-up
}

The patients were seen in our outpatient clinic 4 weeks, 3 months, 6 months and then every 6 months after the ablation procedure. Anti-arrhythmic drug therapy was continued for 1 month in patients with history of paroxysmal and for 3 months in patients with persistent and long-standing persistent AF. All patients were asked to keep a log of the duration and frequency of their symptoms. During each follow-up visit, $24 \mathrm{~h}$ ECG monitoring was performed. AF recurrence was 
defined as any documented AF episode with duration of more than $30 \mathrm{~s}$. The first 3 months following ablation was a blanking period during which AF recurrences were not evaluated. In cases when symptoms occurred outside the recording periods, patients were advised to contact our institution or the referring physician to obtain ECG documentation. At 3 months, a cardiac magnetic resonance imaging was performed for documentation of any PV stenosis.

\section{Statistical analysis}

Data were expressed as mean \pm standard deviation for continuous variables and percentage of frequency for categorical variables. Distribution of data was assessed by Levene's, KolmogorovSmirnov or Shapiro-Wilk test. Comparative analysis of continuous variables was performed with Student's t test for two groups and with one-way ANOVA for more than two groups, in order to minimize type I errors. Post hoc analysis revealed differences between subgroups. Fisher's exact test or chi-squared $\left(\chi^{2}\right)$ was used to compare categorical variables. Intra-observer and interobserver variability was expressed with the correlation coefficient (r) between measurements. How well LAV or ASI differentiated patients with and without recurrence of AF was assessed by means of the area under the receiver operating characteristic curve, which ranged from 0 to 1 , with 0.5 corresponding to no discrimination (i.e., random performance) and 1.0 to perfect discrimination.

Clinical variables were evaluated with univariate analysis to determine a significant association with the dependent variable. Variables selected by univariate analysis were then incorporated into multivariable binary regression analysis and fitted by a forward stepwise selection procedure (probability values for entry and removal 0.05 and 0.10, respectively). Stepwise multivariable regression analysis was performed to determine which independent variables were significantly associated with recurrence of AF. All statistical analyses were performed using SPSS 17.0 (SPSS, Chicago, IL, USA).

\section{Results}

The patients' baseline characteristics are summarized in Table 5.1. The majority of patients were males (72 pts., $63 \%$ ) with a mean age of $59 \pm 11$ years. Left ventricular ejection fraction was $64 \pm 8 \%$. LAD and LAV were $45 \pm 7 \mathrm{~mm}$ and $134 \pm 38 \mathrm{ml}$, respectively.

Table 5.1. Baseline characteristics for the control group and the AF patients.

\begin{tabular}{|l|c|c|c|c|c|}
\hline Group: & Control & Paroxysmal AF & Persistent AF & Long-standing AF & P \\
\hline Patients, $\mathrm{n}$ & 25 & 63 & 34 & 18 & \\
\hline Men, n (\%) & $14(56 \%)$ & $39(62 \%)$ & $19(56 \%)$ & $14(78 \%)$ & 0.43 \\
\hline Age, years & $47 \pm 11^{*}$ & $58 \pm 11$ & $61 \pm 11$ & $60 \pm 10$ & $0.04^{*}$ \\
\hline BMI, kg/m2 & $27 \pm 5$ & $28 \pm 3$ & $27 \pm 4$ & $29 \pm 3$ & 0.12 \\
\hline Obesity, n (\%) & $7(28 \%)$ & $16(25 \%)$ & $9(27 \%)$ & $4(22 \%)$ & 0.93 \\
\hline Hypertension, n (\%) & $12(48 \%)$ & $33(52 \%)$ & $18(53 \%)$ & $11(56 \%)$ & 0.96 \\
\hline Diabetes, n (\%) & $3(12 \%)$ & $5(8 \%)$ isEp: & $2(6 \%)$ & $2(11 \%)$ & 0.08 \\
\hline CAD, n (\%) & $0 *$ & $9(14 \%)$ & $8(24 \%)$ & $6(33 \%)$ & $0.02 *$ \\
\hline LV-EF, \% & $65 \pm 9$ & $65 \pm 8$ & $62 \pm 11$ & $63 \pm 10$ & 0.95 \\
\hline LAD, mm & $38 \pm 8$ & $43 \pm 8$ & $47 \pm 7$ & $49 \pm 6$ & 0.02 \\
\hline
\end{tabular}


Patients from the control group had similar characteristics, but had no CAD ( $p=0.02)$ and were younger $(p \leq 0.04)$ than the patients with atrial fibrillation (AF). CAD $(p \geq 0.29)$ and age $(p \geq 0.2)$ between the AF groups was not significantly different * Statistically significant difference

\section{Intra- and inter-observer variability}

The intra-observer correlation coefficients among 20 randomly selected patients were 0.94, $0.90,0.89$ and 0.93 for the measurement of the LAV, LA-Ant., LA-Post. and LAA volumes, respectively. The respective inter-observer correlation coefficients were $0.93,0.89,0.90$ and 0.92 . 3.2 Outcome of catheter ablation

Mean follow-up was 25 7 months (range 12-32 months); 102 (89\%) patients attended all scheduled follow-up visits, six (5\%) patients missed one follow-up visit and four (3\%) patients two follow-up visits. Three patients were lost to follow-up. A second procedure was performed in 40 patients $(35 \%)$ because of recurrences of AF $126 \pm 32$ days after the first intervention. Eightyfour patients $(73 \%)$ remained in sinus rhythm during follow-up (22 of them on previously ineffective antiarrhythmic medication). The respective success rates for the three different $\mathrm{AF}$ types were as follows: $86 \%$ for paroxysmal AF, $72 \%$ for persistent $\mathrm{AF}$ and $36 \%$ for long-standing persistent AF. A cardiac magnetic resonance examination was performed 3 months after AF ablation in $104(90 \%)$ patients excluded a significant ( $>50 \%$ lumen reduction) PV stenosis.

3.3 Left atrial volume and asymmetry index

Compared to the control group, patients with paroxysmal AF had significantly higher LAV $(131 \pm 31$ vs. $95 \pm 18 \mathrm{ml}, \mathrm{p}<0.001)$ and ASI $(61 \pm 6 \%$ vs. $57 \pm 4 \%, \mathrm{p}=0.001)$. The difference of the partial volumes between the two groups was also statistically significant (LA-Ant. $81 \pm 21$ vs. $54 \pm 11 \mathrm{ml}, \mathrm{p}<0.001$ and LA-Post. $49 \pm 14$ vs. $40 \pm 9 \mathrm{ml}, \mathrm{p}=0.007)$.

Patients with persistent AF had larger LAV compared to paroxysmal AF $(154 \pm 44 \mathrm{vs} .131 \pm 31 \mathrm{ml}$, $\mathrm{p}=0.007)$. The difference of the partial volumes between the two groups was also statistically significant (LA-Ant. $94 \pm 20$ vs. $81 \pm 21 \mathrm{ml}, \mathrm{p}=0.01$ and LA-Post. $59 \pm 23$ vs. $49 \pm 14 \mathrm{ml}, \mathrm{p}=0.01$ ). However, there was no significant difference of the ASI between patients with persistent AF and paroxysmal AF ( $60 \pm 8$ vs. $61 \pm 6 \%$, $p=0.63$; Table 5.2).

Table 5.2. The volumes and the asymmetry index in the control group and in the different subgroups of paroxysmal (Py), persistent (Ps) or long-standing persistent (LT-PS) AF patients.

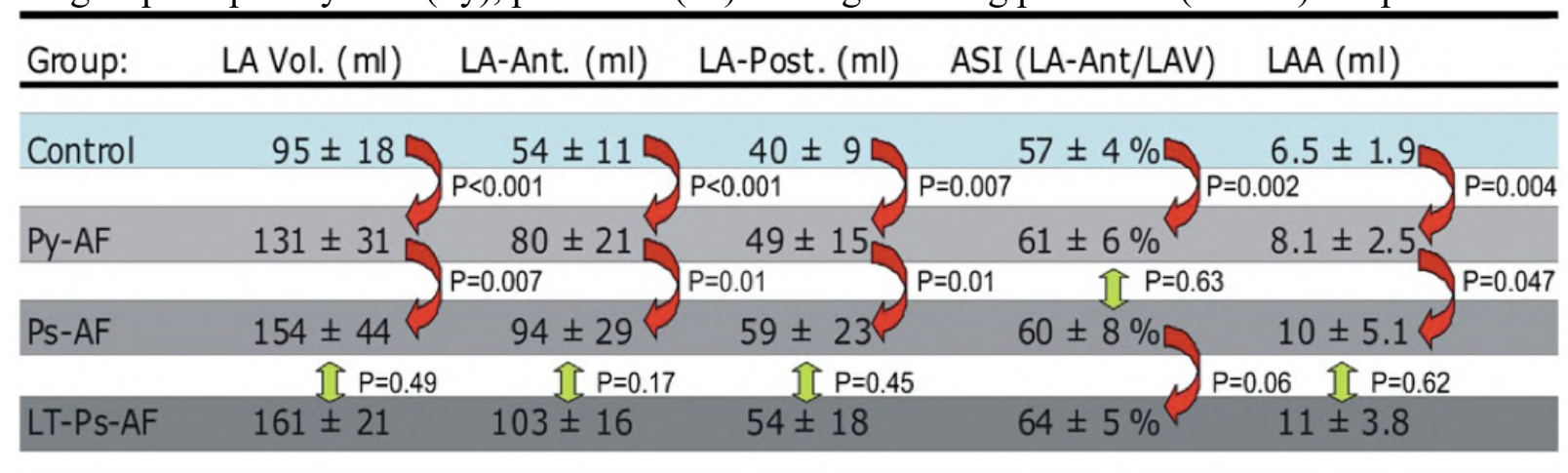

LAV of patients with long-standing persistent AF did not differ significantly from LAV of patients with persistent AF ( $161 \pm 22$ vs. $154 \pm 44 \mathrm{ml}, \mathrm{p}=0.57)$. The same was also true for the partial volumes (LA-Ant $103 \pm 16$ vs. $94 \pm 29 \mathrm{ml}, \mathrm{p}=0.24$ and LA-Post. $54 \pm 18$ vs. $59 \pm 23 \mathrm{ml}$, $\mathrm{p}=0.45)$. ASI in long-standing persistent AF was tendentially higher than ASI in persistent AF, but this did not reach statistical significance $(64 \pm 6 \%$ vs. $60 \pm 8 \%, p=0.06$; Figure 5.1). ASI and LAV correlated poorly with each other $(\mathrm{r}=0.23, \mathrm{p}=0.002)$. 


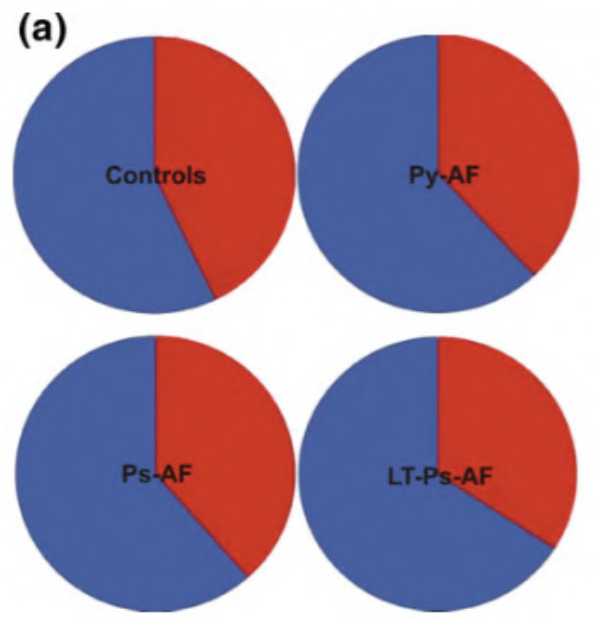

(b)

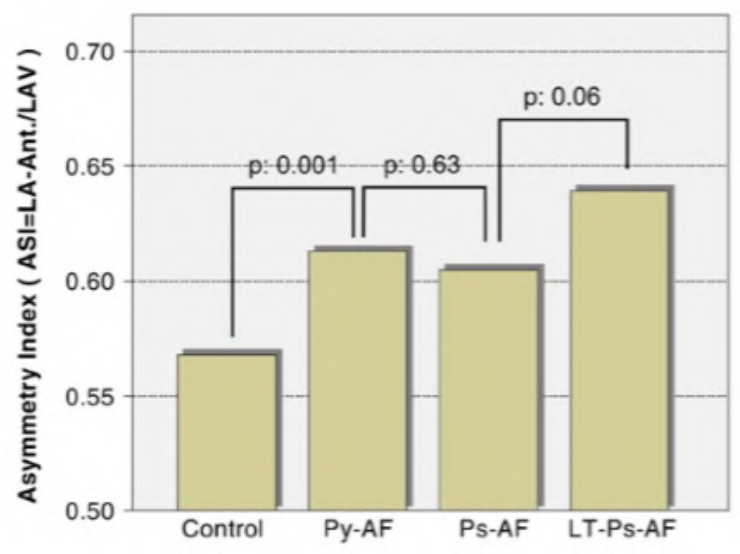

Figure 5.1. The mean LA volumes in circle graphs (a) and the mean asymmetry index (b), in controls and patients with paroxysmal (Py-AF), persistent (Ps-AF) and long-standing persistent (LT-Ps-AF) atrial fibrillation. Blue represents the anterior LA and red the posterior LA volume

The LAA volume in patients with paroxysmal AF was significantly larger than in the control group ( $8 \pm 3$ vs. $6 \pm 2 \mathrm{ml}, \mathrm{p}=0.004$ ) but significantly smaller than in the patients with persistent $\mathrm{AF}(10 \pm 5$ vs. $8 \pm 3 \mathrm{ml}, \mathrm{p}=0.047)$. Between persistent and long-standing persistent $\mathrm{AF}$ groups, there was no significant difference in LAA volume ( $11 \pm 4$ vs. $10 \pm 5 \mathrm{ml}, \mathrm{p}=0.62$; Figure 5.2).

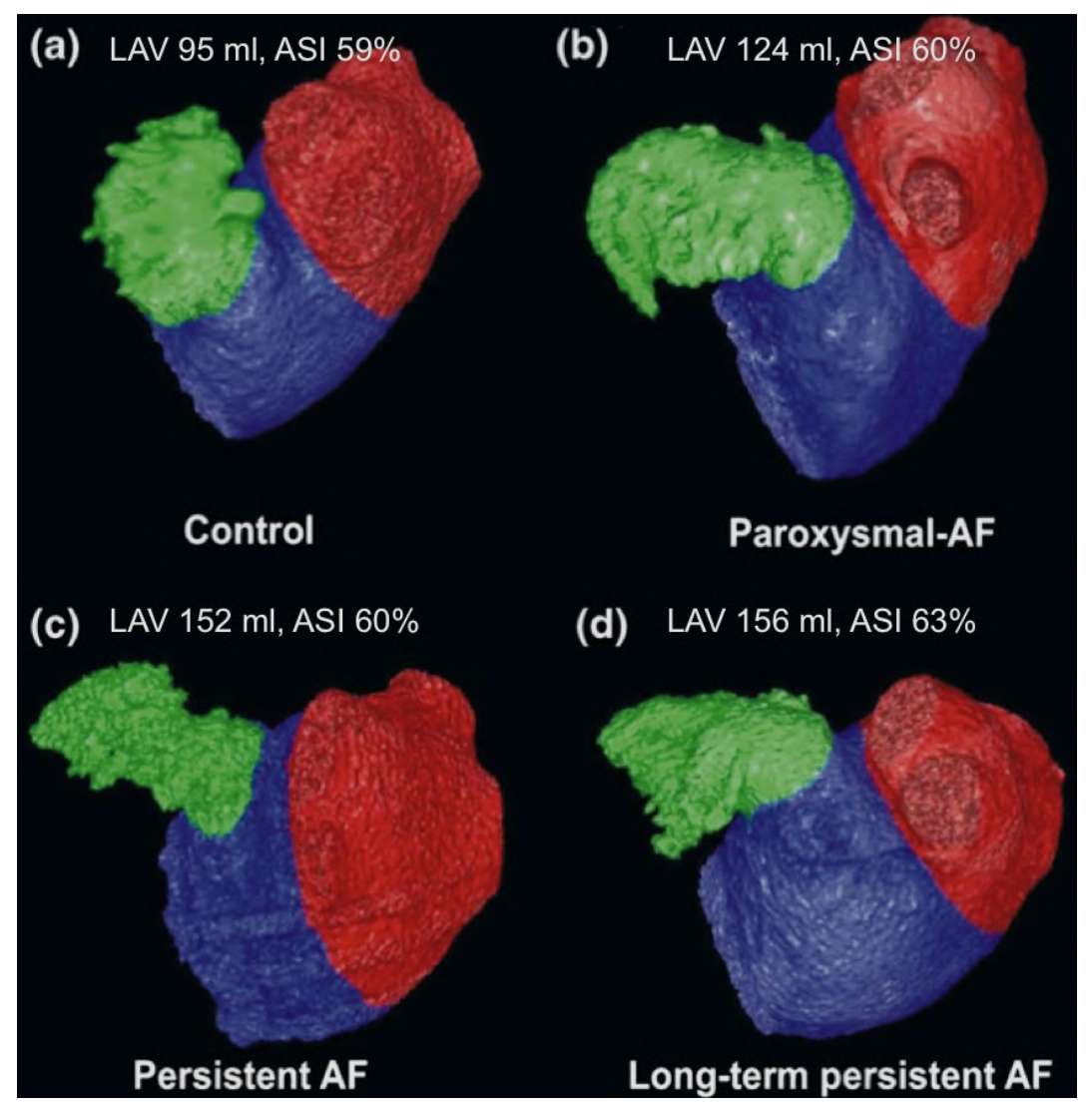

Figure 5.2. The LA structure and symmetry in a patient without organic heart disease (a), in comparison with a patient with paroxysmal (b), persistent (c) and long-standing persistent (d) AF. 


\section{Predictors of recurrence of atrial fibrillation}

Univariate analysis was performed for the following varia- bles: age, gender, BMI, arterial hypertension, structural heart disease, duration of AF, LA diameter, LAA volume, ASI, and LAV. Predictors of AF recurrence following catheter ablation with univariate analysis included LA diameter $(p=0.01)$, LAA volume $(p=0.02)$, ASI $(p=0.01)$, and LAV $(p=0.001)$. At multivariate analysis, the only two predictors that remained significant were LAV (OR 0.970, $95 \%$ confidence interval $0.947-0.993, \mathrm{p}=0.015)$ and ASI (OR $0.890,95 \%$ confidence interval $0.801-0.989, \mathrm{p}=0.010)$. At discrimination analysis, an ASI of more than $60 \%$ predicted recurrence of AF with a sensitivity of $74 \%$ and specificity of $73 \%$.

\section{Discussion}

This study has two main findings: between patients with paroxysmal, persistent and longstanding persistent AF exist structural differences that involve besides volume also the threedimensional shape of LA. Secondly, ASI is together with a LAV a significant predictor of outcome after pulmonary vein isolation.

Compared to normal individuals, patients with paroxysmal AF tend to have larger volumes and also higher ASI of the LA. This reflects a comparatively higher increase of the anterior LA compared to the whole LA. Patients with persistent AF have higher LA volumes than patients with paroxysmal AF, without any significant difference in ASI. Thus, it seems that progression from paroxysmal to persistent AF associates with further LA enlargement while the relation of the anterior LA to LAV remains relatively stable. Finally, patients with long-standing persistent AF have similar LAV but a significantly higher ASI than patients with persistent AF. This provides evidence for a further increase of the anterior LA during progression from persistent to long-standing persistent AF, while LAV remains relatively stable.

In accordance to other studies, ${ }^{26,27}$ we have shown that success rates after PVI are significantly reduced from paroxysmal to persistent and long-standing persistent AF. Besides the duration of AF itself, left atrial volume plays a central role as predictor of outcome. In this study, we have shown that ASI is another significant factor that influences outcome after PVI. Independent of duration of $\mathrm{AF}$ and $\mathrm{LAV}$, an ASI of more than $60 \%$ is associated with low success rates after AF ablation.

We have shown that persistent AF is characterized mainly by LA enlargement as compared to paroxysmal AF. Long-standing persistent AF is characterized by an increase of LA asymmetry compared to persistent AF without significant differences in LA volume. This irregular LA dilatation could reflect the physical constraints of the spine and the sternum ${ }^{28}$ and the changing of the LA wall properties. LA enlargement ${ }^{29}$ and LA wall thickening ${ }^{30}$ is known to be related with the domestication of chronic AF. The posterior LA wall though is thinner than the anterior, ${ }^{31}$ has a higher wall stress and provides the main substrate for the arrhythmia. ${ }^{32,33}$ The thicker anterior wall has a minor role in $\mathrm{AF}, 34,35$ but as shown in this study, it undergoes continuous expansion during progression from paroxysmal to persistent and long-standing persistent AF.

Identifying predictors of success after PVI may improve patient selection, reduce health care costs and avoid exposing patients to unnecessary procedures or related complications. Prior studies emphasized the pre-procedural evaluation of the LA volume for patient selection and treatment modification. ${ }^{3-5}$ To the best of our knowledge, this study is the first to show that ASI is an equally important prognostic parameter as LAV. According to the odds ratio, a $10 \mathrm{ml}$ increase of the LAV or a $3 \%$ increase of the asymmetry index could lead to $24 \%$ or $30 \%$ reduction of the PVI success rate, respectively. Independent of LAV, an ASI over $60 \%$ predicts recurrence of AF with a sensitivity of $75 \%$ and specificity of $78 \%$. 
Finally, our study suggests that in patients with persistent/long-standing persistent AF, enlarged left atria and increased ASI, PVI is not effective as single ablative treatment. PVI in these patients should rather be considered as the first step of an ablative strategy that includes additional targets after PVI has been achieved.

\section{Limitations}

This study has several limitations. Firstly, the number of patients was relatively small. Larger patient cohorts with follow-up data are needed in order to confirm the characteristic changes of LAV and ASI described here, as well as their potential influence on the AF ablation outcome. Secondly, classification of patients according to AF types was based on symptoms, Holter monitoring and 12 lead ECG. Considering the progressive and partially silent nature of the disease, the total time since the first diagnosis of AF and the exact AF burden (real time in AF) were difficult to assess and were not included in the study. Since long-term imaging data of one cohort over time are difficult to gather, these findings build upon differences between AF types as surrogates of different times in the natural AF history. Data from further observational trials are needed to confirm our results. Finally, no data about changes of LAV and ASI during followup are available and for that reason it remains unclear whether these changes reverse after restoration of a stable sinus rhythm.

\section{Conclusion}

Characteristic differences of both left atrial volume and geometry exist between the different forms of atrial fibrillation (paroxysmal, persistent and long-standing persistent). Asymmetry index is a simple parameter derived from volumetric CT data that reflects geometrical changes of LA and predicts outcome after pulmonary vein isolation.

\section{Acknowledgements:}

The authors would like to thank Anne M. Gale (Deutsches Herzzentrum Berlin) for her editorial assistance.

Funding: S. Nedios received a grant from the Greek State Scholarship Foundation (IKY) 


\section{References}

1. Estes NA, 3rd, Halperin JL, Calkins H, et al. ACC/AHA/Physician Consortium 2008 clinical performance measures for adults with nonvalvular atrial fibrillation or atrial flutter: a report of the American College of Cardiology/American Heart Association Task Force on Performance Measures and the Physician Consortium for Performance Improvement (Writing Committee to Develop Clinical Performance Measures for Atrial Fibrillation): developed in collaboration with the Heart Rhythm Society. Circulation Feb 26 2008;117:1101-1120.

2. Cappato R, Calkins H, Chen SA, Davies W, Iesaka Y, Kalman J, Kim YH, Klein G, Packer $\mathrm{D}$, Skanes A. Worldwide survey on the methods, efficacy, and safety of catheter ablation for human atrial fibrillation. Circulation Mar 8 2005;111:1100-1105.

3. Abecasis J, Dourado R, Ferreira A, Saraiva C, Cavaco D, Santos KR, Morgado FB, Adragao $\mathrm{P}$, Silva A. Left atrial volume calculated by multi-detector computed tomography may predict successful pulmonary vein isolation in catheter ablation of atrial fibrillation. Europace Oct 2009;11:1289-1294.

4. Hof I, Chilukuri K, Arbab-Zadeh A, Scherr D, Dalal D, Nazarian S, Henrikson C, Spragg D, Berger R, Marine J, Calkins H. Does left atrial volume and pulmonary venous anatomy predict the outcome of catheter ablation of atrial fibrillation? J Cardiovasc Electrophysiol Sep 2009;20:1005-1010.

5. Helms AS, West JJ, Patel A, Lipinski MJ, Mangrum JM, Mounsey JP, Dimarco JP, Ferguson JD. Relation of left atrial volume from three-dimensional computed tomography to atrial fibrillation recurrence following ablation. Am J Cardiol Apr 1 2009;103:989-993.

6. Vasamreddy CR, Lickfett L, Jayam VK, Nasir K, Bradley DJ, Eldadah Z, Dickfeld T, Berger $\mathrm{R}$, Calkins H. Predictors of recurrence following catheter ablation of atrial fibrillation using an irrigated-tip ablation catheter. J Cardiovasc Electrophysiol Jun 2004;15:692-697.

7. Berruezo A, Tamborero D, Mont L, Benito B, Tolosana JM, Sitges M, Vidal B, Arriagada G, Mendez F, Matiello M, Molina I, Brugada J. Pre-procedural predictors of atrial fibrillation recurrence after circumferential pulmonary vein ablation. Eur Heart J Apr 2007;28:836-841.

8. Jiang H, Lu Z, Lei H, Zhao D, Yang B, Huang C. Predictors of early recurrence and delayed cure after segmental pulmonary vein isolation for paroxysmal atrial fibrillation without structural heart disease. J Interv Card Electrophysiol Apr 2006;15:157-163.

9. Chilukuri K, Dalal D, Gadrey S, Marine JE, Macpherson E, Henrikson CA, Cheng A, Nazarian S, Sinha S, Spragg D, Berger R, Calkins H. A prospective study evaluating the role of obesity and obstructive sleep apnea for outcomes after catheter ablation of atrial fibrillation. J Cardiovasc Electrophysiol May 2010;21:521-525.

10. Jongnarangsin K, Chugh A, Good E, et al. Body mass index, obstructive sleep apnea, and outcomes of catheter ablation of atrial fibrillation. J Cardiovasc Electrophysiol Jul 2008;19:668-672.

11. Henry WL, Morganroth J, Pearlman AS, Clark CE, Redwood DR, Itscoitz SB, Epstein SE. Relation between echocardiographically determined left atrial size and atrial fibrillation. Circulation Feb 1976;53:273-279.

12. Knackstedt C, Gramley F, Schimpf T, et al. Association of echocardiographic atrial size and atrial fibrosis in a sequential model of congestive heart failure and atrial fibrillation. Cardiovasc Pathol Sep-Oct 2008;17:318-324.

13. Everett THt, Li H, Mangrum JM, McRury ID, Mitchell MA, Redick JA, Haines DE. Electrical, morphological, and ultrastructural remodeling and reverse remodeling in a canine model of chronic atrial fibrillation. Circulation Sep 19 2000;102:1454-1460. 
14. Schotten U, Duytschaever M, Ausma J, Eijsbouts S, Neuberger HR, Allessie M. Electrical and contractile remodeling during the first days of atrial fibrillation go hand in hand. Circulation Mar 18 2003;107:1433-1439.

15. Morillo CA, Klein GJ, Jones DL, Guiraudon CM. Chronic rapid atrial pacing. Structural, functional, and electrophysiological characteristics of a new model of sustained atrial fibrillation. Circulation Mar 1 1995;91:1588-1595.

16. Hobbs WJ, Fynn S, Todd DM, Wolfson P, Galloway M, Garratt CJ. Reversal of atrial electrical remodeling after cardioversion of persistent atrial fibrillation in humans. Circulation Mar 14 2000;101:1145-1151.

17. Raitt MH, Kusumoto W, Giraud G, McAnulty JH. Reversal of electrical remodeling after cardioversion of persistent atrial fibrillation. J Cardiovasc Electrophysiol May 2004;15:507512.

18. Lehto M, Jurkko R, Parikka H, Mantynen V, Vaananen H, Montonen J, Voipio-Pulkki LM, Toivonen L, Laine M. Reversal of atrial remodeling after cardioversion of persistent atrial fibrillation measured with magnetocardiography. Pacing Clin Electrophysiol Feb 2009;32:217-223.

19. Reant P, Lafitte S, Jais P, Serri K, Weerasooriya R, Hocini M, Pillois X, Clementy J, Haissaguerre M, Roudaut R. Reverse remodeling of the left cardiac chambers after catheter ablation after 1 year in a series of patients with isolated atrial fibrillation. Circulation Nov 8 2005; 112:2896-2903.

20. Ausma J, van der Velden HM, Lenders MH, van Ankeren EP, Jongsma HJ, Ramaekers FC, Borgers M, Allessie MA. Reverse structural and gap-junctional remodeling after prolonged atrial fibrillation in the goat. Circulation Apr 22 2003;107:2051-2058.

21. Hof I, Arbab-Zadeh A, Scherr D, Chilukuri K, Dalal D, Abraham T, Lima J, Calkins H. Correlation of left atrial diameter by echocardiography and left atrial volume by computed tomography. Journal of cardiovascular electrophysiology Feb 2009;20:159-163.

22. Imada M, Funabashi N, Asano M, Uehara M, Ueda M, Komuro I. Anatomical remodeling of left atria in subjects with chronic and paroxysmal atrial fibrillation evaluated by multislice computed tomography. Int J Cardiol Jul 31 2007;119:384-388.

23. Fuster V, Ryden LE, Cannom DS, et al. ACC/AHA/ESC 2006 Guidelines for the Management of Patients with Atrial Fibrillation: a report of the American College of Cardiology/American Heart Association Task Force on Practice Guidelines and the European Society of Cardiology Committee for Practice Guidelines (Writing Committee to Revise the 2001 Guidelines for the Management of Patients With Atrial Fibrillation): developed in collaboration with the European Heart Rhythm Association and the Heart Rhythm Society. Circulation Aug 15 2006;114:e257-354.

24. Kriatselis C, Tang M, Nedios S, Roser M, Gerds-Li H, Fleck E. Intraprocedural reconstruction of the left atrium and pulmonary veins as a single navigation tool for ablation of atrial fibrillation: a feasibility, efficacy, and safety study. Heart Rhythm Jun 2009;6:733741.

25. Tang M, Kriatselis C, Ye G, Nedios S, Roser M, Solowjowa N, Fleck E, Gerds-Li JH. Reconstructing and registering three-dimensional rotational angiogram of left atrium during ablation of atrial fibrillation. Pacing Clin Electrophysiol Nov 2009;32:1407-1416.

26. Pappone C, Rosanio S, Augello G, et al. Mortality, morbidity, and quality of life after circumferential pulmonary vein ablation for atrial fibrillation: outcomes from a controlled nonrandomized long-term study. J Am Coll Cardiol Jul 16 2003;42:185-197.

27. Themistoclakis S, Schweikert RA, Saliba WI, Bonso A, Rossillo A, Bader G, Wazni O, Burkhardt DJ, Raviele A, Natale A. Clinical predictors and relationship between early and 
late atrial tachyarrhythmias after pulmonary vein antrum isolation. Heart Rhythm May 2008;5:679-685.

28. Hoffmeister PS, Chaudhry GM, Mendel J, Almasry I, Tahir S, Marchese T, Haffajee CI, Orlov MV. Evaluation of left atrial and posterior mediastinal anatomy by multidetector helical computed tomography imaging: relevance to ablation. J Interv Card Electrophysiol Apr 2007;18:217-223.

29. Sanfilippo AJ, Abascal VM, Sheehan M, Oertel LB, Harrigan P, Hughes RA, Weyman AE. Atrial enlargement as a consequence of atrial fibrillation. A prospective echocardiographic study. Circulation Sep 1990;82:792-797.

30. Nakamura K, Funabashi N, Uehara M, Ueda M, Murayama T, Takaoka H, Komuro I. Left atrial wall thickness in paroxysmal atrial fibrillation by multislice-CT is initial marker of structural remodeling and predictor of transition from paroxysmal to chronic form. Int $\mathrm{J}$ Cardiol Apr 14 2011;148:139-147.

31. Pan NH, Tsao HM, Chang NC, Chen YJ, Chen SA. Aging dilates atrium and pulmonary veins: implications for the genesis of atrial fibrillation. Chest Jan 2008;133:190-196.

32. Huang JL, Tai CT, Lin YJ, Ting CT, Chen YT, Chang MS, Lin FY, Lai WT, Chen SA. The mechanisms of an increased dominant frequency in the left atrial posterior wall during atrial fibrillation in acute atrial dilatation. Journal of cardiovascular electrophysiology Feb 2006; 17:178-188.

33. Kalifa J, Tanaka K, Zaitsev AV, et al. Mechanisms of wave fractionation at boundaries of high-frequency excitation in the posterior left atrium of the isolated sheep heart during atrial fibrillation. Circulation Feb 7 2006;113:626-633.

34. Schmitt C, Estner H, Hecher B, Luik A, Kolb C, Karch M, Ndrepepa G, Zrenner B, Hessling G, Deisenhofer I. Radiofrequency ablation of complex fractionated atrial electrograms (CFAE): preferential sites of acute termination and regularization in paroxysmal and persistent atrial fibrillation. J Cardiovasc Electrophysiol Sep 2007;18:1039-1046.

35. Haissaguerre M, Sanders P, Hocini M, et al. Catheter ablation of long-lasting persistent atrial fibrillation: critical structures for termination. Journal of cardiovascular electrophysiology Nov 2005; 16:1125-1137. 
Chapter 6 Atrial diameters as predictors of success after AF ablation is

Adapted from "Comparison of left atrial dimensions in CT and echocardiography as predictors of long-term success after catheter ablation of atrial fibrillation."

Published in J Interv Card Electrophysiol. 2015 Sep. doi: 10.1007/s10840-015-0010-8

Sotirios Nedios, Jedrzej Kosiuk, Emmanuel Koutalas, Jelena Kornej, Philipp Sommer, Arash Arya, Sergio Richter, Sascha Rolf, Daniela Husser, Gerhard Hindricks, MD, Andreas Bollmann 


\begin{abstract}
Background:

Left atrium (LA) size is a common predictor of ablation-outcomes in atrial fibrillation (AF), but different LA diameters have not been adequately studied yet. We aimed to find the best predictor of ablation outcomes using single-linear LA dimensions by computed tomography (CT) or echocardiography.

\section{Methods:}

Patients ( $\mathrm{n}=103,72$ males, 59 \pm 9 years) undergoing AF ablation were analyzed. LA diameter (LA-D) was measured by transthoracic echocardiography (parasternal long-axis). After 3D reconstruction of CT data (EnSite Verismo, SJM, MN), maximal LA dimensions were measured on a coronal plane (superior-inferior, SI and transversal, TV) and a sagittal plane (anteriorposterior, AP). Volume (LAV) was rendered after LA appendage and pulmonary vein exclusion.
\end{abstract}

\title{
Results:
}

Patients with persistent AF ( $\mathrm{n}=40)$ had significantly larger LA size than those with paroxysmal AF $(n=63)$. After $26 \pm 14$ months, $31(30 \%)$ patients had AF recurrence. Univariate cox-regression analysis revealed that LA-D, LA-SI, LA-TV, LAV and LAV-index (LAV/body surface area) were associated with AF recurrence. Multivariate cox-regression analysis revealed that LAV was the strongest independent predictor of AF-recurrence (HR=1.011 per ml, 95\% CI: 1.003-1.020, $\mathrm{p}=0.002)$. LA-TV had the best correlation with LAV $(\mathrm{r}=0.69, \mathrm{p}<0.01)$ and was the strongest single-linear predictor $(\mathrm{HR}=1.07$ per $\mathrm{mm}, 95 \% \mathrm{CI}$ : 1.022-1.121, $\mathrm{p}=0.004)$. Independent of LA-D, an LA-TV $>74.5 \mathrm{~mm}$ predicted AF-recurrence similarly to LAV $>126 \mathrm{ml}$.

\section{Conclusions:}

LA dilatation, especially on the coronal plane, is associated with reduced long-term success after catheter ablation. LA-TV is the best linear predictor of AF recurrence, stronger than the commonly used LA-D. 


\section{Introduction}

The assessment of the left atrial (LA) size is important, since LA enlargement has been associated with cardiovascular outcomes and the success of atrial fibrillation (AF) therapy. ${ }^{1-4}$ Accordingly, current guidelines recommend the assessment of the LA size and function by standard two-dimensional echocardiography in the clinical work-up of all AF patients. ${ }^{5}$

There are many different imaging modalities to assess the LA size, but echocardiography is the most frequently used, because it is widely available, cheap and harmless. The anterior-posterior LA diameter (LA-D), either from M-mode tracings or two-dimensional images has been extensively used in clinical routine and research work as a simple and representative indicator of LA size. However, it is now clear that this diameter cannot reliably reflect the true size of an asymmetric LA shape. This is particularly relevant in pathological LA, when due to constriction between the sternum and the spine LA enlargement occurs non-uniformly, mainly along the superior-inferior and medial-lateral directions and less in anterior-posterior direction. ${ }^{6}$ This asymmetric dilatation correlates with AF progression and reduced success after AF ablation. ${ }^{7}$

Computed tomography (CT) is another modality that has been increasingly used to obtain $3 \mathrm{D}$ data and image integration for AF ablation procedures. The widespread application of CT has provided new insights on the LA shape and volume, which have been proved to be better predictors of AF recurrence after LA ablation in comparison to the anterior-posterior LA-D. ${ }^{7-9}$ Although the LA volume has low correlation with the LA-D and a closer relationship with cardiovascular outcomes, ${ }^{10}$ the relationship of volume and the importance of other LA diameters have not been adequately studied yet.

The aim of this study was to analyze the value of different LA dimensions derived from CT or echocardiography data, as predictors of long-term success after catheter ablation of AF and to identify the best predictive single-linear dimension.

\section{Patient characteristics}

\section{Methods}

Patients referred for the first catheter ablation of symptomatic AF refractory to medical management, were included prospectively in the registry of our institution. We retrospectively analyzed CT data of 103 consecutive patients, acquired one day prior to the ablation procedure. $\mathrm{AF}$ type and oral anticoagulation were determined according to current guidelines. Written informed consent has been obtained from all patients according to the Declaration of Helsinki.

\section{Echocardiography}

Echocardiography was performed on all patients $(2 \pm 1$ days $)$ before the procedure at a designated laboratory and intracardiac thrombi were ruled out. Images were acquired with the patients in the left lateral decubitus position (Vivid-7/9 General Electric Vingmed, Milwaukee, WI, USA). Standard M-mode and 2D images, including color Doppler data from 3 consecutive heartbeats, were obtained according to the recommendations of the American Society of Echocardiography. ${ }^{11}$ The anteroposterior diameter of the left atrium was measured at end-systole on the M-mode images from the parasternal long-axis view. Left ventricular end-diastolic diameters, as well as interventricular septum, were measured from the parasternal short-axis view. Left ventricular end-diastolic and end-systolic volumes were assessed from the apical 2and 4-chamber images, and LV-EF was calculated according to the Simpson method. Echocardiographic LA volume (LAVe) was calculated according to the area-length method when available. 


\section{Computed tomography}

Cardiac-CT imaging was performed with a multidetector 64-row helical system (Brilliance 64, Philips Medical Systems, Best, Netherlands). Image acquisition was electrogram-gated when possible and the parameters included: $70-120 \mathrm{KV}, 850 \mathrm{mAs}, 0.6 \mathrm{~mm}$ beam collimation, $0.625-$ $1.25 \mathrm{~mm}$ thickness and $20-30 \mathrm{~cm}$ field-of-view. During an end-inspiratory breath-hold of approximately 20 seconds, and following a timing bolus-chase injection $(20 \mathrm{~mL}, 5 \mathrm{~mL} / \mathrm{s}), 90 \mathrm{~mL}$ of an iodinated contrast medium (Ultravist 370, Bayer, Cologne, Germany) was administrated. Finally end-systolic imaging data were used for three-dimensional (3D) reconstruction.

Image analysis was performed offline by an experienced single observer blinded to the results of the procedure and the patient's follow-up. Initial measurements of 20 random patients were repeated 4 weeks later by the same investigator and a second reviewer in a blinded fashion.

$\mathrm{CT}$ data was reviewed using multiplanar reconstruction, maximum intensity projection, and 3D volume rendering, with a specialized image processing software (EnSite Verismo, SJM, MN). The left atrial volume (LAV) after exclusion of the atrial appendage (LAA) and the pulmonary veins (PV) was determined by LA area summation. The LA was then centered on all three cutting planes and the maximal LA dimensions were measured from superior to inferior (SI) and transversal (TV) on the coronal plane and from anterior to posterior (AP) on the sagittal plane. Figure 6.1 illustrates the measurement of LA diameters.

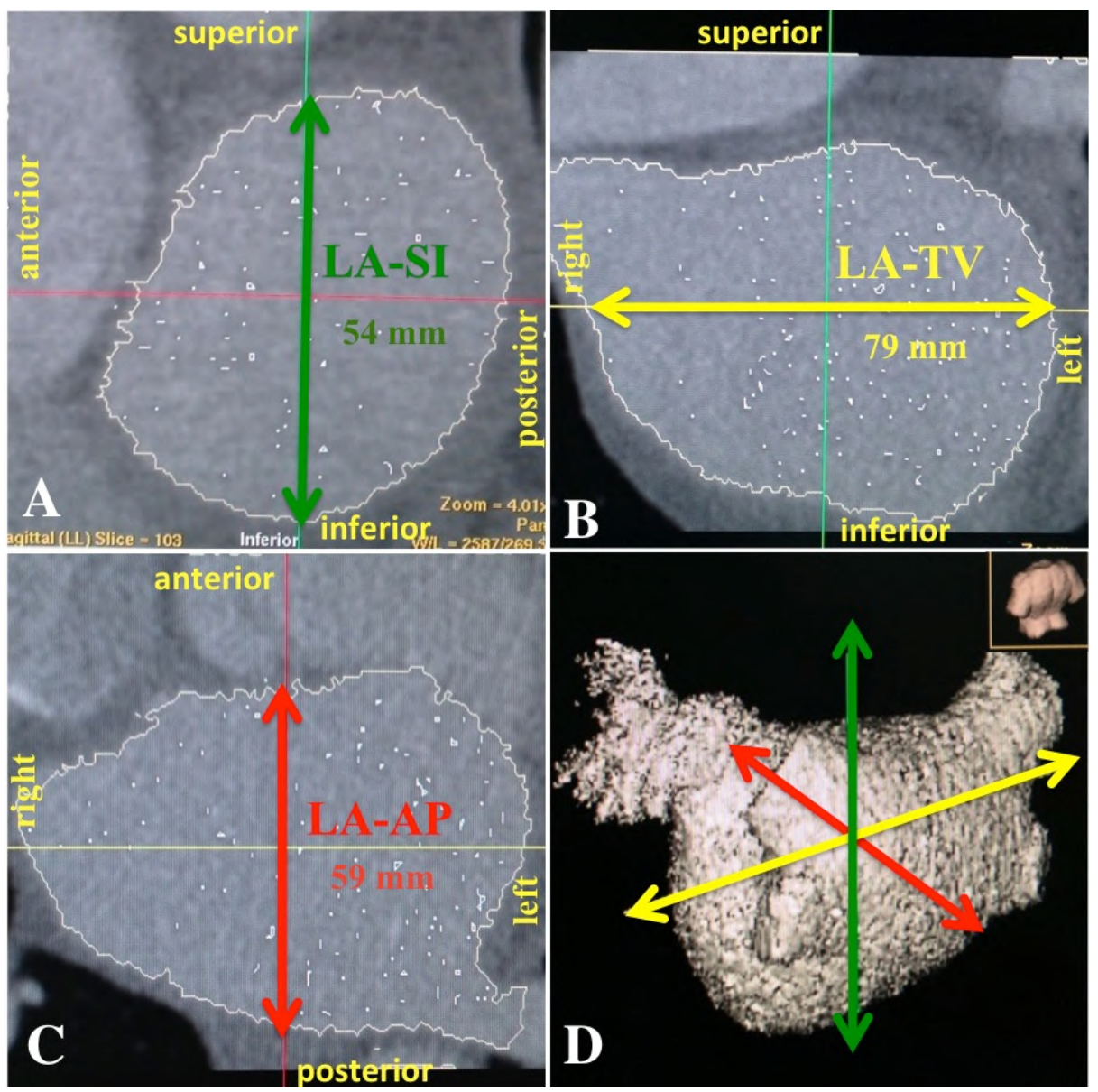

Figure 6.1. Left atrial diameters measured from CT-data by Ensite Verismo: A. supero-inferior and B. transversal diameter on a coronal plane, C. antero-posterior on a saggital plane and D. on the three-dimensional reconstruction model. 
In order to adjust for the different body type, indexed parameters corrected for the body surface area (BSA) were calculated as follows: LA-D-index $=$ LA-D/BSA, LA-AP-index=LA-AP/BSA, LA-SI-index $=$ LA-SI/BSA, LA-TV-index $=$ LA-TV/BSA and LAV-index $=$ LAV $/$ BSA $^{12}$.

\begin{abstract}
Ablation procedure and follow-up
LA catheter ablation was performed as previously described. ${ }^{13}$ Transseptal access and catheter navigation were performed with a steerable sheath (Agilis, St. Jude Medical, St. Paul, MN, USA) and electroanatomic mapping systems $\left(\right.$ EnSite $^{\mathrm{TM}} \mathrm{NavX}^{\mathrm{TM}}$, St. Jude Medical; or CARTO ${ }^{\mathrm{TM}}$, Biosense Webster, Diamond Bar, CA, USA), after integration of CT image datasets. All patients received circumferential ablation lines around the antrum of the ipsilateral pulmonary veins (irrigated tip catheter, pre-selected tip temperature of $\leq 48^{\circ} \mathrm{C}$, and power of $30-45 \mathrm{~W}$ ). Complete pulmonary vein isolation was verified with a multipolar circular mapping catheter. In patients with persistent $\mathrm{AF}$, additional linear lesions were added between the circular lesions, at the mitral isthmus and the posterior LA wall to create a "box" lesion.

Follow-up was performed with repeated 7-day-holter ECG recordings (Lifecard CF, DelmarReynolds Medical Inc, Irvine, CA, USA) at 6, 12, 24 and 36 months of follow-up. Recurrence was defined as a ECG-documented AF episode or organized LA tachycardia of $\geq 30$ seconds. Episodes occurring during a 3 months blanking period after the ablation were not included in the analysis. Class I and III antiarrhythmic drugs were discontinued and in case of AF recurrence, the medication was adapted on an individual basis.
\end{abstract}

\title{
Statistical analysis
}

Continuous variables are expressed as mean and standard deviation (SD). Categorical variables are reported as frequencies and percentage. Kolmogorov-Smirnoff test was used to analyse the distribution of continuous variables. On that basis, parametric variables were compared by means of paired Student's t-test and non-parametric variables by Wilcoxon-test or chi-square test. Intraobserver and inter- observer variability was expressed with the correlation coefficient ( $r$ ) between measurements. How well LAV or each LA diameter differentiated patients with and without recurrence of $\mathrm{AF}$ was assessed by means of the area under the receiver operating curve (AUC, ranging $0-1$ ), with 0.5 corresponding to no discrimination and 1.0 to perfect discrimination. The association between LAV and LA diameters was expressed with Pearson's correlation coefficient (r). Comparison between ROC curves was performed with DeLong's method.

Clinical variables and LA measurements were evaluated with univariate Cox-regression analysis to determine their association with AF recurrence. Variables with a $p<0.1$ in univariate analysis were included in the multivariate cox-regression analysis by a forward stepwise selection procedure and the hazard ratio (HR) with $95 \%$ confidence interval (CI) was determined. A model was used to evaluate the predictive value of LAV without LA diameters and a second model was used to evaluate LA diameters without LAV. A two-tailed P-value $<0.05$ was considered significant. Analysis was performed with R-statistics and SPSS 20.0 (SPSS Inc., Chicago, USA).

\section{Patient characteristics}

\section{Results}

Baseline characteristics of the patients are summarized in Table 6.1. The majority of patients were males $(\mathrm{n}=72,70 \%)$ with a mean age of $59 \pm 9$ years. Left ventricular ejection fraction was $61 \pm 7 \%$. LA-D was $45 \pm 6 \mathrm{~mm}$ (range: $30-59 \mathrm{~mm}$ ), LA-AP $45 \pm 9 \mathrm{~mm}$ (range: $25-72 \mathrm{~mm}$ ), LA-SI $59 \pm 8 \mathrm{~mm}$ (range: 19-75), LA-TV $74 \pm 8 \mathrm{~mm}$ (range: $54-94 \mathrm{~mm}$ ) and LAV $127 \pm 35 \mathrm{ml}$ (range: 66- 
$240)$ respectively. There was a significant correlation of LA-D ( $r=0.43, p<0.001)$, LA-AP $(\mathrm{r}=0.60, \mathrm{p}<0.001)$, LA-SI $(\mathrm{r}=0.58, \mathrm{p}<0.001)$ and LA-TV $(\mathrm{r}=0.69, \mathrm{p}<0.001)$ with LA volume. This correlation remained significant for indexed values of LA diameters in relation to LAV-index. Patients with persistent AF ( $\mathrm{n}=40)$ had significantly larger LAV and LAV-index, LA-AP, LA-SI and LA-TV than those with paroxysmal AF $(n=63)$. LAVe was available in $51(50 \%)$ patients and had a good correlation with LAV $(\mathrm{r}=0.65, \mathrm{p}<0.001)$. The prevalence of AF type in these patients was similar to the total cohort (paroxysmal: $54 \%$ vs. $61 \%, p=0.48$ ). LAVe was significantly lower than LAV $(103 \pm 48$ vs. $132 \pm 42 \mathrm{ml}, \mathrm{p}<0.001)$ and was similar between paroxysmal and persistent AF ( $96 \pm 44$ vs. $110 \pm 52 \mathrm{ml}, \mathrm{p}=0.31)$.

Table 6.1. Clinical characteristics and measurements according to atrial fibrillation (AF) type.

\begin{tabular}{|c|c|c|c|c|}
\hline Variables & Total & Paroxysmal AF & Persistent AF & $\mathrm{P}$ \\
\hline Number, n (\%) & 103 & $63(61 \%)$ & $40(39 \%)$ & \\
\hline Age, years & $59 \pm 10$ & $58 \pm 10$ & $60 \pm 9$ & 0.45 \\
\hline Male, n (\%) & $72(70 \%)$ & $41(65 \%)$ & $31(76 \%)$ & 0.19 \\
\hline Height, cm & $176 \pm 9$ & $175 \pm 10$ & $177 \pm 8$ & 0.31 \\
\hline Weight, kg & $89 \pm 15$ & $87 \pm 15$ & $92 \pm 14$ & 0.13 \\
\hline Body mass index, $\mathrm{kg} / \mathrm{m}^{2}$ & $28 \pm 5$ & $28 \pm 5$ & $29 \pm 4$ & 0.31 \\
\hline Body surface area, $\mathrm{m}^{2}$ & $2 \pm 0.2$ & $2 \pm 0.2$ & $2 \pm 0.2$ & 0.13 \\
\hline Hypertension, n (\%) & $63(62 \%)$ & $40(64 \%)$ & $23(56 \%)$ & 0.68 \\
\hline Diabetes mellitus, n (\%) & $18(18 \%)$ & $13(21 \%)$ & $5(13 \%)$ & 0.43 \\
\hline Previous stroke/TIA, n (\%) & $6(6 \%)$ & $6(10 \%)$ & $0(0 \%)$ & 0.08 \\
\hline Coronary artery disease, $\mathrm{n}(\%)$ & $13(13 \%)$ & $8(13 \%)$ & $5(13 \%)$ & 1.00 \\
\hline Dilated cardiomyopathy, $\mathrm{n}(\%)$ & $4(4 \%)$ & $1(2 \%)$ & $3(7 \%)$ & 0.30 \\
\hline Heart failure, $\mathrm{n}(\%)$ & $7(7 \%)$ & $5(8 \%)$ & $3(7 \%)$ & 1.00 \\
\hline $\mathrm{CHADS}_{2}-\mathrm{VASc}$ score & $1.4 \pm 1.1$ & $1.5 \pm 1.2$ & $1.3 \pm 0.9$ & 0.29 \\
\hline $\mathrm{CHA}_{2} \mathrm{DS}_{2}-\mathrm{VASc}$ score & $1.4 \pm 1.1$ & $1.9 \pm 1.4$ & $1.5 \pm 1.1$ & 0.13 \\
\hline AF recurrence, $\mathrm{n}(\%)$ & $31(30 \%)$ & $13(21 \%)$ & $18(45 \%)$ & 0.02 \\
\hline \multicolumn{5}{|l|}{ Imaging parameters } \\
\hline Left ventricular ejection fraction, $\%$ & $61 \pm 7$ & $62 \pm 6$ & $59 \pm 9$ & 0.13 \\
\hline Left ventricular ed. diameter, $\mathrm{mm}$ & $50 \pm 7$ & $49 \pm 6$ & $50 \pm 7$ & 0.62 \\
\hline LA-D by echocardiography, $\mathrm{mm}$ & $43 \pm 6$ & $42 \pm 6$ & $43 \pm 7$ & 0.22 \\
\hline LA-AP, ${ }^{*} \mathrm{~mm}$ & $45 \pm 9$ & $43 \pm 9$ & $47 \pm 9$ & 0.02 \\
\hline LA-SI, $*$ mm & $59 \pm 9$ & $58 \pm 9$ & $61 \pm 7$ & 0.04 \\
\hline $\mathrm{LA}-\mathrm{TV}, * \mathrm{~mm}$ & $74 \pm 8$ & $72 \pm 8$ & $78 \pm 7$ & $<0.001$ \\
\hline $\mathrm{LAV}, * \mathrm{ml}$ & $127 \pm 35$ & $116 \pm 27$ & $144 \pm 39$ & $<0.001$ \\
\hline LAA volume, ${ }^{*} \mathrm{ml}$ & $6 \pm 3$ & $6 \pm 2$ & $6 \pm 3$ & 0.39 \\
\hline LA-D-index, ${ }^{*} \mathrm{~mm} / \mathrm{m}^{2}$ & $21 \pm 3$ & $21 \pm 3$ & $21 \pm 3$ & 0.92 \\
\hline LA-AP-index, ${ }^{*} \mathrm{~mm} / \mathrm{m}^{2}$ & $22 \pm 5$ & $21 \pm 5$ & $22 \pm 5$ & 0.16 \\
\hline LA-SI-index, ${ }^{*} \mathrm{~mm} / \mathrm{m}^{2}$ & $29 \pm 5$ & $28 \pm 6$ & $29 \pm 4$ & 0.50 \\
\hline LA-TV-index, ${ }^{*} \mathrm{~mm} / \mathrm{m}^{2}$ & $36 \pm 5$ & $35 \pm 4$ & $37 \pm 5$ & 0.06 \\
\hline LAV-index,$* \mathrm{ml} / \mathrm{m}^{2}$ & $62 \pm 17$ & $57 \pm 14$ & $69 \pm 20$ & 0.002 \\
\hline
\end{tabular}

$\mathrm{AP}=$ antero-posterior, $\mathrm{D}=$ diameter, $\mathrm{LA}=$ left atrial, $\mathrm{LAA}=\mathrm{LA}$ appendage, $\mathrm{SI}=$ supero-inferior, $\mathrm{TV}=$ transversal, $*$ by computed tomography. 
There was no other difference between persistent and paroxysmal AF. Patients with sinus rhythm during CT scan had similar measurements and clinical characteristics when compared with patients in AF both in the paroxysmal and in the persistent AF group.

\section{Intra- and inter-observer variability}

The intra-observer correlation coefficients among 20 random patients were $0.91,0.89,0.92$, 0.94 and 0.95 for the measurement of the LA-D, LA-AP, LA-SI, LA-TV and LAV respectively. The respective inter-observer correlation coefficients were $0.92,0.89,0.91,0.95$ and 0.96 .

\section{Outcome of catheter ablation}

During a mean follow-up of $26 \pm 14$ months, 95 (92\%) patients attended all scheduled follow-up visits, four (4\%) patients missed one follow-up visit and four (4\%) patients two follow-up visits. A second procedure was performed in 27 patients $(27 \%)$ because of recurrences of AF $20 \pm 13$ months (interquartile range 9-29) after the first intervention. Seventy-two patients $(70 \%)$ remained in sinus rhythm during follow-up (18 of them on previously ineffective antiarrhythmic medication) and $31(30 \%)$ patients experienced a recurrence. AF recurrence was $45 \%$ for patients with persistent AF and significantly lower $(21 \%)$ for paroxysmal-AF $(\mathrm{p}=0.02)$. There was one major complication with a pericardial tamponade requiring subxiphoidal puncture and one femoral pseudoaneurysm requiring ultrasound-guided compression.

\section{Predictors of AF recurrence}

Patients with recurring AF had a higher incidence of persistent AF (58\% vs. 30\%, $\mathrm{p}=0.02)$ and heart failure $(16 \%$ vs. $4 \%, \mathrm{p}=0.05)$, a larger LA-D ( $45 \pm 7 \mathrm{~mm}$ vs. $42 \pm 6 \mathrm{~mm}, \mathrm{p}=0.02)$, LA-TV $(78 \pm 8 \mathrm{~mm}$ vs. $73 \pm 8 \mathrm{~mm}, \mathrm{p}=0.002)$ and LA-SI $(62 \pm 7 \mathrm{~mm}$ vs. $58 \pm 9 \mathrm{~mm}, \mathrm{p}=0.04)$. There was no significant difference in LA-AP $(46 \pm 9 \mathrm{~mm}$ vs. $44 \pm 9 \mathrm{~mm}, \mathrm{p}=0.31)$ or in clinical characteristics (Table 6.2). Receiver operating curve (ROC) analysis revealed that the value of differentiating patients with and without recurrence of AF was comparable $(\mathrm{p}=0.779)$ between LAV (AUC 0.684, 95\% CI: 0.571-0.798) and LA-TV (AUC 0.697, 95\% CI: 0.583-0.811).

Although LATVi, AF and heart failure had a $\mathrm{p}$ value $<0.1$ in direct group comparison (Table 6.2) they did not reach significance when compared with cox-regression analysis (Table 6.3), so that variables analyzed in the multivariate models were only: LA-D, LA-SI, LA-TV, LAV and LAV-index with $\mathrm{p}<0.1$ in univariable cox-regression analysis.

Using Cox-regression analysis, first in a model including all significant variables except LA diameters, we showed that that LAV was the strongest independent predictor of AF-recurrence $(\mathrm{HR}=1.011$ per $\mathrm{ml}, 95 \% \mathrm{CI}: 1.003-1.020, \mathrm{p}=0.002)$. Choosing between single-linear dimension measurements, Cox-regression analysis in a second model without LAV revealed that LA-TV was the strongest independent predictor for AF recurrence (HR=1.07 per mm, 95\% CI: 1.022 1.121, $\mathrm{p}=0.004)$. Independent of LA-D, an LA-TV over $74.5 \mathrm{~mm}$ predicts AF recurrence with the highest combination of sensitivity $(65 \%)$ and specificity $(64 \%)$. This was similar to the best cutoff value of $126 \mathrm{ml}$ for LAV. Patients with LA-TV over $74.5 \mathrm{~mm}(\mathrm{n}=46)$ or LAV over $126 \mathrm{ml}$ $(n=46)$ had significantly higher rate of AF recurrence $(65 \%$ vs. $36 \%, p=0.01)$. Both LA-TV and LAV had a positive predictive value of $43 \%$ and a negative predictive value of $81 \%$. Among patients with LAV $>126 \mathrm{ml}$ those with LA-TV $<74.5 \mathrm{~mm}(\mathrm{n}=14,30 \%)$ had a tendency for less AF recurrence $(21 \%$ vs. $53 \%, p=0.06)$ in comparison to the rest of the patients with LAV $>126 \mathrm{ml}$. Figure 6.2 depicts the predicted proportion of patients with AF recurrence in relation to LAV or LA-TV, based on these two regression models, in the total population or according to AF type. 
Table 6.2. Patient characteristics according to the maintenance of sinus rhythm or atrial fibrillation (AF) recurrence.

\begin{tabular}{|c|c|c|c|}
\hline Variables & Sinus rhythm & $\mathrm{AF}$ recurrence & $\mathrm{P}$ \\
\hline Number, $\mathrm{n}(\%)$ & $72(70 \%)$ & $31(30 \%)$ & \\
\hline Age, years & $60 \pm 10$ & $57 \pm 10$ & 0.25 \\
\hline Male, $\mathrm{n}(\%)$ & $51(71 \%)$ & $21(68 \%)$ & 0.81 \\
\hline Paroxysmal AF, n (\%) & $50(79 \%)$ & $13(21 \%)$ & 0.02 \\
\hline Persistent AF, n (\%) & $22(55 \%)$ & $18(45 \%)$ & \\
\hline Height, cm & $176 \pm 9$ & $176 \pm 10$ & 0.68 \\
\hline Weight, kg & $87 \pm 15$ & $92 \pm 16$ & 0.19 \\
\hline Body mass index, $\mathrm{kg} / \mathrm{m}^{2}$ & $28 \pm 5$ & $29 \pm 4$ & 0.35 \\
\hline Body surface area, $\mathrm{m}^{2}$ & $2 \pm 0.2$ & $2 \pm 0.2$ & 0.24 \\
\hline Hypertension, n (\%) & $45(63 \%)$ & $18(58 \%)$ & 0.67 \\
\hline Diabetes mellitus, n (\%) & $14(19 \%)$ & $4(13 \%)$ & 0.58 \\
\hline Prior stroke/TIA, n (\%) & $6(8 \%)$ & $0(0 \%)$ & 0.17 \\
\hline Coronary artery disease, $\mathrm{n}(\%)$ & $12(17 \%)$ & $1(3 \%)$ & 0.10 \\
\hline Dilated cardiomyopathy, n (\%) & $3(4 \%)$ & $1(3 \%)$ & 1.00 \\
\hline Heart failure, $\mathrm{n}(\%)$ & $3(4 \%)$ & $5(16 \%)$ & 0.05 \\
\hline $\mathrm{CHADS}_{2}$ score & $1.5 \pm 1.1$ & $1.3 \pm 1.1$ & 0.26 \\
\hline $\mathrm{CHA}_{2} \mathrm{DS}_{2}$-VASc score & $1.8 \pm 1.3$ & $1.6 \pm 1.3$ & 0.43 \\
\hline \multicolumn{4}{|l|}{ Imaging parameters } \\
\hline Left ventricular ejection fraction, $\%$ & $62 \pm 6$ & $59 \pm 9$ & 0.15 \\
\hline Left ventricular ed. diameter, $\mathrm{mm}$ & $49 \pm 6$ & $50 \pm 7$ & 0.45 \\
\hline LA-D by echocardiography, mm & $42 \pm 6$ & $45 \pm 7$ & 0.02 \\
\hline LA-AP, $* \mathrm{~mm}$ & $44 \pm 9$ & $46 \pm 9$ & 0.31 \\
\hline LA-SI, $*$ mm & $58 \pm 9$ & $62 \pm 7$ & 0.04 \\
\hline $\mathrm{LA}-\mathrm{TV}, * \mathrm{~mm}$ & $73 \pm 8$ & $78 \pm 8$ & 0.002 \\
\hline $\mathrm{LAV}, * \mathrm{ml}$ & $116 \pm 27$ & $144 \pm 39$ & 0.001 \\
\hline LAA volume, ${ }^{*} \mathrm{ml}$ & $6 \pm 2$ & $7 \pm 3$ & 0.14 \\
\hline LA-D-index ${ }^{*} \mathrm{~mm} / \mathrm{m}^{2}$ & $21 \pm 3$ & $21 \pm 3$ & 0.92 \\
\hline LA-AP-index, ${ }^{*} \mathrm{~mm} / \mathrm{m}^{2}$ & $22 \pm 5$ & $22 \pm 5$ & 0.70 \\
\hline LA-SI-index, ${ }^{*} \mathrm{~mm} / \mathrm{m}^{2}$ & $28 \pm 6$ & $29 \pm 4$ & 0.37 \\
\hline LA-TV-index, ${ }^{*} \mathrm{~mm} / \mathrm{m}^{2}$ & $36 \pm 4$ & $37 \pm 5$ & 0.10 \\
\hline LAV-index ${ }^{*} \mathrm{ml} / \mathrm{m}^{2}$ & $59 \pm 16$ & $68 \pm 18$ & 0.007 \\
\hline
\end{tabular}

$\mathrm{AP}=$ antero-posterior, $\mathrm{D}=$ diameter, $\mathrm{LA}=$ left atrial, $\mathrm{LAA}=\mathrm{LA}$ appendage, $\mathrm{SI}=$ supero-inferior, $\mathrm{TV}=$ transversal, $*$ by computed tomography.

Sub-analysis in patients with available LAVe, revealed a tendency for higher volumes in case of AF recurrence $(118 \pm 46$ vs. $93 \pm 47 \mathrm{ml}, \mathrm{p}=0.076)$. Accordingly, univariate analysis showed a predictive value for LAVe $(\mathrm{HR}=1.012$ per $\mathrm{ml}, 95 \% \mathrm{CI}: 0.998-1.025, \mathrm{p}=0.087)$ that did not reach statistical significance in the multivariate models. 
Table 6.3. Echocardiographic predictors of atrial fibrillation (AF) recurrence in a cox-regression model with left atrial (LA) volume (Model 1) or LA diameters (Model 2).

\begin{tabular}{|c|c|c|c|c|c|c|c|c|c|}
\hline \multirow[b]{2}{*}{ Variable } & \multicolumn{3}{|c|}{ UV } & \multicolumn{3}{|c|}{ MV Model 1} & \multicolumn{3}{|c|}{ MV Model 2} \\
\hline & HR & $95 \% \mathrm{CI}$ & $\mathrm{P}$ & HR & $95 \%$ CI & $\mathrm{P}$ & HR & $95 \% \mathrm{CI}$ & $\mathrm{P}$ \\
\hline LAD & 1.081 & $1.018-1.147$ & 0.011 & \multirow{8}{*}{1.011} & \multirow{8}{*}{$1.003-1.020$} & \multirow{8}{*}{0.012} & \multirow{8}{*}{1.07} & \multirow{8}{*}{$1.022-1.121$} & \multirow{8}{*}{0.004} \\
\hline LA-SI & 1.049 & $0.998-1.103$ & 0.058 & & & & & & \\
\hline LA-TV & 1.070 & $1.022-1.121$ & 0.004 & & & & & & \\
\hline LATVi & 1.054 & $0.979-1.134$ & 0.165 & & & & & & \\
\hline LAV & 1.011 & $1.003-1.020$ & 0.012 & & & & & & \\
\hline LAVi & 1.016 & $0.999-1.034$ & 0.066 & & & & & & \\
\hline AF type & 0.655 & $0.319-1.345$ & 0.249 & & & & & & \\
\hline $\mathrm{CHF}$ & 0.542 & $0.206-1.423$ & 0.213 & & & & & & \\
\hline
\end{tabular}

$\mathrm{D}=$ diameter, $(\mathrm{i})=$ indexed to body surface area, $\mathrm{LA}=$ left atrial, $\mathrm{SI}=$ supero-inferior, $\mathrm{TV}=$ transversal, $\mathrm{MV}=$ multivariate analysis, $\mathrm{UV}=$ univariate analysis.
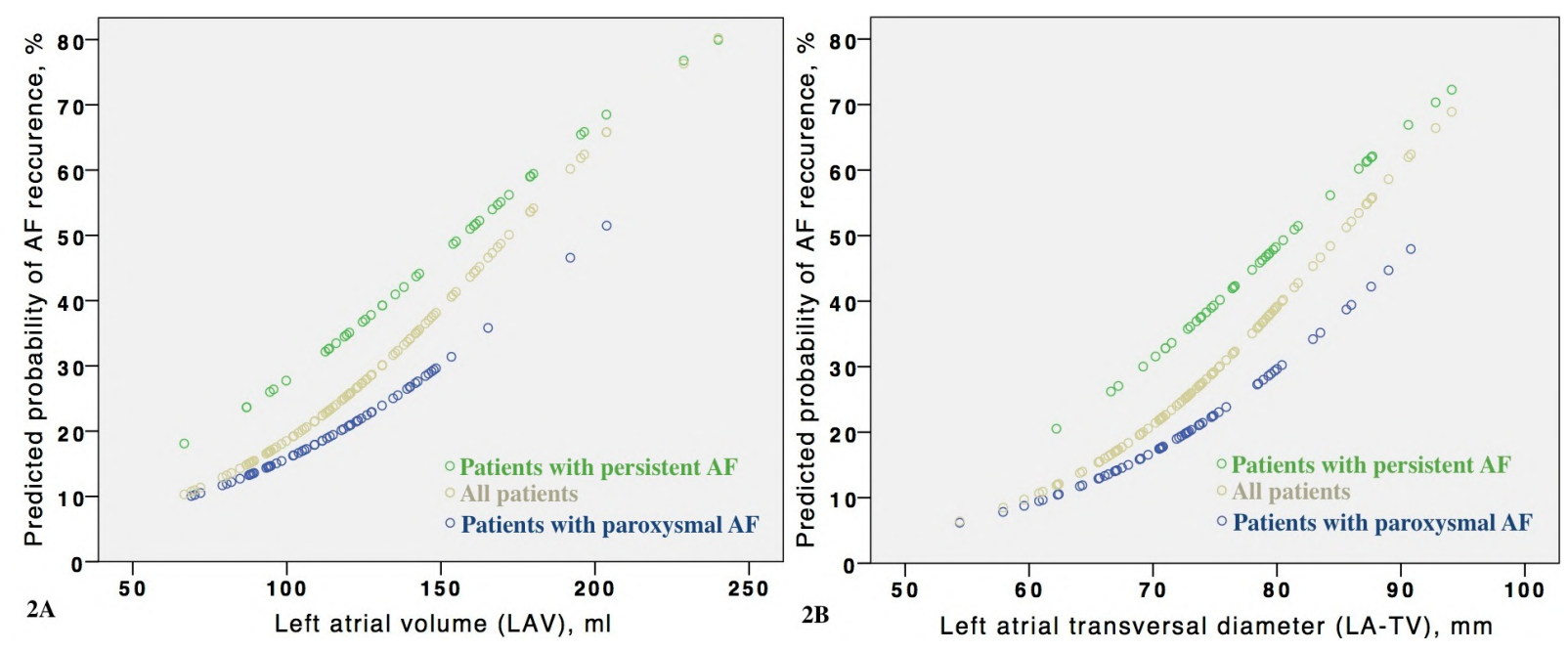

Figure 6.2. The mean predicted proportion of patients with atrial fibrillation (AF) recurrence after an ablation procedure in relation to A. the LA volume (LAV) and B. the transversal LA diameter in CT (LA-TV) in the total population or according to AF type.

\section{Main findings}

\section{Discussion}

This study evaluates the value of LA volume and of single-linear LA dimensions for the prediction of AF recurrence after AF ablation procedures. Systematic long-term follow-up data including 7-day-Holter recordings allowed us to carefully assess the relationship between LA size and AF recurrence. There are two main findings in this study. First, LA dilatation is associated with advanced AF stage (persistent) and it is better detected by computed tomography than by echocardiography. Second, dilatation is asymmetrical and more pronounced on the coronal plane, as represented by the transversal LA diameter. LA-TV $(>74.5 \mathrm{~mm})$ is associated with reduced long-term success after catheter ablation and remains the best single-linear predictor similar to LAV $(>126 \mathrm{ml})$ and stronger than the common echocardiographic LA-D. 


\section{Clinical implications}

The assessment of the LA size and anatomy using the proper imaging technique and reliable parameters is very important, since it provides important prognostic information and guides AF management. Current guidelines recommend the assessment of the LA size by echocardiography (LA-D), but this cannot reliably reflect the asymmetric enlargement of LA in advanced AF that has also been reported in some previous studies. ${ }^{6,7,9}$ This irregular LA dilatation could reflect the physical constraints ${ }^{14}$ or LA wall changes due to chronic $\mathrm{AF}^{15}$ and is not fairly represented with LA-D or LAVe, as shown in the present study.

Our study showed that LA-D has lower correlation and lower predictive value in comparison to other diameters or to LA volume (LAV). LATV $(>74.5 \mathrm{~mm})$ was the strongest linear predictor of AF recurrence and could predict AF recurrence similarly to LAV $(>126 \mathrm{ml})$, independent of body surface area. According to the hazard ratio above, a $4 \mathrm{~mm}$ increase of the LA-TV could lead to $30 \%$ higher AF recurrence rate. The high negative predictive value for both LA-TV and LAV (81\%) means a good differentiating value for the identification of patients with AF freedom on a long-tem follow-up. Finally, there seems to be an additional predictive value of LA-TV that reflects the LA remodeling in patients with high LAV and that should be further examined. Therefore, ablation should not be withheld from these patients, even if the echocardiographic diameter or the LAV is enlarged ( $7 \%$ with LA-TV $\leq 74.5 \mathrm{~mm}$ and LA-D $\geq 50 \mathrm{~mm}$ or LAV $>126 \mathrm{ml}$ in our cohort).

These results supplement previous studies, showing that LAD measured by echocardiography correlates poorly with LA volume measured by CT, which is a better surrogate of true LA size and of AF ablation success. ${ }^{4,}{ }^{16-20}$ Abecasis et al. showed that patients with LAV $>145 \mathrm{ml}$ had significantly higher AF recurrence rates after AF ablation. ${ }^{4}$ Helms et al. found a LAV cutoff point of $135 \mathrm{ml}$ to have $96 \%$ specificity for AF recurrence. ${ }^{17}$ Similar results have been reported by other studies in different patient cohorts, but cut-off values $(117-135 \mathrm{ml})$ increased proportionally to the percentage of included patients with persistent AF. ${ }^{20-22}$ In contrast, von Bary et al. found that in a larger cohort with exclusive paroxysmal AF, LAV ( $>95 \mathrm{ml})$ has only a marginal predictive value. ${ }^{23}$

A recent study by den Uijl et al. examined LA dimensions from CT data of 100 patients undergoing AF catheter ablation and found that enlargement of the antero-posterior LA diameter in $\mathrm{CT}$ and a normal anatomy of the right pulmonary veins were independent risk factors for $\mathrm{AF}$ recurrence. ${ }^{24}$ However, this study had a shorter follow-up (12 vs. 26 months) and included fewer patients with persistent AF ( $28 \%$ vs. $40 \%$ ) with low LA volume ( $82 \mathrm{vs.} 127 \mathrm{ml}$ ) in comparison to our study. Since advanced AF stages are associated with a more prominent dilatation on the coronal plane and ablation is increasingly being used for patients with persistent AF, transversal LA size seems to be a better surrogate of LA size for these patients and deserves further investigation.

Volume measurement requires $3 \mathrm{D}$ reconstruction, cutting out anatomical structures and thus remains a time-consuming process. Therefore, an easily measured single-linear LA dimension would be better for clinical routine use. The current data indicate that the transversal LA diameter (LA-TV) can represent LA dilatation and can predict success after AF-ablation similarly to LAV. In contrast, the commonly used LA-D and LAVe showed poorer correlation with LAV and low predictive value for AF-recurrence, when compared with LAV and other LA diameters. As previously described, LAVe appeared to underestimate the LA volume compared to Cardiac-CT and thus had lower predictive value in our study. ${ }^{25,26}$ Interestingly, in accordance with previous reports, all parameters had worse statistical performance when adjusted for BSA. ${ }^{23}$ Thus, future studies should take into consideration that indexed variables could reduce the mass effect. In this sense, our findings emphasize that LA-D and indexed values could be misleading for clinical 
decision making in AF patients. LA-TV on the other hand is a simple parameter that could be easily measured and reliably guide AF management, by identifying patients in whom successful $\mathrm{AF}$ ablation can be achieved with simpler ablation procedures.

\section{Limitations}

This is a single-center study with the inherent limitations of a post-hoc analysis. Asymptomatic AF recurrence may have been underestimated, but systematic 7-day-Holter recordings tried to limit this effect. The effect of parameter-collinearity is difficult to assess with Cox regression, but since the variance inflation factor remained at about 2.5 this effect was limited. In order to further restrict this effect we performed a two-model analysis. Analysis with collinearity adjustment and inclusion of all LA diameters though did not change the significance of our findings. Although LAVe data were limited, our results confirmed the systematic underestimation of LA volume and thus the lower predictive value of LAVe. Additionally, LAV and LA-TV was assessed with computed tomography, the application of which is largely limited by radiation exposure and need for contrast injection. This certainly prohibits the use of LA-TV in repeated routine follow-up studies, but since $\mathrm{CT}$ is the most common imaging for 3D data prior to AF-ablation, LA-TV is a readily available parameter. However, newer techniques, such as magnetic-resonance tomography or 3D echocardiography, are entering the clinical routine and could potentially provide this information with less radiation in the future.

\section{Conclusion}

In conclusion, the left atrial dilatation, especially on the coronal plane, is associated with advanced stages of AF and worse long-term rhythm outcomes after catheter ablation. The transversal LA diameter is the best single-linear predictor, comparable to LA volume and stronger than the commonly used LA diameter measured by echocardiography. 


\section{References}

1. Tsang MY, Barnes ME, Tsang TS. Left atrial volume: clinical value revisited. Curr Cardiol Rep Jun 2012;14:374-380.

2. Berruezo A, Tamborero D, Mont L, Benito B, Tolosana JM, Sitges M, Vidal B, Arriagada G, Mendez F, Matiello M, Molina I, Brugada J. Pre-procedural predictors of atrial fibrillation recurrence after circumferential pulmonary vein ablation. Eur Heart J Apr 2007;28:836-841.

3. Shin SH, Park MY, Oh WJ, Hong SJ, Pak HN, Song WH, Lim DS, Kim YH, Shim WJ. Left atrial volume is a predictor of atrial fibrillation recurrence after catheter ablation. $\mathrm{J}$ Am Soc Echocardiogr Jun 2008;21:697-702.

4. Abecasis J, Dourado R, Ferreira A, Saraiva C, Cavaco D, Santos KR, Morgado FB, Adragao P, Silva A. Left atrial volume calculated by multi-detector computed tomography may predict successful pulmonary vein isolation in catheter ablation of atrial fibrillation. Europace Oct 2009;11:1289-1294.

5. Camm AJ, Lip GY, De Caterina R, et al. 2012 focused update of the ESC Guidelines for the management of atrial fibrillation: an update of the 2010 ESC Guidelines for the management of atrial fibrillation. Developed with the special contribution of the European Heart Rhythm Association. Eur Heart J Nov 2012;33:2719-2747.

6. Badano LP, Pezzutto N, Marinigh R, Cinello M, Nucifora G, Pavoni D, Gianfagna P, Fioretti PM. How many patients would be misclassified using M-mode and two-dimensional estimates of left atrial size instead of left atrial volume? A three-dimensional echocardiographic study. J Cardiovasc Med (Hagerstown) May 2008;9:476-484.

7. Nedios S, Tang M, Roser M, Solowjowa N, Gerds-Li JH, Fleck E, Kriatselis C. Characteristic changes of volume and three-dimensional structure of the left atrium in different forms of atrial fibrillation: predictive value after ablative treatment. J Interv Card Electrophysiol Nov 2011;32:87-94.

8. Sohns C, Sohns JM, Vollmann D, Luthje L, Bergau L, Dorenkamp M, Zwaka PA, Hasenfuss G, Lotz J, Zabel M. Left atrial volumetry from routine diagnostic work up prior to pulmonary vein ablation is a good predictor of freedom from atrial fibrillation. Eur Heart J Cardiovasc Imaging Jul 2013;14:684-691.

9. Bisbal F, Guiu E, Calvo N, et al. Left atrial sphericity: a new method to assess atrial remodeling. Impact on the outcome of atrial fibrillation ablation. Journal of cardiovascular electrophysiology Jul 2013;24:752-759.

10. Tsang TS, Abhayaratna WP, Barnes ME, Miyasaka Y, Gersh BJ, Bailey KR, Cha SS, Seward JB. Prediction of cardiovascular outcomes with left atrial size: is volume superior to area or diameter? J Am Coll Cardiol Mar 7 2006;47:1018-1023.

11. Lang RM, Bierig M, Devereux RB, et al. Recommendations for chamber quantification. Eur J Echocardiogr Mar 2006;7:79-108.

12. Mosteller RD. Simplified calculation of body-surface area. N Engl J Med Oct 22 1987;317:1098.

13. Eitel C, Hindricks G, Sommer P, et al. Circumferential pulmonary vein isolation and linear left atrial ablation as a single-catheter technique to achieve bidirectional conduction block: the pace-and-ablate approach. Heart Rhythm 2010;7:157-164.

14. Hoffmeister PS, Chaudhry GM, Mendel J, Almasry I, Tahir S, Marchese T, Haffajee CI, Orlov MV. Evaluation of left atrial and posterior mediastinal anatomy by multidetector helical computed tomography imaging: relevance to ablation. J Interv Card Electrophysiol Apr 2007;18:217-223. 
15. Sanfilippo AJ, Abascal VM, Sheehan M, Oertel LB, Harrigan P, Hughes RA, Weyman AE. Atrial enlargement as a consequence of atrial fibrillation. A prospective echocardiographic study. Circulation Sep 1990;82:792-797.

16. Vandenberg BF, Weiss RM, Kinzey J, Acker M, Stark CA, Stanford W, Burns TL, Marcus ML, Kerber RE. Comparison of left atrial volume by two-dimensional echocardiography and cine-computed tomography. Am J Cardiol Apr 1 1995;75:754-757.

17. Helms AS, West JJ, Patel A, Lipinski MJ, Mangrum JM, Mounsey JP, Dimarco JP, Ferguson JD. Relation of left atrial volume from three-dimensional computed tomography to atrial fibrillation recurrence following ablation. Am J Cardiol Apr 1 2009;103:989-993.

18. Montefusco A, Biasco L, Blandino A, Cristoforetti Y, Scaglione M, Caponi D, Di Donna P, Boffano C, Cesarani F, Coin D, Perversi J, Gaita F. Left atrial volume at MRI is the main determinant of outcome after pulmonary vein isolation plus linear lesion ablation for paroxysmal-persistent atrial fibrillation. J Cardiovasc Med (Hagerstown) Aug 2010;11:593598.

19. Hauser TH, McClennen S, Katsimaglis G, Josephson ME, Manning WJ, Yeon SB. Assessment of left atrial volume by contrast enhanced magnetic resonance angiography. $\mathrm{J}$ Cardiovasc Magn Reson 2004;6:491-497.

20. Hof I, Arbab-Zadeh A, Scherr D, Chilukuri K, Dalal D, Abraham T, Lima J, Calkins H. Correlation of left atrial diameter by echocardiography and left atrial volume by computed tomography. Journal of cardiovascular electrophysiology Feb 2009;20:159-163.

21. Parikh SS, Jons C, McNitt S, Daubert JP, Schwarz KQ, Hall B. Predictive capability of left atrial size measured by CT, TEE, and TTE for recurrence of atrial fibrillation following radiofrequency catheter ablation. Pacing Clin Electrophysiol May 2010;33:532-540.

22. Shin SY, Yong HS, Na JO, et al. A simplified method to determine left atrial volume and transport function using multi-slice computed tomography in patients with atrial fibrillation: comparison with transthoracic echocardiography. Int $\mathbf{J}$ Cardiovasc Imaging Jun 2012;28:1205-1216.

23. von Bary C, Dornia C, Eissnert C, et al. Predictive value of left atrial volume measured by non-invasive cardiac imaging in the treatment of paroxysmal atrial fibrillation. J Interv Card Electrophysiol Aug 2012;34:181-188.

24. den Uijl DW, Tops LF, Delgado V, Schuijf JD, Kroft LJ, de Roos A, Boersma E, Trines SA, Zeppenfeld K, Schalij MJ, Bax JJ. Effect of pulmonary vein anatomy and left atrial dimensions on outcome of circumferential radiofrequency catheter ablation for atrial fibrillation. Am J Cardiol Jan 15 2011;107:243-249.

25. Avelar E, Durst R, Rosito GA, Thangaroopan M, Kumar S, Tournoux F, Chan RC, Hung J, Hoffmann U, Abbara S, Brady T, Cury RC. Comparison of the accuracy of multidetector computed tomography versus two-dimensional echocardiography to measure left atrial volume. Am J Cardiol Jul 1 2010;106:104-109.

26. Al-Mohaissen MA, Kazmi MH, Chan KL, Chow BJ. Validation of two-dimensional methods for left atrial volume measurement: a comparison of echocardiography with cardiac computed tomography. Echocardiography Nov 2013;30:1135-1142. 



\section{Chapter 7 Atrial remodeling and long-term success after AF ablation}

Adapted from "Impact of asymmetrical dilatation of the left atrium on the long-term success after catheter ablation of atrial fibrillation"

Published in Int J Cardiol. 2015 Apr 1;184:315-7. Sep. DOI: 10.1016/j.ijcard.2015.02.078

Sotirios Nedios, Emmanuel Koutalas, Jedrzej Kosiuk, Philipp Sommer, Arash Arya, Sergio Richter, Sascha Rolf, Daniela Husser, Gerhard Hindricks, MD, Andreas Bollmann 


\begin{abstract}

\section{Background:}

Left atrium (LA) dilatation is associated with atrial fibrillation (AF) progression and reduced success after catheter ablation. We studied the pattern of LA asymmetry in regard to dilatation and its predictive value, especially in advanced AF stage.
\end{abstract}

\title{
Methods:
}

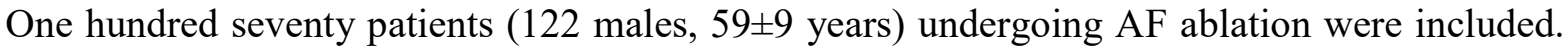
Pre-interventional CT data were used to determine the LA volume (LAV). A cutting plane, between the pulmonary vein ostia and the appendage and parallel to the posterior wall, divided LAV into anterior- (LA-A) and posterior-LA (LA-P) parts. The ratio LA-A/LAV was defined as asymmetry index (ASI).

\section{Results:}

Patients with persistent AF ( $\mathrm{n}=56$ ) had higher LA volumes and asymmetry (ASI: $63 \pm 6 \%$ vs. $60 \pm 6, p=0.004)$ than those with paroxysmal AF $(n=114)$. LAV increase was associated with an ASI increase $(\mathrm{r}=0.31, \mathrm{p}<0.001)$. After 24 months, AF recurred in 55(32\%) patients. Univariate analysis revealed AF-type, heart failure, LA volumes, diameter (LA-D) and ASI as recurrence predictors. Multivariate analysis showed that LA-A $(\mathrm{OR}=1.02$ per $\mathrm{ml}, 95 \% \mathrm{CI}$ : 1.002-1.0037, $\mathrm{p}=0.025$ ) was the only independent recurrence predictor for patients with paroxysmal AF. In patients with persistent AF though, asymmetry was the only predictor (ASI, OR $=1.21$ per $1 \%$, 95\%CI: $1.03-1.42, \mathrm{p}=0.02$ ) independent of volumes.

\section{Conclusions:}

Advanced AF is associated with asymmetric LA dilatation, negatively affecting long-term success after ablation. LA-A and ASI are outcome predictors with higher value than LA-D. 


\title{
Introduction
}

Left atrium (LA) dilatation is associated with atrial fibrillation (AF) progression ${ }^{1}$. Recent data though revealed that atrial remodeling not only involves enlargement but symmetry changes too, which have been associated with reduced success after catheter ablation ${ }^{2-4}$. Despite the growing evidence of LA remodeling and the need for additional ablation targets in patients with persistent $\mathrm{AF}$, the relation of LA asymmetry and long-term outcomes is still not well studied.

Consequently, the present study evaluated 170 consecutive patients of our prospective registry for the impact of asymmetrical LA dilatation on the long-term success after pulmonary vein isolation (PVI) for paroxysmal AF or additional substrate modification for persistent AF.

\section{Methods}

All patients gave informed consent according to institutional guidelines and the Declaration of Helsinki. Echocardiography and cardiac-CT with a multidetector 64-row helical system (Brilliance 64, Philips, Best, Netherlands) was performed ( $2 \pm 1$ days) before the procedure ${ }^{5}$. CT data were reviewed using 3D reconstruction (EnSite Verismo, SJM, MN) and LA volume (LAV) was determined after exclusion of the atrial appendage (LAA) and the pulmonary veins (PV). LA was then centered on all three cutting planes and the superior-inferior (SI), transversal (TV) and anterior-posterior (AP) diameters were measured. The LAV was then arbitrarily divided by a cutting plane, between the anterior segment of the PV ostia and the LAA and parallel to the posterior wall. The partial LA volumes, the anterior (LA-A) and the posterior (LA-P) were calculated and the ratio LA-A/LAV was defined as an asymmetry index (ASI). Figure 7.1.

We also calculated a simplified left atrial sphericity parameter (LAS), similarly to a previous method ${ }^{3}$. The average radius [AR] of such a sphere was calculated as the mean of of the LA radius in all 3 dimensions (SI, TV and AP). The coefficient of variation of the sphere (CVS $=\mathrm{AR}$ standard deviation/AR) was obtained to define the LAS [(1- CVS $) * 100]$.

Measurements were performed offline by an experienced observer and were repeated 4 weeks later by the same investigator and a second reviewer in a blinded fashion.

\begin{abstract}
Ablation procedure and follow-up
Catheter ablation was performed under propofol sedation as previously described ${ }^{6}$. All patients underwent circumferential ablation around the ipsilateral pulmonary veins, verified with a multipolar circular catheter. In patients with persistent AF, additional linear lesions were added between the circular lesions, at the mitral isthmus and the posterior LA wall to create a "box" lesion. Follow-up was performed with repeated 7-day-holter ECG recordings at 6, 12, 24 and 36 months. Recurrence was defined as any documented atrial tachycardia or fibrillation episodes of $\geq 30$ seconds (after a 3 months blanking period).
\end{abstract}

\section{Statistical analysis}

Continuous variables are expressed as mean and standard deviation (SD) when normally distributed or as median and interquartile range (IQR). Categorical variables are reported as frequencies and percentage. Parametric variables were compered by means of paired Student's ttest and non-parametric variables by Wilcoxon-test or chi-square test. Intra-observer and interobserver variability expressed with Pearson's correlation coefficient (r).

Baseline variables with a $p$-value $<0.1$ in the univariate regression analysis were included in a forward stepwise multivariate model to determine the odds ratio (OR) and $95 \%$ confidence interval (CI) of predictors. Separate models were used to evaluate the predictors of success 
according to AF type. A two-tailed P-value $<0.05$ was considered significant. Data were analysed with SPSS v20.0 (SPSS Inc., Chicago, USA).

\section{Results}

\section{Patients' characteristics}

The characteristics and LA measurements of the patient cohort are summarized in Table 7.1. The intra- and inter-observer correlation coefficients were all $\geq 0.89$. LAV correlated with ASI $(\mathrm{r}=0.31, \mathrm{p}<0.001)$ and LAD with LAV $(\mathrm{r}=0.51, \mathrm{p}<0.01)$, but not with ASI $(\mathrm{r}=0.5, \mathrm{p}=0.18)$. LAS $(73 \pm 7 \%)$ correlated with LA volumes but not with ASI, AF type or outcomes.

Table 7.1. Clinical characteristics and measurements according to atrial fibrillation (AF) type.

\begin{tabular}{|c|c|c|c|c|}
\hline Variables & Total & Paroxysmal AF & Persistent AF & $\mathrm{P}$ \\
\hline Number, n (\%) & 170 & $114(67 \%)$ & $56(33 \%)$ & \\
\hline Age, years & $59 \pm 10$ & $58 \pm 10$ & $60 \pm 8$ & 0.16 \\
\hline Male, $\mathrm{n}(\%)$ & $122(72 \%)$ & $78(68 \%)$ & $44(79 \%)$ & 0.20 \\
\hline Body mass index, $\mathrm{kg} / \mathrm{m}^{2}$ & $28 \pm 4$ & $28 \pm 4$ & $29 \pm 4$ & 0.10 \\
\hline Body surface area, $\mathrm{m}^{2}$ & $2 \pm 0.2$ & $2 \pm 0.2$ & $2 \pm 0.2$ & 0.11 \\
\hline Hyperlipidemia, n (\%) & $53(31 \%)$ & $35(31 \%)$ & $18(32 \%)$ & 0.86 \\
\hline Hypertension, $\mathrm{n}(\%)$ & $94(55 \%)$ & $62(57 \%)$ & $32(54 \%)$ & 0.75 \\
\hline Diabetes mellitus, $\mathrm{n}(\%)$ & $23(14 \%)$ & $17(15 \%)$ & $6(11 \%)$ & 0.63 \\
\hline Previous stroke/TIA, n (\%) & $11(7 \%)$ & $9(8 \%)$ & $2(4 \%)$ & 0.34 \\
\hline Coronary artery disease, $\mathrm{n}(\%)$ & $18(11 \%)$ & $11(10 \%)$ & $7(13 \%)$ & 0.60 \\
\hline Dilated cardiomyopathy, n (\%) & $7(4 \%)$ & $3(3 \%)$ & $4(7 \%)$ & 0.22 \\
\hline Heart failure, $\mathrm{n}(\%)$ & $11(7 \%)$ & $7(6 \%)$ & $4(7 \%)$ & 0.75 \\
\hline $\mathrm{CHADS}_{2}$ score & $1.3 \pm 1.1$ & $1.3 \pm 1.2$ & $1.2 \pm 0.9$ & 0.67 \\
\hline $\mathrm{CHA}_{2} \mathrm{DS}_{2}$-VASc score & $1.6 \pm 1.4$ & $1.7 \pm 1.5$ & $1.5 \pm 1.3$ & 0.38 \\
\hline \multicolumn{5}{|l|}{ Imaging parameters } \\
\hline Left ventricular ejection fraction, $\%$ & $60 \pm 8$ & $62 \pm 8$ & $58 \pm 8$ & 0.17 \\
\hline Left ventricular ed. Diameter, mm & $49 \pm 6$ & $49 \pm 6$ & $49 \pm 7$ & 1.00 \\
\hline LAD by echocardiography, $\mathrm{mm}$ & $43 \pm 6$ & $42 \pm 6$ & $43 \pm 7$ & 0.30 \\
\hline $\mathrm{LAV},{ }^{*} \mathrm{ml}$ & $129 \pm 43$ & $123 \pm 45$ & $143 \pm 35$ & 0.003 \\
\hline LA-A, ${ }^{*} \mathrm{ml}$ & $79 \pm 31$ & $74 \pm 32$ & $90 \pm 25$ & 0.001 \\
\hline LA-P, ${ }^{2} \mathrm{ml}$ & $50 \pm 15$ & $49 \pm 15$ & $54 \pm 13$ & 0.029 \\
\hline ASI (LA-A/LA-P), $\%$ & $61 \pm 6$ & $60 \pm 6$ & $63 \pm 6$ & 0.009 \\
\hline LA Sphericity, $\%$ & $73 \pm 7$ & $72 \pm 8$ & $74 \pm 6$ & 0.10 \\
\hline LAA volume, ${ }^{*} \mathrm{ml}$ & $7 \pm 3$ & $7 \pm 4$ & $7 \pm 3$ & 0.39 \\
\hline \multicolumn{5}{|l|}{ Procedural/outcome data } \\
\hline Procedure time, $\min$ & $166 \pm 52$ & $157 \pm 53$ & $183 \pm 47$ & 0.68 \\
\hline Fluoroscopy time, $\min$ & $36 \pm 17$ & $34 \pm 15$ & $40 \pm 19$ & 0.08 \\
\hline Fluoroscopy dose, cGy*cm2 & $1.6 \pm 1.7$ & $1.4 \pm 1.1$ & $2.0 \pm 2.0$ & 0.08 \\
\hline Ablation time, $\min$ & $55 \pm 23$ & $50 \pm 22$ & $65 \pm 25$ & 0.08 \\
\hline Follow-up time, months & $27 \pm 16$ & $26 \pm 17$ & $30 \pm 15$ & 0.15 \\
\hline Reablation, $\mathrm{n}(\%)$ & $62(36 \%)$ & $38(33 \%)$ & $24(43 \%)$ & 0.26 \\
\hline AF recurrence, $\mathrm{n}(\%)$ & $54(32 \%)$ & $30(27 \%)$ & $25(45 \%)$ & 0.02 \\
\hline
\end{tabular}

$\mathrm{LA}=$ left atrial; $\mathrm{LAA}=\mathrm{LA}$ appendage; $\mathrm{LA}-\mathrm{A}=$ anterior $\mathrm{LA}$ volume; $\mathrm{LAD}=\mathrm{LA}$ diameter; $\mathrm{LA}-\mathrm{P}=$ posterior LA volume; LAV= LA volume; $\mathrm{ASI}=$ asymmetry index, * by computed tomography. 


\section{Atrial remodeling and ablation outcomes}

Patients with persistent AF had higher volumes and asymmetry than those with paroxysmal AF. The LAV-ASI correlation was present in paroxysmal AF $(\mathrm{r}=0.25, \mathrm{p}=0.007)$ but did not reach statistical significance in persistent AF patients $(\mathrm{r}=0.26, \mathrm{p}=0.056)$.

After 24 months, AF recurred in $55(32 \%)$ patients. Univariate analysis revealed persistent $\mathrm{AF}$ ( $45 \%$ vs. $27 \%, \mathrm{p}=0.02)$, heart failure ( $13 \%$ vs. $4 \%, \mathrm{p}=0.04)$, LAD ( $45 \pm 8$ vs. $41 \pm 5 \mathrm{~mm}, 0.007)$, LAV ( $148 \pm 54$ vs. $121 \pm 33 \mathrm{ml}, \mathrm{p}<0.001)$, LA-A ( $94 \pm 41$ vs. $72 \pm 22 \mathrm{ml}, \mathrm{p}<0.001)$, LA-P $(55 \pm 16$ vs. $48 \pm 14 \mathrm{ml}, \mathrm{p}=0.011)$, LAA volume $(8 \pm 4$ vs. $7 \pm 3 \mathrm{ml}, \mathrm{p}=0.02)$ and asymmetry ( $63 \pm 6$ vs. $59 \pm 6 \%$, $\mathrm{p}<0.00)$ as recurrence predictors.

In patients with paroxysmal AF, multivariate analysis showed that LA-A (OR=1.02 per ml, $95 \%$ CI: $1.002-1.0037, p=0.025$ ) was the only independent recurrence predictor. An LA-A $\geq 78 \mathrm{ml}$ could predict AF recurrence with the highest sensitivity (66\%), specificity (67\%), PPV 66\% and NPV $67 \%$. In patients with persistent AF though, asymmetry was the only predictor (ASI, $\mathrm{OR}=1.21$ per $1 \%, 95 \% \mathrm{CI}: 1.03-1.42, \mathrm{p}=0.02$ ) independent of volumes. An ASI $\geq 62.5 \%$ had the highest sensitivity (75\%), specificity (72\%), PPV 67\% and NPV 79\%. Accordingly, a 2\% ASI increase could almost double (42\%) the risk of AF recurrence.

\section{Discussion}

Our study has shown that LA remodeling involves two interactive components: dilatation and asymmetry, both associated with AF-type and long-term success after an AF-tailored ablation. This could reflect the physical constraints (spine/sternum) ${ }^{7}$, the changing tissue characteristics ${ }^{8,9}$ and the increased anterior wall stress ${ }^{10}$, which as shown undergoes continuous expansion during AF progression.

We found that asymmetry increases as the LA volume expands, but this effect is less pronounced in patients with already asymmetric dilated atria, such as in persistent AF. Although, dilatation is the most important predictor after PVI for paroxysmal AF, in patients with persistent $\mathrm{AF}$, asymmetry (ASI) supersedes volume and remains the most significant predictor of AF recurrence after PVI and additional substrate modification. Since LAD and LAS did not correlate with ASI and could not represent LA shape, the present findings support the use of LA asymmetry as a surrogate for better patient selection and treatment strategy in advanced AF stages. Therefore, in patients with persistent AF and low ASI, ablative treatment could be advocated despite greater LA volumes, whereas in those with higher ASI alternative treatments should be carefully considered (Figure 7.1).

These results confirm previous observations that asymmetry can predict outcomes and that PVI alone is not an effective treatment for persistent $\mathrm{AF}^{2}$. In contrast to Bisbal et al., ${ }^{3}$ LA sphericity was not found to be a significant recurrence predictor. Patients in our cohort though had lower LAS $(73 \pm 7 \%$ vs. $83 \pm 3 \%$ ), higher LAV $(129 \pm 43 \mathrm{ml}$ vs. $82 \pm 26)$ and more advanced age (59 vs. 52 years old), which could support the observation that in patients with advanced AF, asymmetry is a better surrogate of ablation outcomes.

\section{Conclusion}

Our results can be seen as hypothesis generating and point out the potential importance of LA asymmetry, expressed as proportional LA-A/LAV dilatation, for better pre-procedural patient selection. However, a larger prospective study is needed to confirm these findings. 


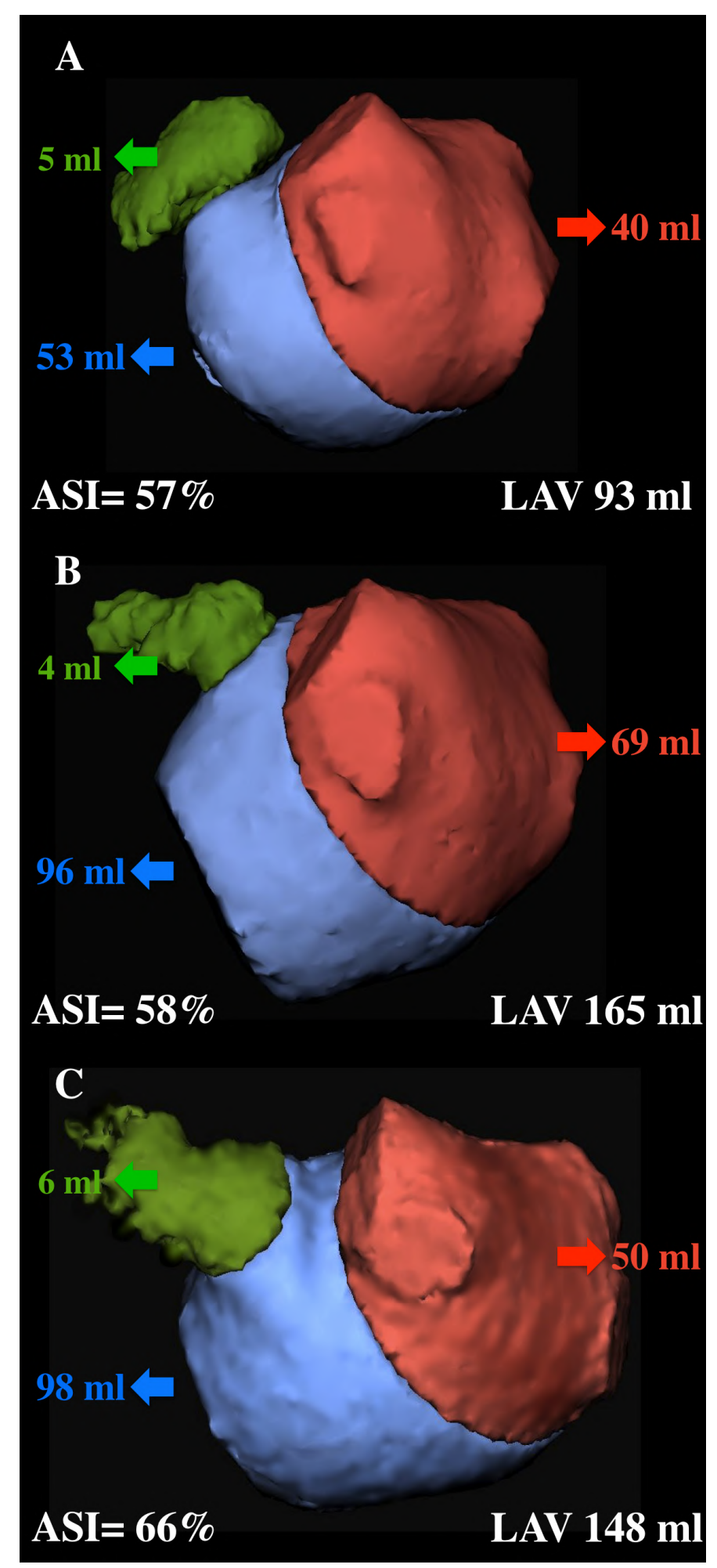

Figure 7.1. The asymmetry index (ASI) in a patient with A. paroxysmal atrial fibrillation (AF) and in two patients with persistent AF: although left atrial volume (LAV) was higher for patient B., ASI and thus ablation outcome were better than for patient $\mathrm{C}$. 


\section{References:}

1. Sanders P, Morton JB, Davidson NC, Spence SJ, Vohra JK, Sparks PB, Kalman JM. Electrical remodeling of the atria in congestive heart failure: electrophysiological and electroanatomic mapping in humans. Circulation Sep 23 2003;108:1461-1468.

2. Nedios S, Tang M, Roser M, Solowjowa N, Gerds-Li JH, Fleck E, Kriatselis C. Characteristic changes of volume and three-dimensional structure of the left atrium in different forms of atrial fibrillation: predictive value after ablative treatment. J Interv Card Electrophysiol Nov 2011;32:87-94.

3. Bisbal F, Guiu E, Calvo N, et al. Left atrial sphericity: a new method to assess atrial remodeling. Impact on the outcome of atrial fibrillation ablation. Journal of cardiovascular electrophysiology Jul 2013;24:752-759.

4. Abecasis J, Dourado R, Ferreira A, Saraiva C, Cavaco D, Santos KR, Morgado FB, Adragao $\mathrm{P}$, Silva A. Left atrial volume calculated by multi-detector computed tomography may predict successful pulmonary vein isolation in catheter ablation of atrial fibrillation. Europace Oct 2009;11:1289-1294.

5. Nedios S, Kornej J, Koutalas E, Bertagnolli L, Kosiuk J, Rolf S, Arya A, Sommer P, Husser D, Hindricks G, Bollmann A. Left atrial appendage morphology and thromboembolic risk after catheter ablation for atrial fibrillation. Heart Rhythm Dec 2014;11:2239-2246.

6. Eitel C, Hindricks G, Sommer P, et al. Circumferential pulmonary vein isolation and linear left atrial ablation as a single-catheter technique to achieve bidirectional conduction block: the pace-and-ablate approach. Heart Rhythm 2010;7:157-164.

7. Hoffmeister PS, Chaudhry GM, Mendel J, Almasry I, Tahir S, Marchese T, Haffajee CI, Orlov MV. Evaluation of left atrial and posterior mediastinal anatomy by multidetector helical computed tomography imaging: relevance to ablation. J Interv Card Electrophysiol Apr 2007;18:217-223.

8. Nakamura K, Funabashi N, Uehara M, Ueda M, Murayama T, Takaoka H, Komuro I. Left atrial wall thickness in paroxysmal atrial fibrillation by multislice-CT is initial marker of structural remodeling and predictor of transition from paroxysmal to chronic form. Int $\mathrm{J}$ Cardiol Apr 14 2011;148:139-147.

9. Roberts-Thomson KC, Stevenson I, Kistler PM, Haqqani HM, Spence SJ, Goldblatt JC, Sanders P, Kalman JM. The role of chronic atrial stretch and atrial fibrillation on posterior left atrial wall conduction. Heart Rhythm Aug 2009;6:1109-1117.

10. Hunter RJ, Liu Y, Lu Y, Wang W, Schilling RJ. Left atrial wall stress distribution and its relationship to electrophysiologic remodeling in persistent atrial fibrillation. Circ Arrhythm Electrophysiol Apr 2012;5:351-360. 



\section{Chapter 8 Atrial remodeling and ventricular diastolic dysfunction}

Adapted from "Asymmetrical left atrial remodelling in atrial fibrillation: relation with diastolic dysfunction and long-term ablation outcomes"

Published in Europace. 2017 Sep 1;19(9):1463-1469. DOI:10.1093/europace/euw225

Sotirios Nedios, Emmanuel Koutalas, Philipp Sommer, Arash Arya, Sascha Rolf, Daniela Husser, Andreas Bollmann, Gerhard Hindricks, and Ole-Alexander Breithardt 


\begin{abstract}

\section{Background:}

The association between anatomical left atrial (LA) remodeling and ventricular diastolic dysfunction (DD) in atrial fibrillation (AF) patients is not well studied. We aimed to examine the effect of DD on anatomic LA remodeling and their relation with ablation outcomes.

\section{Methods:}

In 104 patients $(58 \pm 10$ years, $69 \%$ male) referred for AF ablation, LA volume (LAV) was determined by computed tomography. A cutting plane, between the pulmonary vein (PV) ostia and the appendage and parallel to the posterior wall, divided LAV into anterior- (LA-A) and posterior-LA parts. The ratio of LA-A and LAV was defined as the LA asymmetry index (ASI). According to the current guidelines, the presence of DD was evaluated by echocardiography. Regression analysis was used to identify predictors of asymmetry changes and long-term success. Univariate linear regression revealed that ASI is associated with LAV, the presence of DD, and mitral regurgitation.
\end{abstract}

\title{
Results:
}

Asymmetry index was higher in patients with DD ( $\mathrm{n}=35,62 \pm 5$ vs. $59 \pm 6 \%, \mathrm{P}=0.013)$ or mitral regurgitation $(\mathrm{n}=67,61 \pm 6$ vs. $58 \pm 5 \%, \mathrm{P}=0.025)$. Multiple linear regression analysis showed that $\mathrm{DD}(\mathrm{B}=2.6, \beta=0.207,95 \%$ confidence interval, $\mathrm{CI}$ : $0.167-5.011, \mathrm{P}=0.036)$ and LAV $(B=0.037, \beta=0.211,95 \% \mathrm{CI}: 0.003-0.071, \mathrm{P}=0.033)$ were the only factors independently associated with ASI (adjusted $\mathrm{r} 2=0.92, \mathrm{~F}=6.2, \mathrm{P}=0.003$ ). Regression analysis showed that AF recurrence (33\% after 24 months) is associated with asymmetric LA changes, while DD is not.

\section{Conclusions:}

Left atrial symmetry changes are associated with DD and dilatation. Since DD could cause LA remodeling, appropriate early treatment should be considered for AF patients with DD, before geometrical changes occur. 


\section{Introduction}

Atrial fibrillation (AF) progression is an established cause of left atrial (LA) remodeling, characterized not only by dilatation but also by changes of LA symmetry. ${ }^{1-5}$ This is particularly prominent in larger LAs, when due to constriction between the sternum and the spine LA extension occurs non-uniformly, mainly along the superior-inferior and medial-lateral directions and to a lesser degree in the anterior-posterior axis. This asymmetric LA dilatation is a strong predictor of poor outcome after catheter ablation. ${ }^{1-5}$ Recently, advanced AF stages have been also associated with increased prevalence of left ventricular diastolic dysfunction (DD). ${ }^{6}$ However, hitherto there is no data about the relation between DD, LA asymmetry and the effect on the long-term success after AF ablation.

This study aimed to explore patterns of LA asymmetry in regard to DD in AF patients referred for catheter ablation and assessed its potential association with long-term rhythm outcomes.

\section{Patient characteristics}

\section{Methods}

The study population comprised patients with symptomatic therapy-refractory AF who underwent radiofrequency catheter ablation at the Heart Center Leipzig (2009-2011). Patients with an echocardiography of at least 14 days after cardioversion were included, so that after exclusion of patients with prior AF ablation, implanted pacemaker or defibrillator, or mitral valve-surgery, the final study population comprised 104 patients. All patients provided written informed consent and data were collected and anonymized in accordance with institutional guidelines and the Declaration of Helsinki. Paroxysmal AF was defined as self-terminating within 7 days and persistent $\mathrm{AF}$ was defined as an $\mathrm{AF}$ episode of $>7$ days or requiring cardioversion for termination.

\section{Echocardiography}

All patients underwent a comprehensive transthoracic and transesophageal echocardiographic exam during sinus rhythm before catheter ablation according to the recommendations of the American Society of Echocardiography. Images were acquired at a designated echo-laboratory using a commercially available system (GE Healthcare Vivid 9, Philips Medical Systems iE33). Intracardiac thrombi were ruled out. The LA dimension was measured in the parasternal long axis view at end-systole. The left ventricular ejection fraction (LVEF) was assessed by the modified Simpson's method.

Mitral diastolic inflow was interrogated using pulsed-wave Doppler from the apical 4-chamber view at the level of the mitral leaflet tips. Mitral early diastolic peak (E-wave) and late peak (Awave) velocities, E/A ratio, and deceleration time (DT) of mitral early velocity were measured. An apical 4-chamber view was also used to obtain longitudinal myocardial velocities by tissue Doppler imaging of both the medial and lateral mitral annulus. Early diastolic mitral annular peak velocity was measured, and the ratio of trans-mitral diastolic peak velocity to the average mitral annular diastolic peak velocity $\left(\mathrm{E} / \mathrm{e}^{\prime}\right)$ was calculated. DD was graded according to current recommendations as grade 1: mitral $\mathrm{E} / \mathrm{A} \leq 0.8, \mathrm{DT}>200$ milliseconds $(\mathrm{ms})$, and $\mathrm{E} / \mathrm{e}^{\prime} \leq 8$; grade 2 : $0.8<\mathrm{E} / \mathrm{A}<1.5,160 \mathrm{~ms}<\mathrm{DT}<200 \mathrm{~ms}$, and $9<\mathrm{E} / \mathrm{e}^{\prime}<12$; or grade $3: \mathrm{E} / \mathrm{A} \geq 2, \mathrm{DT}<160 \mathrm{~ms}, \mathrm{E} / \mathrm{e}^{\prime}>12$.

\section{Computed tomography}

Cardiac-CT was performed before ablation with a multi-detector 64-row helical system (Brilliance 64, Philips Medical Systems, Best, The Netherlands). Image acquisition was electrogram-gated and the parameters included: $70-120 \mathrm{KV}, 850 \mathrm{mAs}, 0.6 \mathrm{~mm}$ beam collimation, 
0.625-1.25 mm thickness and 20-30 cm field-of-view. During an end-inspiratory breath-hold of 20 seconds, and following a timing bolus-chase injection $(20 \mathrm{ml}, 5 \mathrm{ml} / \mathrm{s}), 90 \mathrm{~mL}$ of an iodinated contrast medium (Ultravist 370, Bayer Vital, Germany) was administered. Finally end-systolic imaging data were recorded and used for three-dimensional (3D) reconstruction.

CT data were reviewed using 3D volume rendering (EnSite Verismo, SJM, MN). Left atrial volume (LAV) after exclusion of the atrial appendage (LAA) and the pulmonary veins (PV) was determined by LA area summation. The LAV was then divided by a cutting plane, between the anterior segment of the PV ostia and the atrial appendage and parallel to the posterior wall. The resulting anterior (LA-A) and posterior (LA-P) partial volumes were calculated and the ratio LA$\mathrm{A} / \mathrm{LAV}$ was defined as the asymmetry index (ASI, Figure 8.1).

Image analysis was performed offline by an experienced observer blinded to ablation data and the patient's clinical follow-up. Initial measurements of 20 random patients were repeated 4 weeks later by the same investigator and a second reviewer (S.N., E.K) in a blinded fashion.

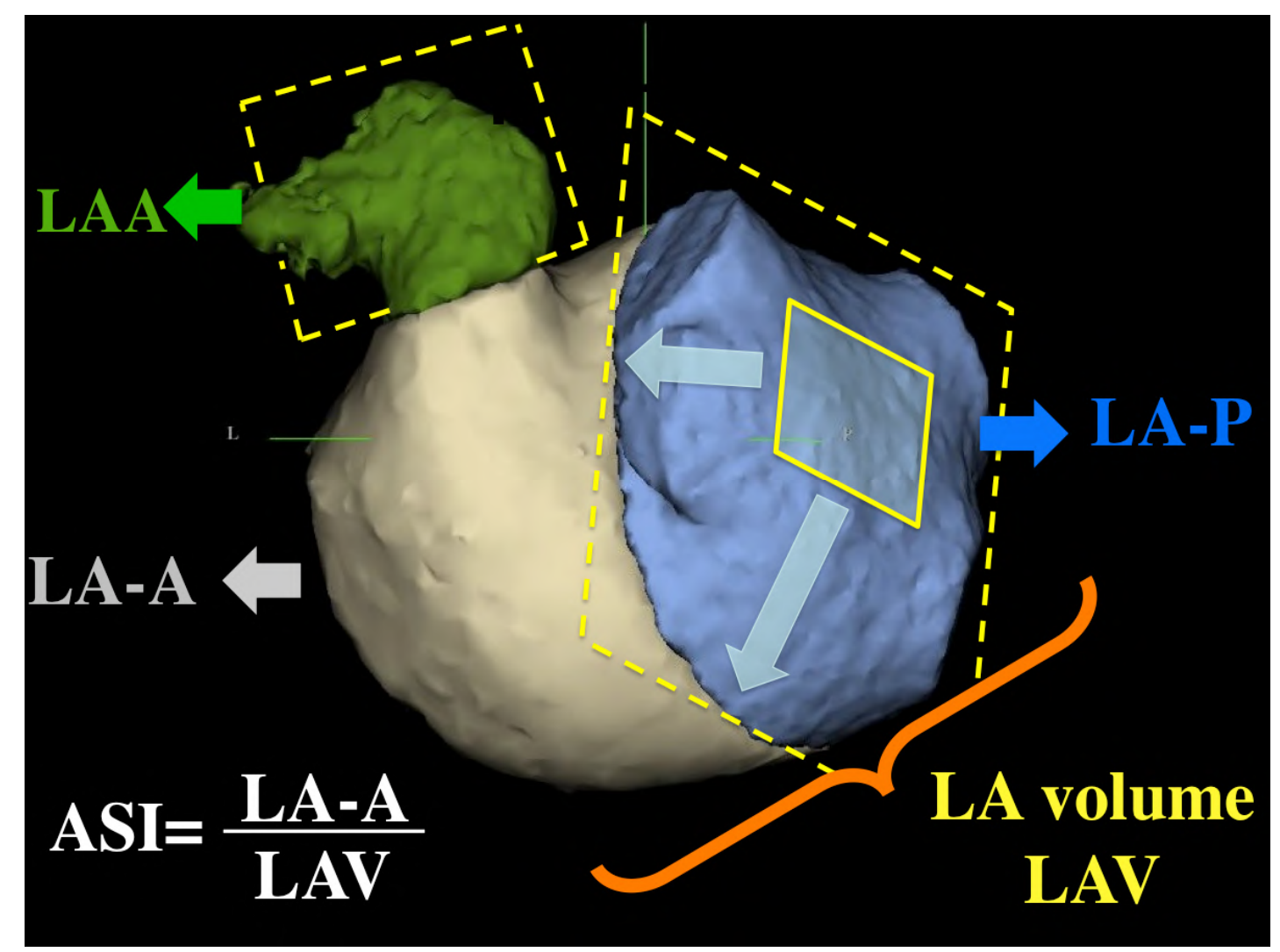

Figure 8.1. The division of LA volume (LAV) into anterior (LA-A) and posterior (LA-P) parts by a cutting plane, between the pulmonary veins and the LA appendage (LAA) and parallel to the posterior wall. The asymmetry index (ASI) equals LA-A/LAV.

\section{Ablation procedure and follow-up}

LA catheter ablation was performed as previously described. ${ }^{5}$ In brief, transseptal access and catheter navigation were performed with a steerable sheath (Agilis, St. Jude Medical, St. Paul, $\mathrm{MN}$, USA) and electroanatomic mapping systems (EnSite ${ }^{\mathrm{TM}} \mathrm{NavX}^{\mathrm{TM}}$, St. Jude Medical; or CARTO $^{\text {TM }}$, Biosense Webster, Diamond Bar, CA, USA), after integration of CT image datasets. 
All patients received circumferential ablation lines around the antrum of the ipsilateral pulmonary veins (irrigated tip catheter, temperature of $\leq 48^{\circ} \mathrm{C}$, power of $20-45 \mathrm{~W}$ ).

Complete pulmonary vein isolation was verified with a multipolar circular mapping catheter. In patients with persistent AF, additional linear lesions were added between the circular lesions, at the mitral isthmus and the posterior LA wall to create a "box" lesion.

Follow-up was performed with regular routine clinical examinations and repeated 7-day-Holter ECG recordings (Lifecard CF, Delmar-Reynolds Medical Inc, Irvine, CA, USA) at 6, 12, 24 and 36 months of follow-up. Recurrence of AF was defined as an ECG documented AF episode or an organised LA macroreentry tachycardia of $\geq 30$ seconds documented in holter ECG.

Episodes occurring during an initial 3-month blanking period after the ablation were not included in the analysis. Class I and III antiarrhythmic drugs were routinely discontinued after catheter ablation. In case of AF recurrence, the antiarrhythmic drugs (AADs) were adapted on an individual basis (preferably previously effective AADs without contraindications or adverse effects). A repeat ablation was based on the completion of lesions applied during the $1^{\text {st }}$ procedure.

\section{Statistical analysis}

Continuous variables are expressed as mean and standard deviation (SD). Categorical variables are reported as frequencies and percentage. Kolmogorov-Smirnoff test was used to analyse the distribution of continuous variables. On that basis, parametric variables were compared by means of paired Student's t-test (for 2 groups) and non-parametric variables by Wilcoxon-test or chisquare test. Intra-observer and inter-observer variability was assessed with Pearson's r-values.

Clinical variables and LA measurements were then evaluated with univariate linear regression analysis to determine their association with LA asymmetry. Variables with $p<0.1$ were included in a forward stepwise multivariate model to determine factors independently associated with ASI increase, their correlation coefficients (B unstandardized, $\beta$ standardized) with $95 \%$ confidence interval $(\mathrm{CI})$. The percentage of ASI variation explained by these factors was expressed by the adjusted $\mathrm{r}^{2}$ and the goodness of fit (F value).

Univariate und multivariate logistic models were used to evaluate the predictors of $\mathrm{AF}$ recurrence. In order to mitigate the effect of collinearity we used different regression models for each of the collinear variables. A two-tailed P-value less than 0.05 was considered statistically significant. Analysis was performed with SPSS 21.0 (SPSS Inc., Chicago, USA).

\section{Results}

The patients' baseline characteristics are summarized in Table 8.1. The majority of patients were males $(69 \%)$ with paroxysmal AF $(67 \%)$, a mean age of $58 \pm 10$ years and a LVEF of $60 \pm 8 \%$. DD was present in 35 patients (33\%), showing grade I in $18(17 \%)$, grade II in $14(13 \%)$, and grade III in $3(3 \%)$ patients.

DD was associated with increased age, $\mathrm{CHADS}_{2}$ and $\mathrm{CHA}_{2} \mathrm{DS}_{2}-\mathrm{VASc}$ scores, LA size and asymmetry (Table 8.1). LA diameter (LAD), LAV and ASI were $42 \pm 6 \mathrm{~mm}, 125 \pm 35 \mathrm{ml}$ and $60 \pm 6 \%$ respectively.

The intra-observer correlation coefficients were $0.92,0.89,0.90$ and 0.92 for the measurement of the LAV, LA-A, LA-P and LAA volumes, respectively. The respective inter-observer values were $0.91,0.89,0.90$ and 0.91 . 
Table 8.1. Patients characteristics in relation to the presence of diastolic dysfunction.

\begin{tabular}{|c|c|c|c|c|c|}
\hline \multirow{2}{*}{ Variables } & \multirow[t]{2}{*}{ Total } & \multicolumn{3}{|c|}{ Diastolic dysfunction } & \multirow[t]{2}{*}{$\mathrm{P}$} \\
\hline & & No & Grade 1 & Grade 2-3 & \\
\hline Numbers of patients, (\%) & 104 & $69(67)$ & $18(17)$ & $17(16)$ & \\
\hline Age, years & $58 \pm 10$ & $56 \pm 9$ & $64 \pm 9$ & $60 \pm 9$ & 0.003 \\
\hline Male, n (\%) & $72(69)$ & $50(73)$ & $13(72)$ & $9(53)$ & 0.28 \\
\hline Body mass index, $\mathrm{kg} / \mathrm{m}^{2}$ & $28 \pm 4$ & $28 \pm 4$ & $29 \pm 4$ & $27 \pm 4$ & 0.14 \\
\hline Persistent atrial fibrillation, $\mathrm{n}(\%)$ & $34(33)$ & $23(33)$ & $4(22)$ & $7(41)$ & 0.48 \\
\hline Hyperlipidemia, n (\%) & $33(32)$ & $21(30)$ & $4(22)$ & $8(47)$ & 0.27 \\
\hline Hypertension, $\mathrm{n}(\%)$ & $56(54)$ & $34(49)$ & $12(67)$ & $10(59)$ & 0.38 \\
\hline Diabetes mellitus, $\mathrm{n}(\%)$ & $17(16)$ & $8(12)$ & $4(22)$ & $5(29)$ & 0.16 \\
\hline Previous stroke/TIA, n (\%) & $3(3)$ & $1(1)$ & $1(6)$ & $1(6)$ & 0.47 \\
\hline Coronary artery disease, $\mathrm{n}(\%)$ & $9(9)$ & $4(6)$ & $2(11)$ & $3(18)$ & 0.27 \\
\hline Dilated cardiomyopathy, n (\%) & $6(6)$ & $4(6)$ & - & $2(12)$ & 0.32 \\
\hline Heart failure, $\mathrm{n}(\%)$ & $6(6)$ & $3(4)$ & $1(6)$ & $2(12)$ & 0.51 \\
\hline NYHA score & $1.2 \pm 1.0$ & $1.0 \pm 1.2$ & $1.2 \pm 0.7$ & $1.3 \pm 0.9$ & 0.66 \\
\hline CHADS $_{2}$ score & $1.2 \pm 1.1$ & $1.0 \pm 1.1$ & $1.8 \pm 1.2$ & $1.5 \pm 1.3$ & 0.03 \\
\hline $\mathrm{CHA}_{2} \mathrm{DS}_{2}$-VASc score & $1.6 \pm 1.4$ & $1.3 \pm 1.2$ & $2.3 \pm 1.3$ & $2.2 \pm 1.8$ & 0.003 \\
\hline \multicolumn{6}{|l|}{ Imaging parameters } \\
\hline LV ejection fraction, $\%$ & $60 \pm 8$ & $61 \pm 6$ & $60 \pm 7$ & $57 \pm 10$ & 0.30 \\
\hline LV ed. diameter, $\mathrm{mm}$ & $48 \pm 6$ & $48 \pm 6$ & $50 \pm 7$ & $49 \pm 9$ & 0.83 \\
\hline LAD by echocardiography, mm & $42 \pm 6$ & $42 \pm 5$ & $45 \pm 7$ & $42 \pm 8$ & 0.16 \\
\hline Mitral regurgitation, $\mathrm{n}(\%)$ & $67(64)$ & $43(62)$ & $6(67)$ & $5(71)$ & 0.79 \\
\hline $\mathrm{E}, \mathrm{cm} / \mathrm{s}$ & $78 \pm 20$ & $79 \pm 15$ & $56 \pm 11$ & $99 \pm 27$ & $<0.001$ \\
\hline $\mathrm{A}, \mathrm{cm} / \mathrm{s}$ & $55 \pm 18$ & $52 \pm 14$ & $70 \pm 15$ & $50 \pm 26$ & 0.001 \\
\hline $\mathrm{E} / \mathrm{A}$ & $1.5 \pm 0.6$ & $1.6 \pm 0.6$ & $0.8 \pm 0.2$ & $1.5 \pm 0.6$ & $<0.001$ \\
\hline $\mathrm{E} / \mathrm{E}^{\prime}$ & $11 \pm 4$ & $7 \pm 2$ & $7 \pm 3$ & $13 \pm 4$ & 0.001 \\
\hline $\mathrm{LAV}^{*}{ }^{*} \mathrm{ml}$ & $125 \pm 35$ & $119 \pm 27$ & $132 \pm 33$ & $142 \pm 47$ & 0.02 \\
\hline LA-A, $*$ ml & $75 \pm 23$ & $70 \pm 18$ & $81 \pm 24$ & $90 \pm 34$ & 0.002 \\
\hline LA-P,* ml & $50 \pm 13$ & $49 \pm 13$ & $51 \pm 11$ & $53 \pm 15$ & 0.43 \\
\hline ASI (LA-A/LAV), $\%$ & $59 \pm 6$ & $59 \pm 6$ & $61 \pm 6$ & $63 \pm 5$ & 0.002 \\
\hline LAA volume, ${ }^{*} \mathrm{ml}$ & $7 \pm 3$ & $7 \pm 3$ & $6 \pm 3$ & $8 \pm 3$ & 0.06 \\
\hline
\end{tabular}

$\mathrm{ASI}=$ asymmetry index; $\mathrm{LA}=$ left atrial; $\mathrm{LAA}=\mathrm{LA}$ appendage; $\mathrm{LA}-\mathrm{A}=$ anterior $\mathrm{LA}$ volume; $\mathrm{LAD}=\mathrm{LA}$ diameter; LA-P= posterior LA volume; LAV= LA volume; $\mathrm{DD}=$ Left Ventricular Diastolic Dysfunction, * by computed tomography. ${ }^{1}$ standardized

\section{Relation of LA asymmetry, dilatation and diastolic dysfunction}

Univariate linear regression revealed that ASI is associated with DD, LAV and mitral regurgitation of 1 st-2nd Grade (Table 8.2). Patients with DD ( $n=35,34 \%)$ had higher ASI $(62 \pm 5 \%$ vs. $59 \pm 6 \%, \mathrm{p}=0.013)$ than those without DD. Patients with mild $(\mathrm{n}=60)$ or moderate $(\mathrm{n}=7)$ mitral regurgitation had higher ASI $(61 \pm 6 \%$ vs. $58 \pm 5 \%, \mathrm{p}=0.025)$ than those with no mitral regurgitation. LAV increase was associated with an ASI increase $(r=0.26, p=0.008)$. Multiple linear regression analysis revealed that $\mathrm{DD}(\mathrm{B}=2.589$ and $\beta=0.207$ standardized, $95 \% \mathrm{CI}$ : $0.167-$ 5.011, $\mathrm{p}=0.036)$ and LAV $(\mathrm{B}=0.037$ and $\beta=0.211$ standardized, 95\% CI: 0.003-0.071, $\mathrm{p}=0.033)$ were independently associated with ASI (adjusted $\mathrm{r}^{2}=0.92, \mathrm{~F}=6.2, \mathrm{p}=0.003$ ). According to the adjusted $\mathrm{r}^{2}$ value, $92 \%$ of the ASI variation could be explained by the LAV increase and the DD presence. 
Table 8.2. Linear regresion analysis for predictors of LA asymmetry (ASI).

\begin{tabular}{|c|c|c|c|c|c|c|}
\hline \multirow[t]{2}{*}{ Variables } & \multicolumn{3}{|c|}{ Univariate } & \multicolumn{3}{|c|}{ Multivariate } \\
\hline & $\beta$ & $95 \% \mathrm{CI}$ & $\mathrm{p}$ & $\beta^{1}$ & $95 \%$ CI & $\mathrm{P}$ \\
\hline Age, years & 0.11 & $0.01-0.23$ & 0.07 & & & \\
\hline Male, n (\%) & 0.34 & $-2.16-2.83$ & 0.79 & & & \\
\hline Body mass index, $\mathrm{kg} / \mathrm{m}^{2}$ & 1.26 & $-4.11-1.59$ & 0.38 & & & \\
\hline Persistent atrial fibrillation, $\mathrm{n}(\%)$ & 1.73 & $-0.70-4.17$ & 0.16 & & & \\
\hline Hyperlipidemia, n (\%) & -0.47 & $-2.96-2.0$ & 0.71 & & & \\
\hline Hypertension, n (\%) & 0.33 & $-1.99-2.64$ & 0.78 & & & \\
\hline Diabetes mellitus, $\mathrm{n}(\%)$ & -1.38 & $-4.49-1.72$ & 0.38 & & & \\
\hline Previous stroke/TIA, n (\%) & 0.05 & $-5.04-8.62$ & 0.59 & & & \\
\hline Coronary artery disease, $\mathrm{n}(\%)$ & -1.65 & $-5.75-2.44$ & 0.42 & & & \\
\hline Dilated cardiomyopathy, n (\%) & 1.77 & $-3.16-6.72$ & 0.48 & & & \\
\hline Heart failure, $\mathrm{n}(\%)$ & 2.74 & $-2.18-7.67$ & 0.27 & & & \\
\hline NYHA score & 0.1 & $-1.01-1.2$ & 0.97 & & & \\
\hline CHADS $_{2}$ score & -0.1 & $-1.02-1.0$ & 0.98 & & & \\
\hline $\mathrm{CHA}_{2} \mathrm{DS}_{2}$-VASc score & 0.8 & $-0.47-1.2$ & 0.38 & & & \\
\hline \multicolumn{7}{|l|}{ Imaging parameters } \\
\hline LV ejection fraction, $\%$ & -0.12 & $-0.35-0.11$ & 0.28 & & & \\
\hline LV ed. diameter, $\mathrm{mm}$ & 0.04 & $-0.4-0.32$ & 0.81 & & & \\
\hline LAD by echocardiography, mm & 0.04 & $-0.15-0.24$ & 0.65 & & & \\
\hline Mitral regurgitation, $\mathrm{n}(\%)$ & 2.71 & $0.35-5.06$ & 0.025 & & & \\
\hline LV diastolic dysfunction, $\mathrm{n}(\%)$ & 3.02 & $0.65-5.39$ & 0.013 & 0.207 & $0.167-5.011$ & 0.036 \\
\hline $\mathrm{E}, \mathrm{cm} / \mathrm{s}$ & 0.03 & $-0.03-0.82$ & 0.37 & & & \\
\hline $\mathrm{A}, \mathrm{cm} / \mathrm{s}$ & 0.01 & $-0.07-0.06$ & 0.99 & & & \\
\hline $\mathrm{E} / \mathrm{A}$ & 0.33 & $-1.57-2.24$ & 0.73 & & & \\
\hline $\mathrm{E} / \mathrm{E}^{\prime}$ & 0.33 & $-0.24-0.92$ & 0.24 & & & \\
\hline $\mathrm{LAV}, * \mathrm{ml}$ & 0.05 & $0.01-0.08$ & 0.008 & 0.211 & $0.003-0.071$ & 0.033 \\
\hline LA-A, ${ }^{*} \mathrm{ml}$ & 0.13 & $0.09-0.18$ & $<0.001$ & & & \\
\hline LA-P,* ml & 0.12 & $0.2-0.031$ & 0.008 & & & \\
\hline LAA volume, ${ }^{*} \mathrm{ml}$ & 0.48 & $0.12-0.85$ & 0.01 & & & \\
\hline
\end{tabular}

$\mathrm{ASI}=$ asymmetry index; $\mathrm{LA}=$ left atrial; $\mathrm{LAA}=\mathrm{LA}$ appendage; $\mathrm{LA}-\mathrm{A}=$ anterior $\mathrm{LA}$ volume; $\mathrm{LAD}=\mathrm{LA}$ diameter; LA-P= posterior LA volume; LAV = LA volume; LV $=$ Left Ventricular, * by $\mathrm{CT}^{1}{ }^{1}$ standardized

\section{Predictors of AF recurrence}

After a median of 24 months and 35 repeat-procedures, 34 patients $(33 \%)$ experienced an AF recurrence. Repeat ablation and AAD use was similar between groups (Table 8.3). In univariate analysis persistent AF, heart failure, LA diameter, LA volumes and LA asymmetry (ASI) were associated with AF recurrence, while other clinical or echocardiographic variables were not. Multivariate regression analysis (MV1) including all the above parameters in the total cohort revealed LA-A as the only independent predictor of AF recurrence (OR 1.033 per $1 \mathrm{ml}, 95 \% \mathrm{CI}$ 1.009-1.057, $\mathrm{P}=0.006$ ). Collinearity diagnostics revealed that LA volumes are strongly associated with ASI (variance inflation factor $>2.5$ ). In order to mitigate this effect we used different regression models. A regression model without ASI (MV2) confirmed the importance of LA-A as an independent predictive factor. A regression model (MV3) without the LA volumes revealed ASI (OR 1.117 per 1\%, 95\% CI 1.026-1.216, $\mathrm{P}=0.011$ ) as the only independent predictor of AF recurrence. A subanalysis in patients with persistent AF (M4) showed that ASI is 
the only recurrence predictor (OR 1.346 per $1 \%, 95 \%$ CI $1.056-1.715, \mathrm{P}=0.016$ ), even when the volumes are included in the model. The presence or the grade of diastolic dysfunction was not found to be associated with procedural success. Patients with high DD showed a tendency for increased AF recurrence ( $53 \%$ vs. $29 \%, p=0.09$ ), but did not significantly change our findings.

Table 8.3 Clinical and imaging variables in patients with and without AF recurrence

\begin{tabular}{|c|c|c|c|}
\hline \multirow[t]{2}{*}{ Variables } & \multicolumn{2}{|c|}{$\mathrm{AF}$ recurrence } & \multirow[t]{2}{*}{$\mathrm{P}$} \\
\hline & No & Yes & \\
\hline Number, n (\%) & $70(67)$ & $34(33)$ & \\
\hline Age, years & $59 \pm 9$ & $57 \pm 10$ & 0.27 \\
\hline Male, n (\%) & $48(69)$ & $24(71)$ & 1.00 \\
\hline Body mass index, $\mathrm{kg} / \mathrm{m}^{2}$ & $28 \pm 4$ & $28 \pm 4$ & 0.77 \\
\hline Atrial fibrillation type, paroxysmal, n (\%) & $52(74)$ & $18(53)$ & 0.044 \\
\hline Hyperlipidemia, n (\%) & $22(31)$ & $11(32)$ & 1.00 \\
\hline Hypertension, n (\%) & $35(50)$ & $21(62)$ & 0.75 \\
\hline Diabetes mellitus, $\mathrm{n}(\%)$ & $13(19)$ & $4(12)$ & 0.57 \\
\hline Previous stroke/TIA, n (\%) & $2(3)$ & $1(3)$ & 1.00 \\
\hline Coronary artery disease, $\mathrm{n}(\%)$ & $7(10)$ & $2(6)$ & 0.71 \\
\hline Dilated cardiomyopathy, n (\%) & $3(4)$ & $3(9)$ & 0.39 \\
\hline Heart failure, $\mathrm{n}(\%)$ & $2(3)$ & $4(12)$ & 0.09 \\
\hline NYHA score & $1.2 \pm 0.9$ & $1.2 \pm 1.1$ & 0.45 \\
\hline $\mathrm{CHADS}_{2}$ score & $1.3 \pm 1.2$ & $1.2 \pm 1.1$ & 0.83 \\
\hline \multicolumn{4}{|l|}{ Imaging parameters } \\
\hline LV ejection fraction, $\%$ & $62 \pm 6$ & $58 \pm 11$ & 0.17 \\
\hline LV ed. diameter, $\mathrm{mm}$ & $48 \pm 6$ & $49 \pm 5$ & 0.76 \\
\hline LAD by echocardiography, mm & $42 \pm 5$ & $44 \pm 7$ & 0.08 \\
\hline Mitral regurgitation, $\mathrm{n}(\%)$ & $43(61)$ & $24(71)$ & 0.39 \\
\hline LV diastolic dysfunction, $\mathrm{n}(\%)$ & $23(33)$ & $12(35)$ & 0.82 \\
\hline $\mathrm{E}, \mathrm{cm} / \mathrm{s}$ & $76 \pm 20$ & $81 \pm 23$ & 0.25 \\
\hline $\mathrm{A}, \mathrm{cm} / \mathrm{s}$ & $56 \pm 17$ & $53 \pm 20$ & 0.57 \\
\hline $\mathrm{E} / \mathrm{A}$ & $1.5 \pm 0.6$ & $1.6 \pm 0.7$ & 0.41 \\
\hline $\mathrm{E} / \mathrm{E}^{\prime}$ & $9 \pm 4$ & $13 \pm 5$ & 0.11 \\
\hline $\mathrm{LAV}, * \mathrm{ml}$ & $118 \pm 28$ & $139 \pm 39$ & 0.002 \\
\hline LA-A,* ml & $70 \pm 19$ & $86 \pm 27$ & 0.003 \\
\hline LA-P, ${ }^{*} \mathrm{ml}$ & $48 \pm 13$ & $53 \pm 14$ & 0.099 \\
\hline ASI (100*LA-A/LAV), $\%$ & $58 \pm 5$ & $62 \pm 5$ & 0.002 \\
\hline LAA volume, ${ }^{*} \mathrm{ml}$ & $7 \pm 3$ & $8 \pm 3$ & 0.16 \\
\hline \multicolumn{4}{|l|}{ Procedural data } \\
\hline Procedure time, $\min$ & $160 \pm 54$ & $171 \pm 44$ & 0.32 \\
\hline Fluoroscopy time, $\min$ & $36 \pm 15$ & $38 \pm 19$ & 0.41 \\
\hline Fluoroscopy dose, $\mathrm{cGy}^{*} \mathrm{~cm}^{2}$ & $1.5 \pm 1.1$ & $1.9 \pm 2.0$ & 0.38 \\
\hline Ablation time, $\min$ & $52 \pm 24$ & $61 \pm 24$ & 0.09 \\
\hline Follow-up time, months & $26 \pm 17$ & $30 \pm 16$ & 0.15 \\
\hline Amiodarone/ sotalol/ flecainid use, n (\%) & $3(4) / 1(1) / 1(1)$ & $2(6) / 0 / 1(3)$ & 0.53 \\
\hline Reablation, $\mathrm{n}(\%)$ & $21(30)$ & $14(41)$ & 0.28 \\
\hline - pulmonary vein isolation, n (\%) & $12(57)$ & $9(64)$ & 0.73 \\
\hline - additional lesions, $\mathrm{n}(\%)$ & $9(43)$ & $5(36)$ & \\
\hline
\end{tabular}

$\mathrm{ASI}=$ asymmetry index; $\mathrm{LA}=$ left atrial; $\mathrm{LAA}=\mathrm{LA}$ appendage; $\mathrm{LA}-\mathrm{A}=$ anterior $\mathrm{LA}$ volume; $\mathrm{LAD}=\mathrm{LA}$ diameter; LA-P= posterior LA volume; LAV $=$ LA volume; $\mathrm{LV}=$ left ventricular, * by CT 


\section{Main findings}

\section{Discussion}

We studied the changes of LA shape in relation to LA enlargement and left ventricular diastolic dysfunction as well as their relation to ablation outcomes in 104 patients. Systematic evaluation of LA shape through an asymmetry index allowed us to carefully assess the impact of DD on anatomical LA remodeling. We found that LA symmetry changes are associated with LA dilatation and diastolic dysfunction and that increased asymmetry is associated with reduced success after AF ablation. Interestingly, diastolic dysfunction was not associated with AF recurrences. These findings add to our knowledge by clarifying the association between increased LV filling pressures and LA remodeling. This may help to develop future strategies to prevent advanced LA changes or improve AF therapy by better and earlier selection of patients.

\section{Atrial remodeling and diastolic dysfunction}

The prevalence of diastolic dysfunction (DD 34\%) in our study population of symptomatic AF patients was similar to previously published data on AF patient populations. ${ }^{6}$

The present data supplement previous findings reporting on the multifactorial origin of LA remodeling and provide a more complete analysis of the interaction between LA changes and LV diastolic dysfunction. ${ }^{4,5}$ Since both the left atrium and the left ventricle are intricately coupled, DD has a direct negative impact on the left atrium. During LV systole, the LA functions as a passive reservoir, depending on LV systolic function and its own relaxation properties. During diastole the LA is under the direct influence of LV diastolic pressure through the open mitral valve. ${ }^{7}$ Therefore, a higher LA afterload due to increased LV stiffness or decreased relaxation translates into higher LA pressure with reduced LA emptying and finally atrial dilatation, all contributing significantly to the increased risk for $\mathrm{AF}^{8}$

Previous studies have shown that in older patients with non-valvular AF, DD leads to LA dilatation. ${ }^{9-11}$ This atrial remodeling process in the presence of DD is associated with electromechanical delay in hypertensive patients, ${ }^{12}$ decreased LA-wall endomyocardial voltages and worse outcomes after AF catheter ablation. ${ }^{13}$ Our results supplement these findings and reveal that DD is associated with a specific, asymmetric pattern of LA remodeling (Figure 8.2). In the early phase of AF, the LA geometry including the symmetry between the anterior and the posterior parts of the LA is still preserved and the region around the pulmonary vein ostia is the main target region for ablation therapy. Later, with progression of the disease asymmetric LA dilatation develops and more substrate is found in the anterior and septal parts of the LA. This asymmetric dilatation reflects the anatomical constraints ${ }^{14}$ and the changing LA wall properties. ${ }^{15,16}$ ASI is a surrogate of this remodeling process and correlates with reduced success after AF ablation (especially in persistent AF), better than DD or LAV alone.

Although diastolic dysfunction (DD) was not an independent predictor for AF recurrence in our analysis, it was clearly associated with LA remodeling. This association is confounded by evidence of reverse remodeling after DD improvement through improved blood pressure treatment or successful rhythm control therapy. ${ }^{17}$ Cha at al. ${ }^{18}$ described DD improvement in 30\% of these patients while Reant at al. ${ }^{19}$ demonstrated reversal of LA remodeling and LV-EF improvement after sinus rhythm restoration. Similar results of reverse LA and LV remodeling were published for patients undergoing surgical radiofrequency ablation. ${ }^{20}$ Accordingly, LV dysfunction was partially attributed to AF. Therefore, LA ablation therapy may achieve both improvement in DD and elimination of AF and stop this vicious circle of LA remodeling. 


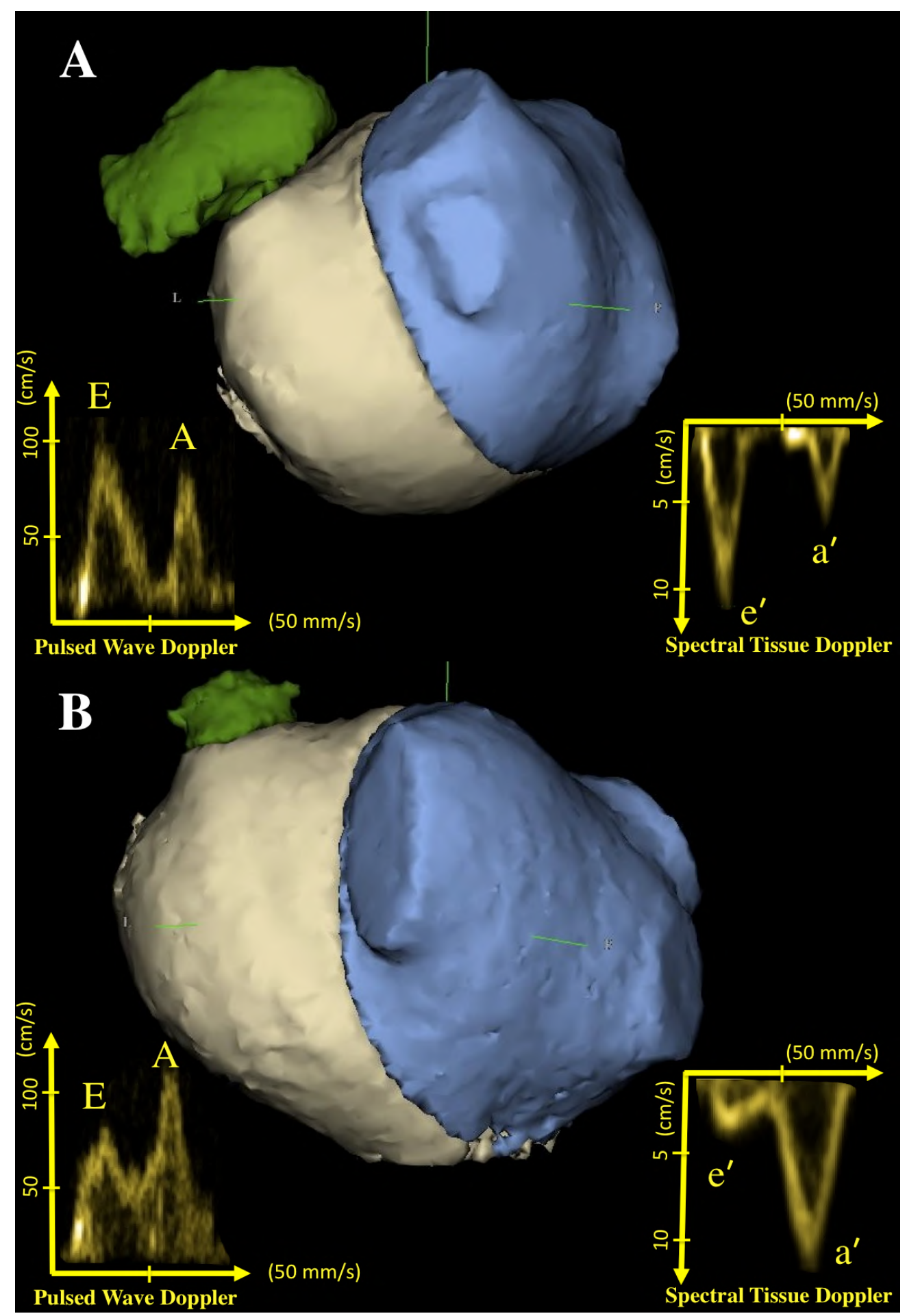

Figure 8.2. Left atrial (LA) asymmetry index (ASI) in a) a patient without and b) a patient with left ventricular diastolic dysfunction seen in the pulsed wave and spectral tissue Doppler. White represents the anterior (LA-A), blue the posterior volume of LA and green the appendage. a) LAV 124 ml, LA-A 72 ml, ASI 58\%; b) LAV 230 ml, LA-A 147 ml, ASI 64\% 


\section{Clinical implications}

The present findings emphasize the pathophysiological importance of diastolic dysfunction on LA remodeling. Despite the significant effect of diastolic dysfunction (DD) on asymmetric LA changes, DD was not an independent predictor for AF recurrence in our analysis. In line with previously published data, we found that LA remodeling is better than DD as a predictor of ablation outcomes. Therefore, appropriate medical treatment and more aggressive rhythm control should be considered early for patients with DD, before advanced LA symmetry changes occur.

\section{Limitations}

This is a post-hoc analysis of symptomatic AF patients referred for an ablative treatment. In order to evaluate the diastolic dysfunction, we enrolled patients with complete echocardiographic exams within 14 days after restoration of sinus rhythm. In order to avoid the effect of stimulation on the DD patients with pacemakers/defibrillators were excluded. For that purpose we had to recruit data from more patients $(n=69)$, different than in our previous studies. ${ }^{4,5}$ The quality of rate control during AF episodes was not available and thus the effects of ventricular rate during AF on DD could not be evaluated. Moreover, the effect of atrial stunning (lack of mechanical activity) after rhythm restoration could not be measured. However, since the presence of DD was associated with asymmetry changes a larger number of patients may have shown an association with AF recurrence, but in the present study this did not reach statistical significance. Additionally, the collinearity of parameters did not affect the DD and was limited by the use of different regression models, which all pointed out the importance of LA asymmetry. Calculation of ASI required radiation exposure and contrast injection, which prohibited follow-up studies that could reveal the effect of ablation on LA asymmetry. However, diastolic dysfunction (by echocardiography) and ASI (by CT) are parameters that could be obtained prior to AF-ablation and since newer techniques, such as magnetic-resonance tomography or 3D echocardiography are entering the clinical routine, they could potentially provide this information with less radiation in the future. In summary, our findings may be viewed as hypothesis generating and outline the need for further studies.

\section{Conclusions}

There is a specific pattern of LA asymmetry changes that is mainly associated with dilatation and diastolic dysfunction. Although diastolic dysfunction correlates to these changes it does not predict recurrence after AF ablation. Therefore, appropriate early treatment should be considered for AF patients with $\mathrm{DD}$, before LA symmetry changes progress.

Conflict of interest: None declared. 


\section{References:}

1. Nedios S, Tang M, Roser M, Solowjowa N, Gerds-Li JH, Fleck E, Kriatselis C. Characteristic changes of volume and three-dimensional structure of the left atrium in different forms of atrial fibrillation: predictive value after ablative treatment. J Interv Card Electrophysiol Nov 2011;32:87-94.

2. Bisbal F, Guiu E, Cabanas P, Calvo N, Berruezo A, Tolosana JM, Arbelo E, Vidal B, de Caralt TM, Sitges M, Brugada J, Mont L. Reversal of spherical remodelling of the left atrium after pulmonary vein isolation: incidence and predictors. Europace Jun 2014;16:840-847.

3. Kurotobi T, Iwakura K, Inoue K, Kimura R, Toyoshima Y, Ito N, Mizuno H, Shimada Y, Fujii K, Nanto S, Komuro I. The significance of the shape of the left atrial roof as a novel index for determining the electrophysiological and structural characteristics in patients with atrial fibrillation. Europace Jun 2011;13:803-808.

4. Nedios S, Koutalas E, Kosiuk J, Sommer P, Arya A, Richter S, Rolf S, Husser D, Hindricks G, Bollmann A. Impact of asymmetrical dilatation of the left atrium on the long-term success after catheter ablation of atrial fibrillation. Int J Cardiol Apr 1 2015;184:315-317.

5. Nedios S, Kosiuk J, Koutalas E, Kornej J, Sommer P, Arya A, Richter S, Rolf S, Husser D, Hindricks G, Bollmann A. Comparison of left atrial dimensions in CT and echocardiography as predictors of long-term success after catheter ablation of atrial fibrillation. J Interv Card Electrophysiol Sep 2015;43:237-244.

6. Kosiuk J, Van Belle Y, Bode K, Kornej J, Arya A, Rolf S, Husser D, Hindricks G, Bollmann A. Left ventricular diastolic dysfunction in atrial fibrillation: predictors and relation with symptom severity. Journal of cardiovascular electrophysiology Oct 2012;23:1073-1077.

7. Tsang TS, Barnes ME, Gersh BJ, Bailey KR, Seward JB. Left atrial volume as a morphophysiologic expression of left ventricular diastolic dysfunction and relation to cardiovascular risk burden. Am J Cardiol Dec 15 2002;90:1284-1289.

8. Tsang TS, Gersh BJ, Appleton CP, Tajik AJ, Barnes ME, Bailey KR, Oh JK, Leibson C, Montgomery SC, Seward JB. Left ventricular diastolic dysfunction as a predictor of the first diagnosed nonvalvular atrial fibrillation in 840 elderly men and women. J Am Coll Cardiol Nov 6 2002;40:1636-1644.

9. Lee JS, Shim CY, Wi J, Joung B, Ha JW, Lee MH, Pak HN. Left ventricular diastolic function is closely associated with mechanical function of the left atrium in patients with paroxysmal atrial fibrillation. Circ J 2013;77:697-704.

10. El Aouar LM, Meyerfreud D, Magalhaes P, Rodrigues SL, Baldo MP, Brasil Y, El Aouar SM, El Aouar NA, Mill JG, Campos Filho O. Relationship between left atrial volume and diastolic dysfunction in 500 Brazilian patients. Arq Bras Cardiol Jul 2013;101:52-58.

11. Pritchett AM, Mahoney DW, Jacobsen SJ, Rodeheffer RJ, Karon BL, Redfield MM. Diastolic dysfunction and left atrial volume: a population-based study. J Am Coll Cardiol Jan 4 2005;45:87-92.

12. Yavuz B, Deniz A, Ertugrul DT, Deveci OS, Yalcin AA, Ata N, Kucukazman M, Dal K, Tutal E. A novel echocardiographic marker in hypertensive patients: is diastolic dysfunction associated with atrial electromechanical abnormalities in hypertension? J Clin Hypertens (Greenwich) Sep 2010;12:687-692.

13. Hu YF, Hsu TL, Yu WC, et al. The impact of diastolic dysfunction on the atrial substrate properties and outcome of catheter ablation in patients with paroxysmal atrial fibrillation. Circ J Oct 2010;74:2074-2078.

14. Hoffmeister PS, Chaudhry GM, Mendel J, Almasry I, Tahir S, Marchese T, Haffajee CI, Orlov MV. Evaluation of left atrial and posterior mediastinal anatomy by multidetector 
helical computed tomography imaging: relevance to ablation. J Interv Card Electrophysiol Apr 2007;18:217-223.

15. Nakamura K, Funabashi N, Uehara M, Ueda M, Murayama T, Takaoka H, Komuro I. Left atrial wall thickness in paroxysmal atrial fibrillation by multislice-CT is initial marker of structural remodeling and predictor of transition from paroxysmal to chronic form. Int $\mathrm{J}$ Cardiol Apr 14 2011;148:139-147.

16. Roberts-Thomson KC, Stevenson I, Kistler PM, Haqqani HM, Spence SJ, Goldblatt JC, Sanders P, Kalman JM. The role of chronic atrial stretch and atrial fibrillation on posterior left atrial wall conduction. Heart Rhythm Aug 2009;6:1109-1117.

17. Tsai CT, Hwang JJ, Shih YC, Chiang FT, Lai LP, Lin JL. Evolution of left atrial systolic and diastolic functions in different stages of hypertension: distinct effects of blood pressure control. Cardiology 2008;109:180-187.

18. Cha YM, Wokhlu A, Asirvatham SJ, et al. Success of ablation for atrial fibrillation in isolated left ventricular diastolic dysfunction: a comparison to systolic dysfunction and normal ventricular function. Circ Arrhythm Electrophysiol Oct 2011;4:724-732.

19. Reant P, Lafitte S, Jais P, Serri K, Weerasooriya R, Hocini M, Pillois X, Clementy J, Haissaguerre M, Roudaut R. Reverse remodeling of the left cardiac chambers after catheter ablation after 1 year in a series of patients with isolated atrial fibrillation. Circulation Nov 8 2005;112:2896-2903.

20. Onorati F, Bilotta M, Borrello F, Vatrano M, di Virgilio A, Comi MC, Perticone F, Renzulli A. Successful radiofrequency ablation determines atrio-ventricular remodelling and improves systo-diastolic function at tissue Doppler-imaging. Eur J Cardiothorac Surg Mar 2007;31:414-421; discussion 421-412. 



\section{Chapter 9 Atrial remodeling and plasma markers}

Adapted from "Association between peripheral plasma markers and left atrial anatomy in patients with atrial fibrillation"

Published in Int J Cardiol. 2016 Jan 15;203:621-3. doi: 10.1016/j.ijcard.2015.11.022

Sotirios Nedios, Timm Seewöster, Gregory Y.H. Lipb, Daniela Hussera, Gerhard Hindricks, Andreas Bollmann, Jelena Kornej 


\begin{abstract}
Background:

Left atrial (LA) dilatation on the coronal plane measured by the transversal LA diameter (LATV) is associated with atrial fibrillation (AF) recurrence after catheter ablation, better than the echocardiographic LA diameter. Pro-inflammatory plasma markers are also associated with AF recurrences. Aim of this study was to evaluate the association between LA size parameters and peripheral plasma markers.
\end{abstract}

\title{
Methods:
}

In 51 patients referred for AF ablation undergoing pre-procedural computed tomography (CT), LA volume (LAV) was determined after exclusion of the atrial appendage (LAA) and the pulmonary veins (PV). LA was then centered on all three cutting planes and the superior-inferior (SI), transversal (TV) and anterior-posterior (AP) diameters were measured. High sensitive interleukin 6 (hsIL-6) was analyzed from pre-procedural blood samples using a commercially available assay. Parameters with a p-value $<0.1$ in the univariable analysis (UV), were introduced in multivariable analyses (MV) in order to identify with hsIL-6 levels independently associated parameters. A two-tailed $\mathrm{p}$ value $<0.05$ was considered significant.

\section{Results:}

There was a significant correlation between peripheral hsIL-6 and LA-TV $\left(\mathrm{r}^{2}=0.34, \mathrm{p}=0.017\right)$ but not with LAV ( $p=$ N.S.). On univariable analysis, advanced age, higher BMI and lower eGFR as well as left atrial dimensions e.g. LA-AP, LA-TV and LAD (but not LAV) - were significantly associated with hsIL-6 levels. On multivariable analysis, the levels of hsIL-6 remained associated with age $\left(\mathrm{r}^{2}=0.28, \mathrm{p}=0.029\right)$, BMI $\quad\left(\mathrm{r}^{2}=0.33, \mathrm{p}=0.011\right)$, renal dysfunction $\quad(\mathrm{eGFR}<60$ $\left.\mathrm{ml} / \mathrm{min} / 1,73 \mathrm{~m}^{2}, \mathrm{r}^{2}=0.29, \mathrm{p}=0.019\right)$, and LA-TV $\left(\mathrm{r}^{2}=0.38, \mathrm{p}=0.012\right)$ but not with LAD or LA-AP.

\section{Conclusions:}

The levels of hsIL-6 are associated with age, BMI, renal dysfunction and LA-TV but not with LAD or LA-AP. These findings point out the potential importance and scientific prominence of inflammation state in patients with AF. Further studies are needed to examine the practical implications of hsIL-6 or LA measurements for better patient selection and treatment strategy in early or advanced AF stages. 


\section{Introduction}

Left atrial (LA) size has been associated with cardiovascular outcomes and the success of different therapy strategies in patients with atrial fibrillation (AF). ${ }^{1,2}$ The assessment of LA is therefore recommended in the clinical routine in all AF patients. ${ }^{3}$ There are several imaging modalities to assess the LA, though echocardiography is widely available and thus the most frequently used. However, the echocardiographic LA diameter (LA-D) does not reliably reflect the true size of LA anatomy, as pathological LA is often enlarged asymmetrically during AF progression. ${ }^{4-6}$

Computer tomography $(\mathrm{CT})$ is a modality that has been increasingly used to obtain threedimensional (3D) images prior to AF catheter ablation. This provided new insights on the LA shape and volume, which have been proven to be better predictors of AF recurrences after LA ablation in comparison to the commonly used anterior-posterior LA diameter. ${ }^{4-6}$ Recently we demonstrated that LA dilatation is more pronounced on the coronal plane, as represented by the transversal LA diameter (LA-TV) ${ }^{7}$. Furthermore, LA-TV was associated with AF recurrences and remained stronger predictor for rhythm outcomes compared with the echocardiographic LA diameter. We also demonstrated strong association between pro-inflammatory plasma markers and AF recurrences. ${ }^{8,9}$ However, whether LA size parameters are associated with peripheral plasma markers of inflammation is unknown.

\section{Patients and measurements}

\section{Methods}

Consequently, the present study (approved by the ethics committee) recruited 51 consecutive patients (Table 9.1) presenting for their first AF catheter ablation at Heart Center Leipzig. All patients gave informed consent according to institutional guidelines and the Declaration of Helsinki. Echocardiography and cardiac-CT with a multidetector 64-row helical system (Brilliance 64, Philips, Best, Netherlands) were performed ( $2 \pm 1$ days) before the procedure. CT data were reviewed using 3D reconstruction (EnSite Verismo, SJM, MN) and LA volume (LAV) was determined after exclusion of the atrial appendage (LAA) and the pulmonary veins (PV). LA was then centered on all three cutting planes and the superior-inferior (SI), transversal (TV) and anterior-posterior (AP) diameters were measured. Measurements were performed offline by an experienced observer and were repeated 4 weeks later by the same investigator and a second blinded reviewer. High sensitive interleukin 6 (hsIL-6) was analyzed from pre-procedural blood samples using a commercially available assay.

\footnotetext{
Ablation procedure and follow-up

Catheter ablation was performed as previously described ${ }^{10}$, with circumferential ablation of the ipsilateral pulmonary veins, verified with a multipolar circular catheter. In patients with persistent $\mathrm{AF}$, additional linear lesions were added at the mitral isthmus and the posterior LA wall to create a "box" lesion. Follow-up was performed with repeated 7-day-Holter ECG recordings at 6, 12, 24 and 36 months. Recurrence was defined as any documented atrial tachycardia or fibrillation episodes of $\geq 30 \mathrm{~s}$ (after a 3 month blanking period).

\section{Statistical analysis}

Statistical analyses were performed with SPSS 17 (SPSS Inc., Chicago, USA). Parameters with a p-value $<0.1$ in the univariable analysis (UV), were introduced in multivariable analyses (MV) in order to identify with hsIL-6 levels independently associated parameters. A two-tailed $p$ value $<0.05$ was considered significant.
} 
Table 9.1. Baseline characteristics of the study population

\begin{tabular}{|l|c|}
\hline Variables & Study patients \\
\hline Age, years & $62 \pm 10$ \\
\hline Females, $\mathrm{n}(\%)$ & $37 \%$ \\
\hline Persistent atrial fibrillation (AF), $\mathrm{n}(\%)$ & $59 \%$ \\
\hline Body Mass Index (BMI), kg/cm2 & $30 \pm 4.6$ \\
\hline estimated glomerular filtration rate (eGFR), $\mathrm{ml} / \mathrm{min} / 1.73 \mathrm{~m}^{2}$ & $98 \pm 30$ \\
\hline Hypertension, $\mathrm{n}(\%)$ & $88 \%$ \\
\hline Diabetes mellitus, $\mathrm{n}(\%)$ & $18 \%$ \\
\hline CHA ${ }_{2} \mathrm{DS}{ }_{2}$-VASs score, $\mathrm{n}$ (interquartile range, IQR) & $2(2-3)$ \\
\hline LA diameter, mm (Echo) & $44 \pm 6.5$ \\
\hline LV-EF, ejection fraction, $\%$ & $57 \pm 11$ \\
\hline LA-TV, transversal, mm by computed tomography & $77 \pm 11$ \\
\hline LA-SI, supero-inferior, mm by computed tomography & $64 \pm 8$ \\
\hline LA-AP, antero-posterior, mm by computed tomography & $51 \pm 12$ \\
\hline LA-V, volume, ml by computed tomography & $141 \pm 50$ \\
\hline high sensitive interleukin 6 (hsIL-6), ng/ml (IQR) & $1.6(0.9-2.9)$ \\
\hline
\end{tabular}

\section{Results}

The clinical characteristics of the study population are presented in Table 9.1. The intra- and inter-observer correlation coefficients were $\geq 0.88$. We found a significant correlation between peripheral hsIL-6 and LA-TV $\left(r^{2}=0.34, p=0.017\right)$ but not with LAV ( $p=N$.S., Figure 9.1). On univariable analysis, advanced age, higher BMI and lower eGFR as well as left atrial dimensions - e.g. LA-AP, LA-TV and LAD (but not LAV) - were significantly associated with hsIL-6 levels. On multivariable analysis, the levels of hsIL- 6 remained associated with age $\left(\mathrm{r}^{2}=0.28\right.$, $\mathrm{p}=0.029)$, BMI $\left(\mathrm{r}^{2}=0.33, \mathrm{p}=0.011\right)$, renal dysfunction $\left(\mathrm{eGFR}<60 \mathrm{ml} / \mathrm{min} / 1,73 \mathrm{~m}^{2}, \mathrm{r}^{2}=0.29\right.$, $\mathrm{p}=0.019)$, and LA-TV $\left(\mathrm{r}^{2}=0.38, \mathrm{p}=0.012\right)$ but not with LAD or LA-AP.

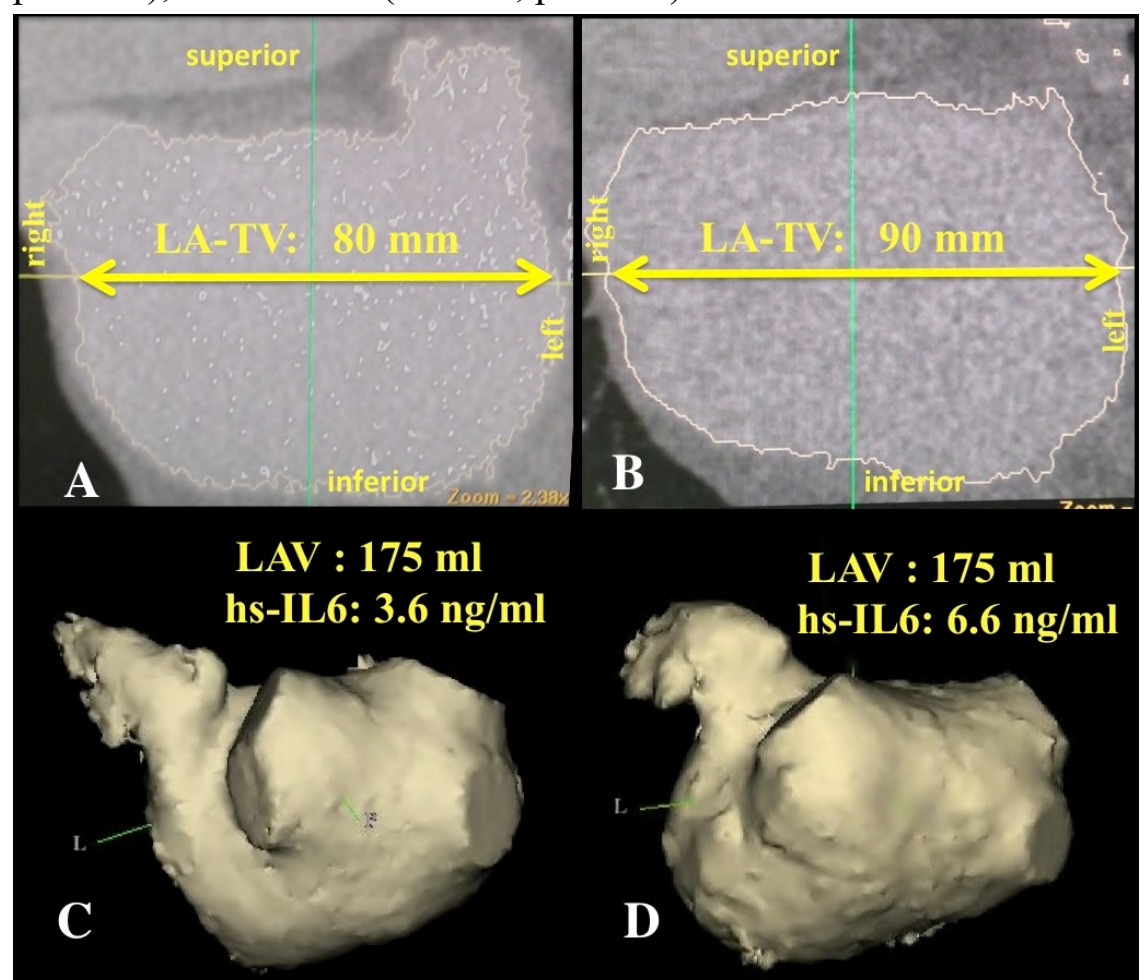

Figure 9.1. Left atrial (LA) parameters and high sensitive interleukin 6 (hsIL-6) of two patients with the same LA volume. Anatomical changes on the coronal plane (bigger transversal diameter, LATV) are associated with higher values of hsIL-6 (B, D). 


\section{Discussion}

Both electrical-anatomical remodeling and inflammation are known factors in AF pathogenesis. The present study demonstrates a significant association between different left atrial measurements and peripheral pro-inflammatory markers and adds to our understanding about the remodeling processes in patients with AF. The role of inflammation in AF pathogenesis is a wellknown factor. Pro-inflammatory reactions may modulate the treatment success and, as previously demonstrated by our group, positively correlate with $\mathrm{AF}$ recurrences after radiofrequency catheter ablation ${ }^{8,9}$. Recently, we also showed that anatomical LA changes cary a predictive value that is better represented with LA-TV or LAV than with the commonly used LAD ${ }^{7}$. The present data extend these studies and reveal the strong correlation between the plasma marker hsIL-6 and the anatomical atrial remodeling, as represented by the transversal (LA-TV) and not just the global (LAV) dilatation. These findings link pro-inflammatory changes with the left atrial remodeling and emphasize the close relationship between these important $\mathrm{AF}$ co-variables.

The small size of this study cohort and the limitations (loss) of follow-up prohibited further analysis of the impact of LA remodeling and hsIL-6 on ablation outcomes. The use of CT for the measurement of LA-TV prohibits its use in repeated routine follow-up studies, but since newer techniques, such as magnetic resonance imaging or 3D echocardiography, are becoming more widely available, soon this information could be assessed with no radiation.

\section{Conclusion}

These findings should be seen as hypothesis generating and point out the potential importance and scientific prominence of inflammation state in patients with AF. Certainly, larger clinical studies are needed to examine the practical implications of hsIL-6 or LA measurements for better patient selection and treatment strategy in early or advanced AF stages. Since a pro-inflammatory state is associated with anatomical LA remodeling, it remains to be examined whether AF patients might profit from anti-inflammatory treatment during or after invasive treatment.

Conflict of interest: None.

\section{Disclosure:}

Dr. Kornej was supported by the German Cardiac Society St. Jude Medical Stipend. 


\section{References}

1. Berruezo A, Tamborero D, Mont L, Benito B, Tolosana JM, Sitges M, Vidal B, Arriagada G, Mendez F, Matiello M, Molina I, Brugada J. Pre-procedural predictors of atrial fibrillation recurrence after circumferential pulmonary vein ablation. Eur Heart J Apr 2007;28:836-841.

2. Abecasis J, Dourado R, Ferreira A, Saraiva C, Cavaco D, Santos KR, Morgado FB, Adragao P, Silva A. Left atrial volume calculated by multi-detector computed tomography may predict successful pulmonary vein isolation in catheter ablation of atrial fibrillation. Europace Oct 2009;11:1289-1294.

3. Camm AJ, Lip GY, De Caterina R, et al. 2012 focused update of the ESC Guidelines for the management of atrial fibrillation: an update of the 2010 ESC Guidelines for the management of atrial fibrillation. Developed with the special contribution of the European Heart Rhythm Association. Eur Heart J Nov 2012;33:2719-2747.

4. Nedios S, Tang M, Roser M, Solowjowa N, Gerds-Li JH, Fleck E, Kriatselis C. Characteristic changes of volume and three-dimensional structure of the left atrium in different forms of atrial fibrillation: predictive value after ablative treatment. J Interv Card Electrophysiol Nov 2011;32:87-94.

5. Nedios S, Koutalas E, Kosiuk J, Sommer P, Arya A, Richter S, Rolf S, Husser D, Hindricks G, Bollmann A. Impact of asymmetrical dilatation of the left atrium on the long-term success after catheter ablation of atrial fibrillation. Int J Cardiol Apr 1 2015;184:315-317.

6. Bisbal F, Guiu E, Calvo N, et al. Left atrial sphericity: a new method to assess atrial remodeling. Impact on the outcome of atrial fibrillation ablation. Journal of cardiovascular electrophysiology Jul 2013;24:752-759.

7. Nedios S, Kosiuk J, Koutalas E, Kornej J, Sommer P, Arya A, Richter S, Rolf S, Husser D, Hindricks G, Bollmann A. Comparison of left atrial dimensions in CT and echocardiography as predictors of long-term success after catheter ablation of atrial fibrillation. J Interv Card Electrophysiol Sep 2015;43:237-244.

8. Kornej J, Dinov B, Blann AD, Rolf S, Arya A, Schmidl J, Husser D, Hindricks G, Bollmann A, Lip GY. Effects of radiofrequency catheter ablation of atrial fibrillation on soluble Pselectin, von Willebrand factor and IL-6 in the peripheral and cardiac circulation. PLoS One 2014;9:e111760.

9. Kornej J, Reinhardt C, Kosiuk J, Arya A, Hindricks G, Adams V, Husser D, Bollmann A. Response of high-sensitive C-reactive protein to catheter ablation of atrial fibrillation and its relation with rhythm outcome. PLoS One 2012;7:e44165.

10. Esato M, Hindricks G, Sommer P, Arya A, Gaspar T, Bode K, Bollmann A, Wetzel U, Hilbert S, Kircher S, Eitel C, Piorkowski C. Color-coded three-dimensional entrainment mapping for analysis and treatment of atrial macroreentrant tachycardia. Heart Rhythm Mar 2009;6:349-358. 


\section{Chapter 10 Atrial remodeling and low-voltage areas}

"Association of low-voltage areas with the regional wall deformation and the left atrial shape in patients with atrial fibrillation." under review

Sotirios Nedios, Soroosh Sanatkhani, Michael Oladosu, Timm Seewoester, Sergio Richter, Arash Arya, Philipp Sommer, Jordi Heijman, Harry J.G.M. Crijns, Gerhard Hindricks, Andreas Bollmann, Prahlad G. Menon 


\begin{abstract}
Background:

Left atrium (LA) remodeling is associated with atrial fibrillation (AF) and reduced success after AF ablation, but its relation with low-voltage areas (LVA) is not known. This study aimed to evaluate the relation between regional LA changes and LVAs in AF patients.

\section{Methods:}

Pre-interventional CT data of patients $(\mathrm{n}=24)$ with LA-LVA $(<0.5 \mathrm{mV})$ in voltage mapping after AF ablation were analyzed (Surgery Explorer, QuantMD LLC). To quantify asymmetry $(\mathrm{ASI}=\mathrm{LA}-\mathrm{A} / \mathrm{LAV})$ a cutting plane parallel to the rear wall and along the pulmonary veins divided the LA-volume (LAV) into anterior (LA-A) and posterior parts. To quantify sphericity (LAS=1$\mathrm{R} / \mathrm{S}$ ), a patient-specific best-fit LA sphere was created. The average radius (R) and the mean deviation (S) from this sphere were calculated. The average local deviation (D) was measured for the roof, posterior, septum, inferior septum, inferior-posterior and lateral walls.
\end{abstract}

\title{
Results:
}

The roof, posterior and septal regions had negative local deviations. There was a correlation between roof and septum $(\mathrm{r}=0.42, \mathrm{p}=0.04)$, lateral and inferior-posterior $(\mathrm{r}=0.48, \mathrm{p}=0.02)$ as well as posterior and inferior-septal deviations $(r=-0.41, p=0.046)$. ASI correlated with septum deformation $(\mathrm{r}=-0.43, \mathrm{p}=0.04)$. LAS correlated with dilatation (LAV, $\mathrm{r}=0.49, \mathrm{p}=0.02)$, roof $(\mathrm{r}=0.52, \mathrm{p}=0.009)$ and posterior deformation $(\mathrm{r}=-0.56, \mathrm{p}=0.005)$. LVA extent correlated with local deformation of all LA walls $(p<0.01)$, except the roof $(p=0.69)$. LVA association with LAV, ASI and LAS did not reach statistical significance.

\section{Conclusion:}

The LVA extent correlates with local wall deformations better than other remodeling surrogates. Therefore, their calculation could help predict LVA presence and deserve further evaluation in clinical studies. 


\section{Introduction}

Atrial fibrillation (AF) is associated with left atrial (LA) remodeling, characterized not only by dilatation but also by changes of LA symmetry. This is particularly true for greater LAs, when due to anatomical constrictions LA extension occurs non-uniformly. This asymmetric LA dilatation is a strong predictor of poor outcome after catheter ablation. ${ }^{1-3}$

Extended low voltage areas (LVAs) as seen during intra-procedural mapping have been associated with worse outcomes that may reflect the need for further ablation. ${ }^{4}$ While patients without AF substrate could benefit the most from a simple elimination of AF triggers by pulmonary vein isolation (PVI), patients with LVAs require modification of AF maintaining substrate to avoid recurrence. Therefore, the presence or extent of LA substrate as well as its localization can have a profound clinical impact on managing AF patients.

LA remodeling could provide pre-procedural information about AF substrate and help plan the procedure. The relationship of LA remodeling with LVAs though has not been adequately examined yet. This study aimed to use a new software suite and evaluate the relation between regional LA changes and LVAs in AF patients using novel geometry metrics.

\section{Patients}

\section{Methods}

We prospectively studied a total of 24 patients that underwent catheter ablation for symptomatic AF in 2011. All patients had a pre-procedural computed tomography (CT) for accurate depiction of LA and all patients had LVAs in the voltage mapping during sinus rhythm at the end of the procedure. Exclusion criteria were previous ablation for other arrhythmias, impaired left ventricular ejection fraction (LV-EF), severe valvular disorders, pacemaker stimulation and age <18years. All patients gave written informed consent, the institutional committee approved the study and data were collected in accordance with the Declaration of Helsinki.

\section{Echocardiography}

Transthoracic and trans-esophageal echocardiography was performed ( $2 \pm 1$ days) before the procedure at a designated echo-laboratory and intracardiac thrombi were ruled out. Images were acquired with the patients in the left lateral decubitus position using a commercially available system (Vivid-9 General Electric Vingmed, Milwaukee, WI, USA). Image acquisition was performed in the standard parasternal and apical views. Standard M-mode and 2D images, including color Doppler data from 3 consecutive heartbeats, were obtained according to current guidelines. $^{5}$

\section{Computed tomography}

Cardiac-CT was performed with a multidetector 64-row helical system (Brilliance 64, Philips Medical Systems, Best, The Netherlands). Image acquisition was electrogram-gated when possible and the parameters included: $70-120 \mathrm{KV}, 850 \mathrm{mAs}, 0.6 \mathrm{~mm}$ beam collimation, $0.625-$ $1.25 \mathrm{~mm}$ thickness and 20-30 cm field-of-view. During an end-inspiratory breath-hold of 20 seconds, and following a timing bolus-chase injection $(20 \mathrm{~mL}, 5 \mathrm{~mL} / \mathrm{s}), 90 \mathrm{~mL}$ of an iodinated contrast medium (Ultravist 370, Bayer Vital, Cologne, Germany) was administered. Finally endsystolic imaging data were used for three-dimensional (3D) reconstruction. 


\section{Novel anatomy and shape analysis}

CT data were reviewed using 3D volume-rendering by a specialized software (EnSite Verismo, SJM, MN). Left atrial volume (LAV) after exclusion of the atrial appendage (LAA) and the pulmonary veins (PV) was determined by LA area summation. The LAV was then arbitrarily divided by a cutting plane, between the PV ostia and the LAA and parallel to the posterior wall. The partial volumes of LA, the anterior (LA-A) and the posterior (LA-P) were calculated and the ratio LA-A/LAV was defined as an index of asymmetry (ASI).

Additional analysis was performed using a novel Visualization Tool Kit (VTK) of a software suite, specially designed to quantify LA shape, sphericity (LAS) and regional deformations (Surgery Explorer, Quant MD LLC). DICOM images were segmented in 3D to extract the LA surface and an optimal sphere was fitted (i.e. radius and center) on a patient specific basis to each LA, using an iterative closest point registration tool (Figure 10.1). Regions $>10 \mathrm{~mm}$ from the fitted spherical surface were excluded. The average radius $(\mathrm{R})$ and the mean deviation $(\mathrm{S})$ from this sphere were used to compute LAS $(=1-\mathrm{S} / \mathrm{AR}){ }^{2}$

Next, each LA was partitioned into six surface segments (shown in) for regional characterization of shape, visualizing the inferior-posterior wall, inferior septum, anterior septum, roof, posterior wall and lateral wall segments (Figure 10.2). Vertices belonging to each segment were then independently characterized for regional shape differences from each patient's respective patient-specific optimal sphere. The mean of the computed regional proximity of these segments from their respective closest locations on their respective atrium-specific best-fit spheres were recorded as a regional metric of segmental sphericity, named as average local wall deviation (D).

Image analysis was performed offline by an experienced observer blinded to the results of the intra-procedural voltage mapping and the patient's characteristics. Initial measurements of 5 random patients were repeated 4 weeks later by the same investigator and a second independent reviewer in a blinded fashion.

Figure 10.1. The average radius $(\mathrm{R})$ and the mean deviation $(\mathrm{S})$ from a best-fit sphere in two patient-specific LA models, using iterative closest point registration. Regional deviation from the best-fit sphere is illustrated as a color-map, plotted in LA surface with blue for concave and red for convex areas. Regions $>10 \mathrm{~mm}$ from the fitted spherical surface were excluded.
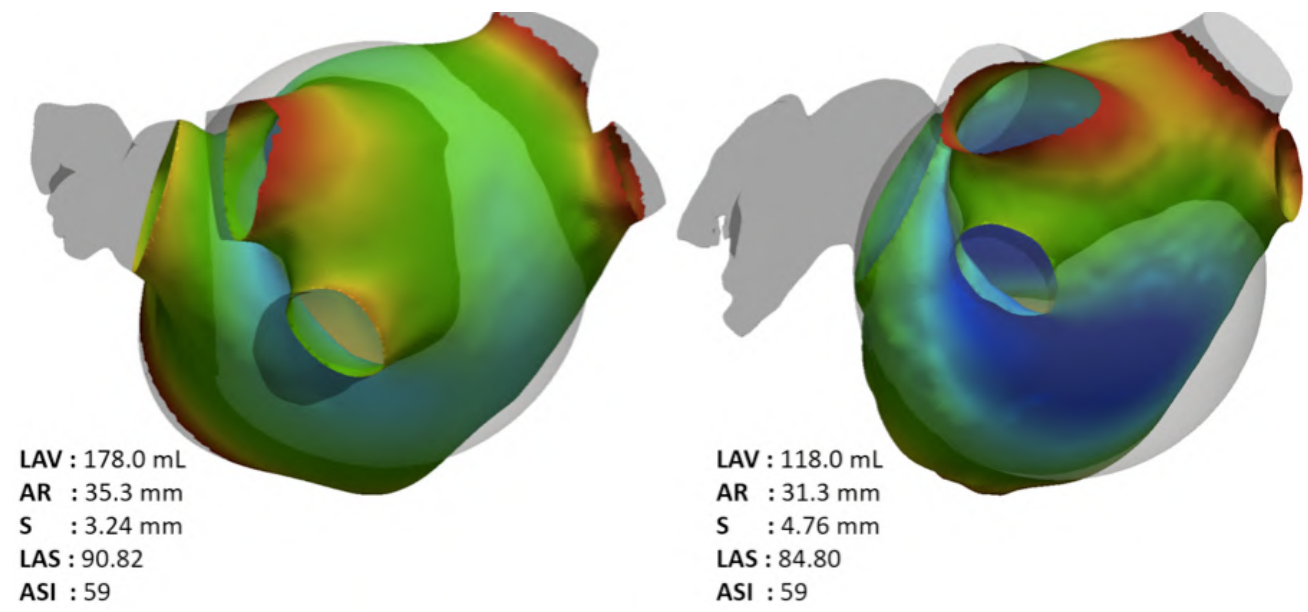

Variation from Best-fit sphere $(\mathrm{mm})$

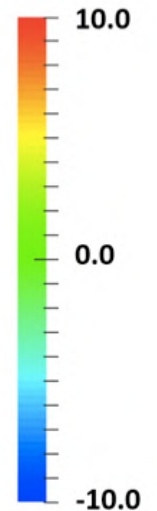


Figure 10.2. Illustration of regional partitioning of the patient-specific LA surface.
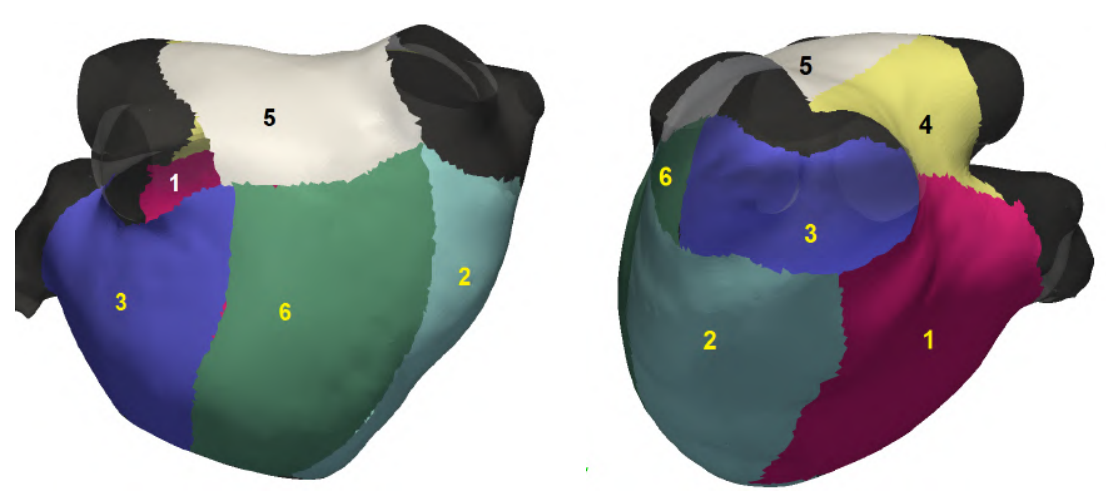

1: septum
2: inferior septum
3: lateral wall
4: roof
5: posterior wall
6: inferior posterior

\section{Mapping and ablation procedure}

Catheter mapping and ablation was performed under propofol sedation as previously described. ${ }^{4}$ Transseptal access and catheter navigation were performed with a steerable sheath (Agilis, St. Jude Medical, St. Paul, MN, USA) and electroanatomic mapping systems (EnSite ${ }^{\mathrm{TM}}$ NavX ${ }^{\mathrm{TM}}$, St. Jude Medical; or CARTO ${ }^{\mathrm{TM}}$, Biosense Webster, Diamond Bar, CA, USA), after integration of CT image datasets. All patients received circumferential ablation lines around the antrum of the ipsilateral pulmonary veins (irrigated tip catheter, temperature of $\leq 48^{\circ} \mathrm{C}$, power of $30-45 \mathrm{~W}$ ). Complete pulmonary vein isolation (PVI) was verified with a multipolar circular mapping catheter (Inquiry Optima or Reflexion Spiral; St. Jude Medical or Lasso; BiosenseWebster) and then a detailed bipolar LA voltage map was acquired during sinus rhythm. Additional substrate modification was performed as needed. Patients with AF at the beginning of the procedure had an external cardioversion. Mapping points were systematically acquired with an interpolation threshold of $10 \mathrm{~mm}$ and all color gaps were filled. The ablation catheter was used to create high-density maps in LVAs, using different catheter angulations and maneuvers, to rule out insufficient wall contact. In accordance with previous studies, ${ }^{6-9}$ LVAs were defined as sites of $\geq 3$ adjacent points $<0.5 \mathrm{mV}$. The LA was categorized into 6 areas, and the location of scar was classified as roof, posterior, septum, inferior septum, inferior-posterior and lateral walls.

\section{Statistical analysis}

Continuous variables are expressed as mean and standard deviation (SD) when normally distributed (positive Kolmogorov-Smirnoff test) or as median and interquartile range (IQR). Categorical variables are reported as frequencies and percentage. Parametric variables were compered by means of paired Student's t-test and non-parametric variables by Wilcoxon-test or chi-square test. Signed Spearman rank correlations between wall deformation metrics and LAV as well as global LAS were evaluated to derive an association of regional and global features of atrial shape.s[i. Intra-observer and inter-observer variability was expressed with Pearson's correlation coefficient (r). A two-tailed P-value less than 0.05 was considered statistically significant. Analysis was performed with SPSS v20.0 (SPSS Inc., Chicago, USA).

\section{Results}

\section{Patient characteristics}

Patients had a mean age of $71 \pm 8$ years, CHADS-VASc of $2.8 \pm 1.5$, LAV $155 \pm 35 \mathrm{ml}$, ASI $67 \pm 5 \%$ and LAS of $82 \pm 6 \%$ (Table 10.1). The intra- und inter-observer correlation of LA 
measurements (LAV, LA-A, LA-P, ASI and regional local wall deviations) was found to have coefficients of $\geq 88 \%$. ${ }^{1,3}$ The roof, posterior and septal regions had negative, whereas other regions had positive local deviations.

Table 10.1. Clinical characteristics and LA measurements (global and regional) for AF patients with low voltage areas during sinus rhythm.

\begin{tabular}{|c|c|c|c|}
\hline Baseline characteristics & & \multicolumn{2}{|l|}{ LA measurements } \\
\hline Age, years & $66 \pm 8$ & \multicolumn{2}{|l|}{ Echocardiography } \\
\hline Female, n (\%) & $14(58)$ & LV ejection fraction, $\mathrm{mm}$ & $57 \pm 11$ \\
\hline Persistent AF, n (\%) & $19(79)$ & LV diameter, $\mathrm{mm}$ & $45 \pm 7$ \\
\hline Heart failure, $\mathrm{n}(\%)$ & $3(13)$ & LA diameter, $\mathrm{mm}$ & $45 \pm 6$ \\
\hline Coronary disease, $\mathrm{n}(\%)$ & $4(17)$ & \multicolumn{2}{|l|}{ Computed tomography } \\
\hline Stroke, $\mathrm{n}(\%)$ & $1(4)$ & LA volume (LAV), ml & $155 \pm 35$ \\
\hline Diabetes, $\mathrm{n}(\%)$ & $6(25)$ & Asymmetry index (ASI), \% & $67 \pm 5$ \\
\hline Hypertension, $\mathrm{n}(\%)$ & $21(88)$ & LA sphericity (LAS) \% & $82 \pm 6$ \\
\hline Hyperlipidemia, $\mathrm{n}(\%)$ & $12(35)$ & Average radius $(\mathrm{R}), \mathrm{mm}$ & $32 \pm 4$ \\
\hline $\mathrm{CHA}_{2} \mathrm{DS}_{2}$-VASc score, $\mathrm{n}$ & $2.8 \pm 1.5$ & Mean deviation (S), mm & $6 \pm 2$ \\
\hline Low voltage areas & & \multicolumn{2}{|l|}{ Local wall deviation } \\
\hline - roof & $16(67)$ & $-\operatorname{roof}(\mathrm{D}), \mathrm{mm}$ & $-0.9 \pm 3$ \\
\hline - posterior & $13(54)$ & - posterior $(\mathrm{D}), \mathrm{mm}$ & $-0.6 \pm 2$ \\
\hline - septum & $15(63)$ & - septum (D), mm & $-1.6 \pm 2$ \\
\hline - inferior septum & $2(8)$ & - inferior septum (D), mm & $3.2 \pm 3$ \\
\hline - inferior posterior & $7(29)$ & - inferior posterior (D), $\mathrm{mm}$ & $0.8 \pm 2$ \\
\hline - lateral & $2(8)$ & - lateral (D), mm & $2.8 \pm 3$ \\
\hline
\end{tabular}

$\mathrm{LA}=$ left atrial, $\mathrm{LV}=$ left ventricular

\section{LA remodeling and low-voltage}

There was a correlation between roof and septum $(\mathrm{r}=0.42, \mathrm{p}=0.04)$, lateral and inferiorposterior walls $(\mathrm{r}=0.48, \mathrm{p}=0.02)$ as well as posterior and inferior-septal local deviations $(\mathrm{D}, \mathrm{r}=-$ $0.41, \mathrm{p}=0.046)$. Asymmetry (ASI) correlated with septum deformation $(\mathrm{r}=-0.43, \mathrm{p}=0.04)$. Sphericity (LAS) correlated with LA dilatation (LAV, $r=0.49, \mathrm{p}=0.02)$, roof $(\mathrm{r}=0.52, \mathrm{p}=0.009)$ and posterior LA changes $(\mathrm{r}=-0.56, \mathrm{p}=0.005)$.

The number of LVAs was associated with significant differences in local deformation of all LA walls $(p<0.01)$, except the roof $(p=0.69)$. LVA of lateral or inferior septal walls $(n=2)$ had similar effects whereas inferior posterior LVA $(n=7)$ resulted only in local changes. LVA association with LAV, ASI \& LAS did not reach statistical significance.

\section{Main findings}

\section{Discussion}

We created a novel descriptive metric of atrial wall deformation measured by a specially designed software and compared this with current surrogates of atrial remodeling for their association with the presence of low-voltage areas (LVA) in patients presenting for an AF ablation. We found that the local deviation (from a best-fit sphere) of the atrial walls correlates with the LVA extent better than other remodeling surrogates, such as asymmetry of sphericity. To the best of our knowledge, this is the first study that applies a new metric of regional shape 
changes and shows association with electrophysiologic characteristics of the underlying tissue. Therefore, calculation or these changes could help predict LVA presence and deserve further evaluation in clinical studies.

\section{Atrial remodeling and clinical implications}

Historically, atrial remodeling has been mostly studied as LA enlargement that correlated with clinical outcomes such as rhythm stability, thromboembolic risk and mortality. $1,2,10,11$ Atrial dilation is closely related to AF risk, and atrial stretch is known to promote AF. ${ }^{12}$ However, the physical constraints of the spine and the sternum, ${ }^{13}$ the changing tissue characteristics ${ }^{14}$ and the driving mechanism result in a non-uniform enlargement that is more prominent for the anterior LA part. ${ }^{1}$ New surrogates of remodeling, like the asymmetry and sphericity index, have been developed to better reflect these changes, but hitherto no studies have examined the regional wall deformation.

In this proof of concept study, we developed a new Visualization Tool Kit designed to quantify shape and provide novel metrics like regional deformations. We used this tool in a series of patients carefully examined for low-voltage areas and found that atrial wall changes correlate with the extent of fibrotic tissue. This probably represents the cumulative effect of wall stress, atrial expansion and anatomical constrictions that add to the geometrical dispersion of refractoriness and the perpetuation of spiral fibrillatory waves. ${ }^{15,16}$ These results supplement previously published data showing that asymmetry increases as the LA volume expands, especially at the initial (paroxysmal) stages of AF, when remodeling is primary driven by dilatation. ${ }^{3}$ This adds up to the studies that examine the impact of LA shape and fibrosis on atrial arrhythmogenesis, ${ }^{11,}$ 16-18 and emphasizes the importance of patient-specific anatomical information in the context of AF.

Despite the previously reported association of asymmetry or sphericity index with clinical outcomes, these surrogates of remodeling did not correlate with the extent of scar tissue (e.g. LVAs). This could be explained by the small number of the patients, most of which had paroxysmal AF, or by the fact that local changes may better represent the extent of fibrosis. The present findings though suggest that regional wall deformation could provide incremental information that could help plan an ablation strategy using simple one-shot devices or radiofrequency substrate-targeting strategies for advanced AF stages.

\section{Limitations}

This study has several limitations. First, the elaborate analysis of new atrial remodeling metrics, requiring manual segmentation, has limited the number of the patients included in this study. The segmentations were reproducible but time consuming, complex and cumbersome. Thus only 24 patients were used for this proof of concept study. Automatic segmentation and analysis of atrial wall deformation will be soon available allowing for wider application of these metrics. Anatomical data were assessed with computed tomography, requiring radiation and contrast dye exposure and thus prohibiting follow-up studies. Certainly, MRI based imaging may have provided more insights about shape changes and fibrosis or repeat studies. ${ }^{19}$ MRI though is currently not widely or readily available and could potentially correlate or be combined with data that are readily obtainable by shape analysis using CT or even $3 \mathrm{D}$ echocardiography. ${ }^{20}$ Finally, this study included only patients with present substrate (LVA) and could not include reference values from AF patients without LVAs. However, correlation between local wall changes and LVA extent has reached statistical significance and deserves further evaluation. 


\section{Conclusions}

The LVA extent correlates with local wall deformations better than other remodeling surrogates. Therefore, their calculation could help predict LVA presence and deserves further evaluation in clinical studies. 


\section{References:}

1. Nedios S, Tang M, Roser M, Solowjowa N, Gerds-Li JH, Fleck E, Kriatselis C. Characteristic changes of volume and three-dimensional structure of the left atrium in different forms of atrial fibrillation: predictive value after ablative treatment. J Interv Card Electrophysiol Nov 2011;32:87-94.

2. Bisbal F, Guiu E, Calvo N, et al. Left atrial sphericity: a new method to assess atrial remodeling. Impact on the outcome of atrial fibrillation ablation. Journal of cardiovascular electrophysiology Jul 2013;24:752-759.

3. Nedios S, Koutalas E, Kosiuk J, Sommer P, Arya A, Richter S, Rolf S, Husser D, Hindricks G, Bollmann A. Impact of asymmetrical dilatation of the left atrium on the long-term success after catheter ablation of atrial fibrillation. Int J Cardiol Apr 1 2015;184:315-317.

4. Rolf S, Kircher S, Arya A, Eitel C, Sommer P, Richter S, Gaspar T, Bollmann A, Altmann D, Piedra C, Hindricks G, Piorkowski C. Tailored atrial substrate modification based on lowvoltage areas in catheter ablation of atrial fibrillation. Circ Arrhythm Electrophysiol Oct 2014;7:825-833.

5. Lang RM, Bierig M, Devereux RB, et al. Recommendations for chamber quantification. Eur J Echocardiogr Mar 2006;7:79-108.

6. Oakes RS, Badger TJ, Kholmovski EG, et al. Detection and quantification of left atrial structural remodeling with delayed-enhancement magnetic resonance imaging in patients with atrial fibrillation. Circulation Apr 7 2009;119:1758-1767.

7. Verma A, Wazni OM, Marrouche NF, et al. Pre-existent left atrial scarring in patients undergoing pulmonary vein antrum isolation: an independent predictor of procedural failure. J Am Coll Cardiol Jan 18 2005;45:285-292.

8. Sanders P, Morton JB, Davidson NC, Spence SJ, Vohra JK, Sparks PB, Kalman JM. Electrical remodeling of the atria in congestive heart failure: electrophysiological and electroanatomic mapping in humans. Circulation Sep 23 2003;108:1461-1468.

9. Kistler PM, Sanders P, Fynn SP, Stevenson IH, Spence SJ, Vohra JK, Sparks PB, Kalman $\mathrm{JM}$. Electrophysiologic and electroanatomic changes in the human atrium associated with age. J Am Coll Cardiol Jul 07 2004;44:109-116.

10. Bisbal F, Gomez-Pulido F, Cabanas-Grandio P, et al. Left Atrial Geometry Improves Risk Prediction of Thromboembolic Events in Patients With Atrial Fibrillation. Journal of cardiovascular electrophysiology Jul 2016;27:804-810.

11. Marrouche NF, Wilber D, Hindricks G, et al. Association of atrial tissue fibrosis identified by delayed enhancement MRI and atrial fibrillation catheter ablation: the DECAAF study. Jama Feb 5 2014;311:498-506.

12. Heijman J, Algalarrondo V, Voigt N, Melka J, Wehrens XH, Dobrev D, Nattel S. The value of basic research insights into atrial fibrillation mechanisms as a guide to therapeutic innovation: a critical analysis. Cardiovasc Res Apr 01 2016;109:467-479.

13. Hoffmeister PS, Chaudhry GM, Mendel J, Almasry I, Tahir S, Marchese T, Haffajee CI, Orlov MV. Evaluation of left atrial and posterior mediastinal anatomy by multidetector helical computed tomography imaging: relevance to ablation. J Interv Card Electrophysiol Apr 2007;18:217-223.

14. Nakamura K, Funabashi N, Uehara M, Ueda M, Murayama T, Takaoka H, Komuro I. Left atrial wall thickness in paroxysmal atrial fibrillation by multislice-CT is initial marker of structural remodeling and predictor of transition from paroxysmal to chronic form. Int $\mathbf{J}$ Cardiol Apr 14 2011;148:139-147. 
15. Dierckx H, Brisard E, Verschelde H, Panfilov AV. Drift laws for spiral waves on curved anisotropic surfaces. Phys Rev E Stat Nonlin Soft Matter Phys Jul 2013;88:012908.

16. Gonzales MJ, Vincent KP, Rappel WJ, Narayan SM, McCulloch AD. Structural contributions to fibrillatory rotors in a patient-derived computational model of the atria. Europace Nov 2014;16 Suppl 4:iv3-iv10.

17. Whitaker J, Rajani R, Chubb H, Gabrawi M, Varela M, Wright M, Niederer S, O'Neill MD. The role of myocardial wall thickness in atrial arrhythmogenesis. Europace Dec 2016;18:1758-1772.

18. Varela M, Bisbal F, Zacur E, Berruezo A, Aslanidi OV, Mont L, Lamata P. Novel Computational Analysis of Left Atrial Anatomy Improves Prediction of Atrial Fibrillation Recurrence after Ablation. Front Physiol 2017;8:68.

19. Daccarett M, Badger TJ, Akoum N, Burgon NS, Mahnkopf C, Vergara G, Kholmovski E, McGann CJ, Parker D, Brachmann J, Macleod RS, Marrouche NF. Association of left atrial fibrosis detected by delayed-enhancement magnetic resonance imaging and the risk of stroke in patients with atrial fibrillation. J Am Coll Cardiol Feb 15 2011;57:831-838.

20. Lang RM, Badano LP, Tsang W, et al. EAE/ASE recommendations for image acquisition and display using three-dimensional echocardiography. J Am Soc Echocardiogr Jan 2012;25:3-46. 


\section{Chapter 11 General Discussion}

Sotirios Nedios, Prahlad G. Menon, Jordi Heijman, Andreas Bollmann, Gerhard Hindricks, Harry J.G.M. Crijns 


\section{Introduction}

The general aim of this thesis was to unravel the role of pre-procedural imaging concerning the relationship between anatomical characteristics and the clinical outcomes in atrial fibrillation (AF) patients, especially thromboembolic events (Chapters 2-4) and rhythm outcomes after catheter ablation therapy (Chapter 5-9). We used tomography (CT) or magnetic resonance imaging (MRI) data to evaluate 3D changes and elaborate the following aspects:

\section{Part I: Atrial anatomy and thromboembolic risk}

1. What is the prevalence of thromboembolic events after AF ablation (Chapter 2)?

2. Is LAA anatomy associated with thromboembolic events after AF ablation (Chapter 2)?

3. What is the role of LAA anatomy in patients with low CHADS-VASc score (Chapter 3)?

4. What is the prevalence of peri-procedural thromboembolic events (Chapter 4)?

5. Are peri-procedural thromboembolic events related to the LAA anatomy (Chapter 4)?

\section{Part II: Atrial remodeling and atrial fibrillation ablation}

6. What are the characteristics of atrial remodeling in different AF types (Chapter 5)?

7. Can the remodeling of atrial anatomy predict long-term success after AF ablation (Chapter 6)?

8. Could atrial anatomy be used to improve patient selection and ablation outcomes (Chapter 7)?

9. Is atrial remodeling related to left ventricular diastolic dysfunction (Chapter 8)?

10. What is the association between atrial remodeling and plasma markers (Chapter 9)?

11. Is there an association between anatomical atrial remodeling and AF substrate (Chapter 10)?

This chapter discusses the main findings of the chapters above in a more integrative manner.

\subsection{Atrial anatomy and thromboembolic risk}

\section{Atrial fibrillation and thromboembolic risk after AF ablation}

Thromboembolic risk is significantly reduced in AF patients undergoing an ablation procedure, but remains a significant clinical issue. ${ }^{1,2}$ Previous studies identified CHADS/CHA $2 \mathrm{DS}_{2}$-VASc score $^{3-5}$ and AF recurrence ${ }^{5,6}$ as predictors of post-procedural embolic events. In Chapter 2 we compared two $\mathrm{CHA}_{2} \mathrm{DS}_{2}$-VASc matched patient-groups, which were closely followed over a median period of 24 months and found that the occurrence of a thromboembolic event (TE) after ablation is associated with AF recurrence and a higher position of the superior LAA-takeoff, above the respective left superior pulmonary vein (LSPV). The TE risk during follow-up increases six times if there is AF recurrence and almost five times if the LAA has a superior takeoff, whereas LAA morphology was not relevant. Considering these results, patients with superior LAA take off or AF recurrence after an ablative procedure must be followed very closely for adequate anticoagulation and timely recognition or treatment of TE.

Embolic events in AF patients derive mainly from reduced blood flow and thrombus formation in LAA that could be prevented by anticoagulation or obliteration..$^{7-9}$ In accordance with previous studies, we found that an increased heart rate reduces the LAA peak flow velocity and promotes blood stasis. ${ }^{10,11}$ This mechanism is more pronounced with a higher LAA takeoff, remote to the mitral valve rendering this LAA anatomy susceptible to thrombogenic flow at higher heart rates. 
Our findings imply a possible tachycardia-mediated thrombogenic risk for these patients that can be assessed by LAA location and deserves further investigation (Figure 11.1).

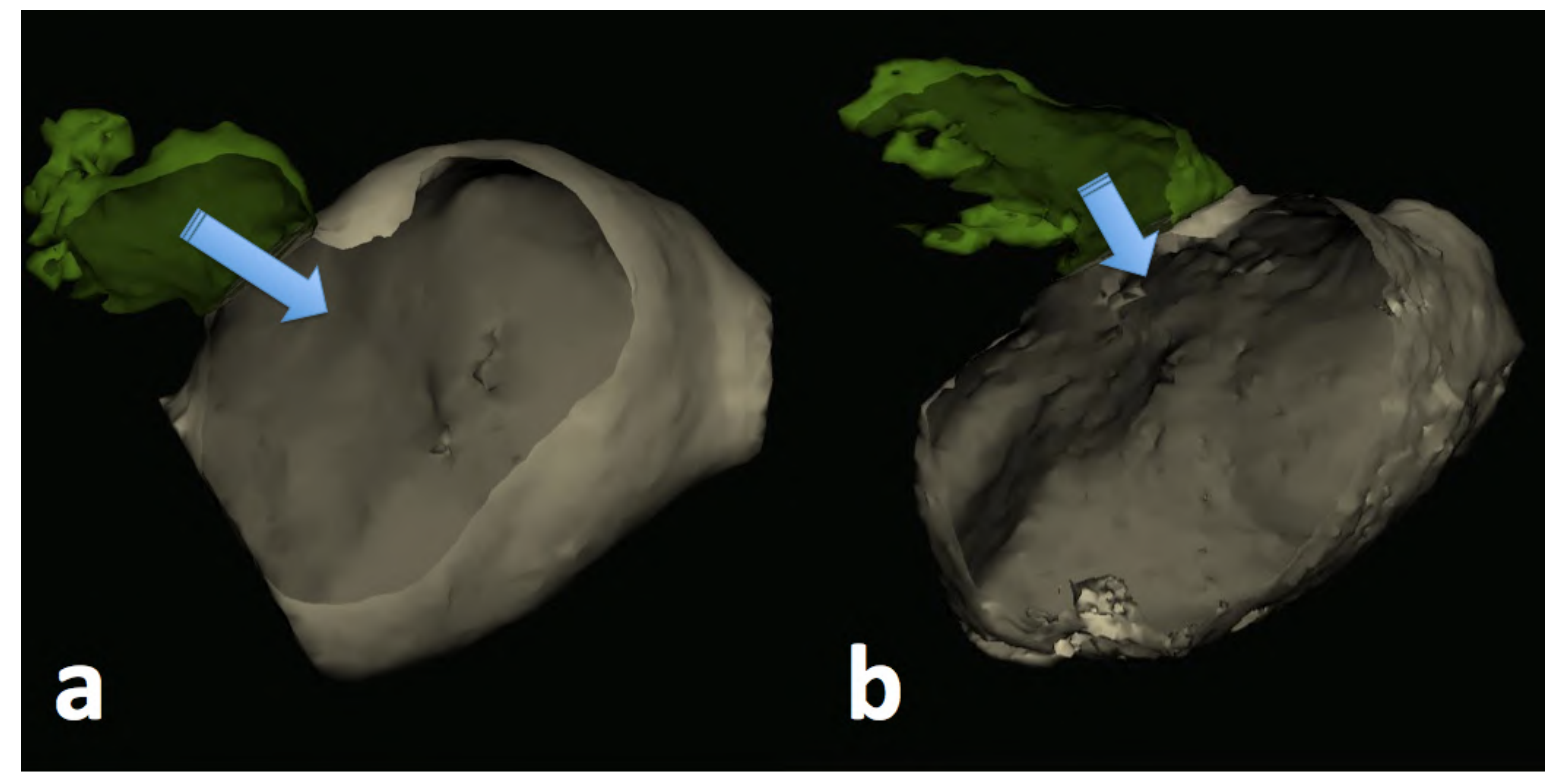

Figure 11.1. Example illustrating though a cutting view a. a low and b. a high superior LAA takeoff in relation to the left superior pulmonary vein. A higher LAA takeoff is associated with reduced LAA flow (blue arrow) during increased heart rate

Previous studies have associated a larger $\mathrm{LAA}^{12-14}$ or a narrow ostium ${ }^{15,16}$ with an increased thromboembolic risk. In our patient cohort though, these characteristics were not significant. Similarly, recent studies found no significant correlation between LAA size and the prevalence of TE prior to CA. ${ }^{17-19}$ Contrary to recent studies ${ }^{16-19}$ LAA morphology was not associated with TE after AF ablation in our study. A possible explanation may be the difference in patients. In comparison to the study of Di Biase et al., ${ }^{17}$ patients in our cohort had a higher prevalence of prior TE $(26 \%$ vs. $8 \%)$ along with higher $\mathrm{CHADS}_{2}$ score $(\geq 2: 79 \%$ vs. $14 \%)$ and a higher prevalence of non-Chicken-Wing LAA ( $80 \%$ vs. 52\%). In comparison to the study of Kimura et al., ${ }^{18}$ patients in our cohort also had a higher $\mathrm{CHADS}_{2}$ score $(\geq 2: 79 \%$ vs. $13 \%)$ and a higher prevalence of non-Chicken-Wing LAA ( $80 \%$ vs. $60 \%)$. In fact, since the prevalence of nonChicken-Wing morphology was higher in our patient population, our findings could support the observation that these patients have increased embolic risk as expressed by clinical risk-scores.

To date, there are no further data correlating the various LAA positions with TE risk in patients with AF. A thorough examination of LAA anatomy in relation to flow-velocity and heart rate in previous studies might have drawn a different picture. Our results though reveal a tachycardiaassociated thrombogenic flow as a possible pathophysiological mechanism for the increased TE risk of a higher LAA position. Therefore, patients with such an LAA anatomy warrant a closer follow-up for appropriate therapy adjustment and timely AF treatment.

\section{Atrial fibrillation and thromboembolic risk in low-risk patients}

Despite the clinical use of risk scores like $\mathrm{CHADS}_{2}$ and $\mathrm{CHA}_{2} \mathrm{DS}_{2}-\mathrm{VASc}$, severe and disabling TEs still remain a problem for relatively young and healthy patients. In Chapter 3 we revealed the importance of LAA anatomy for TEs in patients with low $\mathrm{CHA}_{2} \mathrm{DS}_{2}$-VASc score $(\leq 1)$. Systematic analysis of the characteristics and quantitative parameters of LAA in low-risk patients with and without TE revealed (similar to post-procedural TEs) that a high superior LAA-takeoff 
is associated with a nine-fold higher risk of thrombogenesis. Therefore the LAA anatomy might be useful for guiding anticoagulation in patients with $\mathrm{AF}$ and low $\mathrm{CHA}_{2} \mathrm{DS}_{2}-\mathrm{VASc}$ score.

Most of the patients in our study $(\mathrm{n}=17,68 \%)$ had no anticoagulation at the TE time, although half of them $(n=9,53 \%)$ had a $\mathrm{CHADS}_{2}$ or $\mathrm{CHA}_{2} \mathrm{DS}_{2}-\mathrm{VASc}$ score of 1 . Using the $\mathrm{CHA}_{2} \mathrm{DS}_{2}-$ VASc score would reclassify 7 patients, of which 3 would be female. Therefore, one-third of the TE group $(n=7,28 \%)$ would have a score of 0 and $12 \%(n=3)$ a score of 1 due to female sex. These patients would be classified as 'truly low risk', and thus no antithrombotic therapy would be prescribed. ${ }^{20}$ Knowing the association of higher LAA takeoff with TEs could have significant implications for the anticoagulation management of these patients.

In accordance with our previous findings we found that the mechanism that applies for the occurrence of TE after AF ablation, ${ }^{21}$ also accounts for the thrombogenic flow during increased heart rate in patients with low $\mathrm{CHA}_{2} \mathrm{DS}_{2}$-VASc score. This mechanism is more pronounced in case of a higher LAA takeoff and correlates with a tachycardia-mediated TE risk. Thus, the LAA anatomy might predict thrombogenesis that would be not detected by the $\mathrm{CHA}_{2} \mathrm{DS}_{2}-\mathrm{VASc}$ score.

Although initial studies associated LAA ostium, size or morphology ${ }^{12-15}$ with an increased TE risk in AF patients, this was not confirmed in the present or other more recent studies. ${ }^{17-19}$ This could be explained by the difference of the analyzed patients and the inclusion criteria that have been more sensitive (for TE risk) in the present study. We found though that Cauliflower-LAA was associated with higher LAA-takeoff $(80 \%$ vs. $36 \%, \mathrm{p}=0.04)$, which could support the observation that these patients have increased embolic risk not only because of the LAA morphology, but also through a different anatomical position. In accordance to that we found no Chicken-Wing LAA with a high superior LAA-takeoff.

Indeed, after adjusting for confounding factors, a superior LAA-takeoff over the LSPV was the only factor associated with a nine-fold increased stroke risk. Therefore, a detailed study of LAA anatomy in relation to flow-velocity and heart rate is very important for the understanding of the LAA function and anatomy. Our findings reveal a possible pathophysiological mechanism that deserves further examination. Since LAA orientation increases TE risk especially in case of tachyarrhythmia, these patients need a more aggressive anticoagulation and rhythm/rate control.

\section{Atrial fibrillation and peri-interventional thromboembolic risk}

In Chapter 4 we examined the impact of LAA-morphology on the thromboembolic risk during catheter ablation of AF. We found Chicken-Wing morphology to be associated with seven time higher risk of peri-interventional TE events. This association remained significant after adjustment for possible confounders associated with chicken wing morphology.

Similar to previous studies, ${ }^{17-19}$ we have observed more than three times increased likelihood of prior stroke or TIA in patients with cauliflower LAA morphology. However, when it comes to periprocedural TEs, the chicken wing morphology, which was described as protective, turned out to be the most dangerous one. Our findings suggest that the peri-procedural thrombus formation may have different mechanisms and different predictors. Accordingly, it is the LAA shape rather than the LAA volume that affects the LAA hemodynamics during ablation. The elongated, stretched and curved shape of a chicken wing LAA might be protective against spontaneous TEs by preventing uninhibited release of prominent, large thrombi into the circulation and enhancing the resolution or adhesion of minor ones. However, this protective configuration might act just the opposite during AF ablation: it might become a reservoir for micro-thrombi generated at the catheter tip or on fresh lesions and flashed into LAA by the flow of nowadays universally used catheter irrigation. When considering the spatial relationship to the LA ridge, frequently requiring intensive and extended ablation, this hypothesis becomes persuasive. The load of loose 
thrombogeneous material might afterwards become the source of thromboembolism itself or start a cascade of solid thrombus formation.

Further possible mechanisms mediating this phenomenon could be the differences in coagulations plasma markers, endothelial function or platelet activation potentially related to LAA-morphology and function. Such findings would be of great guidance for periprocedural anticoagulation or the needed ACT level during ablation as shown in patients with spontaneous echo contrast. ${ }^{22}$ However, currently no presumptions can be made and further studies are necessary to illuminate the pathophysiological mechanisms and clinical implications in order to improve the safety of patients undergoing AF ablation.

\section{Assessment of LAA anatomy and thromboembolic risk}

Anatomical variations of the LAA anatomy are so wide and complex almost every individual has a unique variation like a fingerprint. The proposed classifications are based on the general shape of the LAA and it's ostial takeoff position in relation to the pulmonary veins and the mitral valve. Although the intra- and inter-observer variability in our studies was good, the LAA variations inevitably lead to disagreement in same cases, which were resolved by a common consent with a third expert physician. This reflects some current limitations for the feasibility and clinical implications of these findings when compared with the simplicity of the CHADS-VASc score. However, the CHADS-VASc score only explains about $60 \%$ (c-statistics) of the predicted thromboembolic risk and thus studies like this add to our knowledge and our ability to better select and treat patients. Moreover, the increasing use of computational medicine and machine learning may provide a more detailed LAA analysis and standardize LAA classification in an automatically and integrated workflow of cardiac imaging. Therefore, the use of these results may translate into easy to use tools that may change the clinical practice in the future.

\subsection{Atrial remodeling and atrial fibrillation ablation}

\section{Characteristics of atrial remodeling}

In Chapter 5 we performed a detailed analysis of the LA anatomy in healthy individuals and compared them with patients having different types of AF. We found distinct structural differences with respect to LA volume (LAV) and shape. We measured asymmetry with a new index (Asymmetry Index-ASI) and found that ASI and LAV are significantly associated with recurrences after AF ablation.

We found that patients in advanced AF stages tend to have larger LAV and higher ASI, reflecting a disproportional increase of the anterior LA. Persistent AF was associated with higher LAV but not significantly different ASI than paroxysmal AF. Thus, it seems that progression from paroxysmal to persistent AF associates with LA enlargement while the relation of the anterior LA to LAV remains stable. Finally, long-standing persistent AF had similar LAV but higher ASI persistent AF. Consequently, progression from persistent to long-standing persistent AF reflects a further increase of the anterior LA during while LAV remains relatively stable. Since long-term imaging data of one cohort over time are difficult to gather, these findings build upon differences between AF types as surrogates of different times in the natural AF history.

This irregular LA dilatation could reflect the physical constraints of the spine and the sternum and the changing of the LA wall properties. ${ }^{23}$ LA enlargement and LA wall thickening is related with the domestication of chronic AF. ${ }^{24,}{ }^{25}$ The posterior LA wall though is thinner than the anterior, ${ }^{26}$ has a higher wall stress and provides the main substrate for the arrhythmia. ${ }^{27,}{ }^{28}$ The thicker anterior wall has a secondary role, ${ }^{29,30}$ but as shown in our study, it undergoes continuous expansion during progression to persistent and long-standing persistent AF. 
In accordance to previous studies, we have shown that success rates after PVI are significantly reduced from paroxysmal to persistent and long-standing persistent AF. ${ }^{31,32}$ In this study, we have shown that ASI $>60 \%$ is significantly associated with lower success rates after AF ablation.

Identifying predictors of success after PVI may improve patient selection, reduce health care costs and avoid exposing patients to unnecessary procedures or complications. Accordingly the guidelines emphasize the pre-procedural evaluation of the LA volume. ${ }^{33,34}$ This study though was the first study to show that ASI is an equally important prognostic parameter as LAV. According to the odds ratio, a $10 \mathrm{ml}$ increase of the LAV or a $3 \%$ increase of the asymmetry index could lead to $24 \%$ or $30 \%$ reduction of the ostial PVI success rate, respectively.

Therefore in patients with non-paroxysmal AF, enlarged left atria and increased ASI, PVI is not effective as single ablative treatment. PVI in these patients should rather be considered as the first step of an ablative strategy that includes additional targets after PVI has been achieved.

\section{Atrial diameters as predictors of wide circumferential AF ablation}

In Chapter 6 we extented our prior findings and evaluated the prognostic value of LA changes on the outcomes of an improved ablation protocol, including wide-circumferential pulmonary vein isolation for paroxysmal $\mathrm{AF}$ and additional lesions for persistent AF. This study evaluated the value of LA volume and of LA diameters for the prediction of AF recurrence. We found that LA dilatation is more pronounced on the coronal plane, as represented by the transversal LA diameter. An LA-TV $(>74.5 \mathrm{~mm})$ was associated with reduced long-term success after catheter ablation and remained the best predictor (similar to LAV>126 ml) and stronger than the commonly used echocardiographic LA-D diameter that is recommended by the guidelines. ${ }^{35-37}$

Our study showed that LA-D has lower correlation and lower predictive value in comparison to other diameters or to LAV. LATV was the strongest linear predictor of recurrence with a very high negative predictive value (better AF freedom prediction). A $4 \mathrm{~mm}$ increase of the LA-TV could lead to $30 \%$ higher AF recurrence rate. Therefore, LA-TV/LAV should be evaluated wand ablation should not be withheld from patients based on an enlarged echocardiographic diameter.

As previously shown echocardiographic LA diameter correlates poorly with LAV, which is a better surrogate of LA size and ablation outcomes. ${ }^{38-41}$ Abecasis et al. showed that LAV $>145 \mathrm{ml}$ is associated with higher recurrence rates after AF ablation. ${ }^{42} \mathrm{Helms}$ et al. found an LAV cutoff of $135 \mathrm{ml}$ to have $96 \%$ specificity for recurrence. ${ }^{33}$ Similar results have been reported by other studies with cut-off values (117-135 ml) increasing proportionally to the percentage of patients with persistent AF. ${ }^{41,43-45}$ In contrast, von Bary et al. found that in a larger cohort with exclusive paroxysmal AF, LAV ( $>95 \mathrm{ml}$ ) has only a marginal predictive value. ${ }^{46}$ Since advanced AF stages are associated with a more prominent dilatation on the coronal plane and ablation is increasingly being used for patients with persistent AF, transversal LA size seems to be a better surrogate of LA size for these patients and deserves further investigation.

Volume measurement requires $3 \mathrm{D}$ reconstruction, cutting out anatomical structures and thus remains a time-consuming process. Therefore, an easily measured single-linear LA dimension would be better for clinical routine use. The current data indicate that the transversal LA diameter (LA-TV) can represent LA dilatation and can predict success after AF-ablation similarly to LAV. In contrast, the commonly used LA-D showed poorer correlation with LAV and low predictive value for AF-recurrence, when compared with LAV and other LA diameters. Interestingly and in accordance with previous reports, LAV had a lower predictive value than LAV and had worse statistical performance when adjusted for BSA (LAVe). ${ }^{46-48}$ Thus, future studies should take into consideration that indexed variables could reduce the mass effect. In this sense, our findings emphasize that LA-D and indexed values could be misleading for clinical decision making. On 
the other hand, LA-TV is a simple parameter that could be easily measured and reliably guide AF management, by identifying patients who could achieve rhythm stability with simpler procedures.

\section{Atrial remodeling and long-term success after circumferential AF ablation}

In Chapter 7 we found that asymmetry increases as the LA expands, but this effect is less pronounced in patients with already asymmetric dilated atria, such as in persistent AF. Although, dilatation is the most important predictor after PVI for paroxysmal AF, in persistent AF patients undergoing PVI and additional substrate modification, ASI supersedes volume and remains the most significant predictor of recurrence. Since LAD and LAS (sphericity) did not correlate with ASI, LA asymmetry is better for therapy and patient selection in advanced AF stages. Therefore, in persistent AF patients with low ASI, ablative treatment could be advocated despite greater LA volumes, whereas in those with higher ASI alternative treatments should be carefully considered.

The results in Chapter 7 confirm previous observations that asymmetry can predict outcomes and that PVI alone is not an effective treatment for persistent AF. ${ }^{36}$ Contrary to Bisbal et al. ${ }^{37} \mathrm{LA}$ sphericity was not found to be a significant recurrence predictor. In our cohort though there was lower LAS ( $73 \pm 7 \%$ vs. $83 \pm 3 \%$ ), higher LAV (129 $\pm 43 \mathrm{ml}$ vs. $82 \pm 26)$ and older patients (59 vs. 52 years old). This supports the observation that in advanced AF, asymmetry is a better recurrence predictor and should be used more in future studies.

\section{Atrial remodeling and ventricular diastolic dysfunction}

In Chapter 8 we found that LA symmetry changes are associated with LA dilatation and left ventricular (LV) diastolic dysfunction (DD). Contrary to DD, increased asymmetry was again associated with reduced success after AF ablation. These findings illuminate the relation between increased LV filling pressures and LA remodeling and may help to develop future strategies to prevent advanced LA changes or improve AF therapy.

The findings in Chapter 8 provide a more complete analysis of the LA and LV interaction. ${ }^{49,50}$ Since both the LA and the LV are intricately coupled, DD has a direct negative impact on the LA. During LV systole, the LA functions as a passive reservoir, depending on LV systolic function and its own relaxation properties. During diastole the LA is under the direct influence of LV diastolic pressure through the open mitral valve. ${ }^{51}$ Therefore, a higher LA afterload due to increased LV stiffness or decreased relaxation translates into higher LA pressure with reduced LA emptying that results in atrial dilatation and increased AF risk..$^{52}$

Previous studies have shown that DD leads to LA dilatation. ${ }^{53-55}$ This remodeling process due to DD is associated with electromechanical delay in hypertensive patients, ${ }^{56}$ decreased LA-wall voltage and worse outcomes after AF ablation. ${ }^{57}$ Our results supplement these findings and reveal that DD is associated with a specific, asymmetric pattern of LA remodeling. In the early phase of $\mathrm{AF}$, the LA geometry is still preserved and the region around the pulmonary vein ostia is the main target region for ablation therapy. Later, with progression of the disease asymmetric LA dilatation develops and more substrate is found in the anterior and septal parts of the LA. ASI is a surrogate of this remodeling process and correlates with reduced success after AF ablation (especially in persistent AF), better than DD or LAV.

Although diastolic dysfunction (DD) was not an independent predictor for AF recurrence, it was clearly associated with LA remodeling. These results are confounded by evidence of reverse remodeling after DD improvement and improved blood pressure or rhythm control. ${ }^{58}$ Cha at al. ${ }^{59}$ described DD improvement in $30 \%$ of these patients while Reant at al. ${ }^{60}$ demonstrated reverse remodeling and LV-EF improvement after sinus rhythm restoration. Similar results were published for patients undergoing surgical radiofrequency ablation. ${ }^{61}$ Therefore, LA ablation may reduce both $\mathrm{DD}$ and $\mathrm{AF}$ burden and possibly stop this vicious circle of LA remodeling. 
Accordingly, appropriate treatment and more aggressive rhythm control should be considered early for patients with DD, before advanced LA symmetry changes occur.

\begin{abstract}
Atrial remodeling and plasma markers
Our group demonstrated in previous studies that pro-inflammatory reactions may predict AF recurrences after $\mathrm{AF}$ ablation. ${ }^{62,63} \mathrm{We}$ also showed that LA changes carry a predictive value that is better represented with LA-TV or LAV than with the commonly used LAD. ${ }^{50}$ As extension of these studies Chapter 9 examined the relationship between the plasma marker high-sensitive interleukin-6 (hsIL-6) and the anatomical atrial remodeling, as represented by the transversal (LA-TV) and not just the global (LAV) dilatation.

The levels of hsIL-6 were associated with age, BMI, renal dysfunction and LA-TV but not with LAD or LA-AP. These findings linked pro-inflammatory changes with the left atrial remodeling and emphasized the close relationship between these important AF co-variables. These findings emphasized the importance and scientific prominence of inflammation state in AF patients. These results serve as the basis for future studies that could examine the practical implications of hsIL-6 or LA measurements. Since a pro-inflammatory state is associated with anatomical LA remodeling, it remains a subject to further research whether AF patients might profit from anti-inflammatory treatment during or after invasive treatment.
\end{abstract}

\title{
Atrial remodeling and low-voltage areas
}

In Chapter 10 we explored the association of LA remodeling with low-voltage areas (LVA) as surrogates of the underlying substrate in AF patients. We introduced a new computational in order to quantify sphericity (LAS) and regional deformations. A patient-specific best-fit LA sphere was created using iterative closest point registration. The average radius $(\mathrm{R})$ and the mean deviation (S) from this sphere were calculated. The average local deviation (D) was measured for the roof, posterior, septum, inferior septum, inferior-posterior and lateral walls.

This study suggested that atrial wall changes correlate with the extent of low-voltage areas. This could reflect the progressive effect of wall stress, atrial expansion and anatomical constrictions that aggravate to the geometrical dispersion of refractoriness and spiral waves. ${ }^{64,65}$ These results supplement Chapter 7 that showed an increase in asymmetry with LA dilatation, especially during the initial stages of AF. ${ }^{49}$ This adds to our knowledge about the impact of LA shape and fibrosis on arrhythmogenesis, ${ }^{65-68}$ and points out the importance of patient-specific anatomical information in the context of AF. Regional wall deformation for example could provide incremental information that could help differentiate individuals that would benefit more from simple one-shot devices than those in need of more elaborate substrate-targeting strategies.

\subsection{Conclusions}

This thesis elaborated the significance of atrial anatomy for clinical outcomes in AF patients. We found that AF recurrence and a higher LAA takeoff are associated with increased TE risk after AF ablation, while LAA morphology is not. We proposed a mechanism of a tachycardiamediated thrombogenic flow that was also seen in AF patients with low $\mathrm{CHA}_{2} \mathrm{DS}_{2}$-VASc score and higher LAA takeoff. Contrary to previous studies, we found that a chicken-wing LAA morphology is associated with a higher peri-procedural TE risk. The proposed mechanism is an LAA reservoir function for ablation-related microthrombi, the implications of which certainly deserve further research. These findings may have implications for an appropriate clinical or anticoagulation management of AF patients. 
In order to describe the anatomical LA changes, we developed a new index of asymmetry (ASI) and compared between patients with different AF types to healthy individuals. We found that two interactive components for LA remodeling (dilatation and asymmetry) associated with AF-type and AF ablation success. We showed that asymmetry increases as the LA expands, but this is diminished in patients with already asymmetric dilated atria, such as in persistent AF.

As a result, we found that the transversal LA diameter is the best single-linear predictor, comparable to LA volume and stronger than the commonly used echocardiographic LA diameter. Moreover, we have shown that despite dilatation being the most important predictor of success for paroxysmal AF patients, in patients with persistent AF, asymmetry (ASI) supersedes volume and remains the most significant predictor of AF recurrence. These findings support the use of LA asymmetry (ASI) for patient selection and treatment strategy in advanced AF stages.

We also found that LA symmetry changes are associated with LA dilatation, diastolic dysfunction and higher levels of high-sensitive Interleukin-6 (hs-IL6) and that wall-deformation correlates with the extent of low-voltage areas. Therefore, appropriate early (maybe rhythm or anti-inflammatory) treatment should be considered for AF patients with DD (or high hs-IL6 levels), before LA symmetry changes progress. On the other hand a more elaborate substratetargeting strategy should be used for those with advanced atrial wall changes.

Taken together, these findings underline the importance of atrial anatomy in AF patients and the need for patient-specific anatomical information. The results presented here may pave the way for improved anticoagulation and rhythm management of AF patients or further studies that will investigate the hypotheses and the questions generated by this thesis. 


\section{References:}

1. Bunch TJ, Crandall BG, Weiss JP, May HT, Bair TL, Osborn JS, Anderson JL, Muhlestein JB, Horne BD, Lappe DL, Day JD. Patients treated with catheter ablation for atrial fibrillation have long-term rates of death, stroke, and dementia similar to patients without atrial fibrillation. Journal of cardiovascular electrophysiology Aug 2011;22:839-845.

2. Bunch TJ, May HT, Bair TL, Weiss JP, Crandall BG, Osborn JS, Mallender C, Anderson JL, Muhlestein BJ, Lappe DL, Day JD. Atrial fibrillation ablation patients have long-term stroke rates similar to patients without atrial fibrillation regardless of CHADS2 score. Heart Rhythm Sep 2013;10:1272-1277.

3. Chao TF, Lin YJ, Tsao HM, et al. CHADS(2) and CHA(2)DS(2)-VASc scores in the prediction of clinical outcomes in patients with atrial fibrillation after catheter ablation. $\mathrm{J}$ Am Coll Cardiol Nov 29 2011;58:2380-2385.

4. Guiot A, Jongnarangsin K, Chugh A, et al. Anticoagulant therapy and risk of cerebrovascular events after catheter ablation of atrial fibrillation in the elderly. Journal of cardiovascular electrophysiology Jan 2012;23:36-43.

5. Kornej J, Hindricks G, Kosiuk J, Arya A, Sommer P, Husser D, Rolf S, Richter S, Piorkowski C, Gaspar T, Lip GY, Bollmann A. Renal dysfunction, stroke risk scores (CHADS2, CHA2DS2-VASc, and R2CHADS2), and the risk of thromboembolic events after catheter ablation of atrial fibrillation: the Leipzig Heart Center AF Ablation Registry. Circ Arrhythm Electrophysiol Oct 2013;6:868-874.

6. Hunter RJ, McCready J, Diab I, et al. Maintenance of sinus rhythm with an ablation strategy in patients with atrial fibrillation is associated with a lower risk of stroke and death. Heart Jan 2012;98:48-53.

7. Blackshear JL, Odell JA. Appendage obliteration to reduce stroke in cardiac surgical patients with atrial fibrillation. Ann Thorac Surg Feb 1996;61:755-759.

8. Sievert H, Lesh MD, Trepels $\mathrm{T}$, et al. Percutaneous left atrial appendage transcatheter occlusion to prevent stroke in high-risk patients with atrial fibrillation: early clinical experience. Circulation Apr 23 2002;105:1887-1889.

9. Ostermayer SH, Reisman M, Kramer $\mathrm{PH}$, et al. Percutaneous left atrial appendage transcatheter occlusion (PLAATO system) to prevent stroke in high-risk patients with nonrheumatic atrial fibrillation: results from the international multi-center feasibility trials. J Am Coll Cardiol Jul 5 2005;46:9-14.

10. Noda T, Arakawa M, Miwa H, Ito Y, Kagawa K, Nishigaki K, Hirakawa S, Fujiwara H. Effects of heart rate on flow velocity of the left atrial appendage in patients with nonvalvular atrial fibrillation. Clin Cardiol Apr 1996;19:295-300.

11. Obel OA, Luddington L, Maarouf N, Aytemir K, Ekwall C, Malik M, Camm AJ. Effects of ventricular rate and regularity on the velocity and magnitude of left atrial appendage flow in atrial fibrillation. Heart Jun 2005;91:764-768.

12. Somerville W, Chambers RJ. Systemic Embolism in Mitral Stenosis: Relation to the Size of the Left Atrial Appendix. Br Med J Nov 7 1964;2:1167-1169.

13. Ernst G, Stollberger C, Abzieher F, Veit-Dirscherl W, Bonner E, Bibus B, Schneider B, Slany J. Morphology of the left atrial appendage. Anat Rec Aug 1995;242:553-561.

14. Park HC, Shin J, Ban JE, Choi JI, Park SW, Kim YH. Left atrial appendage: morphology and function in patients with paroxysmal and persistent atrial fibrillation. Int $\mathrm{J}$ Cardiovasc Imaging Apr 2013;29:935-944. 
15. Beinart R, Heist EK, Newell JB, Holmvang G, Ruskin JN, Mansour M. Left atrial appendage dimensions predict the risk of stroke/TIA in patients with atrial fibrillation. Journal of cardiovascular electrophysiology Jan 2011;22:10-15.

16. Khurram IM, Dewire J, Mager M, et al. Relationship between left atrial appendage morphology and stroke in patients with atrial fibrillation. Heart Rhythm Dec 2013;10:18431849.

17. Di Biase L, Santangeli P, Anselmino M, et al. Does the left atrial appendage morphology correlate with the risk of stroke in patients with atrial fibrillation? Results from a multicenter study. J Am Coll Cardiol Aug 7 2012;60:531-538.

18. Kimura T, Takatsuki S, Inagawa K, Katsumata Y, Nishiyama T, Nishiyama N, Fukumoto K, Aizawa Y, Tanimoto Y, Tanimoto K, Jinzaki M, Fukuda K. Anatomical characteristics of the left atrial appendage in cardiogenic stroke with low CHADS2 scores. Heart Rhythm Jun 2013;10:921-925.

19. Anselmino M, Scaglione M, Di Biase L, Gili S, Santangeli P, Corsinovi L, Pianelli M, Cesarani F, Faletti R, Righi D, Natale A, Gaita F. Left atrial appendage morphology and silent cerebral ischemia in atrial fibrillation patients. Heart Rhythm Jan 2014;11:2-7.

20. Heidbuchel H, Verhamme P, Alings M, Antz M, Hacke W, Oldgren J, Sinnaeve P, Camm AJ, Kirchhof P. EHRA practical guide on the use of new oral anticoagulants in patients with nonvalvular atrial fibrillation: executive summary. Eur Heart J Jul 2013;34:2094-2106.

21. Nedios S, Kornej J, Koutalas E, Bertagnolli L, Kosiuk J, Rolf S, Arya A, Sommer P, Husser D, Hindricks G, Bollmann A. Left atrial appendage morphology and thromboembolic risk after catheter ablation for atrial fibrillation. Heart Rhythm Dec 2014;11:2239-2246.

22. Ren JF, Marchlinski FE, Callans DJ, Gerstenfeld EP, Dixit S, Lin D, Nayak HM, Hsia HH. Increased intensity of anticoagulation may reduce risk of thrombus during atrial fibrillation ablation procedures in patients with spontaneous echo contrast. J Cardiovasc Electrophysiol May 2005; 16:474-477.

23. Hoffmeister PS, Chaudhry GM, Mendel J, Almasry I, Tahir S, Marchese T, Haffajee CI, Orlov MV. Evaluation of left atrial and posterior mediastinal anatomy by multidetector helical computed tomography imaging: relevance to ablation. J Interv Card Electrophysiol Apr 2007;18:217-223.

24. Sanfilippo AJ, Abascal VM, Sheehan M, Oertel LB, Harrigan P, Hughes RA, Weyman AE. Atrial enlargement as a consequence of atrial fibrillation. A prospective echocardiographic study. Circulation Sep 1990;82:792-797.

25. Nakamura K, Funabashi N, Uehara M, Ueda M, Murayama T, Takaoka H, Komuro I. Left atrial wall thickness in paroxysmal atrial fibrillation by multislice-CT is initial marker of structural remodeling and predictor of transition from paroxysmal to chronic form. Int $\mathrm{J}$ Cardiol Apr 14 2011;148:139-147.

26. Pan NH, Tsao HM, Chang NC, Chen YJ, Chen SA. Aging dilates atrium and pulmonary veins: implications for the genesis of atrial fibrillation. Chest Jan 2008;133:190-196.

27. Huang JL, Tai CT, Lin YJ, Ting CT, Chen YT, Chang MS, Lin FY, Lai WT, Chen SA. The mechanisms of an increased dominant frequency in the left atrial posterior wall during atrial fibrillation in acute atrial dilatation. Journal of cardiovascular electrophysiology Feb 2006;17:178-188.

28. Kalifa J, Tanaka K, Zaitsev AV, et al. Mechanisms of wave fractionation at boundaries of high-frequency excitation in the posterior left atrium of the isolated sheep heart during atrial fibrillation. Circulation Feb 7 2006;113:626-633. 
29. Haissaguerre M, Sanders P, Hocini M, et al. Catheter ablation of long-lasting persistent atrial fibrillation: critical structures for termination. Journal of cardiovascular electrophysiology Nov 2005; 16:1125-1137.

30. Schmitt C, Estner H, Hecher B, Luik A, Kolb C, Karch M, Ndrepepa G, Zrenner B, Hessling G, Deisenhofer I. Radiofrequency ablation of complex fractionated atrial electrograms (CFAE): preferential sites of acute termination and regularization in paroxysmal and persistent atrial fibrillation. J Cardiovasc Electrophysiol Sep 2007;18:1039-1046.

31. Themistoclakis S, Schweikert RA, Saliba WI, Bonso A, Rossillo A, Bader G, Wazni O, Burkhardt DJ, Raviele A, Natale A. Clinical predictors and relationship between early and late atrial tachyarrhythmias after pulmonary vein antrum isolation. Heart Rhythm May 2008;5:679-685.

32. Pappone C, Rosanio S, Augello G, et al. Mortality, morbidity, and quality of life after circumferential pulmonary vein ablation for atrial fibrillation: outcomes from a controlled nonrandomized long-term study. J Am Coll Cardiol Jul 16 2003;42:185-197.

33. Helms AS, West JJ, Patel A, Lipinski MJ, Mangrum JM, Mounsey JP, Dimarco JP, Ferguson JD. Relation of left atrial volume from three-dimensional computed tomography to atrial fibrillation recurrence following ablation. Am J Cardiol Apr 1 2009;103:989-993.

34. Hof I, Chilukuri K, Arbab-Zadeh A, Scherr D, Dalal D, Nazarian S, Henrikson C, Spragg D, Berger R, Marine J, Calkins H. Does left atrial volume and pulmonary venous anatomy predict the outcome of catheter ablation of atrial fibrillation? J Cardiovasc Electrophysiol Sep 2009;20:1005-1010.

35. Badano LP, Pezzutto N, Marinigh R, Cinello M, Nucifora G, Pavoni D, Gianfagna P, Fioretti PM. How many patients would be misclassified using M-mode and two-dimensional estimates of left atrial size instead of left atrial volume? A three-dimensional echocardiographic study. J Cardiovasc Med (Hagerstown) May 2008;9:476-484.

36. Nedios S, Tang M, Roser M, Solowjowa N, Gerds-Li JH, Fleck E, Kriatselis C. Characteristic changes of volume and three-dimensional structure of the left atrium in different forms of atrial fibrillation: predictive value after ablative treatment. J Interv Card Electrophysiol Nov 2011;32:87-94.

37. Bisbal F, Guiu E, Calvo N, et al. Left atrial sphericity: a new method to assess atrial remodeling. Impact on the outcome of atrial fibrillation ablation. Journal of cardiovascular electrophysiology Jul 2013;24:752-759.

38. Vandenberg BF, Weiss RM, Kinzey J, Acker M, Stark CA, Stanford W, Burns TL, Marcus ML, Kerber RE. Comparison of left atrial volume by two-dimensional echocardiography and cine-computed tomography. Am J Cardiol Apr 1 1995;75:754-757.

39. Montefusco A, Biasco L, Blandino A, Cristoforetti Y, Scaglione M, Caponi D, Di Donna P, Boffano C, Cesarani F, Coin D, Perversi J, Gaita F. Left atrial volume at MRI is the main determinant of outcome after pulmonary vein isolation plus linear lesion ablation for paroxysmal-persistent atrial fibrillation. J Cardiovasc Med (Hagerstown) Aug 2010;11:593598.

40. Hauser TH, McClennen S, Katsimaglis G, Josephson ME, Manning WJ, Yeon SB. Assessment of left atrial volume by contrast enhanced magnetic resonance angiography. $\mathrm{J}$ Cardiovasc Magn Reson 2004;6:491-497.

41. Hof I, Arbab-Zadeh A, Scherr D, Chilukuri K, Dalal D, Abraham T, Lima J, Calkins H. Correlation of left atrial diameter by echocardiography and left atrial volume by computed tomography. Journal of cardiovascular electrophysiology Feb 2009;20:159-163.

42. Abecasis J, Dourado R, Ferreira A, Saraiva C, Cavaco D, Santos KR, Morgado FB, Adragao $\mathrm{P}$, Silva A. Left atrial volume calculated by multi-detector computed tomography may predict 
successful pulmonary vein isolation in catheter ablation of atrial fibrillation. Europace Oct 2009;11:1289-1294.

43. Parikh SS, Jons C, McNitt S, Daubert JP, Schwarz KQ, Hall B. Predictive capability of left atrial size measured by CT, TEE, and TTE for recurrence of atrial fibrillation following radiofrequency catheter ablation. Pacing Clin Electrophysiol May 2010;33:532-540.

44. Shin SY, Yong HS, Na JO, et al. A simplified method to determine left atrial volume and transport function using multi-slice computed tomography in patients with atrial fibrillation: comparison with transthoracic echocardiography. Int $\mathrm{J}$ Cardiovasc Imaging Jun 2012;28:1205-1216.

45. den Uijl DW, Tops LF, Delgado V, Schuijf JD, Kroft LJ, de Roos A, Boersma E, Trines SA, Zeppenfeld K, Schalij MJ, Bax JJ. Effect of pulmonary vein anatomy and left atrial dimensions on outcome of circumferential radiofrequency catheter ablation for atrial fibrillation. Am J Cardiol Jan 15 2011;107:243-249.

46. von Bary C, Dornia C, Eissnert C, et al. Predictive value of left atrial volume measured by non-invasive cardiac imaging in the treatment of paroxysmal atrial fibrillation. $\mathrm{J}$ Interv Card Electrophysiol Aug 2012;34:181-188.

47. Avelar E, Durst R, Rosito GA, Thangaroopan M, Kumar S, Tournoux F, Chan RC, Hung J, Hoffmann U, Abbara S, Brady T, Cury RC. Comparison of the accuracy of multidetector computed tomography versus two-dimensional echocardiography to measure left atrial volume. Am J Cardiol Jul 1 2010;106:104-109.

48. Al-Mohaissen MA, Kazmi MH, Chan KL, Chow BJ. Validation of two-dimensional methods for left atrial volume measurement: a comparison of echocardiography with cardiac computed tomography. Echocardiography Nov 2013;30:1135-1142.

49. Nedios S, Koutalas E, Kosiuk J, Sommer P, Arya A, Richter S, Rolf S, Husser D, Hindricks G, Bollmann A. Impact of asymmetrical dilatation of the left atrium on the long-term success after catheter ablation of atrial fibrillation. Int J Cardiol Apr 1 2015;184:315-317.

50. Nedios S, Kosiuk J, Koutalas E, Kornej J, Sommer P, Arya A, Richter S, Rolf S, Husser D, Hindricks G, Bollmann A. Comparison of left atrial dimensions in CT and echocardiography as predictors of long-term success after catheter ablation of atrial fibrillation. J Interv Card Electrophysiol Sep 2015;43:237-244.

51. Tsang TS, Barnes ME, Gersh BJ, Bailey KR, Seward JB. Left atrial volume as a morphophysiologic expression of left ventricular diastolic dysfunction and relation to cardiovascular risk burden. Am J Cardiol Dec 15 2002;90:1284-1289.

52. Tsang TS, Gersh BJ, Appleton CP, Tajik AJ, Barnes ME, Bailey KR, Oh JK, Leibson C, Montgomery SC, Seward JB. Left ventricular diastolic dysfunction as a predictor of the first diagnosed nonvalvular atrial fibrillation in 840 elderly men and women. J Am Coll Cardiol Nov 6 2002;40:1636-1644.

53. Lee JS, Shim CY, Wi J, Joung B, Ha JW, Lee MH, Pak HN. Left ventricular diastolic function is closely associated with mechanical function of the left atrium in patients with paroxysmal atrial fibrillation. Circ J 2013;77:697-704.

54. El Aouar LM, Meyerfreud D, Magalhaes P, Rodrigues SL, Baldo MP, Brasil Y, El Aouar SM, El Aouar NA, Mill JG, Campos Filho O. Relationship between left atrial volume and diastolic dysfunction in 500 Brazilian patients. Arq Bras Cardiol Jul 2013;101:52-58.

55. Pritchett AM, Mahoney DW, Jacobsen SJ, Rodeheffer RJ, Karon BL, Redfield MM. Diastolic dysfunction and left atrial volume: a population-based study. J Am Coll Cardiol Jan 4 2005;45:87-92.

56. Yavuz B, Deniz A, Ertugrul DT, Deveci OS, Yalcin AA, Ata N, Kucukazman M, Dal K, Tutal E. A novel echocardiographic marker in hypertensive patients: is diastolic dysfunction 
associated with atrial electromechanical abnormalities in hypertension? J Clin Hypertens (Greenwich) Sep 2010;12:687-692.

57. Hu YF, Hsu TL, Yu WC, et al. The impact of diastolic dysfunction on the atrial substrate properties and outcome of catheter ablation in patients with paroxysmal atrial fibrillation. Circ J Oct 2010;74:2074-2078.

58. Tsai CT, Hwang JJ, Shih YC, Chiang FT, Lai LP, Lin JL. Evolution of left atrial systolic and diastolic functions in different stages of hypertension: distinct effects of blood pressure control. Cardiology 2008;109:180-187.

59. Cha YM, Wokhlu A, Asirvatham SJ, et al. Success of ablation for atrial fibrillation in isolated left ventricular diastolic dysfunction: a comparison to systolic dysfunction and normal ventricular function. Circ Arrhythm Electrophysiol Oct 2011;4:724-732.

60. Reant P, Lafitte S, Jais P, Serri K, Weerasooriya R, Hocini M, Pillois X, Clementy J, Haissaguerre M, Roudaut R. Reverse remodeling of the left cardiac chambers after catheter ablation after 1 year in a series of patients with isolated atrial fibrillation. Circulation Nov 8 2005;112:2896-2903.

61. Onorati F, Bilotta M, Borrello F, Vatrano M, di Virgilio A, Comi MC, Perticone F, Renzulli A. Successful radiofrequency ablation determines atrio-ventricular remodelling and improves systo-diastolic function at tissue Doppler-imaging. Eur J Cardiothorac Surg Mar 2007;31:414-421; discussion 421-412.

62. Kornej J, Dinov B, Blann AD, Rolf S, Arya A, Schmidl J, Husser D, Hindricks G, Bollmann A, Lip GY. Effects of radiofrequency catheter ablation of atrial fibrillation on soluble Pselectin, von Willebrand factor and IL-6 in the peripheral and cardiac circulation. PLoS One 2014;9:e111760.

63. Kornej J, Reinhardt C, Kosiuk J, Arya A, Hindricks G, Adams V, Husser D, Bollmann A. Response of high-sensitive C-reactive protein to catheter ablation of atrial fibrillation and its relation with rhythm outcome. PLoS One 2012;7:e44165.

64. Dierckx H, Brisard E, Verschelde H, Panfilov AV. Drift laws for spiral waves on curved anisotropic surfaces. Phys Rev E Stat Nonlin Soft Matter Phys Jul 2013;88:012908.

65. Gonzales MJ, Vincent KP, Rappel WJ, Narayan SM, McCulloch AD. Structural contributions to fibrillatory rotors in a patient-derived computational model of the atria. Europace Nov 2014;16 Suppl 4:iv3-iv10.

66. Whitaker J, Rajani R, Chubb H, Gabrawi M, Varela M, Wright M, Niederer S, O'Neill MD. The role of myocardial wall thickness in atrial arrhythmogenesis. Europace Dec 2016;18:1758-1772.

67. Marrouche NF, Wilber D, Hindricks G, et al. Association of atrial tissue fibrosis identified by delayed enhancement MRI and atrial fibrillation catheter ablation: the DECAAF study. Jama Feb 5 2014;311:498-506.

68. Varela M, Bisbal F, Zacur E, Berruezo A, Aslanidi OV, Mont L, Lamata P. Novel Computational Analysis of Left Atrial Anatomy Improves Prediction of Atrial Fibrillation Recurrence after Ablation. Front Physiol 2017;8:68. 


\section{Summary}

Catheter ablation and stroke prevention with anticoagulation or other alternatives have evolved into an established therapy for atrial fibrillation (AF). Although atrial anatomy has an important pathophysiologic role, its relationship with relevant AF outcomes like thromboembolic events (TE) and long-term rhythm stability after AF ablation have not been adequately examined yet.

The aim of this thesis is to elaborate the significance of atrial anatomy and ablation outcomes in the following cases: (1) the relation of left atrial appendage (LAA) and the TEs in patients not well described by the common clinical risk scores, (2) the characterstics of left atrial (LA) remodeling in AF patients, (3) the effect of these changes on ablation outcomes, (4) the relationship of LA remodeling with LV diastolic dysfunction, plasma markers and LA lowvoltage areas as surrogates of AF substrate (Chapter 1).

We found that AF recurrence and a higher LAA takeoff are associated with an increased TE risk after ablation, probably due to a tachycardia-mediated thrombogenic flow that was also seen in $\mathrm{AF}$ patients with low $\mathrm{CHA}_{2} \mathrm{DS}_{2}$-VASc score and higher LAA takeoff (Chapters 2-3). On the contrary, peri-procedural TEs were found to be associated with a chicken-wing LAA morphology due to an LAA reservoir function. These findings may have implications for an appropriate clinical or anticoagulation therapy of these patients and deserve further evaluation (Chapter 4).

In order to describe LA remodeling, we developed a new index of asymmetry (ASI) and compared LA anatomy of AF patients with healthy individuals. We found that LA remodeling involves both size and symmetry changes, which are related to AF-type and recurrences after AF ablation. We have shown that asymmetry increases as the LA expands, but this is diminished in patients with already asymmetric dilated atria, such as in persistent AF (Chapters 5). We found that the transversal LA diameter is the best single-linear predictor, comparable to LA volume and stronger than the commonly used echocardiographic diameter (Chapter 6). Moreover, we have shown that although LA volume is the best predictor of success for paroxysmal AF patients, in patients with persistent AF, asymmetry (ASI) is the most significant predictor (Chapter 7). We also found that LA symmetry changes are associated with LA dilatation, diastolic dysfunction and higher levels of high-sensitive Interleukin-6 (Chapters 8-9). Finally, we found that walldeformation correlates with the extent of low-voltage areas (Chapter 10).

Taken together, these findings point out the importance of atrial anatomy in AF patients and the need for patient-specific anatomical information. The results presented here may pave the way for improved patient-tailored therapy of AF patients or prompt further studies that will elaborate the implications of this thesis. 


\section{Zusammenfassung}

Die Katheterablation und die Schlaganfallprävention gehören zu den etablierten Therapien für Vorhofflimmern (VHF). Obwohl die atriale Anatomie eine wichtige pathophysiologische Rolle spielt, ist ihre Assoziation mit relevanten Ergebnissen wie thromboembolischen Ereignissen (TE) und langfristiger Rhythmusstabilität nach Ablation noch nicht ausreichend untersucht worden.

Ziel dieser Habilitationsschrift ist es, die Bedeutung der atrialen Anatomie und der AblationsErgebnissen in den folgenden Fällen zu erarbeiten: (1) die Relevanz des linken Herzohrs (LAA) für TE bei Patienten mit geringem oder unklarem klinischen Risiko, (2) die Merkmale von linksatrialem (LA) Remodeling, (3) die Bedeutung von LA Remodeling für die AblationsErgebnisse, (4) seine Assoziation mit der LV-diastolischen Dysfunktion, Plasmamarkern und LA Areale mit Niedervoltage (LVAs) als Surrogaten vom VHF-Substrat (Kapitel 1).

Für Patienten nach einer VHF-Ablation wird gezeigt, wie die Rezidive und die höhere LAAPosition mit einem Tachykardie-assoziierten thrombogenen Fluss und einem erhöhten TE-Risiko einher gehen. Der gleiche Mechanismus wird bei VHF-Patienten mit niedrigem klinischen Risiko ( $\mathrm{CHA}_{2} \mathrm{DS}_{2}$-VASc-Score) bestätigt (Kapitel 2-3). Bei Patienten mit peri-prozeduralen TEs zeigt sich aber ein anderer Mechanismus; eine Reservoir-Funktion der Hühnerflügel-LAAMorphologie. Diese Befunde könnten die Therapie solcher Patienten ändern und sollten weiter untersucht werden (Kapitel 4).

Zur Beschreibung des LA-Remodelings wurde ein neuer Asymmetrie-Index (ASI) entwickelt und die Anatomie von VHF-Patienten mit einer Kontrollgruppe verglichen. Als Merkmale des Remodelings zeigten sich die Dilatation und die Asymmetrie, die beide mit dem VHF-Typ und dem langfristigen Erfolg nach Ablation verbunden sind. Es wurde gezeigt, dass die Asymmetrie zunimmt, wenn sich das LA vergrößert, aber dies ist weniger ausgeprägt bei Patienten mit bereits dilatierten Atrien (Kapitel 5). Dementsprechend ist der prädiktiver Wert, des transversalen LADurchmessers, vergleichbar zu dem LA-Volumen und besser als von dem meist-verwendeten echokardiographischen Durchmesser (Kapitel 6). Obwohl sich das LA Volumen als der beste Erfolgsprädiktor für paroxysmales VHF zeigte, war nur ASI der wichtigste Prädiktor für Patienten mit persistentem VHF (Kapitel 7). Darüber hinaus zeigte sich eine Assoziation zwischen ASI, LA-Dilatation, der diastolischen Dysfunktion und erhöhte Werte von Interleukin-6 (Kapitel 8-9). Zusätzlich haben wir gezeigt, dass die Wanddeformation mit der Ausdehnung von Arealen mit Niedervoltage korreliert (Kapitel 10).

Zusammengenommen unterstreichen diese Ergebnisse die Bedeutung der atrialen Anatomie bei VHF-Patienten und den Bedarf an patientenspezifischen anatomischen Informationen vor dem Eingriff. Diese Ergebnisse könnten den Weg für eine verbesserte, auf den Patienten zugeschnittene Therapie bei VHF-Patienten ebnen und weitere Studien veranlassen. 


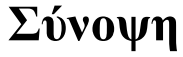

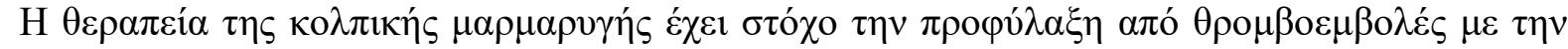

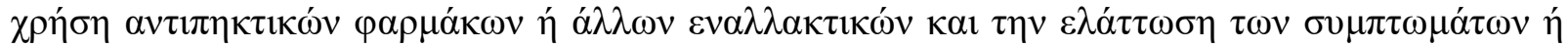

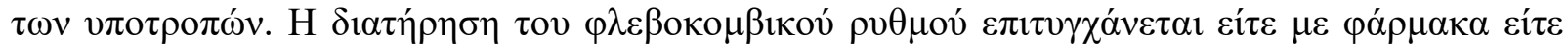

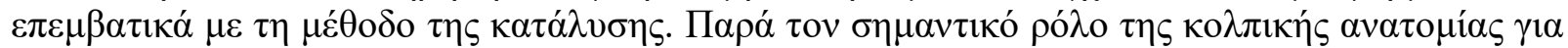

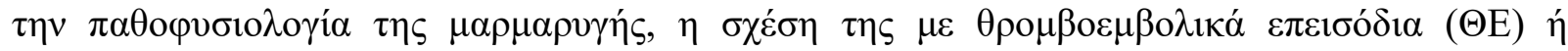

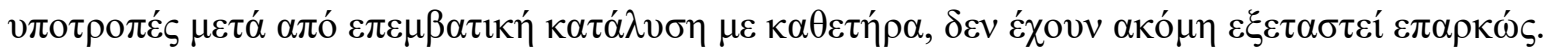

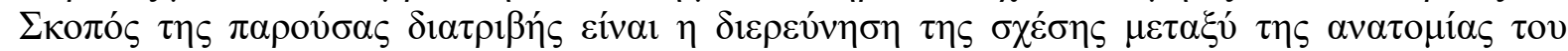

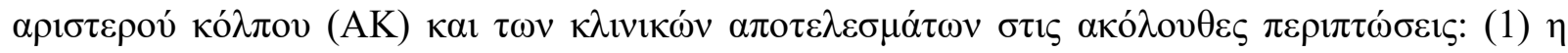

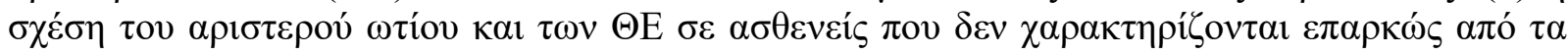

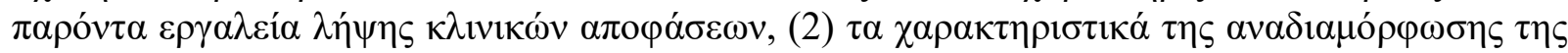

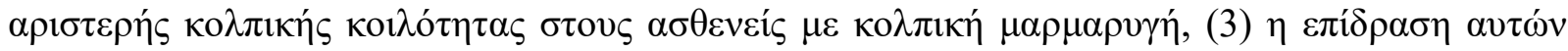

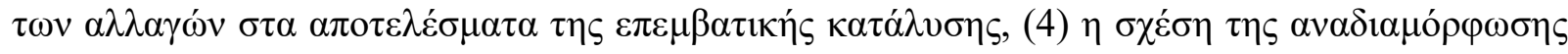

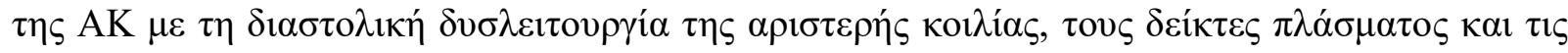

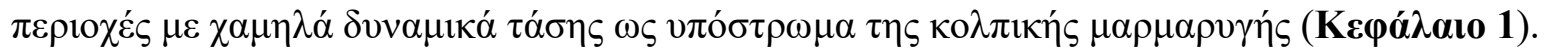

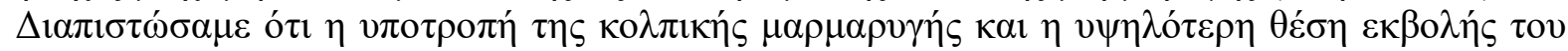

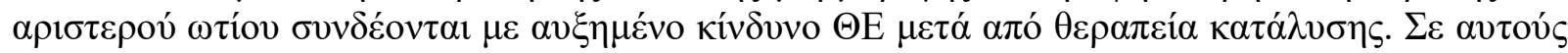

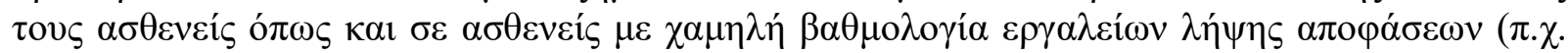

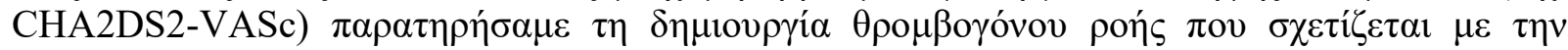

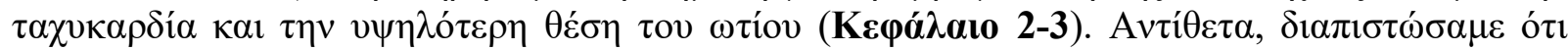

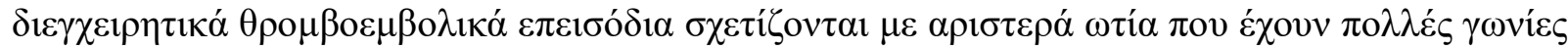

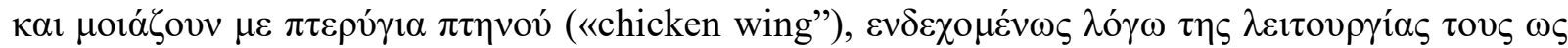

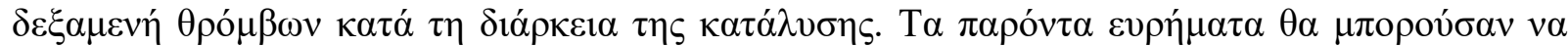

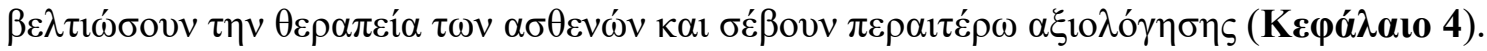

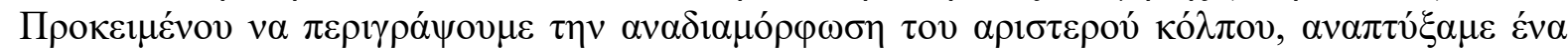

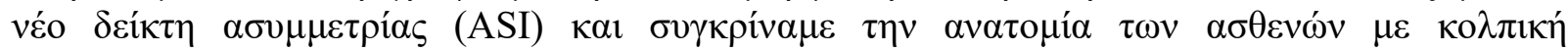

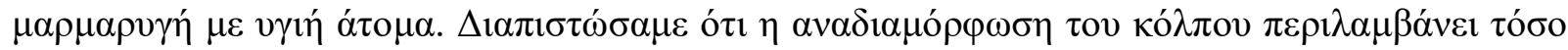

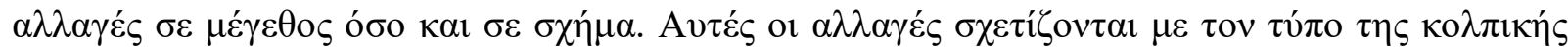

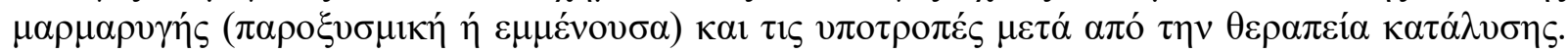

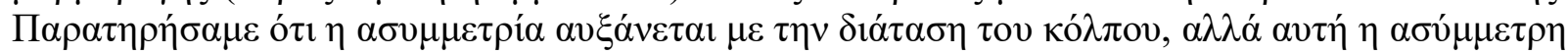

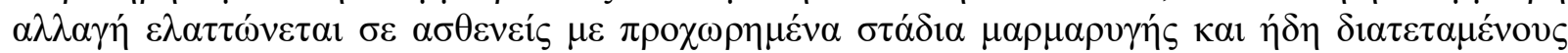

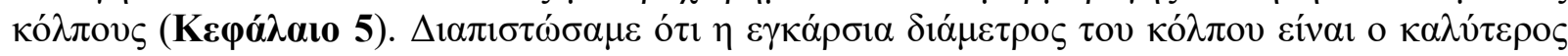

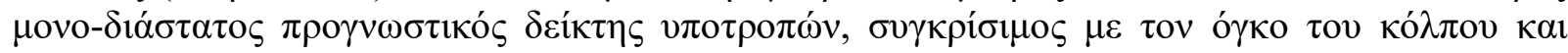

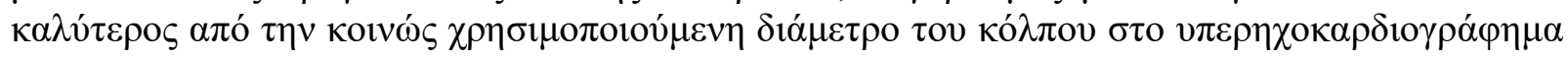

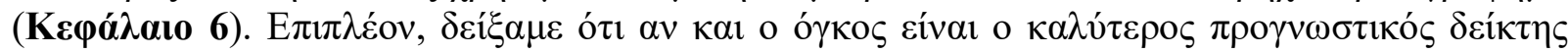

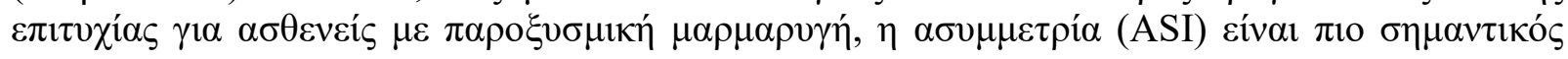

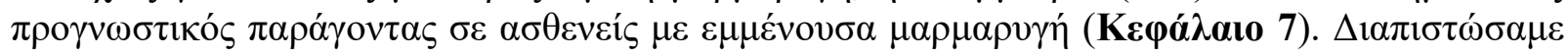

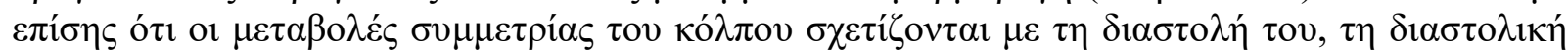

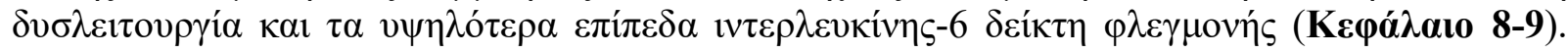

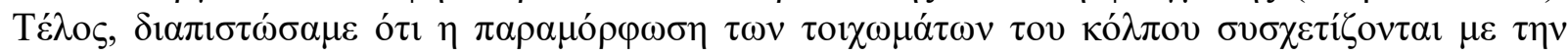

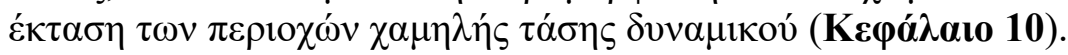

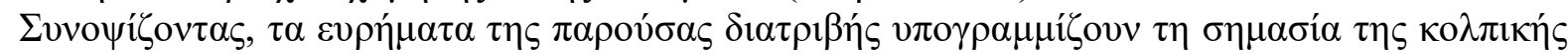

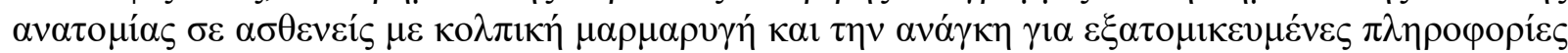

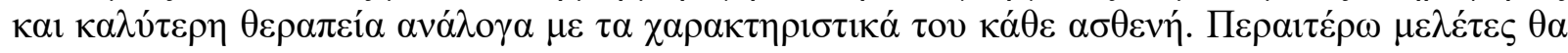

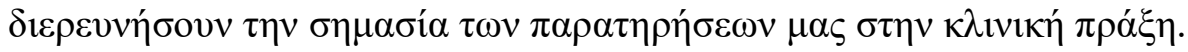




\section{Impact}

This chapter describes how the outcomes of this thesis could contribute to society and specifically to the great number of patients we serve, to the physicians that treat them and the industry. The results described in this thesis are relevant for future research especially for imaging-based prognostic models that will guide clinical management of patients with atrial fibrillation (AF) as explained below. Our publications have influenced the current guidelines and clinical practice; ${ }^{1-6}$ inspired other groups to conduct relevant research ${ }^{7-15}$ and have spawned projects and collaborations ${ }^{16-18}$ that brought together expertise from across different departments of renowned research institutions like the Heart Center Leipzig, the Maastricht University, the Massachusetts General Hospital of Harvard University and the Department of Bioengineering in the University of Pittsburgh. ${ }^{19-22}$

\section{Background}

$\mathrm{AF}$ is the most common arrhythmia with an increasing prevalence in an aging population. AF patients are expected to double in the next 30 years to more than 14 million in Europe alone. ${ }^{23}$ Despite good progress in AF treatment, this arrhythmia remains one of the major causes of stroke, heart failure, sudden death and cardiovascular morbidity. ${ }^{24-26}$ Due to the epidemic proportions of $\mathrm{AF}$ and the significant burden for public health, identification of surrogates associated with AF pathophysiology that could improve treatment of AF patients is very important.

Although the principal clinical determinant of AF is age, potent adjuvants include hypertension, atherosclerosis and ventricular dysfunction. These determinants are unified by their tendency to increase atrial pressure and volume, which in turn causes chronic elevation in wall stress and elicits an adverse biological response in atrial tissue, culminating in an AF promoting substrate. LA remodeling is in-fact a well-recognized factor in AF pathogenesis. Specific LA changes or specific characteristics of the left atrial appendage (LAA) anatomy may have serious implications, as shown in the results of this thesis. Our work focuses on the identification of specific anatomical characteristics that will allow clinical decisions in a patient-specific way.

\section{Contributions of this thesis to society}

This thesis elaborates the significance of atrial anatomy and ablation outcomes in the following specific cases: (1) the relation of LAA and thromboembolic events (TEs) in patients not well described by the common clinical risk scores, (2) the characteristics of LA remodeling in AF patients, (3) the effect of these changes on ablation outcomes, (4) the relationship of LA remodeling with LV diastolic dysfunction or plasma markers and (5) the effect of AF ablation on LV function in patients with heart failure.

In order to evaluate the importance of LAA for the TE risk in patients not adequately described by the common $\mathrm{CHA}_{2} \mathrm{DS}_{2}$-VASc criteria, we compared patients that had prior-, post- or periinterventional TEs with matched patients from our prospective AF catheter ablation registry. We found that TEs after an AF ablation are associated with AF recurrence and a higher LAAtakeoff, implying a possible tachycardia-mediated thrombogenic risk, depending on the distance to the mitral valve rather than the LAA morphology. Although this association was also found in low $\mathrm{CHA}_{2} \mathrm{DS}_{2}$-VASc score $(\leq 1)$ patients, for peri-interventional TE LAA morphology was more important, presumably through a reservoir function. In summary, our findings showed that the LAA anatomy might be useful for predicting strokes and guide anticoagulation in such patients. 
These results have influenced the current guidelines and clinical practice ${ }^{1,2}$ and encouraged further studies from other groups, ${ }^{7-11}$ that elaborated on the TE risk and thus the therapy of patients beyond the limitations of CHAS-VASc score. ${ }^{27}$

Our work on LA remodeling has better described the complex three-dimensional LA shape changes by measuring different diameters and introducing a novel index of LA asymmetry (ASI). We found that ASI is a reliable measurement that together with volume carries a significant predictive value for the rhythm outcomes after AF catheter ablation. We also found that anatomical remodeling is associated with diastolic dysfunction and plasma markers like hsIL-6. These findings have contributed to the establishment of a more comprehensive pre-procedural evaluation of AF patients, a better understanding of atrial cardiomyopathies ${ }^{2-5}$ and further relevant research. ${ }^{12-15}$ Patients could benefit enormously from a better risk stratification process, where those with early stages are rooted to simple single-shot $\mathrm{AF}$ ablation techniques and those with advanced LA remodeling would undergo a more sophisticated approach. However, additional studies are needed to prove the clinical benefit of our studies.

Finally, we studied the changes in LV function following AF ablation in patients with systolic heart failure. We found that the initial LV-EF improvement could be partially attributed to a better heart rate control, but the long-term improvement was independent of rate changes. This supports the presence of an AF-mediated cardiomyopathy that could be reversed by catheter ablation irrespective of rate control. This has since been confirmed by other independent researches ${ }^{28,29}$ and the randomized trial CASTLE-AF, ${ }^{30-33}$ that revealed a reduction in mortality and hospitalization by catheter ablation of heart failure patients. Patients with AF now can better understand the benefits form catheter ablation and discuss it with their physician.

\section{Future perspectives}

Anatomical characterization has been proven to be a difficult task for physicians, since it is associated with high inter- and intra-observer variability. ${ }^{11}$ Currently there is no accurate automated mathematical model relating anatomical characteristics with clinical outcomes. For this purpose we have joined our efforts with the Bioengineering Lab of Prof. Menon in the University of Pittsburgh. We created new mathematical calculations for describing LAA morphologies using principal component analysis ${ }^{21}$ and wall deformation indexes, validating the relationship between quantitative imaging markers and adverse remodeling (Figure 1). ${ }^{34}$
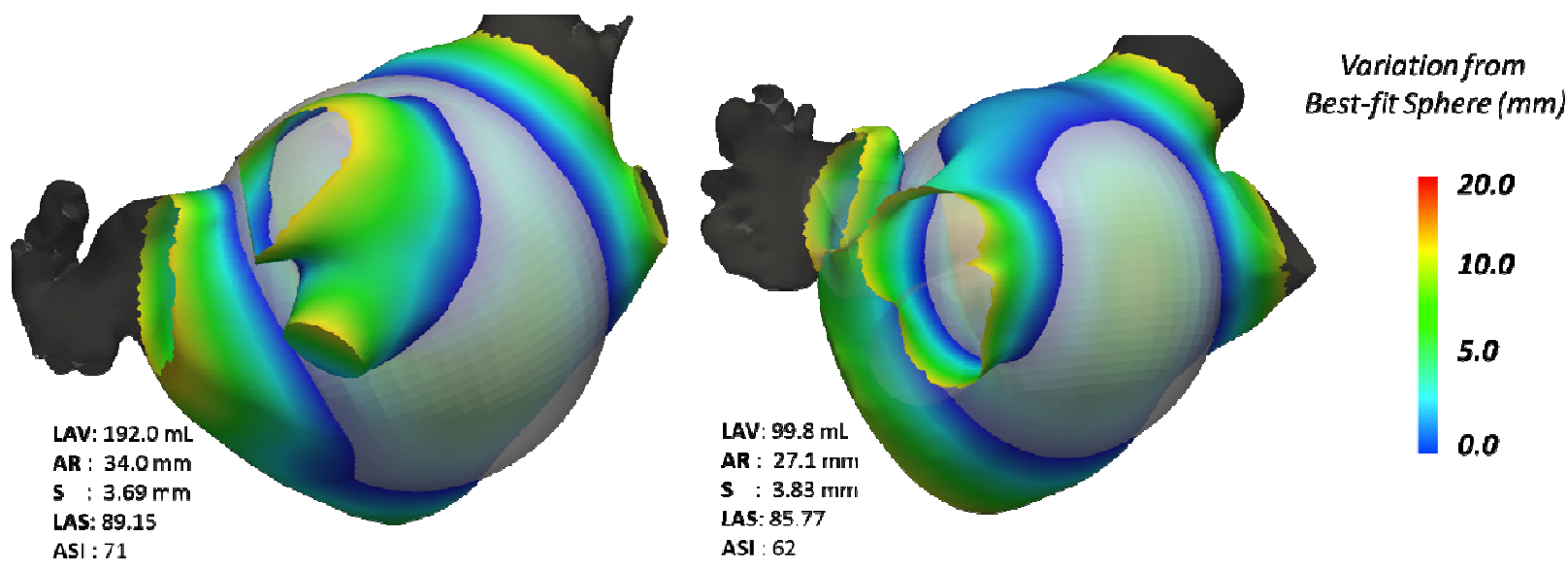

Figure 1. Color-maps of regional shape deviation, volumes (LAV), average radius (AR), LA sphericity (S) and asymmetry (ASI) of two patient-specific anatomical reconstructions. 
Based on our preliminary results, we aim to further investigate the hypothesis that geometry metrics derived from patient-specific LA imaging data can provide an improved characterization of the extent of the disease, as represented by fibrosis or low-voltage areas, and help predict the occurrence of clinical events, such as TEs or recurrence after catheter ablation. To that end we will implement imaging data and plasma markers into a machine-learning based prognostic model developed in collaboration with Prof. Menon (Figure 2, (C) Prof. Menon).
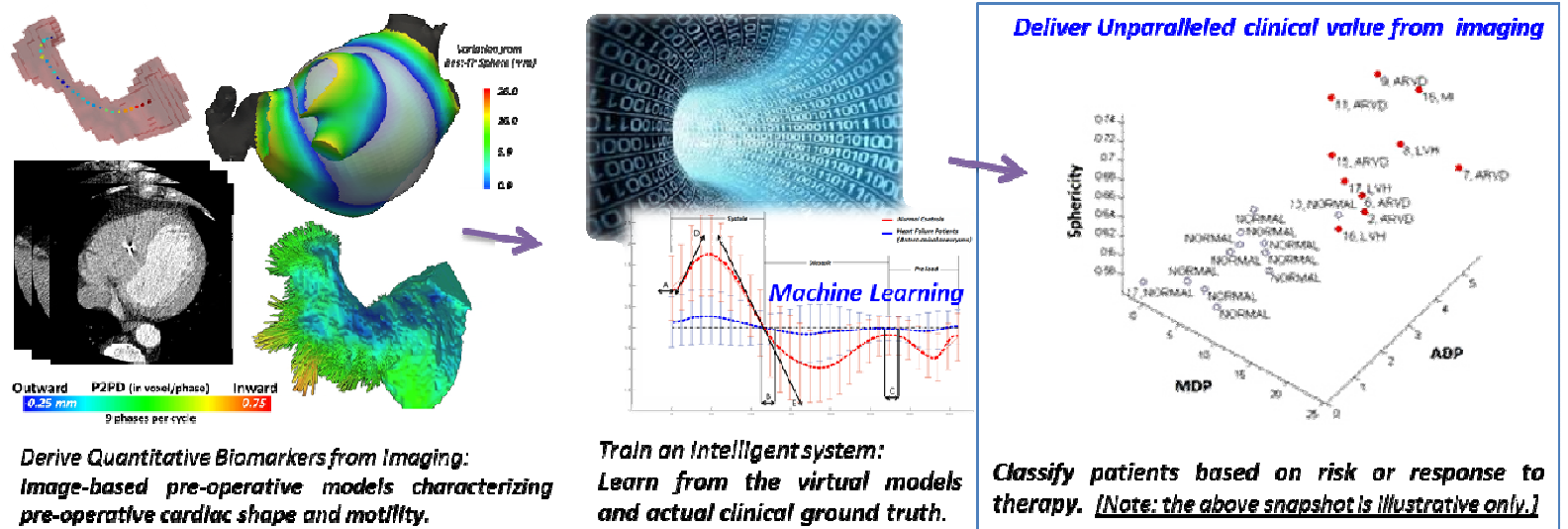

Figure 2. Illustration of the foundation behind the computational research of machine learning.

This represents a kind of artificial intelligence that will spawn simulation projects and results, which are not easy to obtain with common statistical methods. As part of the successful execution of this effort, an open-access software will be released to facilitate 3D atrial model reconstruction, region partitioning and sphericity analysis, starting from DICOM medical images, in the interest of making the science behind this proposal accessible to physicians and surgeons around the world. Additionally, it is proposed to integrate results obtained within a cloud-based system architecture, which facilitates interactive training and testing of specific machine learning classifiers.

This could benefit the society by improving patient selection and thus clinical outcomes, thus reducing healthcare costs. Additionally new opportunities arise for spin-off companies performing such image analysis in a commercial setting and further development of better imaging protocols or tools that could be integrated in the workflow of hospitals. In order to disseminate this knowledge, the results and ongoing research of this thesis will be promoted through the Internet and through established networks of professionals (e.g. DAS-CAM), promoting usage and further collaboration with interested researchers and the future leaders of electrophysiology.

We are entering a new era of "big data" and "artificial intelligence", where collaborations across disciplines will be crucial to implement innovations and advance the field of cardiovascular medicine. ${ }^{35,36}$ There is an urgency to bring together multidisciplinary groups to generate and share "large clean datasets" to expedite the creation of meaningful algorithms. It is towards that end that we extend our expertise to researchers from the bioengineering and medicine fields from around the globe. It is our responsibility to embrace technology and add value to our patient care without loosing our humane touch and keep "technology as a useful servant and not as a dangerous master." 


\section{References}

1. Lupercio F, Carlos Ruiz J, Briceno DF, et al. Left atrial appendage morphology assessment for risk stratification of embolic stroke in patients with atrial fibrillation: A meta-analysis. Heart Rhythm Jul 2016;13:1402-1409.

2. Kirchhof P, Benussi S, Kotecha D, et al. 2016 ESC Guidelines for the management of atrial fibrillation developed in collaboration with EACTS. Eur Heart J Oct 7 2016;37:2893-2962.

3. Goette A, Kalman JM, Aguinaga L, et al. EHRA/HRS/APHRS/SOLAECE expert consensus on atrial cardiomyopathies: definition, characterization, and clinical implication. Europace Oct 2016;18:1455-1490.

4. Njoku A, Kannabhiran M, Arora R, Reddy P, Gopinathannair R, Lakkireddy D, Dominic P. Left atrial volume predicts atrial fibrillation recurrence after radiofrequency ablation: a metaanalysis. Europace Jan 1 2018;20:33-42.

5. Gopinathannair R, Etheridge SP, Marchlinski FE, Spinale FG, Lakkireddy D, Olshansky B. Arrhythmia-Induced Cardiomyopathies: Mechanisms, Recognition, and Management. J Am Coll Cardiol Oct 13 2015;66:1714-1728.

6. Ganesan AN, Nandal S, Luker J, Pathak RK, Mahajan R, Twomey D, Lau DH, Sanders P. Catheter ablation of atrial fibrillation in patients with concomitant left ventricular impairment: a systematic review of efficacy and effect on ejection fraction. Heart Lung Circ Mar 2015;24:270-280.

7. Taina M, Sipola P, Muuronen A, Hedman M, Mustonen P, Kantanen AM, Jakala P, Vanninen R. Determinants of left atrial appendage volume in stroke patients without chronic atrial fibrillation. PLoS One 2014;9:e90903.

8. Hioki M, Matsuo S, Tokutake K, et al. Filling defects of the left atrial appendage on multidetector computed tomography: their disappearance following catheter ablation of atrial fibrillation and the detection of LAA thrombi by MDCT. Heart Vessels Dec 2016;31:20142024.

9. Korhonen M, Parkkonen J, Hedman M, Muuronen A, Onatsu J, Mustonen P, Vanninen R, Taina M. Morphological features of the left atrial appendage in consecutive coronary computed tomography angiography patients with and without atrial fibrillation. PLoS One 2017;12:e0173703.

10. Kelly FR, Hull RA, Arrey-Mbi TB, Williams MU, Lee JS, Slim AM, Thomas DM. Left atrial appendage morphology and risk of stroke following pulmonary vein isolation for drugrefractory atrial fibrillation in low CHA2DS2Vasc risk patients. BMC Cardiovasc Disord Feb $282017 ; 17: 70$.

11. Wu L, Liang E, Fan S, Zheng L, Du Z, Liu S, Hu F, Fan X, Chen G, Ding L, Yao Y. Relation of Left Atrial Appendage Morphology Determined by Computed Tomography to Prior Stroke or to Increased Risk of Stroke in Patients With Atrial Fibrillation. Am J Cardiol Apr 15 2019;123:1283-1286.

12. Bieging ET, Morris A, Wilson BD, McGann CJ, Marrouche NF, Cates J. Left atrial shape predicts recurrence after atrial fibrillation catheter ablation. Journal of cardiovascular electrophysiology Jul 2018;29:966-972.

13. Moon J, Lee HJ, Yu J, Pak HN, Ha JW, Lee MH, Kim YJ, Joung B. Prognostic implication of left atrial sphericity in atrial fibrillation patients undergoing radiofrequency catheter ablation. Pacing Clin Electrophysiol Jun 2017;40:713-720. 
14. Bisbal F, Guiu E, Calvo N, et al. Left atrial sphericity: a new method to assess atrial remodeling. Impact on the outcome of atrial fibrillation ablation. Journal of cardiovascular electrophysiology Jul 2013;24:752-759.

15. Bisbal F, Gomez-Pulido F, Cabanas-Grandio P, et al. Left Atrial Geometry Improves Risk Prediction of Thromboembolic Events in Patients With Atrial Fibrillation. Journal of cardiovascular electrophysiology Jul 2016;27:804-810.

16. Dinov B, Knopp H, Lobe S, Nedios S, Bode K, Schonbauer R, Sommer P, Bollmann A, Arya A, Hindricks G. Patterns of left atrial activation and evaluation of atrial dyssynchrony in patients with atrial fibrillation and normal controls: Factors beyond the left atrial dimensions. Heart Rhythm Sep 2016;13:1829-1836.

17. Lobe S, Knopp H, Le TV, Nedios S, Seewoster T, Bode K, Sommer P, Bollmann A, Hindricks G, Dinov B. Left Atrial Asynchrony Measured by Pulsed-Wave Tissue Doppler Is Associated With Abnormal Atrial Voltage and Recurrences of Atrial Fibrillation After Catheter Ablation. JACC Clin Electrophysiol Dec 2018;4:1640-1641.

18. Seewoster T, Buttner P, Nedios S, Sommer P, Dagres N, Schumacher K, Bollmann A, Hilbert S, Jahnke C, Paetsch I, Hindricks G, Kornej J. Association Between Cardiovascular Magnetic Resonance-Derived Left Atrial Dimensions, Electroanatomical Substrate and NT-proANP Levels in Atrial Fibrillation. J Am Heart Assoc Oct 2 2018;7:e009427.

19. Sanatkhani S, Finoli, M., Shroff, S.G., Menon, P.G. Visualization of Patient-specific Hemodynamics in Atrial Fibrillation Using Computational and Experimental Models. In Proceedings of the 5th International Conference on Computational \& Mathematical Biomedical Engineering Pittsburgh, PA, USA 2017.

20. Sanatkhani S, Menon, P.G. Relating Atrial Appendage Flow Stasis Risk from Computational Fluid Dynamics to Imaging Based Appearance Paradigms for Cardioembolic Risk. Cardoso, MJ (Ed), Imaging for Patient-Customized Simulations and Systems for Point-of-Care Ultrasound BIVPCS 2017, POCUS 2017 Lecture Notes in Computer Science Springer, Québec City, QC, Canada, pp 86-93 2017.

21. Sanatkhani S, Menon, P.G. Generative statistical modeling of left atrial appendage appearance to substantiate clinical paradigms for stroke risk stratification. In Proceedings of the SPIE Medical Imaging Houston, Texas, United States 2018.

22. Menon P.G. NS, Hindricks G., Bollmann A. Investigating Relationships between Left Atrial Volume, Symmetry and Sphericity. SPIE Medical Imaging: International Society for Optics and Photonics Vol 9788 97882J-1 2016.

23. Zoni-Berisso M, Lercari F, Carazza T, Domenicucci S. Epidemiology of atrial fibrillation: European perspective. Clin Epidemiol 2014;6:213-220.

24. Benjamin EJ, Wolf PA, D'Agostino RB, Silbershatz H, Kannel WB, Levy D. Impact of atrial fibrillation on the risk of death: the Framingham Heart Study. Circulation Sep 8 1998;98:946952.

25. Stewart S, Hart CL, Hole DJ, McMurray JJ. A population-based study of the long-term risks associated with atrial fibrillation: 20-year follow-up of the Renfrew/Paisley study. Am J Med Oct 1 2002;113:359-364.

26. Andersson T, Magnuson A, Bryngelsson IL, Frobert O, Henriksson KM, Edvardsson N, Poci D. All-cause mortality in 272,186 patients hospitalized with incident atrial fibrillation 19952008: a Swedish nationwide long-term case-control study. Eur Heart J Apr 2013;34:10611067.

27. Szymanski FM, Lip GY, Filipiak KJ, Platek AE, Hrynkiewicz-Szymanska A, Opolski G. Stroke Risk Factors Beyond the CHA(2)DS(2)-VASc Score: Can We Improve Our 
Identification of "High Stroke Risk" Patients With Atrial Fibrillation? Am J Cardiol Dec 1 2015;116:1781-1788.

28. Barra S, Baran J, Narayanan K, Boveda S, Fynn S, Heck P, Grace A, Agarwal S, Primo J, Marijon E, Providencia R. Association of catheter ablation for atrial fibrillation with mortality and stroke: A systematic review and meta-analysis. Int J Cardiol Sep 1 2018;266:136-142.

29. Anselmino M, Matta M, Castagno D, Giustetto C, Gaita F. Catheter ablation of atrial fibrillation in chronic heart failure: state-of-the-art and future perspectives. Europace May 2016;18:638-647.

30. Littmann L. Catheter Ablation for Atrial Fibrillation with Heart Failure. N Engl J Med Aug 2 2018;379:490.

31. Alvarez P, Bin Abdulhak A, Torner J. Catheter Ablation for Atrial Fibrillation with Heart Failure. N Engl J Med Aug 2 2018;379:490.

32. Link MS. Paradigm Shift for Treatment of Atrial Fibrillation in Heart Failure. N Engl J Med Feb 1 2018;378:468-469.

33. Marrouche NF, Brachmann J, Andresen D, et al. Catheter Ablation for Atrial Fibrillation with Heart Failure. N Engl J Med Feb 1 2018;378:417-427.

34. Menon PG, Nedios S, Hindricks G, Bollmann A. Investigating Relationships between Left Atrial Volume, Symmetry and Sphericity. SPIE Medical Imaging: International Society for Optics and Photonics; 2016.

35. Dey D, Slomka PJ, Leeson P, Comaniciu D, Shrestha S, Sengupta PP, Marwick TH. Artificial Intelligence in Cardiovascular Imaging: JACC State-of-the-Art Review. J Am Coll Cardiol Mar 26 2019;73:1317-1335.

36. Singh JP. It Is Time for Us to Get Artificially Intelligent! JACC Clin Electrophysiol Feb 2019;5:263-265. 


\section{Acknowledgements}

My special thanks go to Prof. Andreas Bollmann, who encouraged and enabled my scientific work in the Heart Center Leipzig and thus the path to this thesis. His continuous and profound support has shaped my scientific work.

I also sincerely wish to thank Prof. Gerhard Hindricks and Prof. Harry Crijns for the constructive feedback as well as for the trust and inspiration provided. The educational program "Diploma of Advanced Studies in Cardiac Arrhythmia Management" by the joint collaboration of the Maastricht University Medical Center (MUMC+), the European Heart Academy (EHA) and the European Heart Rhythm Association (EHRA) has been a transformational travel for me. Thanks to the major contribution of Prof. Hindricks and Prof. Crijns, the DAS-CAM has enabled me to re-define leadership from the inside out and craft my mission in the field of cardiac arrhythmias.

I would also like to thank the staff from the Maastricht University and Heart Center Leipzig for their support of my projects and the various problems encountered. Additionally, I would like to thank the staff from Massachusetts General Hospital, Conor Barrett, Patrick Ellinor, Kevin Heist, Steven Lubitz, Moussa Mansour, Theofanie Mela, David Milan, Farouk Pirzada, Leon Ptaszek, Jeremy Ruskin and Jagmeet Singh for believing and encouraging me even in turbulent times. Finally, I would like to express my deepest appreciation for the time and effort that Jordi Heijman provided for my research culminating into this thesis.

A heartfelt thanks goes to Prof. Prahlad Menon and his students from Pittsburgh, Pennsylvania, who despite the distance trusted me, believed in my ideas and co-created the bioengineering tools necessary to further develop them for the advancement of electrophysiology. I am confident that with their support, machine learning and artificial intelligence will help us shape the electrophysiology of tomorrow and thus improve the care we provide to our patients.

My dearest thanks belong to my parents, Theokleia and Georgios, who always showed understanding for my scientific interest and who supported my endeavors with love and patience. Their support, education and advice have shaped my private and professional career.

Finally, I would like to thank my life partner, Sabrina Wilhelm, who provided me with an environment in which the difficult combination of clinical work, scientific activity, teaching and private life became possible. She reminds me every day that there is no long or difficult road, when you are in good company. 


\section{Curriculum Vitae}

Dr. Sotirios Nedios is a cardiologist with focus on electrophysiology, currently an active researcher and lecturer in the Heart Center, University of Leipzig in Germany. His worked has focused on improving methods of imaging in electrophysiology and elucidating the association between anatomy and clinical outcomes in patients with arrhythmias.

After finishing medical school with honors, he began residency in a tertiary centre in the German capital and gained valuable exposure to interventional cardiology.

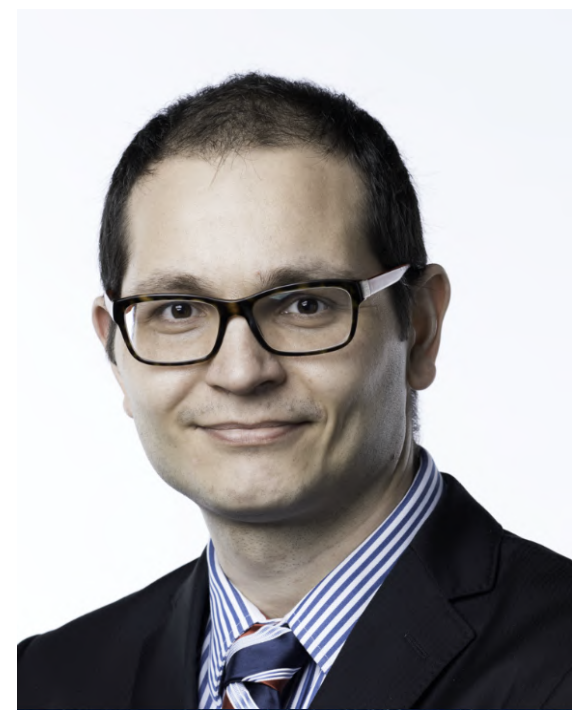

Driven by his interest for EP, his thirst for excellence and supported by research grants he completed his doctoral thesis in the renowned Heart-Centre of Berlin. This study was the first to evaluate rotational atriography (RTA) as a new imaging method for the depiction of the left atrium in atrial fibrillation ablation procedures. It revealed that RTA is feasible, efficient, safe and has less radiation and costs than computed tomography. This experience provided him with broad knowledge and expertise for the imaging of the left atrium, spawning more projects that he continued throughout his postdoctoral research and fellowship training in the Heart Centre of Leipzig and in the Massachusetts General Hospital of Harvard University (MA, USA).

Dr. Nedios was one of the first participants of the groundbreaking programme DAS-CAM: "Diploma of Advanced Studies in Cardiac Arrhythmia Management". This is a joint collaboration between Maastricht University Medical Center (MUMC+), European Heart Academy (EHA) and the European Heart Rhythm Association (EHRA) aiming to train future leaders in arrhythmia management, with focus on cardiovascular innovations, state-of the-art services, research, health economics and modern leadership concepts. The strong collaboration established with MUMC+ during DAS-CAM provided the basis for this PhD thesis.

Among others, Dr. Nedios' research has elucidated the relation of LA shape with predisposing factors and ablation outcomes in patients with atrial fibrillation (AF), the association of left atrial appendage with thromboembolic events before, during or after such ablations and the positive effect of AF therapy in patients with heart failure. His work helped developing novel anatomical indexes, computational approaches and risk stratification models for better patient selection, reduced defibrillator therapies and improved ablation outcomes.

Dr. Nedios has shown commitment to contribute in medical knowledge and to improve patientcentered health care. His earlier faculty appointments included teaching students and residents, established collaborations and led to successful research projects and a number of honors. His academic career is reflected on his prolific publication record over the last years and his on-going collaborations with world-renowned centres. These will facilitate academic partnerships that will advance the state of the art and lead the way to a new era of electrophysiology. 


\section{PERSONAL DATA}

Name: $\quad$ Sotirios Nedios, MD, FHRS

Date of birth: 30.01 .1983

Contact: $\quad$ snedios@,gmail.com

Address: $\quad$ Reichpietschstr. 57, 04317 Leipzig, Germany

EDUCATION - WORK EXPERIENCE

1994-2000 Baccalaureate: Valedictorian 97-99, $2^{\text {nd }}$ in Greece, Grade 199.13/200.00

2000-2006 Graduated from the Faculty of Medicine, $3^{\text {rd }}$ in class, Grade 8.11/10 Aristotle University of Thessaloniki, Thessaloniki, Greece

- Research (animal experiments), ER volunteer for islands, Congress committee

2002-2003 Erasmus academic exchange year, Humboldt University, Berlin, Germany

07/2004 Tropical medicine school, Dept. of Tropical Medicine,

Ain Shams University Hospital, Cairo, Egypt

2007-2008 Residency, Dept. of Internal Medicine \& Cardiology, academic hospital of the Humboldt University, Vivantes am Urban, Berlin, Germany

- Active participation in EP studies

2008-2011 Electrophysiology research, Dept. of Internal Medicine \& Cardiology, German Heart Institute Berlin, Humboldt University, Germany

- Active participation in EP studies, enhancement of statistical knowledge as well as research and presentation skills on a peer-review basis.

2010 Observership, Cleveland Clinic, Electrophysiology Dept., Ohio, USA

- Familiarization with the US health system, pharmacopoeia and education.

Participation in EP studies and conferences. Supervisor Dr. Walid Saliba.

2012 Dissertation (Doctorate): "New imaging methods for the ablation of atrial fibrillation: comparison of rotational angiography with computer tomography" German Heart Institute Berlin, Humboldt University, Germany

2011-2016 Residency/Fellowship, Dept. of Internal Medicine and Cardiology/ Electrophysiology, Heart Center, University of Leipzig, Sachsen, Germany - Active participation in EP studies (i.a. SVT ablation, transeptal puncture)

- Clinical research with focus on improving outcomes in ICD \& AF patients

- Establishment of international cooperation (Netherlands, USA)

- Teaching activity and habilitation (university lecturer/assistant professor)

2016 USMLE Accreditation: United States Medical License Examination Grades: Step 1: 99\%, Step 2 CK: 91\%, Step 2 CS \& Step 3: passed

2016-2018 Diploma of Advanced Studies in Cardiac Arrhythmia Management, DAS-CAM, Maastricht University Medical Center (MUMC+), European Heart Academy (EHA) and European Heart Rhythm Association (EHRA) - Leadership, health economics, epidemiology and arrhythmia training

2017-2018 Clinical and Research Fellowship, Cardiac Arrhythmia Service, Massachusetts General Hospital, Harvard University, Boston, USA

- Advanced training in EP studies, Pacemaker and ICD implantation

- Value-Based Health Care, Harvard Business School, Prof. Porter

- Fellowship Subcommittee Member for HRS 2018

2018- present Dept. of Electrophysiology, Heart Center Leipzig University, Germany Harvard Medical School Global Clinical Scholars Research Training (GCSRT) EHRA \& IBHRE Certification Invasive Electrophysiology \& Cardiac Devices 
AWARDS AND ACCOMPLISHMENTS

$2000 \quad$ Ranked $2^{\text {nd }}$ National Examination, Admission in Medical School, IKY award

2002-2003 Scholarship, Erasmus exchange program, IKY \& European Union

Granted to only 2 out of 100 candidates.

$2004 \quad$ Ranked $4^{\text {th }}$ among 3rd year Medical School graduates

$2005 \quad$ Ranked $5^{\text {th }}$ among 4th year Medical School graduates

2006 Ranked $3^{\text {rd }}$ in the final Medical School graduation, IKY award

2008 Research grant from the "Konstantin Vellios" Legacy Foundation

2009-2011 Scholarship Ph.D. grant, IKY: National Scholarship Foundation, Greece Granted to only 5 out of 160 candidates.

2014 Finalist, Hugo-von-Ziemssen Price, German Society of Cardiology (DGK)

2015 Finalist, Young Investigator Award, European Heart Rhythm Association

\section{SCIENTIFIC ACTIVITIES \& OTHER INTERESTS}

Peer Review: Circulation, Circulation Arrhythmia Electrophysiology, Heart Rhythm, International Journal of Cardiology, Heart and Vessels, Europace, The American Journal of Cardiology, Journal of Cardiovascular CT, Clinical Cardiology, Journal of Atrial Fibrillation: JAFIB,

Minerva Cardioangiologica, Journal of Cardiology Research \& Therapy i.a.

Membership: HRS: Heart Rhythm Society, EHRA: European Heart Rhythm Association ESC: European Society of Cardiology, DGK: German Society of Cardiology Vice President, Society of Greek Scientists in Berlin/Brandenburg 2000-06

Languages: English (fluently), German (fluently), Greek (fluently), French (basic)

Other skills: $\quad$ SPSS and Microsoft Office Specialist, Advanced Cardiovascular (ACLS) and Basic Life Support (BLS) certified by the American Heart Association

Hobbies: Guitar playing, singing, swimming, running, finance, statistics, philosophy 


\section{SElected Congress Presentation}

Nedios S, Heist EK, Ruskin JN et al. Early experience with esophageal retraction for facilitation of catheter ablation for atrial fibrillation. 2018 HRS Congress, Boston, MA.

Nedios S, Darma A, Richter S et al. Cardiac Resynchronization Therapy in patients with Atrial Fibrillation. Predictors of sinUs rhythm REstoration (CRTAF PURE). 2017 ESC Congress, Barcelona, SP

Nedios S, Portugal G, Hindricks G, Bollman A. Left atrial tachycardia due to accessory pulmonary roof-vein- Case report. 2017 EHRA Congress, Vienna, AU

Nedios S, Dinov B, Dagres N et al. Characteristics of left atrial remodelling in patients with atrial fibrillation and hypertrophic cardiomyopathy in comparison to patients without hypertrophy.

2017 EHRA Congress, Vienna, AU

Nedios S, Seewoester T, Arya A, et al. Predictors of pulmonary vein stenosis after ablation of atrial fibrillation. Lessons learned from symptomatic patients presenting for treatment. 2016 ESC Congress, Rome, IT

Nedios S, Loebe S, Knopp H, et al. Left atrial activation changes and asymmetric anatomical remodelling in patients with AF: results of a prospective study using pulsed-wave tissue doppler imaging. 2016 ESC Congress, Rome, IT

Nedios S, Seewoester T, Hilbert S, et al. Pulmonary vein stenosis after ablation of atrial fibrillation. Treatment and long-term outcomes of 34 patients. 2016 DGK Congress, Mannheim, DE

Nedios S, Seewoester T, Koutalas E et al. Predictors of LAA Thrombi in Patients with Atrial Fibrillation \& Low CHADS-VASc Score. 2015 DGK Congress, Mannheim, DE \&ESC Congress, London, GB

Nedios S, Darma A, Kosiuk J et al. Prevalence and predictors of electrical storm in patients with implantable cardioverter defibrillator. Implications for better rhythm control.

2014 DGK HT Congress, Düsseldorf, DE

Nedios S, Stevanello C, Kosiuk J et al. Predictors of inappropriate implantable cardioverter defibrillator therapies in a real-world cohort of patients. Implications for better rhythm control.

2014 DGK Congress Düsseldorf DE

Nedios S, Breithardt OA, Koutalas E et al. Left Atrial Symmetry Changes in Atrial Fibrillation: Relation With Diastolic Dysfunction and Symptom Severity.

2014 AHA Scientific Sessions, Chicago, IL, USA \& DGK HT Congress, Düsseldorf, DE

Nedios S, Kornej J, Koutalas E et al. Left Atrial Appendage Morphology And Thromboembolic Risk After Catheter Ablation For Atrial Fibrillation. Does Shape Really Matter?

2013 AHA Scientific Sessions, Dallas, TX, USA \& DGK Congress, Mannheim, DE

Nedios S, Koutalas E, Pastromas S et al. A. Left atrial volume and symmetry changes as predictors of long-term success after catheter ablation of atrial fibrillation. 2013 HRS Congress, Denver, CO, USA

Nedios S, Kosiuk J, Sommer P et al. Long-term course after atrial fibrillation ablation in patients with impaired LV systolic function: the importance of sinus rhythm maintenance.

2012 ESC Congress, Munich, DE \& DGK Congress, Mannheim, DE

Nedios S, Romero I, Gerds-Li JH, Fleck E, Kriatselis C. Optimal lead placement for QRS wave detection: a trade-off of amplitude for distance. 2012 DGK Congress, Mannheim, DE

Nedios S, Tang M, Roser M, Gerds-Li JH, Fleck E, Kriatselis C. Characteristic Changes in the Three-Dimensional Structure of the Left Atrium in Atrial Fibrillation: Prognostic Significance After Ablative Treatment. 2011 ESC Congress, Paris, FR

Nedios S, Kriatselis C, Chen X, Roser M, Fleck E, Gerds-Li JH. Optimal projections for the angiographic depiction and percutaneous occlusion of the left atrial appendage. Lessons learned from the rotational angiography of the left atrium and the pulmonary veins. 2011 DGK, Mannheim, DE

Nedios S, Tang M, Roser M, Gerds-Li JH, Fleck E, Kriatselis C. Three-dimensional structural changes of the left atrium in patients with paroxysmal, persistent and permanent atrial fibrillation. 2010 DGK Congress, Mannheim, DE Nedios S, Tang M, Gerds-Li JH, Fleck E, Kriatselis C. Adenosine-resistance in patients receiving amiodaron. 2009 ESC Congress, Barcelona, ES \& DGK Congress, Mannheim, DE

Nedios S, Tang M, Roser M, Gerds-Li JH, Fleck E, Kriatselis C. Three-dimensional reconstruction of the left atrium and the pulmonary veins for navigation of atrial fibrillation ablation: a comparison study between rotational angiography and cardiac computed tomography. 2009 ESC Congress, Barcelona, ES, DGK Congress, Mannheim, DE

Nedios S. Critical evaluation of gestational diabetes. 2005 Congress Scientific Student Association, GR

Nedios S, Papaziogas I. Retrospective Study of the therapeutic interventions stomach ulcers in a etriary clinic. 2004 Congress Scientific Association of Medical Students, GR

Nedios S, Vamvini M, Kaldaras N. Effect of ANP injection in the brain of rabbits at the excretion of Aldosteron. 2002 Congress Scientific Association of Medical Students, GR 


\section{Publications}

1. Nedios S, Sommer P, Bollmann A, Hindricks G. Advanced mapping systems to guide atrial fibrillation ablation: electrical information that matters. J Atr Fibrillation 2016 PMID: 27909489

2. Nedios S, Koutalas E, Sommer P, Arya A, Rolf S, Husser D, Bollmann A, Hindricks G, Breithardt OA. Asymmetrical left atrial remodeling in atrial fibrillation: relation with diastolic dysfunction and long-term ablation outcomes. Europace 2017, PMID: 27738076

3. Nedios S, Seewöster T, Lip GH, Husser D, Hindricks G, Bollmann A, Kornej J. Association between peripheral plasma markers and left atrial anatomy in patients with atrial fibrillation. Int J Cardiol. 2016 Jan 15;203:621-3. PMID: 26580343

4. Nedios S, Darma A, Stevanello C, Richter S, Doering M, Rolf S, Sommer P, Hindricks G, Bollmann A, Arya A. Electrical storm in patients with implantable cardioverter-defibrillator in the era of catheter ablation: Implications for better rhythm control. Heart Rhythm. 2015 Dec;12(12):2419-25. PMID: 26232765

5. Nedios S, Kosiuk J, Koutalas E, Kornej J, Sommer P, Arya A, Richter S, Rolf S, Husser D, Hindricks G, Bollmann A. Comparison of left atrial dimensions in CT and echocardiography as predictors of long-term success after catheter ablation of atrial fibrillation. J Interv Card Electrophysiol May 2015. PMID: 25956477

6. Nedios S, Koutalas E, Kosiuk J, Sommer P, Arya A, Richter S, Rolf S, Husser D, Hindricks G, Bollmann A. Impact of asymmetrical dilatation of the left atrium on the long-term success after catheter ablation of atrial fibrillation. Int J Cardiol Feb 24 2015. PMID: 25731848

7. Nedios S, Sommer P, Dagres N, et al. Long-term follow-up after atrial fibrillation ablation in patients with impaired left ventricular systolic function: the importance of rhythm and rate control. Heart rhythm. Mar 2014;11:344-351. PMID: 24374320

8. Nedios S, Romero I, Gerds-Li JH, Fleck E, Kriatselis C. Precordial electrode placement for optimal ECG monitoring: implications for ambulatory monitor devices and event recorders. J Electrocardiol Sep-Oct 2014;47:669-676. PMID: 24857184

9. Nedios S, Kornej J, Koutalas E, Bertagnolli L, Kosiuk J, Rolf S, Arya A, Sommer P, Husser D, Hindricks G, Bollmann A. Left atrial appendage morphology and thromboembolic risk after catheter ablation for atrial fibrillation. Heart rhythm. Dec 2014. PMID: 25128733

10. Nedios S, Koutalas E, Kornej J, Rolf S, Arya A, Sommer P, Husser D, Hindricks G, Bollmann A. Cardiogenic Stroke Despite Low CHADS-VASc Score (ASK LAA) Assessing Stroke risk by left atrial appendage anatomy. J Cardiovasc Electrophysiol. 2015 Jul 14. PMID: 26178767

11. Nedios S, Tang M, Roser M, Solowjowa N, Gerds-Li JH, Fleck E, Kriatselis C. Characteristic changes of volume and three-dimensional structure of the left atrium in different forms of atrial fibrillation: predictive value after ablative treatment. J Interv Card Electrophysiol Nov 2011;32:87-94. PMID: 21667097

12. Nedios S, Tang M, Yi G, Gerds-Li JH, Fleck E, Karabinos I, Kriatselis C. Small loop re-entry tachycardia between left atrium and left superior pulmonary vein: a late arrhythmogenic complication after pulmonary vein ablation isolation. How useful is P-wave morphology? Hellenic J Cardiol 2009. PMID: 19622503

13. Darma A*, Nedios S*, Kosiuk J, Richter S, Doering M, Arya A, Rolf S, Sommer P, Hindricks G, Bollmann A. Differences in predictors of implantable cardioverter defibrillator therapies in patients with ischemic and non-ischemic cardiomyopathies. Europace 2015 Jun PMID: 26056190

14. Kosiuk J*, Nedios S*, Kornej J, Koutalas E, Bertagnolli L, Rolf S, Arya A, Sommer P, Husser D, Hindricks G, Bollmann A. Impact of left atrial appendage morphology on peri-interventional thromboembolic risk during catheter ablation of atrial fibrillation. Heart rhythm. Sep 2014;11:1522-1527. PMID: 24858813

15. Kosiuk J*, Nedios S*, Darma A, Rolf S, Richter S, Arya A, Piorkowski C, Gaspar T, Sommer P, Husser D, Hindricks G, Bollmann A. Impact of single atrial fibrillation catheter ablation on implantable cardioverter defibrillator therapies in patients with ischaemic \& non-ischaemic cardiomyopathies. Europace 2014;16:1322-1326. PMID: 24532559

16. Kriatselis C*, Nedios S*, Akrivakis S, Tang M, Roser M, Gerds-Li JH, Fleck E, Orlov M. Intraprocedural imaging of left atrium and pulmonary veins: a comparison study between rotational angiography and cardiac computed tomography. Pacing Clin Electrophysiol Mar 2011;34:315-322. PMID: 21087292

17. Löbe S, Knopp H, Le TV, Nedios S, Seewöster T, Bode K, Sommer P, Bollmann A, Hindricks G, Dinov B. Left Atrial Asynchrony Measured by Pulsed-Wave Tissue Doppler Is Associated With Abnormal Atrial Voltage and Recurrences of Atrial Fibrillation After Catheter Ablation. JACC Clin Electrophysiol. 2018 Dec;4(12):1640-1641. PMID: 30573131 
18. Seewöster T, Büttner P, Nedios S, Sommer P, Dagres N, Schumacher K, Bollmann A, Hilbert S, Jahnke C, Paetsch I, Hindricks G, Kornej J. Association between cardiovascular magnetic resonance-derived left atrial dimensions, electroanatomical substrate and NT-proANP levels in atrial fibrillation. J Am Heart Assoc. 2018 PMID: 30371296

19. Odening KE, Deiß S, Dilling-Boer D, Didenko M, Eriksson U, Nedios S, Ng FS, Roca Luque I, Sanchez Borque P, Vernooy K, Wijnmaalen AP, Yorgun H. Mechanisms of sex differences in atrial fibrillation: role of hormones and differences in electrophysiology, structure, function, and remodelling. Europace. 2018 Oct PMID: 30351414

20. Schoene K, Arya A, Jahnke C, Paetsch I, Nedios S, Hilbert S, Bollmann A, Hindricks G, Sommer P. Acquired Pulmonary Vein Stenosis After Radiofrequency Ablation for Atrial Fibrillation: Single-Center Experience in Catheter Interventional Treatment. JACC Cardiovasc Interv. 2018 PMID: 30139470

21. Dinov B, Knopp H, Löbe S, Nedios S, Bode K, Schönbauer R, Sommer P, Bollmann A, Arya A, Hindricks G. Patterns of left atrial activation and evaluation of atrial dyssynchrony in patients with atrial fibrillation and normal controls: Factors beyond the left atrial dimensions. Heart Rhythm. 2016 Jun 7. PMID: 27283937

22. Kriatselis C, Kaufmann J, Nedios S, Liu J, Gerds-Li JH, Fleck E. Fast atrial activity predicts recurrence of atrial fibrillation after pulmonary vein isolation: results from a prospective randomized study. J Interv Card Electroph. Mar 2015 PMID: 25591723

23. Romero I, Nedios S, Kriatselis C. Diagnosis and management of atrial fibrillation: an overview. Cardiovasc Ther Oct 2014;32:242-252. PMID: 25130510

24. Kosiuk J, Koutalas E, Doering M, Sommer P, Rolf S, Breithardt OA, Nedios S, Dinov B, Hindricks G, Richter S, Bollmann A. Treatment with novel oral anticoagulants in a real-world cohort of patients undergoing cardiac rhythm device implantations. Europace. Jul 2014;16:1028-1032. PMID: 24489073

25. Kosiuk J, Koutalas E, Doering M, Nedios S, Sommer P, Rolf S, Darma A, Breithardt OA, Dinov B, Hindricks G, Richter S, Bollmann A. Comparison of Dabigatran and Uninterrupted Warfarin in Patients With Atrial Fibrillation Undergoing Cardiac Rhythm Device Implantations. Circ J Aug 22 2014. PMID: 25253506

26. Kriatselis C, Kaufmann J, Nedios S, Tang M, Gerds-Li JH, Fleck E. Prolonged ablation on critical segments of pulmonary vein ostia in paroxysmal atrial fibrillation: a prospective randomized controlled study. Pacing Clin Electrophysiol. 2014 May. PMID: 24883449

27. Kriatselis CD, Nedios S, Kelle S, Helbig S, Gottwik M, von Bary C. Oxygen Kinetics and Heart Rate Response during Early Recovery from Exercise in Patients with Heart Failure. Cardiol Res Pract. 2012;2012:512857. PMID: 22312564

28. Kriatselis C, Nedios S, Roser M, Gerds-Li JH. To the Editor-Differentiation of orthodromic reciprocating tachycardia from atrioventricular nodal reentrant tachycardia. Heart Rhythm. 2012 Dec; PMID: 21215820

29. Kriatselis C, Nedios S, Wellens H. A narrow QRS tachycardia with irregular atrial and ventricular intervals and VA dissociation: what is the mechanism? J Cardiovasc Electrophysiol Jul 2012; PMID: 21955277

30. Tang M, Kriatselis C, Nedios S, Ye G, Roser M, Fleck E, Gerds-Li JH. A novel cryoballoon technique for mapping and isolating pulmonary veins: a feasibility and efficacy study. J Cardiovasc Electrophysiol Jun 2010;21:626-631. PMID: 20021514

31. Tang M, Gerds-Li JH, Nedios S, Roser M, Fleck E, Kriatselis C. Optimal fluoroscopic projections for angiographic imaging of the pulmonary vein ostia: lessons learned from the intraprocedural reconstruction of the left atrium and pulmonary veins. Europace Jan 2010;12:37-44. PMID: 19919969

32. Tang M, Kriatselis C, Nedios S, Roser M, Goetze S, Fleck E, Gerds-Li JH. Combined use of threedimensional rotational angiogram of left atrium and circular multi-electrode ablation catheter for pulmonary vein isolation. Chin Med J Jan 2012; PMID: 22340482

33. von Bary C, Dornia C, Eissnert C, Nedios S, Roser M, Hamer OW, Gerds-Li JH, Paetsch I, Jahnke C, Gebker R, Weber S, Fleck E, Kriatselis C. Predictive value of left atrial volume measured by non-invasive cardiac imaging in the treatment of paroxysmal atrial fibrillation. J Interv Card Electrophysiol Aug 2012;34:181-188. PMID: 22228410

34. Tang M, Kriatselis C, Ye G, Nedios S, Roser M, Solowjowa N, Fleck E, Gerds-Li JH. Reconstructing and registering three-dimensional rotational angiogram of left atrium during ablation of atrial fibrillation. Pacing Clin Electrophysiol Nov 2009 PMID: 19691678

35. Kriatselis C, Tang M, Nedios S, Roser M, Gerds-Li H, Fleck E. Intraprocedural reconstruction of the left atrium and pulmonary veins as a single navigation tool for ablation of atrial fibrillation: a feasibility, efficacy, and safety study. Heart Rhythm Jun 2009. PMID: 19411189 